\title{
Population Health of Spotted Salamanders (Ambystoma maculatum) in Created Vernal Pools: an Integrative Approach
}

Alice R. Millikin

armillikin@mix.wvu.edu

Follow this and additional works at: https://researchrepository.wvu.edu/etd

Part of the Animal Experimentation and Research Commons, Comparative and Evolutionary

Physiology Commons, Endocrinology Commons, Genetics Commons, Integrative Biology Commons, Natural Resources and Conservation Commons, Natural Resources Management and Policy Commons, Population Biology Commons, Terrestrial and Aquatic Ecology Commons, and the Zoology Commons

\section{Recommended Citation}

Millikin, Alice R., "Population Health of Spotted Salamanders (Ambystoma maculatum) in Created Vernal Pools: an Integrative Approach" (2019). Graduate Theses, Dissertations, and Problem Reports. 7461. https://researchrepository.wvu.edu/etd/7461

This Dissertation is protected by copyright and/or related rights. It has been brought to you by the The Research Repository @ WVU with permission from the rights-holder(s). You are free to use this Dissertation in any way that is permitted by the copyright and related rights legislation that applies to your use. For other uses you must obtain permission from the rights-holder(s) directly, unless additional rights are indicated by a Creative Commons license in the record and/ or on the work itself. This Dissertation has been accepted for inclusion in WVU Graduate Theses, Dissertations, and Problem Reports collection by an authorized administrator of The Research Repository @ WVU. For more information, please contact researchrepository@mail.wvu.edu. 


\title{
Population Health of Spotted Salamanders (Ambystoma maculatum) in Created Vernal Pools: an Integrative Approach
}

\author{
Alice R. Millikin \\ Dissertation submitted to the \\ Davis College of Agriculture, Natural Resources, and Design \\ at West Virginia University \\ in partial fulfillment of the requirements for the degree of \\ Doctor of Philosophy \\ in \\ Forest Resource Science \\ with a concentration in \\ Wildlife and Fisheries Resources \\ James T. Anderson, Ph.D., Chair \\ Sarah K. Woodley, Ph.D. \\ Amy B. Welsh, Ph.D. \\ James A. Thompson, Ph.D.
}

Division of Forestry and Natural Resources

\author{
Morgantown, West Virginia \\ 2019
}

Keywords: amphibians, wetlands, restoration, habitat, corticosterone, conservation physiology, conservation genetics, ranavirus, wildlife, Appalachians

(C) 2019 Alice R. Millikin 


\section{ABSTRACT \\ Population Health of Spotted Salamanders (Ambystoma maculatum) in Created Vernal Pools: an Integrative Approach}

Alice R. Millikin

Habitat creation is an important tool for conservation to counteract habitat loss and degradation. Vernal pools are susceptible to destruction due to limited detection, protection, and regulation. These wetlands provide fishless breeding habitat for many amphibian species including spotted salamanders (Ambystoma maculatum) in eastern North America. Determining whether created vernal pool habitat is successful is often determined by demographic data of colonizing populations. I suggest that hormone levels, population genetics, and disease prevalence can improve our understanding of population health in created habitat. The goal of this dissertation was to assess the health of spotted salamander larvae in created vernal pools quantified by corticosterone levels, genetic diversity and structure, and ranavirus prevalence. I also wanted to determine if there were habitat characteristics impacting these parameters to inform future construction techniques and produce habitat conducive to healthy colonizing amphibian populations.

I examined whether habitat traits influenced corticosterone levels of salamander larvae in created vernal pools. The strongest model predicting corticosterone levels included larval total length, pool-water temperature, year sampled, and pool diameter. Annual variation in corticosterone levels and habitat characteristics, and positive associations with water temperature and salamander body size highlighted the importance of controlling for external influences. The negative association between pool diameter and corticosterone indicated that larvae in larger pools (up to $12.75-\mathrm{m}$ maximum diameter) were less stressed and potentially healthier.

Water-borne hormone sampling is relatively new to amphibians, so I attempted to biologically validate the method for spotted salamanders by comparing water-borne and plasma corticosterone concentrations of the same individuals. There were differences in corticosterone concentrations between larvae, metamorphs, and adults, but there were no correlations between water-borne and plasma concentrations for any of the age groups. The two sampling methods have different units of measurement which might affect the association between the two.

I evaluated the genetic structure and genetic diversity of spotted salamander larvae in created vernal pools. I also examined whether local habitat characteristics at the pool level influenced effective number of breeders, relatedness, or genetic diversity. The youngest pools exhibited genetic differentiation, founder's effect, and low effective number of breeders. Effective number of breeders was positively associated with pool age, vegetation cover, pool diameter, and sample size. Pool cover and vegetation cover was also negatively associated with relatedness. Allelic richness and expected heterozygosity did not have strong environmental predictors.

I surveyed spotted salamander larvae in created vernal pools for ranavirus prevalence and measured viral load in individual larvae. I tested associations between ranavirus prevalence and viral load and habitat characteristics, genetic diversity, corticosterone levels, and body size. I detected ranavirus in $62 \%$ of pools in 84 of 1,128 larvae (7\%). Prevalence at pools ranged from 
$0-63 \%$. Salamanders infected with ranavirus had greater total length, which was also positively correlated with viral load. There were no associations between ranavirus prevalence or viral load and habitat characteristics, salamander genetic diversity, relatedness, effective number of breeders, or corticosterone levels.

These results indicate larger pool diameter (up to $12.75 \mathrm{~m}$ ) and greater vegetation cover are important habitat traits to consider when creating vernal pool habitat for spotted salamanders. This research demonstrates that effective number of breeders can increase and genetic differentiation can decrease within 4-5 years of pool creation, a sign of rapid colonization and potential population establishment. The widespread occurrence of ranavirus in created pools illustrates the risk of disease exposure in newly created habitat; even with the generally low prevalence among salamanders in the majority of pools. The correlation between ranavirus and salamander total length could be a reflection of differences in susceptibility through developmental stages or increased risk of exposure over time.

This study contributes to the growing body of knowledge on the association between habitat quality and corticosterone levels and genetic diversity of amphibians. The disease surveillance will add a species and county record for West Virginia, contribute to current distribution maps, and document disease prevalence levels in created habitat. The results of this dissertation will help inform current management and future site selection and habitat creation by highlighting important habitat characteristics for spotted salamanders. Finally, this research illustrates the value of incorporating interdisciplinary approaches to assess the success of habitat creation and colonizing wildlife populations. 


\section{ACKNOWLEDGMENTS}

This work is dedicated to my husband, parents, and grandparents, who believed I could achieve what seemed impossible.

This research was funded by the U.S. Forest Service, Natural Resources Conservation Service, National Science Foundation (01A-1458952), West Virginia University Natural History Museum, National Institute of Food and Agriculture McStennis Project WVA00117, The Explorers Club Washington Group, Society of Wetland Scientists, Society of Wetland Scientists South Atlantic Chapter, West Virginia University Stitzel Graduate Enhancement Fund, and Richard and Lois Bowman. I thank the U.S. Forest Service for allowing me to use their created vernal pools for this research and for providing coordinates and sharing their knowledge of the area. I am grateful to the West Virginia Division of Natural Resources for providing housing and a work space during field work. I also thank the Department of Biological Sciences at Duquesne University for welcoming me into their department while conducting lab work in Sarah Woodley's lab. I thank the Ruby Distinguished Doctoral Fellowship Program for funding the first three years of my Ph.D. program, including travel.

I thank my advisor, Jim Anderson, for giving me the opportunity to conduct this research. He balanced guidance and support with constructive criticism to make me a better scientist. Thank you to Jim for vouching for me and for providing funding for this project, including recommending me for the Ruby Fellowship. Thank you to Sarah Woodley, who provided her lab, supplies, expertise, and time to train me, including catching spotted salamanders on rainy nights in March. She asked the hard questions and made sure I left no stone unturned to 
accurately understand and interpret our data on water-borne hormones. Thank you to Amy Welsh who also contributed her lab, supplies, expertise, and time to make the genetics lab work possible and for her feedback on these chapters. Thank you to James Thompson for his insight into vernal pools. Thank you to Stephanie Coster for training me in the genetics lab and on how to use genetics programs, for providing feedback that improved the quality of my writing and my abilities as a writer, and for providing moral support. Thank you to Drew Davis for contributing his time and knowledge, answering all my questions, and providing prompt feedback on manuscripts that improved the final product. Thank you to Davis \& Elkins College and Michelle Mabry for providing access to her lab and freezer space for my samples and to Sean Stover for his support. Thank you to Ignacio Moore for his collaboration and for running samples in his lab. Thank you to Brady Porter for his participation and help in catching adult spotted salamanders. Thank you to Jessi Rouda, Jonathan Strickland, Meghan Jensen, Sara McClelland, Kenzie Pereira, Lauren Schumacher, Sally Yannuzzi, and all the volunteers for their help in the field and lab. I also thank the people who met up to work independently in coffee shops and libraries: Michelle Fegeas, Sarah Bowman, and Maggie Bennett. Thank you to Mimi Smith, who opened her home to me, my husband, and pup during field and lab work in Pittsburgh, PA.

Thank you to John and Mary Millikin, Richard and Lois Bowman, and Robert and Elizabeth Millikin, who shaped who I am today and always supported me. I also thank John Millikin for his invaluable help in the field. I also thank my brothers, extended family, and friends for supporting me and this research. Finally, thank you to Adam Bucher, who helped with every aspect of the project from the beginning to end, including but not limited to gathering supplies, entering data, field work, as well as moral support through it all. Thank you to Adam and our pup, Zoey, for making adventures in West Virginia's wilderness a major component of 
my Ph.D. experience. Thank you to Adam, my parents, and grandparents for believing in me when I needed it most. 


\section{TABLE OF CONTENTS}

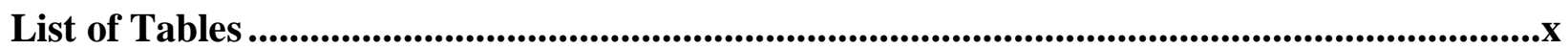

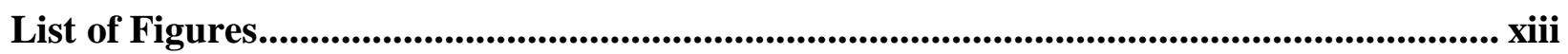

List of Supplemental Material .......................................................................................................... xviii

Chapter 1. Introduction ............................................................................................................1

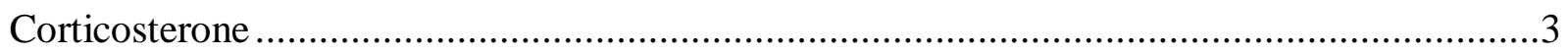

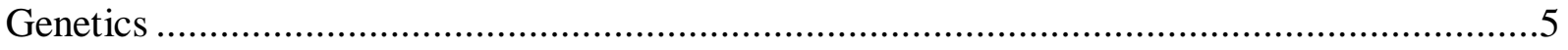

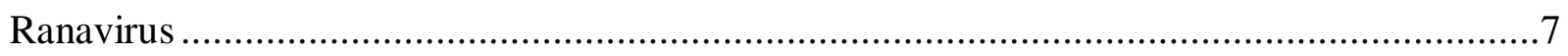

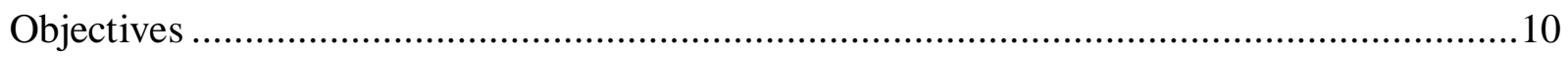

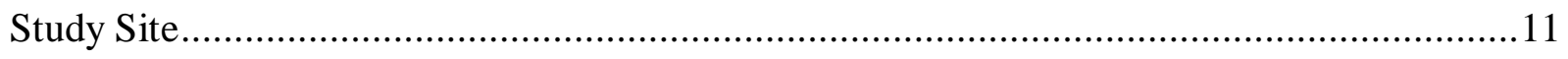

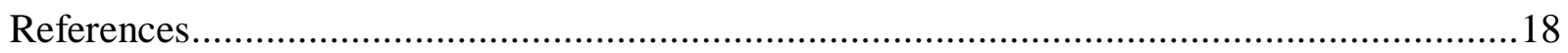

Chapter 2. Habitat Characteristics in Created Vernal Pools Impact Spotted Salamander

Water-borne Corticosterone Levels ........................................................................................32

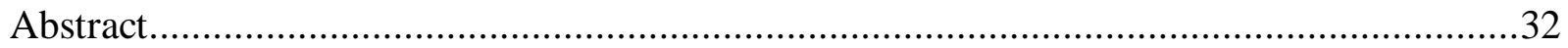

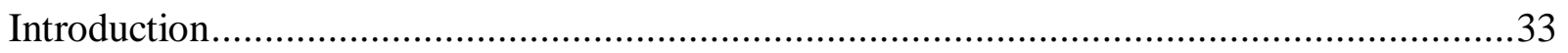

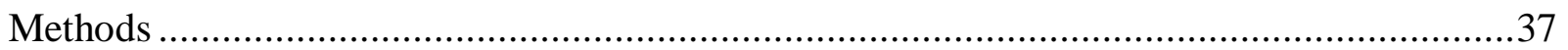

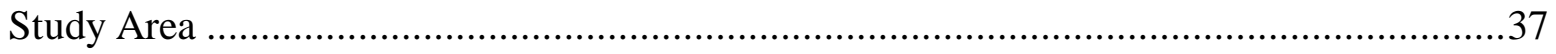

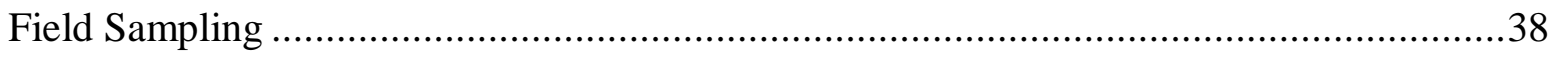

Water-borne Hormone Extraction and Measurement ……................................................39

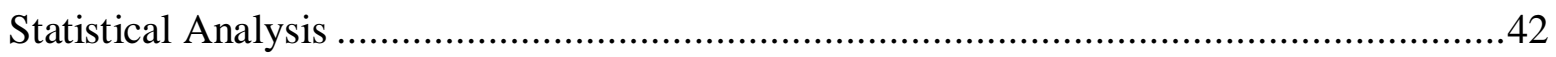

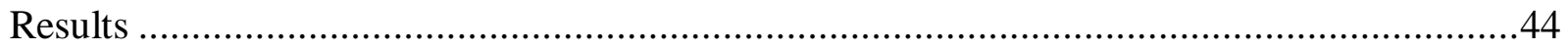

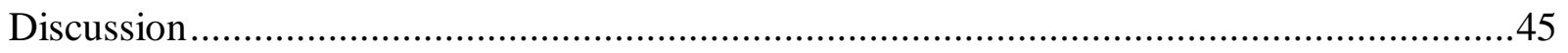


Caveats to Interpretation of Water-borne CORT Levels

Conclusions, Management Implications, and Future Research

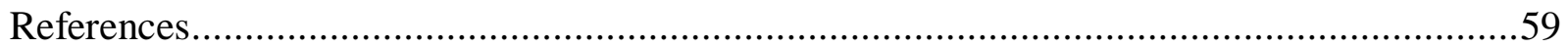

\section{Chapter 3. Water-borne and Plasma Corticosterone are not Correlated in Spotted}

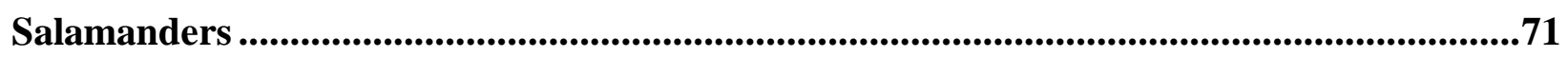

Abstract

\section{Chapter 4. Pool Age and Local Habitat are Associated with Effective Number of Breeders}

in Spotted Salamander Populations Colonizing Created Vernal Pools.................................104

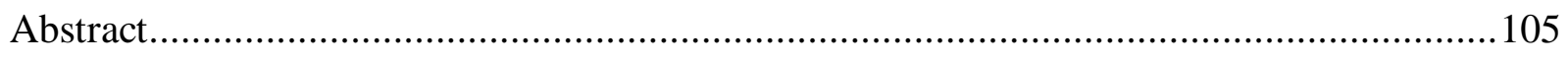

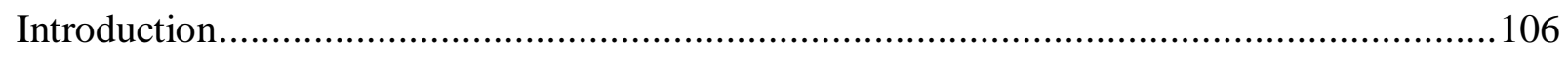

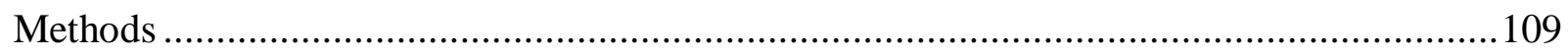

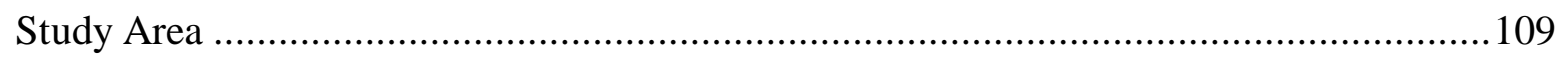

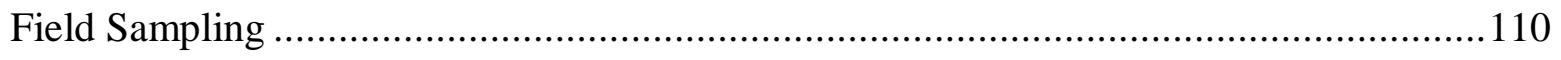

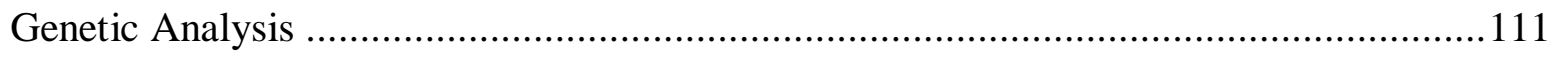

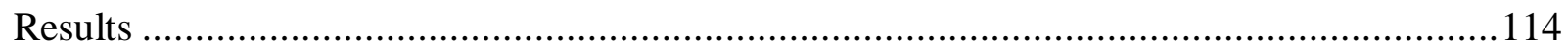




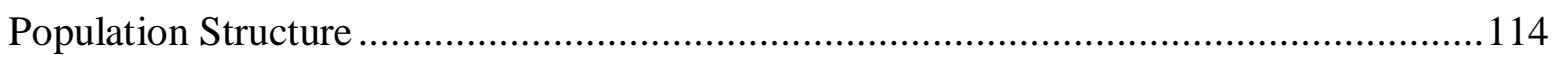

Effective Number of Breeders \& Genetic Diversity ……..............................................115

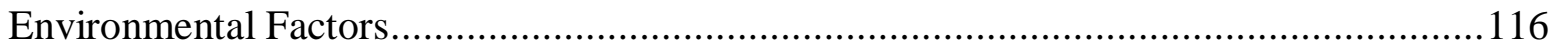

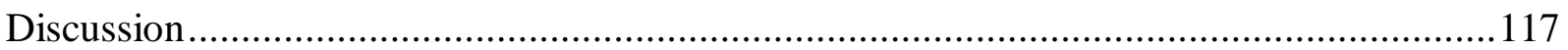

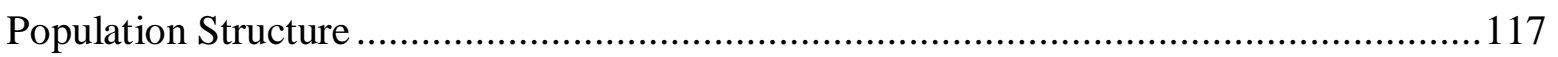

Effective Number of Breeders \& Genetic Diversity …................................................119

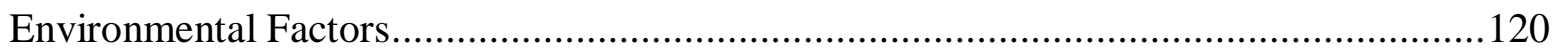

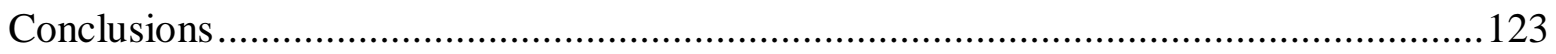

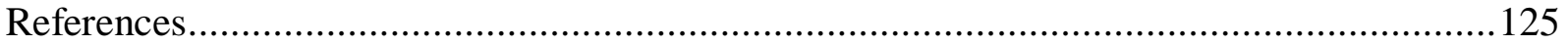

Chapter 5. Prevalence of Ranavirus in Spotted Salamander Larvae from Created Vernal

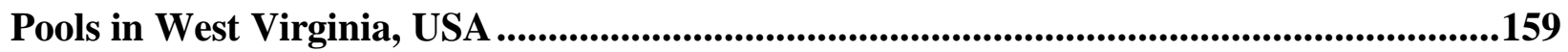

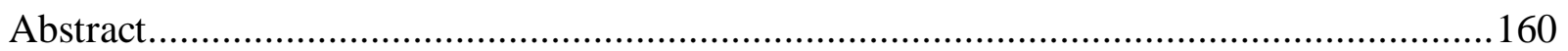

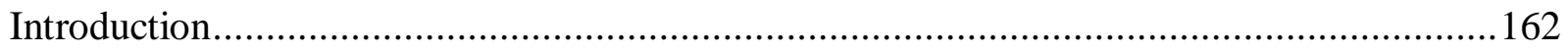

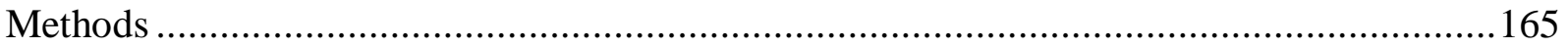

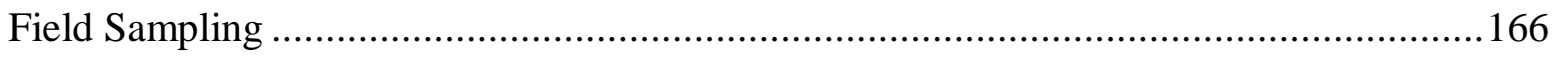

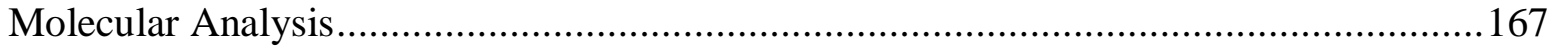

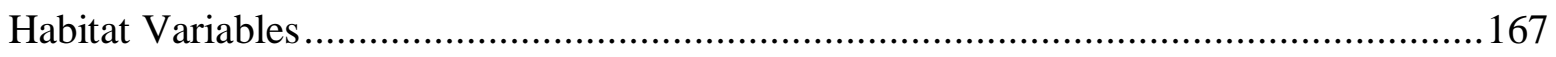

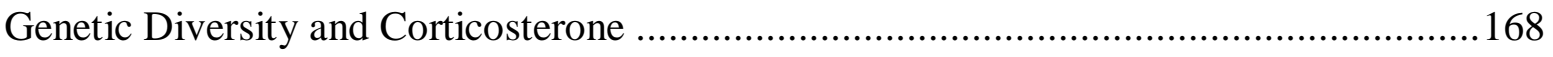

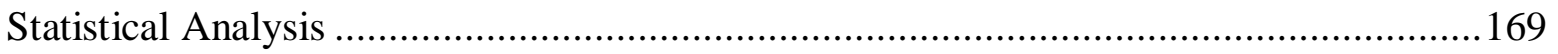

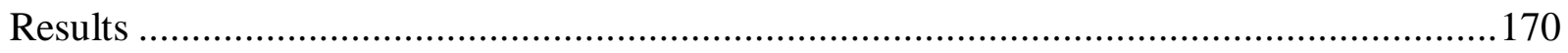

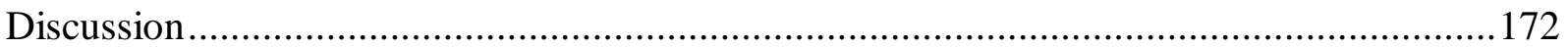

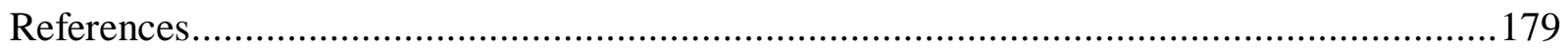

Chapter 6. Conclusion...................................................................................................................200 


\section{List of Tables}

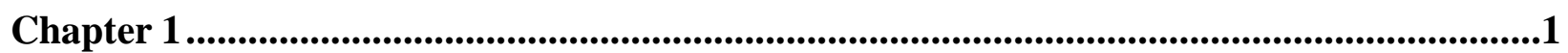

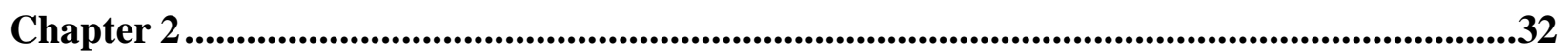

Table 1. Summary data displaying ranges of all predictors of water-borne corticosterone levels (pg/h) for spotted salamanders (Ambystoma maculatum) included in analysis with means separated by sampling year.

Table 2. Hypothesized models explaining variation in corticosterone levels $(\mathrm{pg} / \mathrm{h})$ of spotted salamander (Ambystoma maculatum) larvae. $\triangle \mathrm{AICc}=$ change in AIC corrected for small sample size; $\mathrm{w}_{\mathrm{i}}=$ weight of the model $; \mathrm{TL}=$ salamander total length; $\mathrm{C}=$ water temperature; Year = calendar year sampled; Pool Cover $=$ any form of refuge such as vegetation, rocks, coarse woody debris; Age $=$ time since pool creation

Table 3. Coefficients for the top model explaining water-borne corticosterone levels $(\mathrm{pg} / \mathrm{h})$ for spotted salamanders (Ambystoma maculatum): $\mathrm{y}=$ salamander total length $(\mathrm{TL})+$ water temperature $(\mathrm{C})+$ year sampled (Year) + pool diameter.

\section{Chapter 3}

Table 1. Spearman's correlation of spotted salamander plasma and water-borne corticosterone levels presented across age groups. Correlations are presented for both water-borne corticosterone units of measurement: $\mathrm{pg} / \mathrm{SVL} / \mathrm{h}$ and $\mathrm{pg} / \mathrm{g} / \mathrm{h}$. Also included are statistics for adults after removing females and for adults only including individuals whose blood samples were collected within $3 \mathrm{~min}$ 
Table 1. Hypothesized models predicting effective number of breeders of spotted salamanders (Ambystoma maculatum). Predictors include: age of pool; cover of grass, sedge, cattail, and rush within pool (GSCR); diameter of pool; sample size within pool; canopy cover; predator presence; and the null $\sim 1 . \Delta \mathrm{AICc}=$ change in AIC corrected for small sample size; $\mathrm{w}_{\mathrm{i}}=$ weight of the model; asterisks indicate when all predictors in a model had an estimate and 95\% CI interval not overlapping zero

Table 2. Coefficients for top model predicting effective number of breeders for spotted salamanders (Ambystoma maculatum): y = age of pool + GSCR (grass, sedge, cattail, rush coverage) + diameter of pool + sample size within pool

Table 3. Summary statistics of predictors included in spotted salamander (Ambystoma maculatum) population genetics models including age of pool; canopy cover; diameter (m) of pool; cover of grass, sedge, cattail, and rush within pool (GSCR); cover by any form of refuge within the pool such as vegetation, rocks, and coarse woody debris (pool cover); predator presence; and sample size per pool

Table 4. Hypothesized models predicting relatedness for spotted salamanders (Ambystoma maculatum). Predictors include: pool cover which includes any form of refuge such as vegetation, rocks, coarse woody debris; sample size within pool; cover of grass, sedge, cattail, and rush within pool (GSCR); region; diameter of pool; predator presence; and the null $\sim 1$. $\triangle \mathrm{AICc}=$ change in AIC corrected for small sample size; $\mathrm{w}_{\mathrm{i}}=$ weight of the model; asterisks indicate when all predictors in a model had an estimate and 95\% CI interval not overlapping zero .134

Table 5. Coefficients for top model predicting relatedness for spotted salamanders (Ambystoma maculatum): $\mathrm{y}=$ pool cover + sample size within pool 
Table 1. Spotted salamander (Ambystoma maculatum) ranavirus prevalence and mean quantity of viral copies per 100ng DNA (mean \pm standard error) at each pool separated by sampling year. Data from West Virginia, USA. N: number of larvae tested per pool per sample year; prevalence $=$ percent of larvae positive for ranavirus out of total larvae sampled at a pool; pools include those from Barton Bench (B,BB), Lambert North (LN), and Lambert South (LS)

Table 2. Spotted salamander (Ambystoma maculatum) ranavirus prevalence at each region (Barton Bench, Lambert North, Lambert South) presented by sample year: 2015 and 2016, and with years combined: 2015-2016. Data from West Virginia, USA. Larvae: $n=$ sample size of larvae/region, $\%=$ percent of larvae infected. Pools: $\mathrm{n}=$ sample size of pools $/$ region, $\%=$ percent of pools infected 


\section{List of Figures}

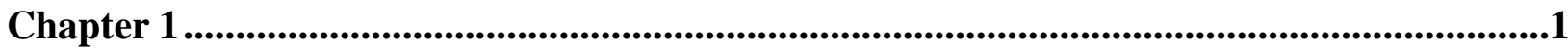

Figure 1. Photographs of a Barton Bench vernal pool (BB6) created in Monongahela National Forest near Huttonsville, West Virginia that retained water March 28, 2015 (left), but dried by May 6, 2015 (right), resulting in desiccation of spotted salamander (Ambystoma maculatum)

egg masses. .13

Figure 2. Photographs of a Lambert South vernal pool (LS125) created in Monongahela National Forest near Huttonsville, West Virginia illustrating changes to the habitat from the first spring (May 20, 2015; left) after initial creation to the second spring (May 25, 2016; right)

Figure 3. Photographs of spotted salamander (Ambystoma maculatum) larva (top left), metamorph (top right), and adult (bottom left) contained in water for water-borne hormone sampling validation.

Figure 4. Photograph showing the surrounding area of a Barton Bench vernal pool (BB8) created in Monongahela National Forest near Huttonsville, West Virginia. Taken May 27, 2015.

Figure 5. Photograph showing proximity to a dirt road for a Lambert North vernal pool (LS2) created in Monongahela National Forest near Huttonsville, West Virginia. Taken June 9, 2016.

Chapter 2

Figure 1. Topographic map displaying the study area in Randolph County, WV in the Greenbrier District of Monongahela National Forest. Circles, diamonds, and squares represent the locations of created vernal pools that were sampled. West Virginia state map shows the 
outline of Monongahela National Forest and general location of the study site marked with a black circle. USA Topo map accessed through ESRI (C) 2013 National Geographic Society, icubed.

Figure 2. Biplots displaying water-borne corticosterone levels $(\mathrm{pg} / \mathrm{h})$ and spotted salamander (Ambystoma maculatum) total length (mm) (a), pool water temperature $\left({ }^{\circ} \mathrm{C}\right)(\mathrm{b})$, and pool diameter (m) (c). Each dot represents average corticosterone (pg/h) levels for one pool in one sampling year $(\mathrm{n}=54)$. Boxplot displaying corticosterone levels in each sampling year $(\mathrm{d}) . .58$

Chapter 3 .71

Figure 1. Photographs of a spotted salamander larva (A), metamorph (B), and adult (C) in individual containers of water for water-borne hormone sampling

Figure 2. Biplots of spotted salamander plasma corticosterone (CORT) and water-borne CORT lacking correlations. Left side: corticosterone is presented in units of pg/SVL/h. Right side: corticosterone is presented in units of $\mathrm{pg} / \mathrm{g} / \mathrm{h}$. From top to bottom: larvae (A, B), metamorphs (C, D), and adults (E, F). Spearman's rho and $P$ values are presented on each graph

Figure 3. Graphs displaying untransformed corticosterone (CORT) \pm SE for spotted salamander baseline and agitation groups measured in different subsets of larvae $(n=8,8)$, metamorphs $(n=6,7)$, and both stages $(n=14,15)$ combined for water-borne CORT $(A, B)$ and plasma levels (C).

Figure 4. Boxplots displaying the median, interquartile range, lowest and highest observations, and outliers for spotted salamander corticosterone (CORT) levels across age groups (larvae: $n=16$, metamorphs: $n=13$, adults: $n=28$ [27 for water-borne $\mathrm{pg} / \mathrm{g} / \mathrm{h}]$ ) for 
water-borne CORT (A, B) and plasma CORT levels (C). Letters indicate differences in CORT levels between age groups $(P<0.01$; Kruskal-Wallis chi-square; Dunn test $) \ldots \ldots \ldots \ldots \ldots \ldots \ldots . . . . . . . .103$

\section{Chapter 4}

Figure 1. Map displaying study area in Randolph County, WV in the Greenbrier District of Monongahela National Forest. Circles represent locations of sampled created vernal pools designated by region. Pools at Barton Bench were created in $2011(\mathrm{n}=11)$, Lambert North pools were created in $2013(n=14)$, and Lambert South pools were created $2014(n=6)$. State map displays Monongahela National Forest and the general area of sampling with a black box. USA topo map accessed through ESRI (C) 2013 National Geographic Society, i-cubed; world impagery source: Esri, DigitalGlobe, GeoEye, Earthstar Geographics, CNES/Airbus DS, USDA, USGS, AeroGRID, IGN, and the GIS User Community..... 136

Figure 2. STRUCTURE Barplots displaying most likely K. Colors indicate the individual membership coefficients for each cluster. Numbers reflect pool IDs. (a) Barplot for entire study area including all three regions (Barton Bench, Lambert North, Lambert South) and displaying cline across regions. (b) Barplot for pools in Barton Bench region created in 2011; most likely $\mathrm{K}=1$. [Presenting barplot $\mathrm{K}=2$ to visually display the allele proportions reflect $\mathrm{K}$ =1.] (c) Barplot for pools in Lambert North region created in 2013; most likely $\mathrm{K}=3$. (d) Barplot for pools in Lambert South region created in 2014; most likely $\mathrm{K}=2$

Figure 3. Boxplots displaying ranges in (a) effective number of breeders $\left(\mathrm{N}_{\mathrm{b}}\right)$, (b) relatedness, (c) expected heterozygosity $\left(\mathrm{H}_{\mathrm{E}}\right)$, and $(\mathrm{d})$ allelic richness $\left(\mathrm{A}_{\mathrm{R}}\right)$ for spotted salamanders (Ambystoma maculatum) across regions: Barton Bench (BB), Lambert South (LN), Lambert North (LS). Letters indicate significant differences between regions (Dunn's Test $p<0.05) 138$ 
Figure 4. Biplots displaying relationship between $\mathrm{N}_{b}$ and predictors from the strongest model including: (a) age of pool, (b) GSCR (0-1) (grass, sedge, cattail, and rush coverage within pool), (c) diameter (m) of pool, and (d) sample size within pool. Some ages are in-between years due to combining samples collected over two years

Figure 5. Biplots displaying relationship between relatedness and predictors from the strongest model including: (a) GSCR (0-1) (grass, sedge, cattail, and rush coverage within pool) and (b) sample size within pool

\section{Chapter 5}

Figure 1. Map displaying study area in Randolph County, West Virginia, USA in the Greenbrier District of Monongahela National Forest. Triangles and circles represent locations of sampled created vernal pools. Regions are separated geographically from north to south: Barton Bench, Lambert North, Lambert South. State map displays Monongahela National Forest and the general area of sampling with a black circle. USA topo map accessed through ESRI @ 2013 National Geographic Society, i-cubed; world impagery source: Esri, DigitalGlobe, GeoEye, Earthstar Geographics, CNES/Airbus DS, USDA, USGS, AeroGRID, IGN, and the GIS User Community 191

Figure 2. Boxplots displaying ranges of ranavirus prevalence in spotted salamander (Ambystoma maculatum) larvae within pools (percentage of larvae with positive detections out of total sampled at a pool) of each region: Barton Bench (BB), Lambert North (LN), and Lambert South (LS), separated by year sampled: 2015 and 2016. Data from West Virginia, USA. BB $2015 n=10$ pools, $2016 n=10$ pools; LN $2015 n=13$ pools, $2016 n=11$ pools; LS $2015 n=6$ pools, $2016 n=5$ pools 
Figure 3. Non-metric multidimensional scaling ordination of vernal pools based on environmental characteristics. Data from West Virginia, USA. Polygons demonstrate overlap of pools with positive and negative detections of ranavirus in spotted salamander (Ambystoma maculatum) larvae from sampling in 2015 and 2016: positive detections in 28 pools, negative in 27 pools.

Figure 4. Boxplot displaying ranges in individual spotted salamander (Ambystoma maculatum) larval total length (TL $(\mathrm{mm})$ ) separated by larvae with negative $(\mathrm{N})$ and positive (P) detections for ranavirus: 1034 larvae tested negative with TL mean \pm SE: 21.00 $\pm 0.19 \mathrm{~mm}$, 84 larvae tested positive with TL mean \pm SE: $22.52 \pm 0.64 \mathrm{~mm}$. Data from West Virginia, USA. Letters indicate significant difference (Kruskal-Wallis chi $\left.^{2}=7.71, \mathrm{p}=0.005\right)$

Figure 5. Biplot displaying correlation between spotted salamander (Ambystoma maculatum) larval total length and individual viral copies of Ranavirus per 100 ng of DNA (Spearman rho $=0.08, p=0.006)$. Data from West Virginia, USA. Note the log scale. Each dot represents one larvae: 1034 larvae that tested negative, and 84 larvae that tested positive for ranavirus .195 Figure 6. Map of West Virginia, USA displaying counties. Counties with ranavirus documented prior to this study are circled: Cabell, Kanawha, Roane, Mineral, Berkely (Smith et al. 2016; Kevin Oxenrider, WV DNR personal communication). Our research detected ranavirus in Randolph County (indicated by a rounded rectangle), adding it to the list of West Virginia counties with ranavirus 


\section{List of Supplemental Material}

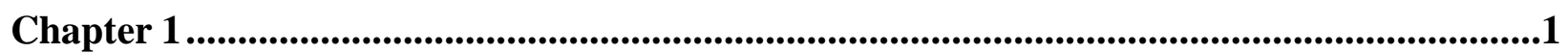

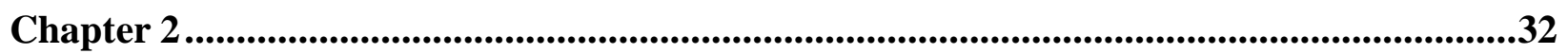

Table S1. Pool level data presenting variation of spotted salamander (Ambystoma maculatum) water-borne corticosterone (CORT) levels $(\mathrm{pg} / \mathrm{h})$ by vernal pool including mean \pm standard error (SE) and coefficient of variation $(\mathrm{CV})$ : the variation of larval CORT levels within each pond. Pool names represent location: Barton Bench (B, BB), Lambert North (LN), and Lambert South (LS). Also listed are the number of samples included in analysis (samples included). All pools were sampled for 10 larval hormone samples (except for pools sampled for 15 in 2016 including B11, B9, LN62, LN77); however, a subset of those were included in analysis after excluding samples with CORT levels too high and too low on the standard curve and below background levels. Finally, time sampling in minutes is how long we spent sampling in the pool for salamanders from start until the last salamander was caught.

Figure S1. Monthly average temperatures separated by sample year based on the 12 months before and including sampling: July 2014 - June 2015 and July 2015 - June 2016. Weather data are from the nearest weather station (Elkins, WV), which is $40.23 \mathrm{~km}$ away. Data from The Weather Underground [United States] Elkins-Randolph County Station, WV....

Figure S2. Monthly total precipitation separated by sample year based on the 12 months before and including sampling: July 2014 - June 2015 and July 2015 - June 2016. Weather data are from the nearest weather station (Elkins, WV), which is $40.23 \mathrm{~km}$ away. Data from The Weather Underground [United States] Elkins-Randolph County Station, WV. 
Appendix 1. Supplemental Methods: PCR Details

Table S1. Details of microsatellites with PCR conditions. Microsatellite loci are from Julian et al. (2003). Universal primers are from Blacket et al. (2012). *Loci excluded from analysis .143 Table S2. List of all pools sampled specifying which were included in analysis. Regions include Barton Bench (BB), Lambert North (LN), and Lambert South (LS). Sample size is the number of spotted salamander (Ambystoma maculatum) larvae per pool included in analysis. Years sampled were 2015, 2016, or both. Years combined indicates whether data from two years were combined: yes Y, no N, or N/A if only sampled one year. Sample year included is bolded for pools with only one year of sampling included in analysis. Final pool sample size included 31 pools: 14 based on one year of sampling and 17 based on two years of sampling

Table S3. $F_{\text {st }}$ table displaying $F_{\text {st }}$ values in the top half and $p$-values in the bottom half. Significant values are bolded. Pool ID listed by region: Barton Bench 1-11 (BB), Lambert North 12-25 (LN), and Lambert South 26-31 (LS) 146

Table S4. Summary statistics of effective number of breeders $\left(\mathrm{N}_{\mathrm{b}}\right)$, relatedness $\left(r_{\mathrm{QG}}\right)$, expected heterozygosity $\left(\mathrm{H}_{\mathrm{E}}\right)$, and allelic richness $\left(\mathrm{A}_{\mathrm{R}}\right)$ for spotted salamanders (Ambystoma maculatum) separated by region: Barton Bench (BB), Lambert North (LN), and Lambert South (LS).

Table S5. Pool level values of effective number of breeders $\left(\mathrm{N}_{b}\right)$, relatedness, expected heterozygosity $\left(\mathrm{H}_{\mathrm{E}}\right)$, and allelic richness $\left(\mathrm{A}_{\mathrm{R}}\right)$ for spotted salamanders (Ambystoma maculatum) with region indicated as Barton Bench (BB), Lambert North (LN), and Lambert South (LS) 150 
Figure S1. Map displaying the Barton Bench study region. Circles represent sampled created vernal pool locations designated by individual pool ID. World imagery source: Esri, DigitalGlobe, GeoEye, Earthstar Geographics, CNES/Airbus DS, USDA, USGS, AeroGRID, IGN, and the GIS User Community 151

Figure S2. Map displaying the Lambert North study region. Circles represent sampled created vernal pool locations designated by individual pool ID. World imagery source: Esri, DigitalGlobe, GeoEye, Earthstar Geographics, CNES/Airbus DS, USDA, USGS, AeroGRID, IGN, and the GIS User Community.... 152

Figure S3. Map displaying the Lambert South study region. Circles represent sampled created vernal pool locations designated by individual pool ID. World imagery source: Esri, DigitalGlobe, GeoEye, Earthstar Geographics, CNES/Airbus DS, USDA, USGS, AeroGRID, IGN, and the GIS User Community 153

Figure S4. Plot of most likely number of spotted salamander (Ambystoma maculatum) populations (K) across the entire study area (encompassing all three regions together) by the mean of estimated ln probability of the data. Analysis included all regions grouped together using 5 microsatellite loci run on STRUCTURE with graph produced by STRUCTURE HARVESTER

Figure S5. Plot of most likely number of spotted salamander (Ambystoma maculatum) populations (K) by the mean of estimated Ln probability of the data for regions (a) Barton Bench (b) Lambert North and (c) Lambert South. Analysis included 5 microsatellite loci run on STRUCTURE with graph produced by STRUCTURE HARVESTER 
Figure S6. Matrix of $\mathrm{F}_{\mathrm{ST}}$ values between pools. Darker color indicates higher genetic differentiation between pools. Pool ID listed by region: Barton Bench 1-11, Lambert North 12-25, and Lambert South 26-31 156

Figure S7. Biplots displaying relationship between $\mathrm{N}_{\mathrm{b}}$ and predictors from significant models including (a) canopy cover and (b) predator presence (predator group presence rating from 0-3 based on eastern newts, diving beetle larvae, and dragonfly larvae). Some values of predator presence are in-between the set values due to combining samples across two years of sampling

Figure S8. Biplots displaying relationship between $\mathrm{H}_{\mathrm{E}}$ and predictors: (a) sample size within the pool and (b) pool cover (which includes any form of refuge within the pool such as vegetation, rocks, and coarse woody debris) 158

\section{Chapter 5}

Table S1. Hypothesized models predicting ranavirus prevalence for spotted salamanders (Ambystoma maculatum). Predictors include: the null 1, pool water temperature, pool diameter, average corticosterone (CORT) per pool (pg/TL/h), pool age, number of positive pools within $1 \mathrm{~km}$, average salamander total length, allelic richness, average distance to all sampled pools, pool water $\mathrm{pH}$, number of sampled pools within $1 \mathrm{~km}$, pool cover, expected heterozygosity, genetic relatedness, predators present, effective number of breeders, and pool depth. $\triangle \mathrm{AICc}$ is the change in AIC corrected for small sample size; $\mathrm{w}_{\mathrm{i}}$ is the weight of the model 197

Figure S1. Boxplots displaying ranges in spotted salamander (Ambystoma maculatum) (a) expected heterozygosity $\left(\mathrm{H}_{\mathrm{E}}\right)$, (b) allelic richness, (c) relatedness, and (d) effective number of 
breeders $\left(\mathrm{N}_{\mathrm{b}}\right)$ at pools with negative and positive detection for ranavirus separated by year sampled. Data from West Virginia, USA

Figure S2. Boxplot displaying ranges in individual spotted salamander (Ambystoma maculatum) larval water-borne corticosterone levels pg/ total body length/ hour (CORT $\mathrm{pg} / \mathrm{TL} / \mathrm{h})$ separated by larvae with negative $(\mathrm{N})$ and positive $(\mathrm{P})$ detections for ranavirus: 401 larvae tested negative, 35 larvae tested positive. Data from West Virginia, USA. There was no difference in corticosterone levels between the two groups............................................ 199 


\section{Chapter 1}

\section{Introduction}

Habitat loss and degradation are among the most serious threats to biodiversity (Cushman 2006; Sodhi et al. 2008; Clipp and Anderson 2014). Since the 1780s, over 50\% of wetland habitat has been lost to agriculture and development in the US (Dahl 1990, 2006, 2011). Wetlands are important ecosystems both ecologically and economically because they prevent flooding, filter water, which improves water quality, and provide recreational opportunities and wildlife habitat. Wetland loss was mitigated through restoration and conservation under the no net loss wetland initiative started in the 1980s. These protections are limited because current regulation under the Clean Water Act does not include small wetlands $(<0.04$ ha) that lack permanent surface-water flow to rivers; which are key characteristics of vernal pools.

Vernal pools are palustrine wetlands that have temporary or seasonal hydroperiods with inundation in the spring or fall and dry periods during the summer or during droughts (Calhoun and deMaynadier 2008). They are difficult to detect due to this intermittent inundation and their small size, particularly in densely forested areas (DiBello et al. 2016). Many species of amphibians depend on wetlands for all or part of their life cycle. Amphibians like spotted salamanders (Ambystoma maculatum), wood frogs (Rana sylvatica), and marbled salamanders (A. opacum) depend on vernal pools specifically. Spotted Salamanders are a common species in the eastern North America and are a species of least concern. They have a biphasic life history. Fossorial adults migrate en masse to breeding pools in early spring on rainy nights with temperatures above $5^{\circ} \mathrm{C}$, typically in March or April in West Virginia. Eggs are deposited in 
vernal pools on submerged logs and vegetation. After 1-2 months, eggs develop into larvae which complete metamorphosis in $2-4$ months. Because vernal pools dry and lack permeant surface water flow to rivers, they prevent establishment of these amphibian's predator, fish. Pools that are colonized with fish can result in $100 \%$ mortality of spotted salamander larvae (Ireland 1989).

Amphibians are declining globally at a faster rate than birds or mammals with $43 \%$ of species in decline (Stuart et al. 2004). They are susceptible to the effects of climate change (Sutton et al. 2015), spread of diseases like ranavirus (Gray et al. 2009) and chytrid (Kilpatrick et al. 2010), habitat loss, environmental degradation, pollution including agricultural (Hayes et al. 2006), noise (Caorsi et al. 2017; Troïanowski et al. 2017) and light pollution (Feuka et al. 2017; Van Grunsven et al. 2017), exposure to endocrine disruptors, and habitat fragmentation as a result of urban development and roads (Cushman 2006; Glista et al. 2008). Of these, habitat loss and degradation are arguably the largest contributors to amphibian declines (Cushman 2006; Sodhi et al. 2008; Clipp and Anderson 2014). Preventing the decline of vernal pool breeding amphibians due to habitat loss and degradation will require active conservation of vernal pool habitat including increased protection, improved detection along with monitoring, and improved construction methods to produce ecologically equivalent habitat.

New vernal pools have been created to mitigate loss and degradation of this vulnerable ecosystem. The success of created vernal pools and the amphibian breeding population has been linked to hydrology, canopy cover, vegetation, slope, and the abundance of amphibians, invertebrates, and fish (reviewed in Calhoun et al. 2014; Fig. 1). Habitat characteristics incorporated during construction may influence population health of colonizing amphibians. It is expected that created pool habitat will change over time post-creation both in terms of 
colonization and with changes to the wetland plant community and accumulation of dead plant material (Fig. 2). In ten created pools, it took two years for species richness to reach equilibrium (Petranka et al. 2003a). Vegetation or cover in the pool is important for oviposition and should provide a water temperature gradient and refuge for larvae from intra- and interspecific predators (Formanowicz and Bobka 1989; Kern et al. 2013). More spotted salamander egg masses are deposited in pools with more complex vegetative structure (Egan and Paton 2004). When pool levels reach a $\mathrm{pH}$ of 4.5-5.5 or lower, it can reduce hatching success, larval growth, development and survival; and lower than 4.0 can be lethal (Gosner and Black 1957; Brodman 1993). Pool water $\mathrm{pH}$, pool size, depth, and hydroperiod are positively correlated with number of spotted salamander eggs present and hatching success (Rowe and Dunson 1993; Clark 1986; Petranka et al. 2003a; Skidds et al. 2007). Egg mass density is also positively correlated with forest cover within 1,000 $\mathrm{m}$ with spotted salamanders seemingly avoiding clear-cut breeding pools (Scheffers et al. 2013; Skidds et al. 2007; Felix et al. 2010). Vernal pools provide habitat unsuitable for predators that require more permanent hydroperiods, making predator presence an important indicator for habitat quality. Density and size of predators increases with extended hydroperiods (Skelly 1996).

\section{CORTICOSTERONE}

The success of created pools as habitat for vernal pool breeding amphibians is often measured by the reproductive effort (i.e. egg mass counts) and number of individuals that complete metamorphosis (Calhoun et al. 2014). Species abundance alone, while a promising indicator of habitat use, is not a guarantee of high quality habitat (Johnson 2007). The field of conservation physiology complements demographic data on populations of created habitat by 
studying physiological responses to habitat quality (Wikelski and Cooke 2006). The physiological condition of individuals in a population should act as an indicator of population health (Wikelski and Cooke 2006; McCormick and Romero 2017). Physiological responses may predict population declines and facilitate detection of vulnerable populations (McCormick and Romero 2017). Corticosterone is a hormone that may be a useful parameter for sublethal impacts and act as an indicator of habitat quality (Romero and Wikelski 2001; Homyack 2010; McCormick and Romero 2017). Corticosterone is a glucocorticoid hormone related to stress, development, and growth in amphibians produced by the hypothalamus-pituitary-interrenal (HPI) axis. This hormone allows an individual to maintain allostasis by increasing available energy when an individual is exposed to a perceived stressor that requires a behavioral and physiological change (McEwen and Wingfield 2003). Chronic stressors can cause prolonged elevation of corticosterone with harmful consequences such as suppressing the immune system and growth (McEwen and Wingfield 2003; Moore and Jessop 2003; Romero 2004; Wingfield et al. 1998; Belden and Kiesecker 2005).

Multiple groups of species have shown correlations between glucocorticoid hormones and environmental conditions. Spotted salamanders had elevated corticosterone levels in habitat with anthropogenic disturbance (Homan et al. 2003). Predator presence is also shown to increase glucocorticoid hormone levels and reduce spotted salamander larval activity and feeding (Scheuerlein et al. 2001; Hossie et al. 2017). Larval spotted salamanders in high intraspecific density environments and juvenile salamanders in low moisture environments had higher levels of corticosterone (Charbonnier et al. 2018). Jefferson salamander (Ambystoma jeffersonianum) larvae in natural pools and mesocosms had higher corticosterone levels in more acidic environments (Chambers et al. 2013). Northern leopard frog (Rana pipiens) tadpoles had higher 
levels of corticosterone when there was limited food or high intraspecific density (Glennemeier and Denver 2002). Western spadefoot toad (Spea hammondii) tadpoles had increased corticosterone levels after food deprivation (Crespi and Denver 2005). Adult common toads (Bufo bufo) inhabiting plowed soil had higher corticosterone levels than toads using forest litter or meadows (Janin et al. 2012). Additionally, exposure to traffic noise increased corticosterone in European tree frogs (Hyla arborea; Troïanowski et al. 2017). Southern toads (Bufo terrestris) exposed to coal combustion waste could not elicit a corticosterone response to acute stress (Hopkins et al. 1999). The relationship between glucocorticoids and environmental quality is also documented in eastern fence lizards (Sceloporus undulatus) exposed to invasive fire ants (Solenopsis invicta; Graham et al. 2012); marine iguanas (Amblyrhynchus cristatus) exposed to oil pollution and famine (Romero and Wikelski 2001; Wikelski et al. 2002); wolves (Canis lupus) and elk (Cervus canadensis) exposed to snowmobiles (Creel et al. 2002); North Atlantic right whales (Eubalaena glacialis) exposed to low-frequency noise from large ships (Rolland et al. 2012); and juvenile hoatzins (Opisthocomus hoazin; Müllner et al. 2004) and West Indian anoles (Anolis cristatellus) exposed to ecotourism (Huang et al. 2011).

\section{GENETICS}

Population genetics is another method that can be used to measure colonization success because it provides information about population structure and genetic diversity. Some created vernal pools do not successfully attract breeders or provide suitable habitat for completion of metamorphosis, because it is difficult to replicate conditions of natural pools such as the ephemeral hydroperiod, pool size, depth, canopy closure, and vegetative composition when 
constructing pools (Calhoun et al. 2014). Estimating number of breeders and genetic diversity at colonized pools can help inform future strategies for vernal pool creation.

Genetics provide a valuable indicator of population resilience by determining a population's risk of extinction and its ability to adapt to a stochastic environment (Spielman et al. 2004; Frankham 2005). Genetic connectivity, or dispersal among pools, sustains populations by allowing recolonization of areas that experience regular extinction events due to annual variations in habitat quality (Beebee 2005). Founder events that result in genetic bottlenecks, due to the small number of individuals establishing a new breeding population, are important to detect because the lack of genetic diversity can decrease chances of surviving stochastic events and may require additional restoration efforts to counteract long-term impacts to the population (Spielman et al. 2004; Frankham 2005). The effective number of breeders $\left(\mathrm{N}_{\mathrm{b}}\right)$ is correlated with effective population size $\left(\mathrm{N}_{\mathrm{e}}\right)$, and negatively related to the rate of increase in inbreeding in a single cohort of the population (Wang 2009; Waples et al. 2013). Therefore, $\mathrm{N}_{\mathrm{b}}$ has implications for whether the population can be sustained long-term (Reed and Frankham 2003; Beebee 2005; Waples et al. 2013). Reduced $\mathrm{N}_{\mathrm{e}}$ can increase inbreeding and decrease genetic diversity (Reed and Frankham 2003; Spielman et al. 2004). High levels of genetic diversity, measured by allelic richness and heterozygosity, can indicate a successful breeding population (Reed and Frankham 2003; Spielman et al. 2004). Heterozygosity is positively correlated with population fitness, where higher heterozygosity indicates lower inbreeding, higher reproductive fitness, and reduced extinction risk (Reed and Frankham 2003; Spielman et al. 2004). This is evident in findings that threatened taxa have lower heterozygosity than closely related nonthreatened taxa (Spielman et al. 2004). 
The genetic diversity and genetic structure of amphibians can be affected by the quality of their habitat. In dwarf salamanders (Eurycea quadridigitata), allelic richness and heterozygosity were higher in areas with more wetlands in the surrounding $2.5 \mathrm{~km}$ (McKee et al. 2017). In marbled newts (Triturus marmoratus), greater genetic structure and higher genetic differentiation $\left(\mathrm{F}_{\mathrm{ST}}\right)$ were observed in areas with more abundant row cropland (Costanzi et al. 2018). Tiger salamanders (Ambystoma tigrinum) had greater genetic differentiation in newly colonized wetlands, indicating a founder's effect (Cosentino et al. 2012). Additionally, larger wetlands, up to 3.8 ha, had tiger salamander larvae with higher allelic richness and lower F $_{\text {ST }}$ values, showing larger pools supported higher genetic diversity and migration (Cosentino et al. 2012).

\section{RANAVIRUS}

Conservation efforts to create vernal pool habitat would benefit from disease surveillance and monitoring as well as prevention. Green et al. (2002) attributed the majority of amphibian die-offs reported in the United States from 1996-2001 to ranaviruses. Ranaviruses are DNA viruses in the family Iridoviridae that can cause infections leading to hemorrhaging and necrosis of multiple organs, resulting in die-offs of amphibian populations (Chinchar 2002; Gray et al. 2009). Ranavirus is considered an emerging infectious disease due to increased detections across wider distributions and due to the resulting mass die-offs and population declines; making it a pathogen of concern for the conservation of amphibians (Earl and Gray 2014; Price et al. 2014;

Duffus et al. 2015). Reptiles and fish are also susceptible to ranaviruses and can act as reservoirs for the pathogen, capable of transmitting it to amphibians (Brenes et al. 2014a, b). The disease can be transmitted to uninfected individuals by physical contact, through shared water or soil, 
and consumption of infected tissue during predation, necrophagy, and cannibalism (Harp and Petranka 2006; Gray et al. 2009; Robert et al. 2011). Susceptibility to ranaviruses varies greatly among amphibian species, with higher susceptibility associated with those species inhabiting semi-permanent pools and larvae with rapid development (Hoverman et al. 2011). Wood frogs and spotted salamanders have high and intermediate susceptibility to ranaviruses, respectively (Hoverman et al. 2011), with die-offs previously documented for both species (Green et al. 2002; Docherty et al. 2003). Ranavirus outbreaks and drought reduced larval survival of spotted salamanders and wood frogs in created and natural pools (Petranka et al. 2003b).

Ranavirus mortality rates of amphibians can be influenced by local habitat characteristics (Gahl and Calhoun 2008, 2010). Arizona tiger salamanders (Ambystoma mavortium nebulosum) in pools with less vegetation cover had higher infection rates of Ambystoma tigrinum virus (ATV), potentially due to the congregation of individuals around pool edges (Greer and Collins 2008). Ranavirus gene copy number and mortality rate of spotted salamander and wood frog larvae were higher in higher water temperatures (Brand et al. 2016; Hall et al. 2018). However, the association between temperature and mortality rates is strain- and species-dependent (Rojas et al. 2005; Echaubard et al. 2014). Environmental manipulation has the potential to reduce disease risk for wild populations (Wobeser 2002; Campbell Grant et al. 2018). Determining which habitat characteristics influence host susceptibility to pathogens, pathogen occurrence and prevalence, and infection intensity would help inform management efforts to create and maintain ideal habitat (Campbell Grant et al. 2018).

Risks associated with disease in amphibians may also be tied to genetic diversity. Populations with higher genetic diversity could be more resilient to disease outbreaks (Daszak et al. 2000). Italian agile frogs (Rana latastei) with lower genetic diversity due to range expansion 
and isolation had higher mortality from Ranavirus infection (Pearman and Garner 2005).

Diseases like ranaviruses have the potential to cause genetic bottlenecks in populations due to mortality of entire age classes (Petranka et al. 2003b; Beebee 2012). In the endangered Bob's robber frog (Craugastor punctariolus), museum specimens and extant populations were infected with the same strain of Ranavirus, and extant populations had lower genetic diversity (Puschendorf et al. 2019). This could indicate Ranavirus has contributed to the decline of this species and its reduced genetic diversity.

Physiological condition could be associated with disease progression and mortality risk in amphibians. Disease can elevate the concentration of corticosterone and impact fitness of amphibian tadpoles (Warne et al. 2011; Gabor et al. 2013). Corticosterone regulates the immune system, development and growth (Rollins-Smith 2017). In wood frogs, tadpoles infected with Ranavirus had higher corticosterone concentrations, and faster development rates, and decreased body weight (Warne et al. 2011). Conversely, in northern leopard frog tadpoles, sublethal infections of Ranavirus reduced growth and development (Echaubard et al. 2010). Susceptibility to ranaviruses can vary by developmental stage. Mortality rates due to ranavirus are higher in wood frog metamorphs than earlier larval stages (Warne et al. 2011; Haislip et al. 2011; Hall et al. 2018). Conversely, prevalence of Frog Virus 3 decreased in American bullfrog (Rana catesbeiana) tadpoles as development progressed (Gray et al. 2007). Additionally, tiger salamander larvae and metamorphs can sustain sublethal infection, allowing the disease to persist in the population (Brunner et al. 2004; Greer et al. 2009). 


\section{OBJECTIVES}

The goal of this dissertation is to assess the health of spotted salamander larvae in created vernal pools quantified by corticosterone levels, genetic diversity and structure, and ranavirus prevalence. I also wanted to determine if there were habitat characteristics impacting these parameters to inform future construction techniques to produce habitat conducive to healthy colonizing amphibian populations. I start with examining which habitat traits impact corticosterone levels of salamander larvae. Because I use a new method of sampling for corticosterone, water-borne sampling, I also attempted to biologically validate the method for this species by comparing the concentration of water-borne and plasma samples from the same individuals (Fig. 3). Next, I evaluated the genetic structure and genetic diversity of spotted salamander larvae in these created vernal pools. I also examined whether local habitat characteristics at the pool level influenced genetic diversity and effective number of breeders. Then, I surveyed the pools for ranavirus prevalence and measured viral load in individual larvae. I tested for associations between ranavirus prevalence and viral load and habitat characteristics, genetic diversity, corticosterone levels, and body size.

The results of this dissertation will help inform current management and future site selection and habitat creation by highlighting important habitat characteristics for spotted salamanders. This research also exemplifies the value of monitoring amphibian physiological condition, population genetics, and disease prevalence when evaluating the success of habitat creation. This study contributes to the growing body of knowledge on the association between habitat quality and corticosterone levels and genetic diversity of amphibians. 


\section{STUDY SITE}

All vernal pools sampled were created by the U.S. Forest Service (USFS) on Cheat Mountain in Monongahela National Forest. The nearest town is Huttonsville, WV, USA. These pools were at altitudes of 1,219-1,296 $\mathrm{m}$ above sea level. Vernal pool construction, including size and location, was based on field conditions without predetermined designs or specifications, as part of larger restoration projects (USFS 2014). Pools created in the same year were geographically proximate: Barton Bench pools were created in 2011 (Fig. 1, 4), Lambert North pools in 2013 (Fig. 5), and Lambert South pools in 2014 (Fig. 2). All pools were located within 5 $\mathrm{km}$ of each other. During construction, branches and logs were placed in some of the vernal pools. Pools were constructed without liners so the pools would dry in mid to late summer most years (Fig. 1). Presence of large green frog (Rana clamitans) tadpoles and crayfish (Decapoda) in over half the pools indicated some pools may have permanent hydroperiods, but I did not conduct surveys to confirm this.

These areas were acquired by the USFS in the 1980s after they were strip-mined for coal in the 1970s. Restoration was initiated in 2009 and included removal of non-native Norway spruce (Picea abies) and red pine (Pinus resinosa) planted during mine reclamation, ripping to mitigate soil compaction, and planting saplings including aspens (Populus spp.), red spruce (Picea rubens), black cherry (Prunus serotina), wild raisin (Viburnum nudum), elderberry (Sambucus nigra), and service berry (Amelanchier arborea; Sandeno 2011; USFS 2014). Most vernal pools included in this study had open canopy due to recent removal of non-native trees. Mean monthly temperatures in Huttonsville, WV range from -1 to $19^{\circ} \mathrm{C}$ with average annual precipitation of $172.5 \mathrm{~cm}$ (Canty 2018). Total precipitation was $135.8 \mathrm{~cm}$ from July 2014-June 
2015 and $102.4 \mathrm{~cm}$ from July 2015-June 2016 (The Weather Underground Elkins-Randolph County Station).

I conducted preliminary surveys in late March and early May 2015 using coordinates for created pools provided by the USFS. I documented which pools retained water and had spotted salamander egg masses present (Fig. 1). In May and June of 2015 and 2016, I attempted to sample 46 pools for spotted salamander larvae.

Note: Vernal pool names assigned by USFS were changed in the genetics chapter to better represent the proximity of sampled pools to each other. 

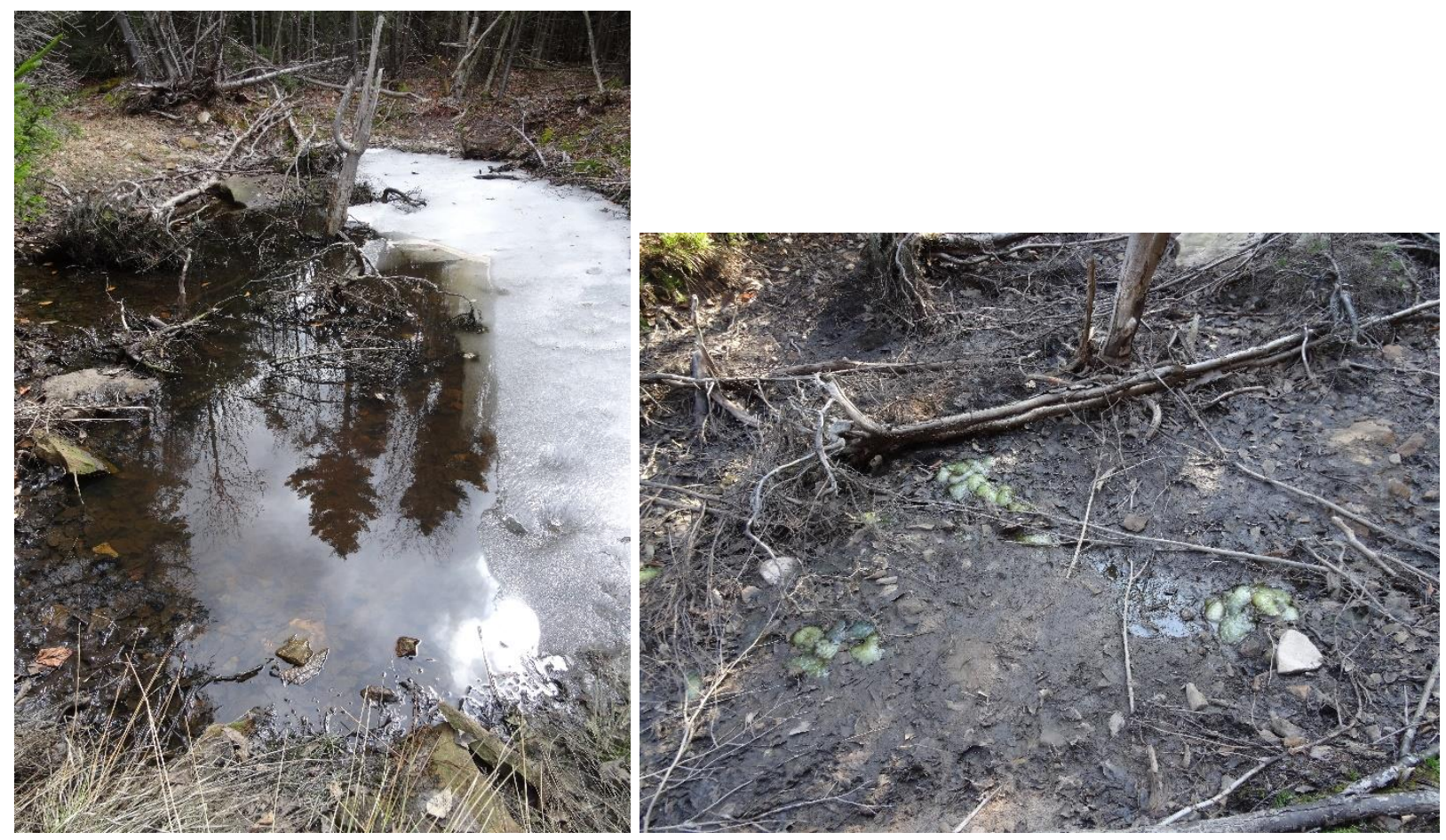

Figure 1. Photographs of a Barton Bench vernal pool (BB6) created in Monongahela National Forest near Huttonsville, West Virginia that retained water March 28, 2015 (left), but dried by May 6, 2015 (right), resulting in desiccation of spotted salamander (Ambystoma maculatum) egg masses. 

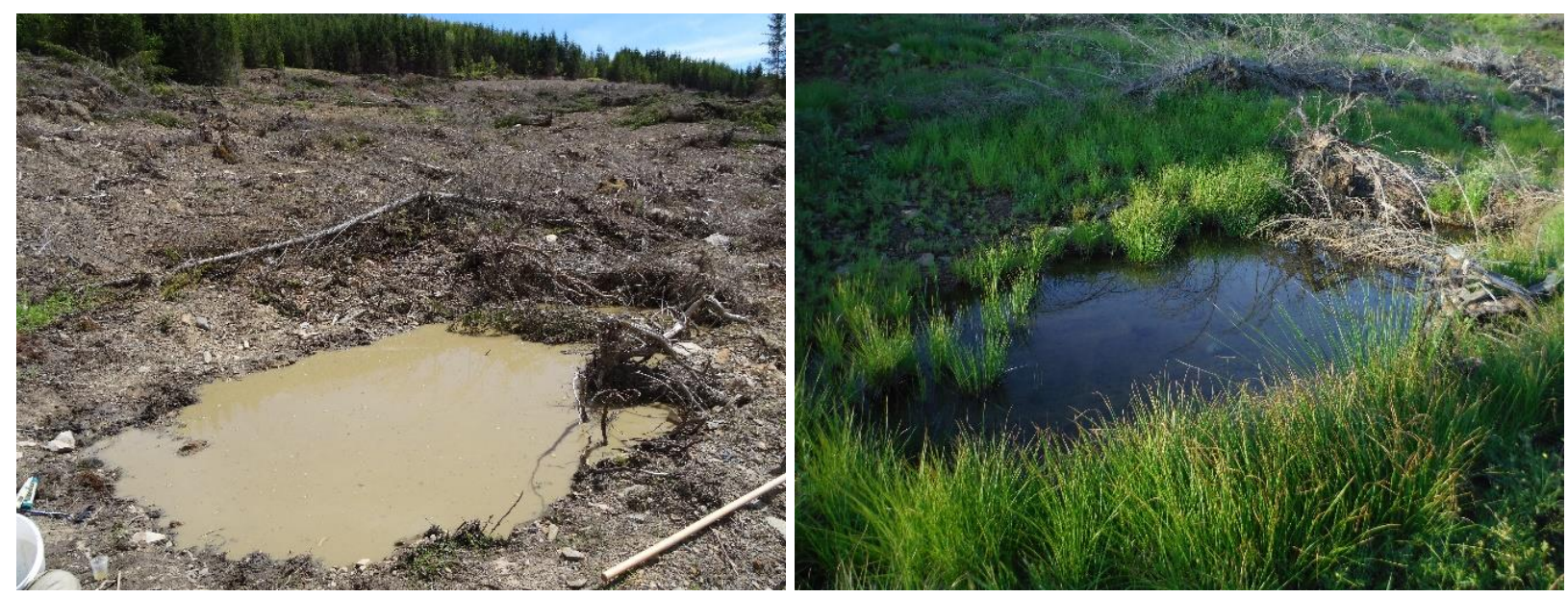

Figure 2. Photographs of a Lambert South vernal pool (LS125) created in Monongahela

National Forest near Huttonsville, West Virginia illustrating changes to the habitat from the first spring (May 20, 2015; left) after initial creation to the second spring (May 25, 2016; right). 

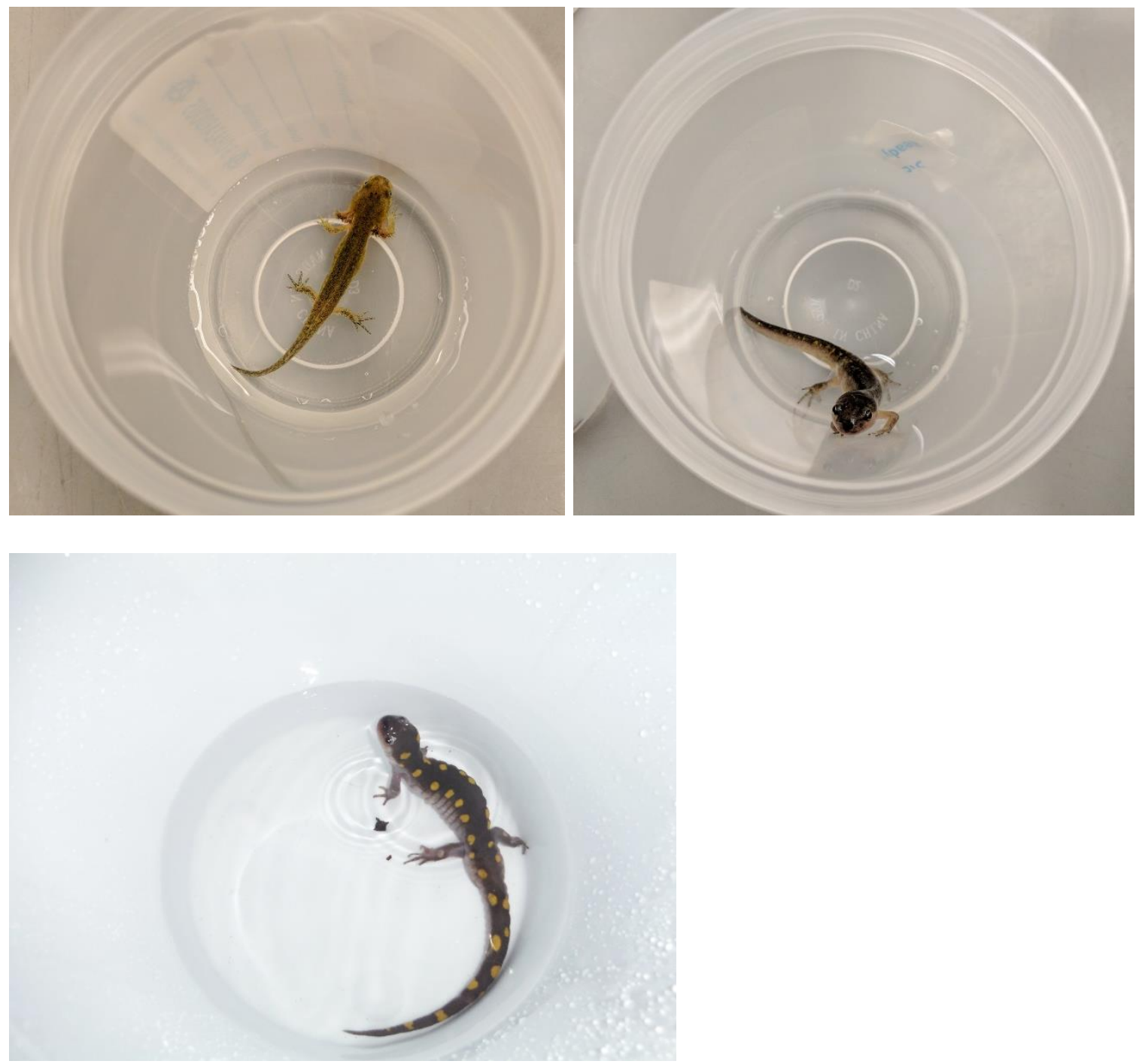

Figure 3. Photographs of spotted salamander (Ambystoma maculatum) larva (top left), metamorph (top right), and adult (bottom left) contained in water for water-borne hormone sampling validation. 


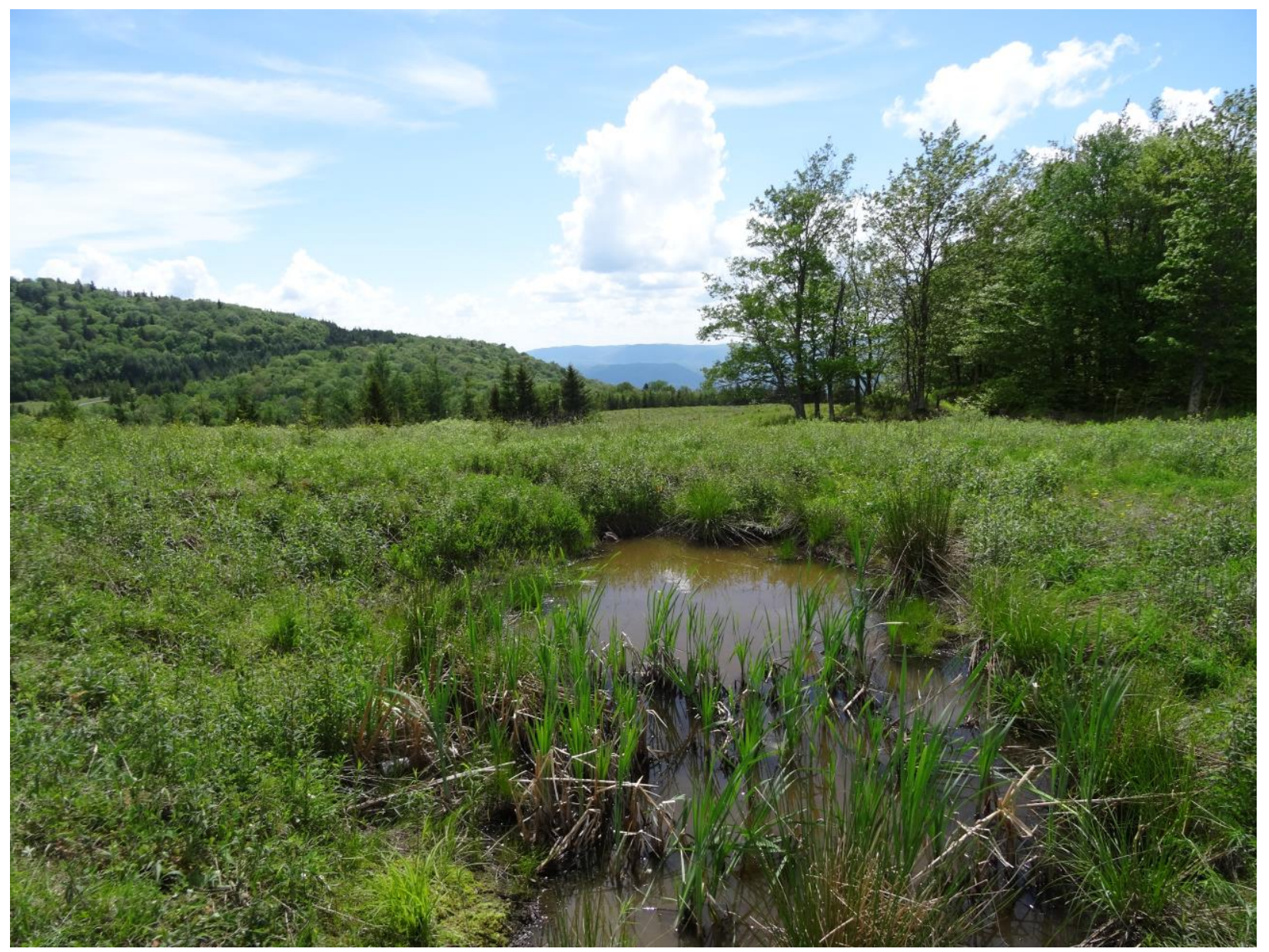

Figure 4. Photograph showing the surrounding area of a Barton Bench vernal pool (BB8) created in Monongahela National Forest near Huttonsville, West Virginia. Taken May 27, 2015. 


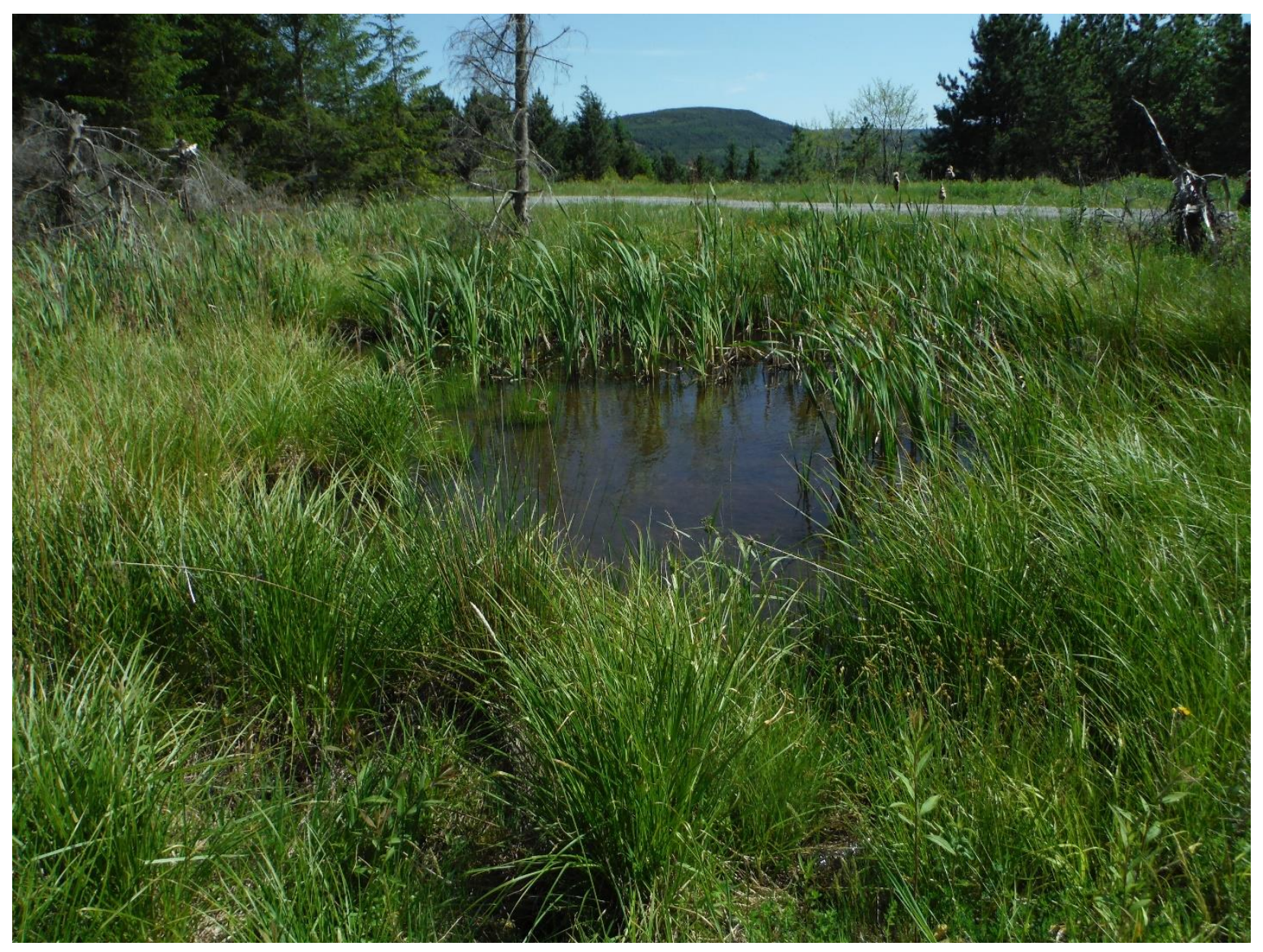

Figure 5. Photograph showing proximity to a dirt road for a Lambert North vernal pool (LS2) created in Monongahela National Forest near Huttonsville, West Virginia. Taken June 9, 2016. 


\section{REFERENCES}

Beebee TJC. 2005. Conservation genetics of amphibians. Heredity 95(6):423-427. https://doi.org/10.1038/sj.hdy.6800736

Beebee T. 2012. Impact of Ranavirus on garden amphibian populations. Herpetological Bulletin 120:1-3.

Belden LK, Kiesecker JM. 2005. Glucocorticosteroid hormone treatment of larval treefrogs increases infection by Alaria sp. trematode cercariae. The Journal of Parasitology 91(3):686688. https://doi.org/10.1645/GE-397R

Brand MD, Hill RD, Brenes R, Chaney J C, Wilkes RP, Grayfer L, Miller DL, Gray MJ. 2016. Water temperature affects susceptibility to ranavirus. EcoHealth 13(2):350-359. https://doi.org/10.1007/s10393-016-1120-1

Brenes R, Gray MJ, Waltzek TB, Wilkes RP, Miller DL. 2014a. Transmission of ranavirus between ectothermic vertebrate hosts. PLoS ONE 9(3):e92476. https://doi.org/10.1371/journal.pone.0092476

Brenes R, Miller DL, Waltzek B, Wilkes RP, Tucker JL, Chaney JC, Hardman RH, Brand MD, Huether RR, Gray MJ. 2014b. Susceptibility of fish and turtles to three ranaviruses isolated from different ectothermic vertebrate classes. Journal of Aquatic Animal Health 26(2):118126. https://doi.org/10.1080/08997659.2014.886637

Brodman R. 1993. The effect of acidity on interactions of Ambystoma salamander larvae. Journal of Freshwater Ecology 8(3):209-214. https://doi.org/10.1080/02705060.1993.9664856

Brunner J, Schock D, Davidson E, Collins J. 2004. Intraspecific reservoirs: complex life history and the persistence of a lethal ranavirus. Ecology 85(2):560-566. https://doi.org/10.1890/02$\underline{0374}$ 
Calhoun AJK, deMaynadier PG. 2008. Preface. In Calhoun AJK and deMaynadier PG. (Eds.). Science and Conservation of Vernal Pools in Northeastern North America (pp. 1127-148). Boca Raton, FL: Taylor \& Francis Group, LLC

Calhoun AJK, Arrigoni J, Brooks RP, Hunter ML, Richter SC. 2014. Creating successful vernal pools: a literature review and advice for practitioners. Wetlands 34(5):1027-1038. https://doi.org/10.1007/s13157-014-0556-8

Campbell Grant EH, Adams MJ, Fisher RN, Grear DA, Halstead BJ, Hossack BR, Muths E, Richgels KLD, Russel RE, Smalling KL, Hardin Waddle J, Wallis SC, LeAnn White C. 2018. Identifying management-relevant research priorities for responding to diseaseassociated amphibian declines. Global Ecology and Conservation 16:e00441.

\section{https://doi.org/10.1016/j.gecco.2018.e00441}

Canty JL. 2018. Weatherbase. http://weatherbase.com. Accessed 22 Jun 2018.

Caorsi VZ, Both C, Cechin S, Antunes R, Borges-Martins M. 2017. Effects of traffic noise on the calling behavior of two Neotropical hylid frogs. PLoS ONE 12(8): e0183342. https://doi.org/10.1371/journal.pone.0183342

Chambers DL, Wojdak JM, Du P, Belden LK. 2013. Pond acidification may explain differences in corticosterone among salamander populations. Physiological and Biochemical Zoology 86(2):224-232. https://doi.org/10.1086/669917

Charbonnier JF, Pearlmutter J, Vonesh JR, Gabor CR, Forsburg ZR, Grayson KL. 2018. Crosslife stage effects of aquatic larval density and terrestrial moisture on growth and corticosterone in the spotted salamander. Diversity 10(3):68. https://doi.org/10.3390/d10030068 
Chinchar VG. 2002. Ranaviruses (family Iridoviridae): emerging cold-blooded killers. Archives of Virology 147(3):447-470. https://doi.org/10.1007/s007050200000

Clark KL. 1986. Responses of Ambystoma maculatum populations in central Ontario to habitat acidity. The Canadian Field-Naturalist 100(4):463-469.

Clipp HL, Anderson JT. 2014. Environmental and anthropogenic factors influencing salamanders in riparian forests: A Review. Forests 5(11): 2679-2703. https://doi.org/10.3390/f5112679

Cosentino BJ, Phillips CA, Schooley RL, Lowe WH, Douglas MR. 2012. Linking extinctioncolonization dynamics to genetic structure in a salamander metapopulation. Proceedings of the Royal Society B 279(1733):1575-1582. https://doi.org/10.1098/rspb.2011.1880

Costanzi J-M, Mège P, Boissinot A, Isselin-Nondedeu F, Guérin S, Lourdais O, Trochet A, Le Petitcorps Q, Legrand A, Varenne F, Grillet P, Morin-Pinaud S, Picard D. 2018. Agricultural landscapes and the Loire River influence the genetic structure of the marbled newt in Western France. Scientific Reports 8(1):14177. https://doi.org/10.1038/s41598-018-32514-y

Creel S, Fox J, Hardy A, Sands J, Garrott B, Peterson R. 2002. Snowmobile activity and glucocorticoid stress responses in wolves and elk. Conservation Biology 16(3):809-814. https://doi.org/10.1046/j.1523-1739.2002.00554.x

Crespi EJ, Denver RJ. 2005. Roles of stress hormones in food intake regulation in anuran amphibians throughout the life cycle. Comparative Biochemistry and Physiology, Part A 141(4):381-390. https://doi.org/10.1016/j.cbpb.2004.12.007

Cushman, S.A. 2006. Effects of habitat loss and fragmentation on amphibians: a review and prospectus. Biological Conservation 128(2):231-240.

https://doi.org/10.1016/j.biocon.2005.09.031 
Dahl TE. 1990. Wetlands losses in the United States 1780 's to 1980's. U.S. Department of the Interior, Fish and Wildlife Service, Washington, D.C. 13pp.

Dahl TE. 2006. Status and trends of wetlands in the conterminous United States 1998 to 2004.

U.S. Department of the Interior; Fish and Wildlife Service, Washington, D.C. 112pp.

Dahl TE. 2011. Status and trends of wetlands in the conterminous United States 2004 to 2009.

U.S. Department of the Interior; Fish and Wildlife Service, Washington, D.C. 108pp.

Daszak P, Cunningham AA, Hyatt AD. 2000. Wildlife ecology - emerging infectious diseases of wildlife - threats to biodiversity and human health. Science 287(5452):443-449.

https://doi.org/10.1126/science.287.5452.443

DiBello FJ, Calhoun AJK, Morgan DE, Shearin AF. 2016. Efficiency and detection accuracy using print and digital stereo aerial photography for remote mapping vernal pools in New England landscapes. Wetlands 36(3):505-514. https://doi.org/10.1007/s13157-016-0759-2

Docherty DE, Meteyer CU, Wang J, Mao J, Case ST, Chinchar VG. 2003. Diagnostic and molecular evaluation of three Iridovirus-associated salamander mortality events. Journal of Wildlife Diseases 39(3):556-566. https://doi.org/10.7589/0090-3558-39.3.556

Duffus ALJ, Marschang RE, Waltzek TB, Stöhr A, Allender MC, Gotesman M, Whittington R, Hick P, Hines M. 2015. Distribution and host range of ranaviruses. In: Gray MJ, Chinchar VG (eds) Ranaviruses: lethal pathogens of ectothermic vertebrates. Springer, Secaucus

Earl JE, Gray MJ. 2014. Introduction of ranavirus to isolated wood frog populations could cause local extinction. Ecohealth 11(4):581. https://doi.org/10.1007/s10393-014-0950-y

Echaubard P, Leduc J, Pauli B, Chinchar G, Robert J, Lesbarrères D. 2014. Environmental dependency of amphibian-ranavirus genotypic interactions: evolutionary perspectives on 
infectious diseases. Evolutionary Applications 7(7):723-733.

https://doi.org/10.1111/eva.12169

Echaubard P, Little K, Pauli B, Lesbarrères D. 2010. Context-dependent effects of ranaviral infection on northern leopard frog life history traits. PLoS ONE 5(10):e13723. https://doi.org/10.1371/journal.pone.0013723

Egan RS, Paton PWC. 2004. Within-pond parameters affecting oviposition by wood frogs and spotted salamanders. Wetlands 24(1):1-13. https://doi.org/10.1672/0277-

\section{2(2004)024[0001:WPAOBW]2.0.CO;2}

Felix ZI, Wang Y, Schweitzer CJ. 2010. Effects of experimental canopy manipulation on amphibian egg deposition. The Journal of Wildlife Management 74(3):496-503.

\section{https://doi.org/10.2193/2008-181}

Feuka AB, Hoffmann KE, Hunter Jr. ML, Calhoun AJK. 2017. Effects of light pollution on habitat selection in post-metamorphic wood frogs (Rana sylvaticus) and unisexual bluespotted salamanders (Ambystoma laterale X jeffersonianum). Herpetological Conservation and Biology, 12(2): 470-476.

Formanowicz DR, Bobka MS. 1989. Predation risk and microhabitat preference: an experimental study of the behavioral responses of prey and predator. The American Midland Naturalist 121(2):379-386. https://doi.org/10.2307/2426042

Frankham R. 2005. Genetics and extinction. Biological Conservation 126(2):131-140. https://doi.org/10.1016/j.biocon.2005.05.002

Gabor CR, Fisher MC, Bosch J. 2013. A non-invasive stress assay shows that tadpole populations infected with Batrachochytrium dendrobatidis have elevated corticosterone levels. PLoS ONE 8(2):e56054. https://doi.org/10.1371/journal.pone.0056054 
Gahl MK, Calhoun AJK. 2008. Landscape setting and risk of Ranavirus mortality events. Biological Conservation 141(11):2679-2689. https://doi.org/10.1016/j.biocon.2008.08.003

Gahl MK, Calhoun AJK. 2010. The role of multiple stressors in ranavirus-caused amphibian mortalities in Acadia National Park wetlands. Canadian Journal of Zoology 88(1):108-121. https://doi.org/10.1139/Z09-124

Glennemeier KA, Denver RJ. 2002. Role for corticoids in mediating the response of Rana pipiens tadpoles in intraspecific competition. Journal of Experimental Zoology 292(1):32-40. https://doi.org/10.1002/jez.1140

Glista DJ, DeVault TL, DeWoody JA. 2008. Vertebrate road mortality predominantly impacts amphibians. Herpetological Conservation and Biology 3(1):77-87.

Gosner KK, Black IH. 1957. The effects of acidity on the development of New Jersey frogs. Ecology 38:256-262

Graham SP, Freidenfelds NA, McCormick GL, Langkilde T. 2012. The impacts of invaders: basal and acute stress glucocorticoid profiles and immune function in native lizards threatened by invasive ants. General and Comparative Endocrinology 176(3):400-408. https://doi.org/10.1016/j.ygcen.2011.12.027

Gray MJ, Miller DL, Hoverman JT. 2009. Ecology and pathology of amphibian ranaviruses. Diseases of Aquatic Organisms 87(3):243-266. https://doi.org/10.3354/dao02138

Gray MJ, Miller DL, Schmutzer AC, Baldwin CA. 2007. Frog Virus 3 prevalence in tadpole populations inhabiting cattle-access and non-access wetlands in Tennessee, USA. Diseases of Aquatic Organisms 77(2):97-103. https://doi.org/10.3354/dao01837 
Green DE, Converse KA, Schrader AK. 2002. Epizootiology of sixty-four amphibian morbidity and mortality events in the USA, 1996-2001. Annals of the New York Academy of Sciences 969(1):323-339. https://doi.org/10.1111/j.1749-6632.2002.tb04400.x

Greer AL, Brunner JL, Collins JP. 2009. Spatial and temporal patterns of Ambystoma tigrinum virus (ATV) prevalence in tiger salamanders Ambystoma tigrinum nebulosum. Diseases of Aquatic Organisms 85(1):1-6. https://doi.org/10.3354/dao02061

Greer AL, Collins JP. 2008. Habitat fragmentation as a result of biotic and abiotic factors controls pathogen transmission through a host population. Journal of Animal Ecology 77(2):364-369. https://doi.org/10.1111/j.1365-2656.2007.01330.x

Haislip NA, Gray MJ, Hoverman JT, Miller DL. 2011. Development and disease: how susceptibility to an emerging pathogen changes through anuran development. PLoS ONE 6(7):e22307. https://doi.org/10.1371/journal.pone.0022307

Hall EM, Goldberg CS, Brunner JL, Crespi EJ. 2018. Seasonal dynamics and potential drivers of ranavirus epidemics in wood frog populations. Oecologia 188(4):1253-1262. https://doi.org/10.1007/s00442-018-4274-4

Harp EM, Petranka JW. 2006. Ranavirus in wood frogs (Rana sylvatica): potential sources of transmission within and between ponds. Journal of Wildlife Diseases 42(2):307-318.

\section{https://doi.org/10.7589/0090-3558-42.2.307}

Hayes TB, Case P, Chui S, Chung D, Haeffele C, Haston K, Lee M, Mai VP, Marjuoa Y, Parker J, Tsui M. 2006. Pesticide mixtures, endocrine disruption, and amphibian declines: are we underestimating the impact? Environmental Health Perspectives 114(Suppl 1):40-50. https://doi.org/10.1289/ehp.8051 
Homan RN, Regosin JV, Rodrigues DM, Reed JM, Windmiller BS, Romero LM. 2003. Impacts of varying habitat quality on the physiological stress of spotted salamanders (Ambystoma maculatum). Animal Conservation 6(1):11-18. https://doi.org/10.1017/S1367943003003032

Homyack JA. 2010. Evaluating habitat quality of vertebrates using conservation physiology tools. Wildlife Research 37(4):332-342. https://doi.org/10.1071/WR08093

Hopkins WA, Mendonca MT, Congdon JD. 1999. Responsiveness of the hypothalamo-pituitaryinterrenal axis in an amphibian (Bufo terrestris) exposed to coal combustion wastes. Comparative Biochemistry and Physiology, Part C 122(2):191-196. https://doi.org/10.1016/S0742-8413(98)10104-4

Hossie TJ, MacFarlane S, Clement A, Murray DL. 2017. Threat of predation alters aggressive interactions among spotted salamander (Ambystoma maculatum) larvae. Ecology and Evolution 8(6):3131-3138. https://doi.org/10.1002/ece3.3892

Hoverman JT, Gray MJ, Haislip NA, Miller DL. 2011. Phylogeny, life history, and ecology contribute to differences in amphibian susceptibility to ranaviruses. EcoHealth 8(3):301-319. https://doi.org/10.1007/s10393-011-0717-7

Huang B, Lubarsky K, Teng T, Blumstein DT. 2011. Take only pictures, leave only... fear? The effects of photography on the West Indian anole Anolis cristatellus. Current Zoology 57(1):77-82. https://doi.org/10.1093/czoolo/57.1.77

Ireland PH. 1989. Larval survivorship in two populations of Ambystoma maculatum. Journal of Herpetology 23(3):209-215. https://doi.org/10.2307/1564441

Janin A, Léna JP, Deblois S, Joly P. 2012. Use of stress-hormone levels and habitat selection to assess functional connectivity of a landscape for an amphibian. Conservation Biology 26(5):923-931. https://doi.org/10.1111/j.1523-1739.2012.01910.x 
Johnson MD. 2007. Measuring habitat quality: a review. Condor 109(3):489-504. https://doi.org/10.1650/8347.1

Kern MM, Nassar AA, Guzy JC, Dorcas ME. 2013. Oviposition site selection by spotted salamanders (Ambystoma maculatum) in an isolated wetland. Journal of Herpetology 47(3):445-449. https://doi.org/10.1670/11-179

Kilpatrick AM, Briggs CJ, Daszak P. 2010. The ecology and impact of Chytridiomycosis: an emerging disease of amphibians. Trends in Ecology \& Evolution 25(2):109-118. https://doi.org/10.1016/j.tree.2009.07.011

McCormick SD, Romero M. 2017. Conservation endocrinology. BioScience 67(5):429-442. https://doi.org/10.1093/biosci/bix026

McEwen BS, Wingfield JC. 2003. The concept of allostasis in biology and biomedicine. Hormones and Behavior 43(1):2-15. https://doi.org/10.1016/S0018-506X(02)00024-7

McKee AM, Maerz JC, Smith LL, Glenn TC. 2017. Habitat predictors of genetic diversity for two sympatric wetland-breeding amphibian species. Ecology and Evolution 7(16):62716283. https://doi.org/10.1002/ece3.3203

Moore IT, Jessop TS. 2003. Stress, reproduction, and adrenocortical modulation in amphibians and reptiles. Hormones and Behavior 43(1):39-47. https://doi.org/10.1016/S0018$\underline{506 X(02) 00038-7}$

Müllner A, Linsenmair KE, Wikelski M. 2004. Exposure to ecotourism reduces survival and affects stress response in hoatzin chicks (Opisthocomus hoazin). Biological Conservation 118(4):549-558. https://doi.org/10.1016/j.biocon.2003.10.003 
Pearman PB, Garner TWJ. 2005. Susceptibility of Italian agile frog populations to an emerging strain of Ranavirus parallels population genetic diversity. Ecology Letters 8(4):401-408. https://doi.org/10.1111/j.1461-0248.2005.00735.x

Petranka JW, Kennedy CA, Murray SS. 2003a. Response of amphibians to restoration of a southern Appalachian wetland: a long-term analysis of community dynamics. Wetlands 23(4):1030-1042. https://doi.org/10.1672/0277-5212(2003)023[1030:ROATRO]2.0.CO;2

Petranka JW, Kennedy CA, Murray SS. 2003b. Response of amphibians to restoration of a southern Appalachian wetland: perturbations confound post-restoration assessment. Wetlands 23(2):278-290. https://doi.org/10.1672/7-20

Price SJ, Garner TW, Nichols RA, Balloux F, Ayres C, de Alba AM, Bosch J. 2014. Collapse of amphibian communities due to an introduced Ranavirus. Current Biology 24(21):2586-2591. http://dx.doi.org/10.1016/j.cub.2014.09.028

Puschendorf R, Wallace M, Chavarría MM, Crawford AJ, Wynne F, Knight M, Janzen DH, Hallwachs W, Palmer CV, Price SJ. 2019. Cryptic diversity and ranavirus infection of a critically endangered Neotropical frog before and after population collapse. Animal Conservation. https://doi.org/10.1111/acv.12498

Reed DH, Frankham R. 2003. Correlation between fitness and genetic diversity. Conservation Biology 17(1):230-237. https://doi.org/10.1046/j.1523-1739.2003.01236.x

Robert J, George E, Andino FD, Chen G. 2011. Waterborne infectivity of the Ranavirus frog virus 3 in Xenopus laevis. Virology 417(2):410-417.

http://dx.doi.org/10.1016/j.virol.2011.06.026 
Rojas S, Richards K, Jancovich JK, Davidson EW. 2005. Influence of temperature on ranavirus infection in larval salamanders Ambystoma tigrinum. Diseases of Aquatic Organisms 63(23):95-100. https://doi.org/10.3354/dao063095

Rolland RM, Parks SE, Hunt KE, Castellote M, Corkeron PJ, Nowacek DP, Wasser SK, Kraus SD. 2012. Evidence that ship noise increases stress in right whales. Proceedings of the Royal Society of London B: Biological Sciences 279(1737): 2363-2368.

\section{https://doi.org/10.1098/rspb.2011.2429}

Rollins-Smith LA. 2017. Amphibian immunity-stress, disease, and climate change.

Developmental and Comparative Immunology 66:111-119. http://dx.doi.org/10.1016/j.dci.2016.07.002

Romero LM. 2004. Physiological stress in ecology: lessons from biomedical research. Trends in Ecology \& Evolution 19(5):249-255. https://doi.org/10.1016/j.tree.2004.03.008

Romero L, Wikelski M. 2001. Corticosterone levels predict survival probabilities of Galápagos marine iguanas during El Nino events. Proceedings of the National Academy of Sciences of the United States of America 98(13):7366-7370. https://doi.org/10.1073/pnas.131091498

Rowe CL, Dunson WA. 1993. Relationships among biotic parameters and breeding effort by three amphibians in temporary wetlands of central Pennsylvania. Wetlands 13(4):237-246. https://doi.org/10.1007/BF03161290

Sandeno CM. 2011. Project status report - Barton Bench ecological restoration Greenbrier ranger district Monongahela National Forest. W.V. Department of Environmental Protection, Division of Mining and Reclamation. 
Scheffers BR, Furman BL, Evans JP. 2013. Salamanders continue to breed in ephemeral ponds following the removal of surrounding terrestrial habitat. Herpetological Conservation and Biology 8(3):715-723

Scheuerlein A, Van’t Hof TJ, Gwinner E. 2001. Predators as stressors? Physiological and reproductive consequences of predation risk in tropical stonechats (Saxicola torquata axillaris). Proceedings of the Royal Society of London B: Biological Sciences 269(1476): 1575-1582. https://doi.org/10.1098/rspb.2001.1691

Skelly, D.K. 1996. Pond drying, predators, and the distribution of Pseudacris tadpoles. Copeia 1996(3):599-605. https://doi.org/10.2307/1447523

Skidds DE, Golet FC, Paton PW, Mitchell JC. 2007. Habitat correlates of reproductive effort in wood frogs and spotted salamanders in an urbanizing watershed. Journal of Herpetology 41(3):439-450. https://doi.org/10.1670/0022-1511(2007)41[439:HCOREI]2.0.CO;2

Sodhi NS, Bickford D, Diesmos AC, Lee TM, Koh LP, Brook BW, Sekercioglu CH, Bradshaw CJ. 2008. Measuring the meltdown: drivers of global amphibian extinction and decline. PloS one 3(2):e1636. https://doi.org/10.1371/journal.pone.0001636

Spielman D, Brook BW, Frankham R. 2004. Most species are not driven to extinction before genetic factors impact them. Proceedings of the National Academy of Sciences 101(42):15261-15264. https://doi.org/10.1073/pnas.0403809101

Stuart SN, Chanson JS, Cox NA, Young BE, Rodrigues AS, Fischman DL, Waller RW. 2004. Status and trends of amphibian declines and extinctions worldwide. Science 306(5702): 1783-1786. https://doi.org/10.1126/science.1103538 
Sutton WB, Barrett K, Moody AT, Loftin CS, deMaynadier PG, Nanjappa P. 2015. Predicted changes in climatic niche and climate refugia of conservation priority salamander species in the northeastern United States. Forests 6(1):1-26. https://doi.org/10.3390/f6010001

Trö̈anowski M, Mondy N, Dumet A, Arcanjo C, Lengagne T. 2017. Effects of traffic noise on tree frog stress levels, immunity, and color signaling. Conservation Biology 31(5):11321140. https://doi.org/10.1111/cobi.12893

United States Forest Service. 2014. Mower Tract ecological restoration final report.

Van Grunsven RH, Creemers R, Joosten K, Donners M, Veenendaal EM. 2017. Behavior of migrating toads under artificial lights differ from other phases of their life cycle. AmphibiaReptilia 38(1):49-55. https://doi.org/10.1163/15685381-00003081

Wang J. 2009. A new method for estimating effective population sizes from a single sample of multilocus genotypes. Molecular Ecology 18(10):2148-2164. https://doi.org/10.1111/j.1365294X.2009.04175.X

Waples RS, Luikart G, Faulker JR, Tallmon DA. 2013. Simple life-history traits explain key effective population size ratios across diverse taxa. Proceedings of the Royal Society B 280(1768):20131339. http://dx.doi.org/10.1098/rspb.2013.1339

Warne RW, Crespi EJ, Brunner JL. 2011. Escape from the pond: stress and developmental responses to ranavirus infection in wood frog tadpoles. Functional Ecology 25(1):139-146. https://doi.org/10.1111/j.1365-2435.2010.01793.x

The Weather Underground Elkins-Randolph County Station. Weather history for ElkinsRandolph County, WV. Weather Underground, The Weather Company. https://www.wunderground.com/history/daily/us/wv/mill-creek/KEKN/date/2019-117?cm_ven=localwx_history. Accessed 15 January 2019. 
Wikelski M, Cookie SJ. 2006. Conservation physiology. Trends in Ecology \& Evolution 21(1):38-46. https://doi.org/10.1016/j.tree.2005.10.018

Wikelski M, Wong V, Chevalier B, Rattenborg N, Snell HL. 2002. Galapagos Islands: marine iguanas die from trace oil pollution. Nature 417(6889):607-608. https://doi.org/10.1038/417607a

Wingfield JC, Maney DL, Breuner CW, Jacobs JD, Lynn S, Ramenofsky M, Richardson RD. 1998. Ecological bases of hormone-behavior interactions: the "emergency life history stage." American Zoologist 38(1):191-206. https://doi.org/10.1093/icb/38.1.191

Wobeser G. 2002. Disease management strategies for wildlife. Revue Scientifique et TechniqueOffice international des epizooties 21(1):159-178. https://doi.org/10.20506/rst.21.1.1326 


\title{
Chapter 2
}

\section{Habitat Characteristics in Created Vernal Pools Impact Spotted Salamander Water-borne Corticosterone Levels}

Alice R. Millikin ${ }^{1 *}$, Sarah K. Woodley ${ }^{2}$, Drew R. Davis ${ }^{3}$, James T. Anderson ${ }^{1}$

${ }^{1}$ School of Natural Resources, West Virginia University, PO Box 6125, Morgantown, WV 26506, USA; e-mail: jim.anderson@mail.wvu.edu

${ }^{2}$ Biological Sciences, Duquesne University, 600 Forbes Avenue, Pittsburgh, PA 15282, USA; email:woodleys@duq.edu

${ }^{3}$ School of Earth, Environmental, and Marine Sciences, University of Texas Rio Grande Valley, 100 Marine Lab Drive, South Padre Island, TX 78597, USA; e-mail: drew.davis@utrgv.edu

*Corresponding author e-mail: alicemillikin@gmail.com

\begin{abstract}
Spotted salamanders (Ambystoma maculatum) require vernal pools for breeding habitat. Limited protection and preservation of vernal pools makes suitable habitat creation important. Differences in corticosterone levels, a hormone associated with growth, development, and stress in amphibians, could indicate population health and habitat quality. Our objective was to
\end{abstract}


determine if habitat characteristics in created vernal pools influence corticosterone levels of spotted salamander larvae. In May and June of 2015 and 2016, we sampled water-borne corticosterone levels of larval spotted salamanders in 34 created vernal pools constructed 1-5 years earlier. Using multiple regression, we determined the best model predicting corticosterone levels included larval total length, pool-water temperature, year sampled, and pool diameter. Pool-water $\mathrm{pH}$, depth, and age; percent cover; and predator presence were not significant predictors. Annual variation in corticosterone levels and habitat characteristics, and positive associations with water temperature and salamander body size highlighted the importance of controlling for external influences. The negative association between pool diameter and corticosterone indicated that larvae in larger pools (up to 12.75 -m maximum diameter) were less stressed and potentially healthier. These results indicate that pool diameter contributes to habitat quality and may be important when constructing vernal pools for spotted salamanders.

Keywords: Ambystoma maculatum; Caudata; habitat creation; hormones; stress

\section{INTRODUCTION}

Vernal pools are seasonal palustrine wetlands that lack permanent, surface-water connections to other bodies of water. These pools provide critical, fishless, breeding habitat for amphibians like spotted salamanders (Ambystoma maculatum). Despite wetland mitigation efforts, vernal pools are susceptible to destruction and degradation. Vernal pools are difficult to detect and regulate due to the ephemeral nature of their pool water, and in some cases, small size (Dibello et al. 2016). Under current interpretation of the Clean Water Act, federal regulation and conservation only apply to larger wetlands, i.e., wetlands $>0.04$ ha, with permanent, surface- 
water flow to rivers. This leaves vernal pool habitat vulnerable to destruction and makes habitat creation an important conservation tool to reduce the impact of habitat losses.

Created vernal pools have varying levels of success, as measured by reproduction and metamorphosis of pool-breeding amphibians. Habitat characteristics incorporated during construction could determine the success of vernal pool creation. When creating pools, it is difficult to replicate conditions of natural pools such as hydroperiod length, pool size, pool depth, canopy closure, and vegetation (Calhoun et al. 2014). Habitat quality in created pools is important for spotted salamander reproductive success and completion of metamorphosis for larvae. Permanent hydroperiods in created pools can support predators that would otherwise be excluded, such as eastern newts (Notophthalmus viridescens), which can be detrimental to vernal pool amphibians (Vasconcelos and Calhoun 2006, Denton and Richter 2013).

Several habitat characteristics have been associated with increased number of spotted salamander eggs present and their hatching success in lab, mesocosm, and field studies including both natural and created wetlands. These habitat characteristics include larger pool size, higher water pH, deeper water, and longer hydroperiod (Clark 1986, Rowe and Dunson 1993, Petranka et al. 2003a, Skidds et al. 2007). Low pH levels $(<5.5)$ in pools reduced hatching success, larval growth, development and survival, and a $\mathrm{pH} \leq 4.0$ was lethal (Gosner and Black 1957, Brodman 1993). Egg mass density was positively correlated with forest cover within 1,000 m of a pool, with spotted salamanders seemingly avoiding pools in clear-cut forests (Skidds et al. 2007, Felix et al. 2010, Scheffers et al. 2013). Vegetation or cover in a pool is important for oviposition, and also provides refuge for larvae from intra- and interspecific predators and a water temperature gradient (Formanowicz and Bobka 1989, Kern et al. 2013). Pools with more complex vegetation structure have been found to have more spotted salamander egg masses (Egan and Paton 2004). 
Time since pool construction is also an important factor when examining vernal pool success to determine if the colonizing population in a pool stabilizes or goes extinct over time (Petranka et al. 2003b, Vasconcelos and Calhoun 2006).

Physiological condition of amphibians inhabiting created pools may also be a valuable measure of habitat creation success. In particular, corticosterone (CORT) is a hormone that could be a useful indicator of sublethal impacts and habitat quality (Romero and Wikelski 2001, Homyack 2010, McCormick and Romero 2017). Corticosterone is a glucocorticoid hormone produced by the hypothalamus-pituitary-interrenal (HPI) axis and is related to stress, development, and growth in amphibians. Corticosterone causes behavioral and physiological changes such as increasing available energy to maintain allostasis (McEwen and Wingfield 2003). Chronic stressors can cause prolonged elevation of CORT with harmful consequences that include suppression of the immune system and growth (Wingfield et al. 1998, McEwen and Wingfield 2003, Moore and Jessop 2003, Romero 2004, Belden and Kiesecker 2005). The CORT-fitness hypothesis posits that baseline CORT levels are negatively related to fitness (Bonier et al. 2009).

Multiple amphibian species have shown associations between glucocorticoid hormones and environmental conditions. For example, spotted salamanders had elevated CORT levels in habitat with anthropogenic disturbance (Homan et al. 2003). Larval spotted salamanders in high intraspecific density environments and juvenile salamanders in low moisture environments had higher levels of CORT (Charbonnier et al. 2018). Jefferson salamander (Ambystoma jeffersonianum) larvae in natural pools and mesocosms had higher CORT levels in more acidic environments (Chambers et al. 2013). Northern leopard frog (Rana pipiens) tadpoles had higher levels of CORT when there was limited food or high intraspecific density (Glennemeier and 
Denver 2002). Western spadefoot toad (Spea hammondii) tadpoles had increased CORT levels after food deprivation (Crespi and Denver 2005). Adult common toads (Bufo bufo) inhabiting plowed soil had higher CORT levels than toads using forest litter or meadows (Janin et al. 2012). Additionally, exposure to traffic noise increased CORT in European tree frogs (Hyla arborea; Troïanowski et al. 2017).

In the eastern United States, created vernal pools should provide breeding habitat for spotted salamanders. This makes it crucial to understand how created habitats affect spotted salamander larvae and to determine which habitat characteristics should be incorporated during construction. Our objective was to determine if habitat characteristics of created vernal pools influence CORT levels in spotted salamander larvae. This information is needed to improve our understanding of the physiological condition of salamanders colonizing created vernal pools. We hypothesized that larvae would exhibit different levels of CORT in response to variation in pool age, pool-water $\mathrm{pH}$, pool depth, pool diameter, refuge within the pool (pool cover), canopy cover, and predator presence. We chose these habitat characteristics because previous studies have shown that they contribute to habitat quality of spotted salamander breeding sites (Petranka et al. 2003a, Egan and Paton 2004, Skidds et al. 2007). We also examined the influence of larval total length, pool-water temperature, and year of sampling as competing null hypotheses to control for their influence and more accurately assess the effects of habitat quality. Water-borne hormone sampling is influenced by body size, so we had to account for differences in order to make comparisons among salamanders (Scott and Ellis 2007). We expected that larvae with larger bodies would produce higher levels of CORT. We expected that warmer temperatures would result in higher CORT levels because this species is ectothermic and subject to natural changes in CORT due to circadian variation (Cree et al. 2003, Novarro et al. 2018). We also 
expected that different sampling years would produce differences in CORT because these were different breeding years with different individual salamanders in environments subject to variation including different levels of precipitation and temperature. To quantify CORT, we measured the CORT levels of water that contained an individual larvae for $1 \mathrm{~h}$. This method of measuring water-borne CORT has been used in many aquatic vertebrates as a less-invasive alternative to measuring plasma CORT (Gabor et al. 2013, Baugh et al. 2018, Charbonnier et al. 2018).

\section{METHODS}

Study Area

We sampled vernal pools on Cheat Mountain in Monongahela National Forest, WV from 19 May-13 June across two years $(\mathrm{n}=28$ in 2015, $\mathrm{n}=26$ in 2016, including 20 pools that were sampled both years). Only 20 pools sampled the first year had larvae present the second sampling season despite standing water and, in some cases, egg mass remains present. All vernal pools sampled were created by the U.S. Forest Service (USFS) between 2011 and 2014 as part of larger restoration projects. All sampled pools were located within $5 \mathrm{~km}$ of each other (Fig. 1). Pools were clustered together by year created: Barton Bench created in 2011, Lambert North created in 2013, and Lambert South created in 2014 (Fig. 1, Table S1). Vernal pool construction, including size and location, was determined by field conditions without predetermined designs or specifications (USFS 2014). During construction of vernal pools, branches and logs were placed in some of the vernal pools. Pools were constructed without liners so the pools would dry in mid to late summer most years. Presence of large green frog (Rana clamitans) tadpoles and crayfish (Decapoda) in $56 \%$ of pools indicated portions of our sample sites could have permanent hydroperiods, but we did not conduct surveys to confirm this. The monthly average air 
temperature and total precipitation varied between sample years with total precipitation from July 2014-June 2015 of $135.8 \mathrm{~cm}$ and from July 2015-June 2016 of $102.4 \mathrm{~cm}$ (Fig. S1 and S2 [The Weather Underground Elkins-Randolph County Station]).

Vernal pools were constructed in areas that had been strip-mined for coal in the 1970s before being acquired by the USFS in the 1980s. Restoration projects were initiated in 2009 and included ripping to mitigate soil compaction; removal of non-native Norway spruce (Picea abies) and red pine (Pinus resinosa) planted during mining reclamation; and planting seedlings, including aspens (Populus spp.), red spruce (Picea rubens), black cherry (Prunus serotina), wild raisin (Viburnum nudum), elderberry (Sambucus nigra), and service berry (Amelanchier arborea; Sandeno 2011, USFS 2014). The recent removal of non-native trees resulted in predominately open canopy for the vernal pools included in this study.

\section{Field Sampling}

Using dipnets and seines, we spent 6-82 min (average $35 \mathrm{~min}$ ) catching 10 spotted salamander larvae per pool for water-borne hormone sampling (Table S1). Larvae capture typically occurred between 07:00-13:00 h. Upon capture, each larva was placed in an individual high density polyethylene specimen cup (Dynarex Model 4254) in $20 \mathrm{ml}$ of distilled water premixed with Kent R/O Right Water Conditioner (to prevent osmotic shock). Larvae were removed from specimen cups after $1 \mathrm{~h}$. Larvae were then measured for total length to the nearest $\mathrm{mm}$, processed for a separate genetics study (i.e., tail clipped), and released back to their original pool. The water-borne hormone samples in the specimen cups were frozen within $8 \mathrm{~h}$ of collection.

We also collected negative and positive hormone control samples to help assess assay quality (see below). Negative control samples consisted of $20 \mathrm{ml}$ of distilled water premixed 
with Kent R/O Right Water Conditioner that was never exposed to salamander larvae. Positive control samples consisted of water-borne samples from 30 extra larvae per year. Within each year, the positive control samples were combined, aliquoted into vials of $20 \mathrm{ml}$ and frozen.

We measured pool diameter as the average length of two transects, one extending across the longest distance of pool diameter and a second perpendicular to the first. Each transect measurement extended to the edge of the water on each side of the pool. We used the line intercept method to quantify cover along the same two transects used to measure the diameter of each pool (Barbour et al. 1999, Egan and Paton 2004). Pool cover included any form of refuge such as vegetation, rocks, and coarse woody debris. We measured the length of the transect covered by any cover type to the nearest $\mathrm{cm}$ and quantified pool cover as the total length of cover along the two transects in a pool divided by the cumulative length of both transects (Egan and Paton 2004). Canopy cover was measured using a spherical densiometer every $1.5 \mathrm{~m}$ along each transect, with 2-3 readings per transect based on pool size. Average pool depth was based on three equally spaced measurements across the longer transect of the pool.

Age of each pool was determined as the sampling year minus the year of pool creation. Water $\mathrm{pH}$ and temperature were measured with a PCTestr ${ }^{\mathrm{TM}} 35$ Oakton ${ }^{\circledR}$ Waterproof MultiParameter $\mathrm{Testr}^{\mathrm{TM}}$. Predator presence was based on a rating of presence/absence (1/0) of eastern newt adults, diving beetle (Dytiscidae) larvae, and dragonfly (Odonata) larvae detected during dipnet and seine surveys for spotted salamander capture. A pool could have a score ranging from 0 when no predators were present, to 3 when all three were observed.

\section{Water-borne Hormone Extraction and Measurement}

Samples collected in 2015, totaling 279 individual water-borne hormone samples from 28 pools, were processed in summer 2015 in 10 batches. Samples collected in 2016, totaling 277 
individual water-borne hormone samples representing 26 pools, were processed in summer 2016 in 10 batches. Samples were evenly distributed into batches of 36 consisting of 32 hormone samples, two positive controls, and two negative controls for processing.

After thawing, water-borne hormone samples were filtered with Q8 Whatman filter paper to remove suspended particles. Samples were purified and concentrated using solid phase extraction with C18 columns (SPE column, SepPak Vac 3 cc/200 mg; Waters, Inc.). Using vacuum pressure, columns were activated with $4 \mathrm{ml}$ of HPLC-grade methanol and $4 \mathrm{ml}$ of nanopure water. Next, samples and controls were loaded onto columns by pulling each into a $25-$ $\mathrm{ml}$ plastic serological pipette placed on the SPE column opening. Parafilm wax was applied around the pipette tip to provide a tight seal as a vacuum drew the sample into the column. CORT was eluted from the SPE column into glass test tubes using $4 \mathrm{ml}$ of methanol. To evaporate off the methanol, test tubes were placed in a $42{ }^{\circ} \mathrm{C}$ water bath, and a gentle stream of nitrogen gas was blown on the surface of the samples. Samples were checked every 15 min until all methanol had evaporated (about $1 \mathrm{~h}$ ). Extracted CORT was resuspended in $400 \mathrm{ul}$ of buffer (95\% buffer from the ELISA kits [Cayman Chemicals Inc., \#501320] and 5\% ethanol). Each sample was vortexed for $10 \mathrm{~s}$, covered, and refrigerated overnight or up to two nights until the ELISAs could be completed. If ELISAs could not be completed within $2 \mathrm{~d}$ of the solid phase extraction, samples were frozen at $-20{ }^{\circ} \mathrm{C}$ in the interim.

Corticosterone concentrations were measured in 96-well plates using CORT ELISA kits following standard instructions provided with the kits. Samples were plated in duplicate, evenly distributed across plates, and randomly assigned to wells to control for intra- and inter-assay variation. Each sample was measured with a plate reader set to $415 \mathrm{~nm}$ (Bio-Rad 3550). 


\section{Assay Quality Control}

The positive control samples included in the plates were used to calculate inter- and intraassay variation. Inter-assay variation was $30 \%$ in $2015(\mathrm{n}=10$ plates $)$ and $19 \%$ in $2016(\mathrm{n}=10$ plates). Intra-assay variation was $14 \pm 11 \%$ across 10 assays in 2015 and $4 \pm<0.0001 \%$ across 10 assays in 2016. This range of assay variation is normal for ELISA assays of water-borne hormone samples (Gabor et al. 2013).

Additional positive control samples were used to demonstrate parallelism between the standard curve of the assay and successive dilutions of the samples. The serial dilution curve (based on eight dilutions 1:1 to 1:128 run in duplicate) was not significantly different from the standard curve $\left(\mathrm{t}_{(12)}=1.26, \mathrm{p}=0.23\right)$ demonstrating parallelism of standards and positive control samples.

To measure recovery, a positive control sample was diluted 1:2 and combined in equal parts with each of the eight standards of the ELISA standard curve. These hormone + standard samples were plated in duplicate along with one unaltered positive control sample diluted 1:2. Expected concentration was quantified as: (known CORT concentration in the unaltered pooled sample + concentration of the standard) / 2 . We calculated recovery by dividing observed CORT concentration by expected CORT concentration. This measured recovery from the ELISA assay. Recovery averaged $111 \%$ and ranged from $64-181 \%$. Observed and expected values were linearly related $\left(\right.$ slope $\left.=1.40, \mathrm{~F}_{(1,7)}=3945, \mathrm{R}^{2}=0.998, \mathrm{p}<0.0001\right)$

\section{Calculating CORT Release}

The amount of CORT measured by the ELISA in $\mathrm{pg} / \mathrm{ml}$ was multiplied by $0.40 \mathrm{ml}$ (the volume of ELISA buffer used to resuspend the sample). Due to matrix effects (Scott and Ellis 2007), negative control samples often have detectable levels of CORT. The standard procedure is 
to subtract the amount measured in negative controls from sample values. Average background CORT in negative control samples was calculated separately for plates run in 2015 and 2016. Annual average background CORT of the processing year was subtracted from salamander water-borne hormone samples. Finally, pg values were divided by $1 \mathrm{~h}$.

To determine CORT pg/h/pool, we averaged CORT pg/h of salamanders caught per pool. We excluded individuals with CORT levels too high and too low on the standard curve and below background levels: $9.87 \%$ of data (Table S1). This resulted in 30 out of 56 pools with $<10$ larvae samples: 25 pools sampled in 2015 and 5 pools sampled in 2016. Larval sample size at a pool ranged from 4-15 with an average of 9.11 (average 7.93 in 2015 and 10.38 in 2016, Table S1).

\section{Statistical Analysis}

All analyses were conducted in R (R Core Team 2017). Our sampling unit was pool, treating each pool as $n=1$. We used multiple regression to determine significant linear relationships between environmental factors and water-borne CORT levels of spotted salamander larvae $(\alpha=0.05)$. Models with hypothesized environmental predictors including pool age, poolwater $\mathrm{pH}$, pool depth, diameter, pool cover, canopy cover, and predator presence were compared using Akaike's Information Criterion (AICc, package 'AICcmodavg' [Mazerolle 2017, Burnham and Anderson 2002]). We also examined deviance explained by each model (package 'BiodiversityR' [Kindt and Coe 2005]). Predictors included in multiple regression models were not correlated (Pearson's correlation $\mathrm{r} \leq 0.33$, VIF $\leq 1.14$; package 'car', Fox and Weisberg 2011). All variables met assumptions of normality and homoscedasticity. Those that did not (CORT, salamander total length, and total pool cover) were natural log transformed to meet 
assumptions of normality and homoscedasticity. Figures and graphs are based on nontransformed data (package 'ggplot2', Wickham 2009).

Initial analysis indicated larval total length, pool-water temperature, and year of sampling were significant predictors of CORT. These were not predictors of interest, but were included in the models as the competing null hypotheses to control for their influence. Pools sampled both years were treated as two different sample units $(n=2)$ because CORT levels were significantly different (paired randomized t-test $\mathrm{p}=0.003$ ), making it inappropriate to average them. Additionally, pool habitat characteristics included in models were different from year to year at pools sampled both years (Hotelling $\mathrm{t}^{2}$ test $\mathrm{p}=0.02$, Table 1 ). Although, when predictors were tested individually, only salamander total length and pool depth differed from year to year (paired t-test $\mathrm{p}=0.003$ and $\mathrm{p}=0.001$, respectively). We included both sample years to control for temporal and population level variation which is necessary because CORT can be influenced by environmental conditions and physiological state. It is critical to consider and control for outside influences on CORT to be able to accurately determine the impact of habitat characteristics of interest.

Other environmental traits had significant linear relationships with CORT, but were not included in the analysis because these predictors were either correlated with other predictors in the final model or the estimated coefficient was not significantly different from zero. These included: larval developmental stage, air temperature, day of the season sampled (mid-May vs mid-June), time of day sampled, and amount of time spent sampling in the pool. Larval stage was correlated with larval total length (Pearson's correlation $r=0.65$ ). Air temperature was correlated with water temperature (Pearson's correlation $r=0.77$ ) and time sampled (Pearson's correlation $r=0.71$ ). Day of the season was correlated with larval total length (Pearson's 
correlation $r=0.61$ ) and the coefficient was not different from zero. Time of day sampled was correlated with water temperature (Pearson's correlation $r=0.67)$ and the coefficient was not different from zero. Finally, the amount of time sampling in the pool (Table S1) had a coefficient not different from zero.

To control for differences in overall body size, we included total length in our models. Previous studies with amphibians corrected for body size by dividing water-borne hormone by salamander length (Gabor et al. 2013, 2016, Baugh et al. 2018). However, our preliminary analysis found that even after dividing by total length (TL), water-borne CORT pg/TL/h was still positively correlated with total length $(\mathrm{mm})$ (Spearman's rank correlation: $\left.\mathrm{r}_{\mathrm{s}}=0.41, \mathrm{p}=0.002\right)$. This indicates larger larvae released more CORT per mm of body length and dividing by total length would not standardize samples or correct for body size influence on CORT.

\section{RESULTS}

We measured water-borne CORT levels of 10 salamander larvae per pool in 28 vernal pools in 2015 and 26 pools in 2016 (Table S1). This included 20 pools sampled both years. Pools varied in numerous environmental variables (Table 1). Pool diameter was a significant environmental predictor for CORT levels in spotted salamander larvae. The model including pool diameter was the top model: salamander total length + water temperature + year sampled + pool diameter $\left(\operatorname{adj} \mathrm{R}^{2}=0.73, \mathrm{~F}_{(4,49)}=36.04, \mathrm{p}<0.01\right.$; Table $\left.1,2,3\right)$. Pool diameter had a negative relationship with CORT (Table 3, Fig. 2c). Salamander total length and pool-water temperature were positively related to CORT levels (Table 3, Fig. 2). This top model outcompeted other predictors and all other null models including total length, total length + water temperature, and total length + water temperature + year sampled (Tables 1 and 2). The top model explained $75 \%$ of the variance in our data and received $80 \%$ of the total weight of all 
models, compared to $\leq 6 \%$ for other models. The model with pool cover had $\triangle \mathrm{AICc}<7$, indicating it could be a significant predictor but only received 3\% of the weight (Tables 1 and 2). The estimate of pool cover in the model was not significantly different from zero. All other models had $\triangle \mathrm{AICc}>7$ and the other predictors expected to influence CORT had non-significant coefficients.

\section{DISCUSSION}

We sampled created vernal pools to determine if environmental characteristics were impacting water-borne CORT levels of spotted salamander larvae. We found that the strongest model included larval total length, pool-water temperature, year of sampling, and pool diameter. Pool diameter had a negative relationship with CORT. We can hypothesize based on the CORTfitness hypothesis that lower baseline CORT levels indicate higher fitness (Bonier et al. 2009), although it is difficult to visualize a simple linear relationship due to the other contributing predictors of larval size and water temperature (Fig. 2c). With this interpretation, larvae in larger pools would have lower CORT and higher fitness. Therefore, larger pools would be considered higher quality habitat for spotted salamanders that could produce larvae with better physiological health than larvae in smaller pools. Our pool sizes were based on average diameter, with a range of 2.08-12.75 m. Support for our interpretation can be found in previous studies showing a positive correlation between pool size and number of egg masses in spotted salamanders, and selection for larger pools (up to 0.08 ha in Petranka et al. 2003a, > 0.05 ha in Egan and Paton 2004). In Maine, larger beaver ponds had greater spotted salamander occupancy and breeding effort than smaller vernal pools (Groff et al. 2017). Our hormone data add to existing data indicating that pool size can be an important factor to consider when creating spotted salamander breeding habitat. Future studies should continue to monitor spotted salamander populations of 
the vernal pools we sampled to determine if reduced CORT and pool diameter are indeed predictors of pool creation success.

The top model also included larval total length, pool-water temperature, and year sampled. The model estimates indicated larval total length and water temperature were positively associated with CORT. This confirmed our expectations that larger animals would produce more CORT. It is also important to note that dividing by body size was not sufficient to control for its impact on CORT, making it necessary to include larval total length in the model. The top model also confirmed that warmer temperatures, which were correlated with time of day, would facilitate higher CORT production in ectotherms and reflect natural changes due to circadian variation (Dupont et al. 1979, Cree et al. 2003). Novarro et al. (2018) also found that warmer temperatures increased water-borne CORT levels in eastern red-backed salamanders (Plethodon cinereus). It is likely that, as was demonstrated in red-legged salamanders (Plethodon shermani), warmer temperatures were associated with increased metabolic rate, facilitating higher CORT levels (Wack et al. 2012). Since time of day and water temperature were correlated, it seems including water temperature in the model also controlled for natural variations in CORT due to circadian rhythms (Dupont et al. 1979, Homan et al. 2003). The annual variation in CORT exemplifies the need for multi-year studies to control for temporal and population level variation. Corticosterone is highly variable and influenced by natural environmental conditions and physiological state. Here we showed CORT levels were influenced by body size and water temperature, and showed annual variation from year to year. Finding differences between years is representative of sampling unique individuals, but also environmental differences. Annual variation in salamander body size, pool-water temperature, pool diameter, pool-water $\mathrm{pH}$, pool depth, pool cover, canopy cover, and predator presence likely contributed to differences in 
CORT levels between years (Table 3, Fig. S1, S2). Additionally, time since pool construction increased from year one to year two which could have influenced the habitat and salamanders. In order to assess the effects of habitat quality, it is imperative to account for all outside influential factors of hormone level by assessing their impact and, if found to be significant, including them in the model. By identifying that the model including pool diameter was the top model, we showed that in addition to all the natural factors influencing CORT, pool diameter was also influential. Including larval total length, water temperature, and year in the model controlled for the influence of these other factors on CORT levels, and facilitated a more accurate determination of habitat quality impacts.

We expected that vegetation would continue to grow and establish as more time passed after pool creation, and pool colonization would continue as an amphibian community was established. However, pool age was not found to be an influential factor for hormone levels of spotted salamander larvae. This could be because the sampled pool ages only varied from 1-5 years. We may have found more variation if our sites included pools that were $>5$ years old. Alternatively, the initial available habitat may be sufficient. Mitigated wetlands in West Virginia were scored higher than reference wetlands in anuran, avian, invertebrate, and vegetation richness, abundance, diversity, density, and biomass (Balcombe et al. 2005). Created pools can be colonized quickly after creation and species richness can reach equilibrium within two years (Petranka et al. 2003a). Spotted salamanders used $90 \%$ of 10 created pools as early as the first year, the same occupation rate as 10 natural pools (Petranka et al. 2003a).

We did not find that $\mathrm{pH}$ was a significant predictor in our models. In Jefferson salamanders, CORT levels were negatively correlated with $\mathrm{pH}(5-7)$ when including ranges with the greatest hatching success ( $\mathrm{pH}$ 5-6) for the species (Pough and Wilson 1977, Chambers et al. 
2013). Allegheny Mountain dusky salamander (Desmognathus ochrophaeus) adults exposed to stream sites with $\mathrm{pH}$ values ranging from 4.1-8.1 did not exhibit correlated plasma CORT levels indicating that environmental $\mathrm{pH}$ levels may not activate the HPI axis to elicit a CORT response (Woodley et al. 2014). It is possible that impact of $\mathrm{pH}$ on salamanders may be based on a threshold. Spotted salamander embryos reared in water with a $4.5 \mathrm{pH}$ had reduced mass compared to those in water with an $8.0 \mathrm{pH}$ (Bianchini et al. 2012). Pool pH levels of 5-6 produced developmental abnormalities in spotted salamander larvae with more severe abnormalities occurring in pools with $\mathrm{pH}<5$ (Pough and Wilson 1977). The greatest hatching success for spotted salamanders was in pools with a pH between 7 and 9 (Pough and Wilson 1977). The limited range of $\mathrm{pH}$ in our created pools (5.37-7.47) may explain the lack of correlation, and it is possible that detection of $\mathrm{pH}$ effects on spotted salamander CORT levels requires a pH range of 4-9 to include both adverse and ideal $\mathrm{pH}$ levels. Future studies should examine a larger range of $\mathrm{pH}$ values in breeding pools to determine if spotted salamander larvae respond to suboptimal $\mathrm{pH}$ values with changes in CORT.

Pool depth, vegetation cover in the pool, and canopy cover have been shown to contribute to the number and density of spotted salamander egg masses with clear positive correlations (Petranka et al. 2003a, Egan and Paton 2004, Skidds et al. 2007, Felix et al. 2010, Kern et al. 2013, Scheffers et al. 2013). However, we did not find that these were significant predictors in competitive models for CORT levels. We had expected to detect a threshold for depth at which a pool would be too shallow to provide suitable habitat. We predicted that pool cover would influence CORT levels because lack of cover within the pool exposes larvae to the sun, elevated temperatures, and predators. These influences may not have been identified as significant due to the limited ranges present at our study sites: pool depths ranged from $0.13-0.67 \mathrm{~m}$ and canopy 
cover varied from 0-62\% (averaging 7\%) with most pools under open canopy. Other studies have incorporated ranges in mean pool depths of $0.64-0.95 \mathrm{~m}$ up to $2.3 \mathrm{~m}$ and canopy cover from 0-100\% (Petranka et al. 2003a, Skidds et al. 2007). Spotted salamander selection for oviposition sites in deeper water and denser submerged vegetation is evident with water depths up to $0.33 \mathrm{~m}$ and vegetation cover up to $100 \%$ (Kern et al. 2013). There may be an ideal depth as oviposition was documented most frequently in water $0.50 \mathrm{~m}$ deep rather than deeper areas up to $2.20 \mathrm{~m}$ (Egan and Paton 2004). While we expected these habitat traits to be important, it is possible that they are only critical as habitat for oviposition to attract breeding adults. Provided the pool does not dry before larvae complete metamorphosis, variation in these characteristics may not be critical for the physiological health of larvae or may not activate the HPI axis to cause changes in CORT.

Predator presence was expected to impact CORT levels but was not a strong predictor. During predatory interactions, prey can exhibit changes in CORT levels to facilitate escape behavior (Wingfield et al. 1998, Davis and Gabor 2015, Harris and Carr 2016). This may vary across species. Allegheny Mountain dusky salamanders exposed to predatory chemical cues did not exhibit a CORT response despite exhibiting reduced behavioral activity (Fonner and Woodley 2015). We are not aware of any research on spotted salamander CORT responses to predators specifically; however, spotted salamanders exposed to predators exhibit antipredator behavior by reducing their activity and feeding (Hossie et al. 2017). Our data suggests that eastern newt, diving beetle larvae, and dragonfly larvae presence alone may not influence CORT levels of spotted salamander larvae. Future research should examine if predator density or occurrence of larval predatory encounters impacts CORT levels in spotted salamander larvae. 


\section{Caveats to Interpretation of Water-borne CORT Levels}

There is debate regarding how to interpret CORT levels in terms of direct correlation to physiological health (Dickens and Romero 2013, Thomas et al. 2017). Previous studies that found associations between CORT levels and habitat variables tend to assume that higher CORT reflects reduced fitness (Glennemeier and Denver 2002, Crespi and Denver 2005, Janin et al. 2012, Chambers et al. 2013, Troïanowski et al. 2017, Charbonnier et al. 2018). This is reasonable considering that very high CORT inhibits reproduction, growth and immune function. Additionally, our data along with multiple other research projects have found a correlation between glucocorticoid hormones and habitat characteristics (Hopkins et al. 1999, Glennemeier and Denver 2002, Homan et al. 2003, Crespi and Denver 2005, Bonier et al. 2009, Janin et al. 2012, Chambers et al. 2013, Troïanowski et al. 2017, Charbonnier et al. 2018). This indicates that both the impact of the environment on CORT and the mechanism behind it are research areas worth pursuing. However, CORT is a naturally occurring hormone that functions to facilitate growth and metamorphosis (Carr and Norris 1988, McEwen and Wingfield 2003, Moore and Jessop 2003, Romero 2004, Chambers et al. 2011). It also facilitates physiological changes in response to unexpected stimuli or stressors to make energy available. The biological meaning of differences in CORT levels is unsettled as it lacks a consistent profile in chronically stressed animals (Gormally et al. 2018). Thus, interpretation of CORT is still open, and more data from free-living animals in the natural environment is necessary.

Water-borne sampling is a relatively new method for sampling CORT levels in amphibians, and water-borne hormones are often assumed to reflect whole-body or plasma hormones. However, plasma CORT reflects a snapshot in time while water-borne CORT reflects cumulative release over a period of time and likely integrates changes to CORT due to handling, 
capture, or containment (Romero and Reed 2005). It has been argued that water-borne CORT may therefore provide a more accurate reflection of overall physiological condition due to its cumulative nature, compared to plasma CORT (Dantzer et al. 2014, Baugh et al. 2018). In support of this argument, associations between high water-borne CORT levels and physiologically relevant impacts have been demonstrated in several amphibian species. Common midwife toads (Alytes obstetrician) with more severe Batrachochytrium dendrobatidis infections had higher water-borne CORT levels and reduced righting response (Gabor et al. 2015). African clawed frogs (Xenopus laevis) had higher water-borne CORT in unnatural housing and greater body mass loss (Holmes et al. 2016). Spotted salamander larvae reared in high intraspecific density had higher water-borne CORT and reduced growth (Charbonnier et al. 2018).

\section{Conclusions, Management Implications, and Future Research}

We found that spotted salamander larvae inhabiting larger pools (diameters up to 12.75 m) have lower baseline CORT levels. This may indicate that pool diameter is an important habitat characteristic contributing to the physiological health of salamander larvae. Research on selection for breeding sites supports the importance of larger pools, provided they do not contain or risk colonization by fish. Size of the pool should be carefully considered when creating breeding habitat for this species. To confirm our interpretation of CORT and its biological meaning, future studies should survey spotted salamander populations in these pools to determine if larger pools produced larger populations. Future research could also focus on determining an ideal pool size for spotted salamander larvae and assessing whether pool size contributes to other beneficial habitat characteristics. When using CORT as an indicator of habitat quality in field studies, it is critical to assess external influences for accurate habitat associations. One way to do this is to collect data over multiple years to account for annual 
variation in the natural environment. Other factors shown to impact CORT levels should also be controlled for or incorporated in analysis such as body size and water temperature for spotted salamanders. Additional studies could include more extensive ranges of age of the pool, poolwater $\mathrm{pH}$, pool depth, canopy cover, specific types of vegetation cover and complexity, and predator density to determine their impacts on spotted salamander larvae. Laboratory studies would be beneficial to determine if $\mathrm{pH}$ influences CORT levels in spotted salamander larvae and at what extremes. Future research should examine how habitat characteristics in natural pools influence larval physiology and whether it differs from created pools.

Measuring physiological responses to habitat quality can improve understanding of population health and could be a useful tool to predict population declines and detect vulnerable populations. Physiological measurements, along with demographic studies, can better inform management decisions regarding habitat creation and restoration. Incorporating these tools will help determine ideal habitat characteristics and how they impact spotted salamander populations.

\section{ACKNOWLEDGMENTS}

This study was completed with approval from West Virginia University Institutional Animal Care and Use Committee (15-0409.3), the U.S. Forest Service, and the West Virginia Division of Natural Resources (Scientific Collecting Permit 2015.133, 2016.205). We thank J Rouda, J Strickland, M Mabry, A Magyan, A Bucher, and J Millikin for field and lab assistance, and D Brown for statistical advice. This research was funded by the U.S. Forest Service, Natural Resources Conservation Service, National Science Foundation (01A-1458952), West Virginia University Natural History Museum, National Institute of Food and Agriculture McStennis Project WVA00117, The Explorers Club Washington Group, Society of Wetland Scientists, Society of Wetland Scientists South Atlantic Chapter, West Virginia University Stitzel Graduate 
Enhancement Fund, and R and L Bowman. We also thank West Virginia Division of Natural Resources, Department of Biological Sciences at Duquesne University, and the Ruby Distinguished Doctoral Fellowship Program. This is scientific article number 3355 of the West Virginia Agricultural and Forestry Experiment Station, Morgantown. 
Table 1. Summary data displaying ranges of all predictors of water-borne corticosterone levels $(\mathrm{pg} / \mathrm{h})$ for spotted salamanders (Ambystoma maculatum) included in analysis with means separated by sampling year.

\begin{tabular}{lcccc}
\hline \multicolumn{1}{c}{ Predictor } & Min & Max & $\begin{array}{c}2015 \\
\text { Mean } \pm \text { SE }\end{array}$ & $\begin{array}{c}2016 \\
\text { Mean } \pm \text { SE }\end{array}$ \\
\hline Salamander Total Length $(\mathrm{mm})$ & 14.00 & 39.71 & $20.17 \pm 0.97$ & $22.20 \pm 1.09$ \\
Water Temperature $\left({ }^{\circ} \mathrm{C}\right)$ & 10.07 & 28.03 & $18.79 \pm 0.78$ & $17.57 \pm 0.77$ \\
Year Sampled & 2015 & 2016 & N/A & N/A \\
Pool Diameter (m) & 2.08 & 12.75 & $6.57 \pm 0.44$ & $6.86 \pm 0.44$ \\
Pool Age (years) & 1.00 & 5.00 & $2.50 \pm 0.23$ & $3.58 \pm 0.24$ \\
Water pH & 5.37 & 7.47 & $6.70 \pm 0.10$ & $6.93 \pm 0.08$ \\
Pool Depth (m) & 0.13 & 0.66 & $0.27 \pm 0.02$ & $0.37 \pm 0.02$ \\
Pool Cover (0-1) & 0.00 & 0.70 & $0.19 \pm 0.03$ & $0.26 \pm 0.02$ \\
Canopy Cover (0-1) & 0.00 & 0.62 & $0.07 \pm 0.03$ & $0.06 \pm 0.03$ \\
Predator Presence $(0-3)$ & 0.00 & 3.00 & $1.96 \pm 0.14$ & $1.50 \pm 0.17$ \\
\hline
\end{tabular}


Table 2. Hypothesized models explaining variation in corticosterone levels $(\mathrm{pg} / \mathrm{h})$ of spotted salamander (Ambystoma maculatum) larvae. $\triangle \mathrm{AICc}=$ change in AIC corrected for small sample size $; \mathrm{w}_{\mathrm{i}}=$ weight of the model $; \mathrm{TL}=$ salamander total length $\mathrm{C}=$ water temperature $;$ Year $=$ calendar year sampled; Pool Cover $=$ any form of refuge such as vegetation, rocks, coarse woody debris; Age $=$ time since pool creation

\begin{tabular}{lcccc}
\hline \multicolumn{1}{c}{ Model } & AAICc & $\mathrm{W}_{\mathrm{i}}$ & $\begin{array}{c}\text { Deviance } \\
\text { Explained }\end{array}$ & $\begin{array}{c}\text { All predictors } \\
\text { significant } \mathrm{p}<0.05\end{array}$ \\
\hline TL, C, Year, Pool Diameter & 0 & 0.80 & $75 \%$ & $*$ \\
TL, C, Year & 5.31 & 0.06 & $71 \%$ & $*$ \\
TL, C, Year, Pool Cover & 6.68 & 0.03 & $71 \%$ & $*$ \\
TL, C, Pool Diameter & 6.77 & 0.03 & $70 \%$ & \\
TL, C, Year, Age & 7.41 & 0.02 & $71 \%$ & \\
TL, C, Year, Predators Present & 7.7 & 0.02 & $71 \%$ & \\
TL, C, Year, pH & 7.71 & 0.02 & $71 \%$ & \\
TL, C, Year, Pool Depth & 7.77 & 0.02 & $71 \%$ & \\
TL, C, Year, Canopy Cover & 7.84 & 0.02 & $71 \%$ & \\
TL, C & 10.83 & 0 & $66 \%$ & \\
TL, C, Year, Pool Diameter, Pool & & & & \\
Cover, Age, Predators, pH, Depth, & & & & \\
Canopy Cover & 15.83 & 0 & $76 \%$ & \\
TL & 31.5 & 0 & $48 \%$ & \\
$\sim 1$ & 64.52 & 0 & $0 \%$ & \\
\hline
\end{tabular}


Table 3. Coefficients for the top model explaining water-borne corticosterone levels $(\mathrm{pg} / \mathrm{h})$ for spotted salamanders (Ambystoma maculatum): $\mathrm{y}=$ salamander total length (TL) + water temperature $(\mathrm{C})+$ year sampled $($ Year $)+$ pool diameter.

\begin{tabular}{lcccccc}
\hline \multicolumn{1}{c}{ Coefficients } & Estimate & Std Error & \multicolumn{2}{c}{$95 \%$ Confidence Interval } & $\mathrm{t}$ & $\mathrm{p}$ \\
\hline Intercept & -820.30 & 268.00 & -1345.49 & -295.09 & -3.06 & $3.57 \mathrm{E}-03$ \\
TL & 2.79 & 0.30 & 2.21 & 3.37 & 9.38 & $1.61 \mathrm{E}-12$ \\
$\mathrm{C}$ & 0.10 & 0.02 & 0.07 & 0.13 & 6.26 & $9.39 \mathrm{E}-08$ \\
Year & 0.40 & 0.13 & 0.14 & 0.66 & 3.04 & $3.83 \mathrm{E}-03$ \\
Pool Diameter & $-8.12 \mathrm{E}-04$ & $2.94 \mathrm{E}-04$ & $-1.39 \mathrm{E}-03$ & $-2.37 \mathrm{E}-04$ & -2.77 & 0.01 \\
\hline
\end{tabular}




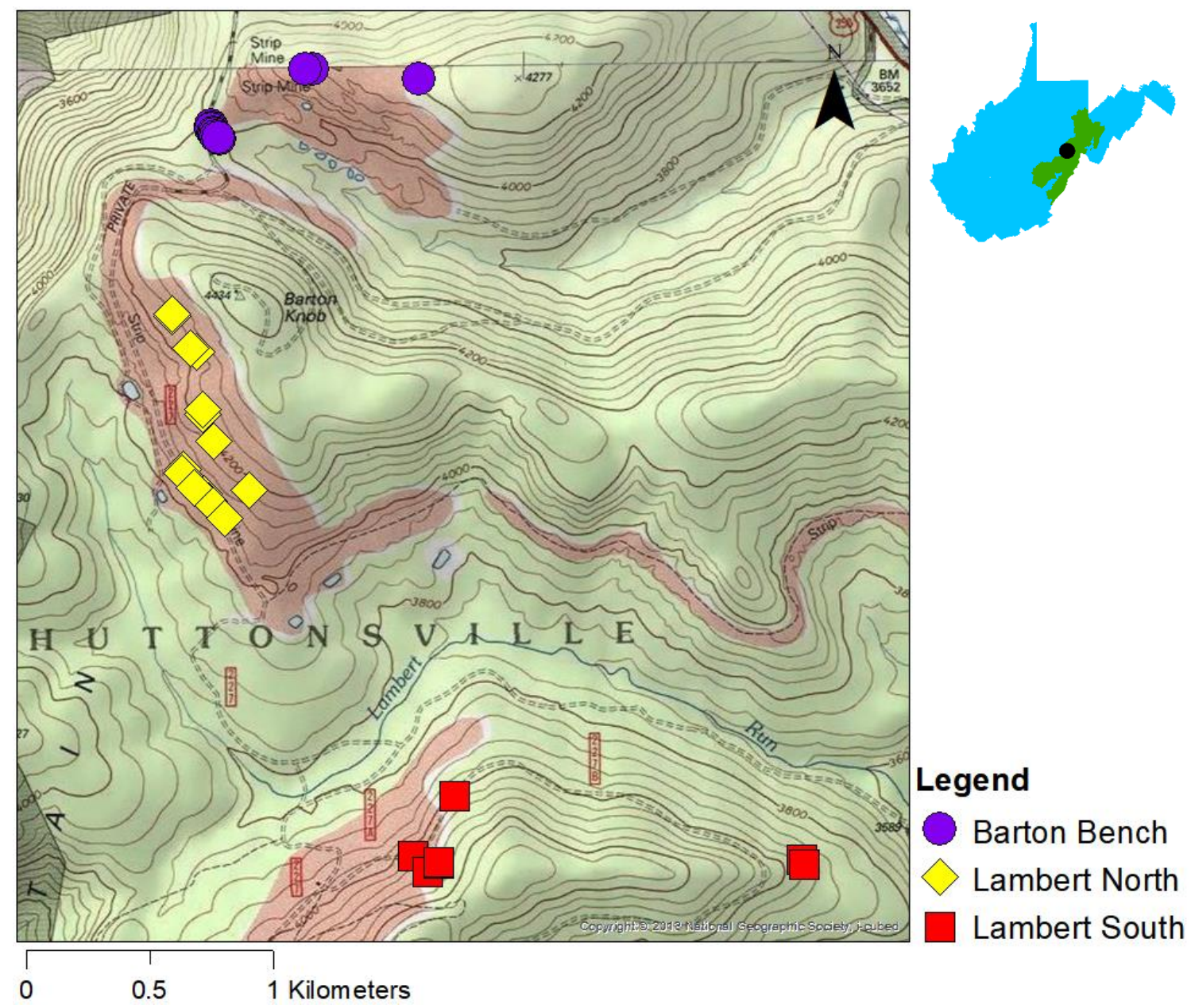

Figure 1. Topographic map displaying the study area in Randolph County, WV in the Greenbrier District of Monongahela National Forest. Circles, diamonds, and squares represent the locations of created vernal pools that were sampled. West Virginia state map shows the outline of Monongahela National Forest and general location of the study site marked with a black circle. USA Topo map accessed through ESRI () 2013 National Geographic Society, i-cubed. 

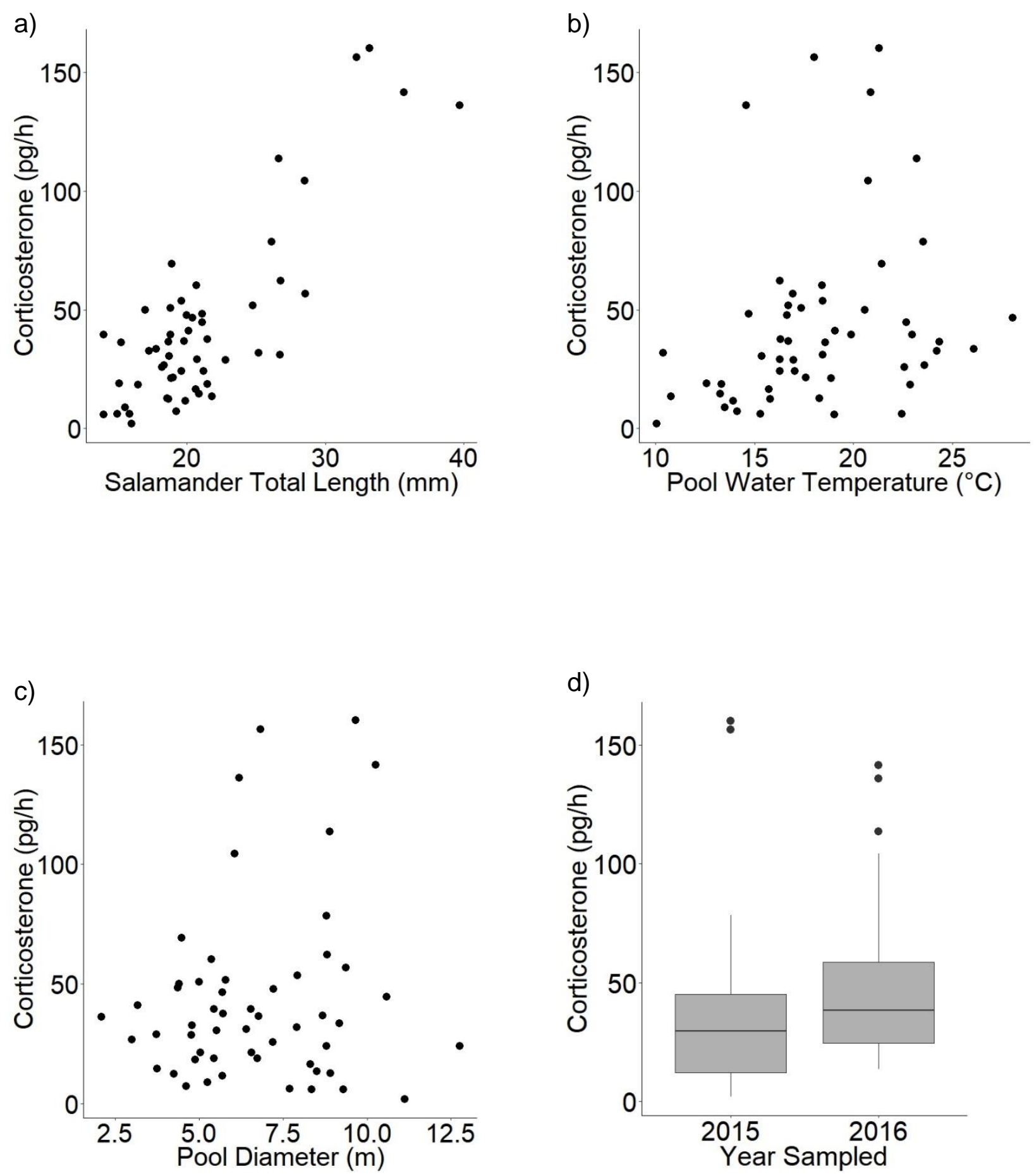

Figure 2. Biplots displaying water-borne corticosterone levels $(\mathrm{pg} / \mathrm{h})$ and spotted salamander (Ambystoma maculatum) total length $(\mathrm{mm})(\mathrm{a})$, pool water temperature $\left({ }^{\circ} \mathrm{C}\right)(\mathrm{b})$, and pool diameter (m) (c). Each dot represents average corticosterone (pg/h) levels for one pool in one sampling year $(n=54)$. Boxplot displaying corticosterone levels in each sampling year $(d)$. 


\section{REFERENCES}

Balcombe CK, Anderson JT, Fortney RH, Kordek WS (2005) Vegetation, invertebrate, and wildlife community rankings and habitat analysis of mitigation wetlands in West Virginia. Wetlands Ecology and Management 13:517-530

Barbour MG, Burk JH, Pitts WD, Gilliam FS, Schwartz MW (1999) Terrestrial Plant Ecology, Third Edition. Benjamin and Cummings, California

Baugh AT, Bastien B, Still M, Stowell N (2018) Validation of water-borne steroid hormones in a tropical frog (Physalaemus pustulosus). General and Comparative Endocrinology 261:67-80

Belden LK, Kiesecker JM (2005) Glucocorticosteroid hormone treatment of larval treefrogs increases infection by Alaria sp. trematode cercariae. The Journal of Parasitology 19:686688

Bianchini K, Tattersall GJ, Sashaw J, Porteus CS, Wright PA (2012) Acid water interferes with salamander-green algae symbiosis during early embryonic development. Physiological and Biochemical Zoology 85:470-480

Bonier F, Martin PR, Moore IT, Wingfield JC (2009) Do baseline glucocorticoids predict fitness? Trends in Ecology \& Evolution 24:634-642

Brodman R (1993) The effect of acidity on interactions of Ambystoma salamander larvae. Journal of Freshwater Ecology 8:209-214

Burnham KP, Anderson DR (2002) Model selection and multimodel inference: a practical information-theoretic approach. Springer Science \& Business Media, LLC, New York

Calhoun AJK, Arrigoni J, Brooks RP, Hunter ML, Richter SC (2014) Creating successful vernal pools: a literature review and advice for practitioners. Wetlands 34:1027-1038 
Carr JA, Norris DO (1988) Interrenal activity during metamorphosis of the tiger salamander, Ambystoma tigrinum. General and Comparative Endocrinology 71:63-69

Chambers DL, Wojdak JM, Du P, Belden LK (2011) Corticosterone level changes throughout larval development in the amphibians Rana sylvatica and Ambystoma jeffersonianum reared under laboratory, mesocosm, or free-living conditions. Copeia 2011:530-538

Chambers DL, Wojdak JM, Du P, Belden LK (2013) Pond acidification may explain differences in corticosterone among salamander populations. Physiological and Biochemical Zoology $86: 224-232$

Charbonnier JF, Pearlmutter J, Vonesh JR, Gabor CR, Forsburg ZR, Grayson KL (2018) Crosslife stage effects of aquatic larval density and terrestrial moisture on growth and corticosterone in the spotted salamander. Diversity 10:68

Clark KL (1986) Responses of Ambystoma maculatum populations in central Ontario to habitat acidity. The Canadian Field-Naturalist 100:463-469

Cree A, Tyrrell CL, Preest MR, Thorburn D, Guillette Jr LJ (2003) Protecting embryos from stress: corticosterone effects and the corticosterone response to capture and confinement during pregnancy in a live-bearing lizard (Hoplodactylus maculatus). General and Comparative Endocrinology 134:316-329

Crespi EJ, Denver RJ (2005) Roles of stress hormones in food intake regulation in anuran amphibians throughout the life cycle. Comparative Biochemistry and Physiology, Part A $141: 381-390$

Dantzer B, Fletcher QE, Boonstra R, Sheriff MJ (2014) Measures of physiological stress: a transparent or opaque window into the status, management and conservation of species? Conservation Physiology 2:cou023 
Davis DR, Gabor CR (2015) Behavioral and physiological antipredator responses of the San Marcos salamander, Eurycea nana. Physiology \& Behavior 139:145-149

Denton RD, Richter SC (2013) Amphibian communities in natural and constructed ridge top wetlands with implications for wetland construction. The Journal of Wildlife Management 77:886-896

DiBello FJ, Calhoun AJK, Morgan DE, Shearin AF (2016) Efficiency and detection accuracy using print and digital stereo aerial photography for remotely mapping vernal pools in New England landscapes. Wetlands 36:505-514

Dickens MJ, Romero LM (2013) A consensus endocrine profile for chronically stressed wild animals does not exist. General and Comparative Endocrinology 191:177-189

Dupont W, Bourgeois P, Reinberg A, Vaillant R (1979) Circannual and circadian rhythms in the concentrations of corticosterone on the plasma of the edible frog (Rana esculenta L.). Journal of Endocrinology 80:117-125

Egan RS, Paton PWC (2004) Within-pond parameters affecting oviposition by wood frogs and spotted salamanders. Wetlands 24:1-13

Felix ZI, Wang Y, Schweitzer CJ (2010) Effects of experimental canopy manipulation on amphibian egg deposition. Journal of Wildlife Management 74:496-503

Fonner CW, Woodley SK (2015) Testing the predation stress hypothesis: behavioural and hormonal responses to predator cues in Allegheny Mountain dusky salamanders. Behaviour $152: 797-819$

Formanowicz DR, Bobka MS (1989) Predation risk and microhabitat preference: an experimental study of the behavioral responses of prey and predator. American Midland Naturalist 121:379-386 
Fox J, Weisberg S (2011) An $\{\mathrm{R}\}$ Companion to applied regression, second edition. Thousand Oaks CA: Sage. URL: http://socserv.socsci.mcmaster.ca/jfox/Books/Companion

Gabor CR, Bosch J, Fries JN, Davis DR (2013) A non-invasive water-borne hormone assay for amphibians. Amphibia-Reptilia 34:151-162

Gabor CR, Fisher MC, Bosch J (2015) Elevated corticosterone levels and changes in amphibian behavior are associated with Batrachochytrium dendrobatidis $(B d)$ infection and $B d$ lineage. PLoS ONE 10:e0122685

Gabor CR, Zabierek KC, Kim DS, da Barbiano LA, Mondelli MJ, Bendik NF, Davis DR (2016) A non-invasive water-borne assay of stress hormones in aquatic salamanders. Copeia 104:172-181

Glennemeier KA, Denver RJ (2002) Role for corticoids in mediating the response of Rana pipiens tadpoles in intraspecific competition. Journal of Experimental Zoology 292:32-40

Gormally BMG, Fuller R, McVey M, Romero LM (2018) DNA damage as an indicator of chronic stress: Correlations with corticosterone and uric acid. Comparative Biochemistry and Physiology, Part A 227:116-122

Gosner KK, Black IH (1957) The effects of acidity on the development of New Jersey frogs. Ecology 38:256-262

Groff LA, Loftin CS, Calhoun AJK (2017) Predictors of breeding site occupancy by amphibians in montane landscapes. The Journal of Wildlife Management 81:269-278

Harris BN, Carr JA (2016) The role of the hypothalamus-pituitary-adrenal/interrenal axis in mediating predator-avoidance trade-offs. General and Comparative Endocrinology 230:110142 
Holmes AM, Emmans CJ, Jones N, Coleman R, Smith TE, Hosie CA (2016) Impact of tank background on the welfare of the African clawed frog, Xenopus laevis (Daudin). Applied Animal Behaviour Science 185:131-136

Homan RN, Regosin JV, Rodrigues DM, Reed JM, Windmiller BS, Romero LM (2003) Impacts of varying habitat quality on the physiological stress of spotted salamanders (Ambystoma maculatum). Animal Conservation 6:11-18

Homyack JA (2010) Evaluating habitat quality of vertebrates using conservation physiology tools. Wildlife Research 37:332-342

Hopkins WA, Mendonca MT, Congdon JD (1999) Responsiveness of the hypothalamo-pituitaryinterrenal axis in an amphibian (Bufo terrestris) exposed to coal combustion wastes. Comparative Biochemistry and Physiology, Part C 122:191-196

Hossie TJ, MacFarlane S, Clement A, Murray DL (2017) Threat of predation alters aggressive interactions among spotted salamander (Ambystoma maculatum) larvae. Ecology and Evolution 8:3131-3138

Janin A, Lena JP, Deblois S, Joly P (2012) Use of stress-hormone levels and habitat selection to assess functional connectivity of a landscape for an amphibian. Conservation Biology 26:923-931

Kern MM, Nassar AA, Guzy JC, Dorcas ME (2013) Oviposition site selection by spotted salamanders (Ambystoma maculatum) in an isolated wetland. Journal of Herpetology 47:445-449

Kindt R, Coe R (2005) Tree diversity analysis. A manual and software for common statistical methods for ecological and biodiversity studies. World Agroforestry Centre (ICRAF), Nairobi. ISBN 92-9059-179-X 
Mazerolle MJ (2017) AICcmodavg: model selection and multimodel inference based on

(Q)AIC(c). R package version 2.1-1. https://cran.r-project.org/package=AICcmodavg

McCormick SD, Romero M (2017) Conservation endocrinology. Bioscience 67:429-442

McEwen BS, Wingfield JC (2003) The concept of allostasis in biology and biomedicine.

Hormones and Behavior 43:2-15

Moore IT, Jessop TS (2003) Stress, reproduction, and adrenocortical modulation in amphibians and reptiles. Hormones and Behavior 43:39-47

Novarro AJ, Gabor CR, Goff CB, Mezebish TD, Thompson LM, Grayson KL (2018)

Physiological responses to elevated temperature across the geographic range of a terrestrial salamander. Journal of Experimental Biology 221:jeb178236

Petranka JW, Kennedy CA, Murray SS (2003a) Response of amphibians to restoration of a southern Appalachian wetland: A long-term analysis of community dynamics. Wetlands 23:1030-1042

Petranka JW, Kennedy CA, Murray SS (2003b) Response of amphibians to restoration of a southern Appalachian wetland: Perturbations confound post-restoration assessment. Wetlands 23:278-290

Pough FH, Wilson RE (1977) Acid precipitation and reproductive success of Ambystoma salamanders. Water, Air, and Soil Pollution 7:307-316

R Core Team (2017) R: a language and environment for statistical computing. R Foundation for Statistical Computing, Vienna, Austria. URL https://www.R-project.org/

Romero LM (2004) Physiological stress in ecology: lessons from biomedical research. Trends in Ecology and Evolution 19:249-255 
Romero LM, Reed JM (2005) Collecting baseline corticosterone samples in the field: is under 3 min good enough? Comparative Biochemistry and Physiology, Part A 140:73-79

Romero L, Wikelski M (2001) Corticosterone levels predict survival probabilities of Galápagos marine iguanas during El Nino events. Proceedings of the National Academy of Sciences of the United States of America 98:7366-7370

Rowe CL, Dunson WA (1993) Relationships among biotic parameters and breeding effort by three amphibians in temporary wetlands of central Pennsylvania. Wetlands 13:237-246

Sandeno CM (2011) Project status report - Barton Bench ecological restoration Greenbrier ranger district Monongahela National Forest. WV Department of Environmental Protection, Division of Mining and Reclamation.

Scheffers BR, Furman BL, Evans JP (2013) Salamanders continue to breed in ephemeral ponds following the removal of surrounding terrestrial habitat. Herpetological Conservation and Biology 8:715-723

Scott AP, Ellis T (2007) Measurement of fish steroids in water-a review. General and Comparative Endocrinology 153:392-400

Skidds DE, Golet FC, Paton PW, Mitchell JC (2007) Habitat correlates of reproductive effort in wood frogs and spotted salamanders in an urbanizing watershed. Journal of Herpetology 41:439-450

Thomas JR, Magyan AJ, Freeman PE, Woodley SK (2017) Testing hypotheses about individual variation in plasma corticosterone in free-living salamanders. Journal of Experimental Biology 220:1210-1221

Troïanowski M, Mondy N, Dumet A, Arcanjo C, Lengagne T (2017) Effects of traffic noise on tree frog stress levels, immunity, and color signaling. Conservation Biology 31:1132-1140 
United States Forest Service (2014) Mower Tract ecological restoration final report

Vasconcelos D, Calhoun AJK (2006) Monitoring created seasonal pools for functional success: a six-year case study of amphibian responses, Sears Island, Maine, USA. Wetlands 26:9921003

Wack CL, DuRant SE, Hopkins WA, Lovern MB, Feldhoff RC, Woodley SK (2012) Elevated plasma corticosterone increases metabolic rate in a terrestrial salamander. Comparative Biochemistry and Physiology, Part A 161:153-158

The Weather Underground Elkins-Randolph County Station. Weather history for ElkinsRandolph County, WV. Weather Underground, The Weather Company. https://www.wunderground.com/history/daily/us/wv/mill-creek/KEKN/date/2019-117?cm_ven=localwx_history. Accessed 15 January 2019.

Wickham H (2009) ggplot2: elegant graphics for data analysis. Springer-Verlag, New York Wingfield JC, Maney DL, Breuner CW, Jacobs JD, Lynn S, Ramenofsky M, Richardson RD (1998) Ecological bases of hormone-behavior interactions: the "emergency life history stage.” American Zoologist 38:191-206

Woodley SK, Freeman P, Ricciardella LF (2014) Environmental acidification is not associated with altered corticosterone levels in the stream-side salamander, Desmognathus ochrophaeus. General and Comparative Endocrinology 201:8-15 
Table S1. Pool level data presenting variation of spotted salamander (Ambystoma maculatum) water-borne corticosterone (CORT) levels $(\mathrm{pg} / \mathrm{h})$ by vernal pool including mean \pm standard error (SE) and coefficient of variation (CV): the variation of larval CORT levels within each pond.

Pool names represent location: Barton Bench (B, BB), Lambert North (LN), and Lambert South (LS). Also listed are the number of samples included in analysis (samples included). All pools were sampled for 10 larval hormone samples (except for pools sampled for 15 in 2016 including B11, B9, LN62, LN77); however, a subset of those were included in analysis after excluding samples with CORT levels too high and too low on the standard curve and below background levels. Finally, time sampling in minutes is how long we spent sampling in the pool for salamanders from start until the last salamander was caught.

\begin{tabular}{lcccccc}
\hline Pool Name & $\begin{array}{c}\text { Year } \\
\text { Sampled }\end{array}$ & $\begin{array}{c}\text { Year } \\
\text { Created }\end{array}$ & $\begin{array}{c}\text { Samples } \\
\text { Included }\end{array}$ & $\begin{array}{c}\text { Time } \\
\text { Sampling }\end{array}$ & $\begin{array}{c}\text { Mean CORT } \\
\text { pg } \pm \text { SE }\end{array}$ & CV \\
\hline B1 & 2015 & 2011 & 9 & 62 & $49.93 \pm 7.65$ & $46 \%$ \\
B11 & 2015 & 2011 & 8 & 20 & $7.283 \pm 3.19$ & $124 \%$ \\
B2 & 2015 & 2011 & 9 & 37 & $26.65 \pm 8.48$ & $95 \%$ \\
B5 & 2015 & 2011 & 10 & 55 & $11.56 \pm 5.12$ & $140 \%$ \\
B7 & 2015 & 2011 & 8 & 31 & $51.72 \pm 4.23$ & $23 \%$ \\
B8 & 2015 & 2011 & 9 & 44 & $8.957 \pm 3.87$ & $130 \%$ \\
B9 & 2015 & 2011 & 10 & 21 & $12.47 \pm 3.28$ & $83 \%$ \\
BB2 & 2015 & 2011 & 8 & 51 & $5.974 \pm 3.14$ & $149 \%$ \\
BB8 & 2015 & 2011 & 9 & 23 & $36.42 \pm 8.1$ & $67 \%$ \\
BB9 & 2015 & 2011 & 8 & 63 & $1.89 \pm 1.44$ & $215 \%$ \\
LN10 & 2015 & 2013 & 5 & 9 & $160.2 \pm 48.32$ & $67 \%$ \\
LN104 & 2015 & 2013 & 8 & 21 & $28.95 \pm 9.49$ & $93 \%$ \\
LN11 & 2015 & 2013 & 4 & 18 & $156.4 \pm 36.39$ & $47 \%$ \\
LN18 & 2015 & 2013 & 7 & 29 & $78.5 \pm 12.26$ & $41 \%$ \\
LN2 & 2015 & 2013 & 7 & 17 & $56.78 \pm 10.14$ & $47 \%$ \\
LN24 & 2015 & 2013 & 8 & 27 & $16.57 \pm 3.51$ & $60 \%$ \\
LN5 & 2015 & 2013 & 8 & 38 & $6.183 \pm 3.05$ & $139 \%$ \\
LN56 & 2015 & 2013 & 8 & 60 & $44.63 \pm 7.65$ & $49 \%$ \\
LN62 & 2015 & 2013 & 10 & 27 & $12.61 \pm 3.95$ & $99 \%$ \\
LN78 & 2015 & 2013 & 7 & 35 & $46.51 \pm 11.1$ & $63 \%$ \\
LN94 & 2015 & 2013 & 8 & 35 & $21.39 \pm 7.5$ & $99 \%$ \\
\hline
\end{tabular}


Table S1 continued.

\begin{tabular}{|c|c|c|c|c|c|c|}
\hline Pool Name & $\begin{array}{c}\text { Year } \\
\text { Sampled } \\
\end{array}$ & $\begin{array}{c}\text { Year } \\
\text { Created }\end{array}$ & $\begin{array}{l}\text { Samples } \\
\text { Included }\end{array}$ & $\begin{array}{c}\text { Time } \\
\text { Sampling }\end{array}$ & $\begin{array}{c}\text { Mean CORT } \\
\mathrm{pg} \pm \mathrm{SE}\end{array}$ & $\mathrm{CV}$ \\
\hline LN96 & 2015 & 2013 & 8 & 32 & $31.04 \pm 6.3$ & $57 \%$ \\
\hline LS119 & 2015 & 2014 & 8 & 31 & $21.2 \pm 3.85$ & $51 \%$ \\
\hline LS120 & 2015 & 2014 & 8 & 26 & $30.43 \pm 5.7$ & $53 \%$ \\
\hline LS125-5 & 2015 & 2014 & 8 & 56 & $39.43 \pm 23.28$ & $167 \%$ \\
\hline LS125-34 & 2015 & 2014 & 8 & 21 & $36.24 \pm 5.47$ & $43 \%$ \\
\hline LS49 & 2015 & 2014 & 7 & 30 & $32.7 \pm 11.92$ & $96 \%$ \\
\hline LS69 & 2015 & 2014 & 7 & 39 & $5.769 \pm 2.81$ & $129 \%$ \\
\hline B11 & 2016 & 2011 & 15 & 31 & $48.35 \pm 7.1$ & $57 \%$ \\
\hline B2 & 2016 & 2011 & 10 & 26 & $18.46 \pm 4.37$ & $75 \%$ \\
\hline B4 & 2016 & 2011 & 10 & 61 & $18.87 \pm 5.19$ & $87 \%$ \\
\hline B5 & 2016 & 2011 & 10 & 29 & $37.58 \pm 6.96$ & $59 \%$ \\
\hline B7 & 2016 & 2011 & 10 & 51 & $104.3 \pm 21.41$ & $65 \%$ \\
\hline B8 & 2016 & 2011 & 10 & $<86$ & $60.3 \pm 10.57$ & $55 \%$ \\
\hline B9 & 2016 & 2011 & 14 & 15 & $69.29 \pm 17.45$ & $94 \%$ \\
\hline BB2 & 2016 & 2011 & 10 & 82 & $36.75 \pm 5.64$ & $49 \%$ \\
\hline BB8 & 2016 & 2011 & 10 & 28 & $25.66 \pm 3.72$ & $46 \%$ \\
\hline BB9 & 2016 & 2011 & 10 & 33 & $24.09 \pm 5.89$ & $77 \%$ \\
\hline LN10 & 2016 & 2013 & 10 & 6 & $141.5 \pm 14.49$ & $32 \%$ \\
\hline LN104 & 2016 & 2013 & 8 & 20 & $41.02 \pm 7.43$ & $51 \%$ \\
\hline LN105 & 2016 & 2013 & 9 & 23 & $33.4 \pm 9.77$ & $88 \%$ \\
\hline LN11 & 2016 & 2013 & 7 & 27 & $136 \pm 18.06$ & $35 \%$ \\
\hline LN18 & 2016 & 2013 & 10 & 40 & $31.79 \pm 9.94$ & $99 \%$ \\
\hline LN2 & 2016 & 2013 & 9 & 28 & $113.6 \pm 23.01$ & $61 \%$ \\
\hline LN24 & 2016 & 2013 & 10 & 36 & $53.63 \pm 19.82$ & $117 \%$ \\
\hline LN4 & 2016 & 2013 & 10 & 39 & $13.41 \pm 3.59$ & $85 \%$ \\
\hline LN5 & 2016 & 2013 & 10 & 52 & $24.14 \pm 7.71$ & $101 \%$ \\
\hline LN62 & 2016 & 2013 & 14 & 60 & $62.09 \pm 9.73$ & $59 \%$ \\
\hline LN77 & 2016 & 2013 & 15 & 40 & $39.36 \pm 6.64$ & $65 \%$ \\
\hline LS1 & 2016 & 2014 & 9 & 22 & $14.52 \pm 3.72$ & $77 \%$ \\
\hline LS120 & 2016 & 2014 & 10 & 35 & $50.8 \pm 13.13$ & $82 \%$ \\
\hline LS125-5 & 2016 & 2014 & 10 & 30 & $18.8 \pm 5.22$ & $88 \%$ \\
\hline LS2 & 2016 & 2014 & 10 & 60 & $28.7 \pm 7.35$ & $81 \%$ \\
\hline LS69 & 2016 & 2014 & 10 & 39 & $47.8 \pm 9.91$ & $66 \%$ \\
\hline
\end{tabular}




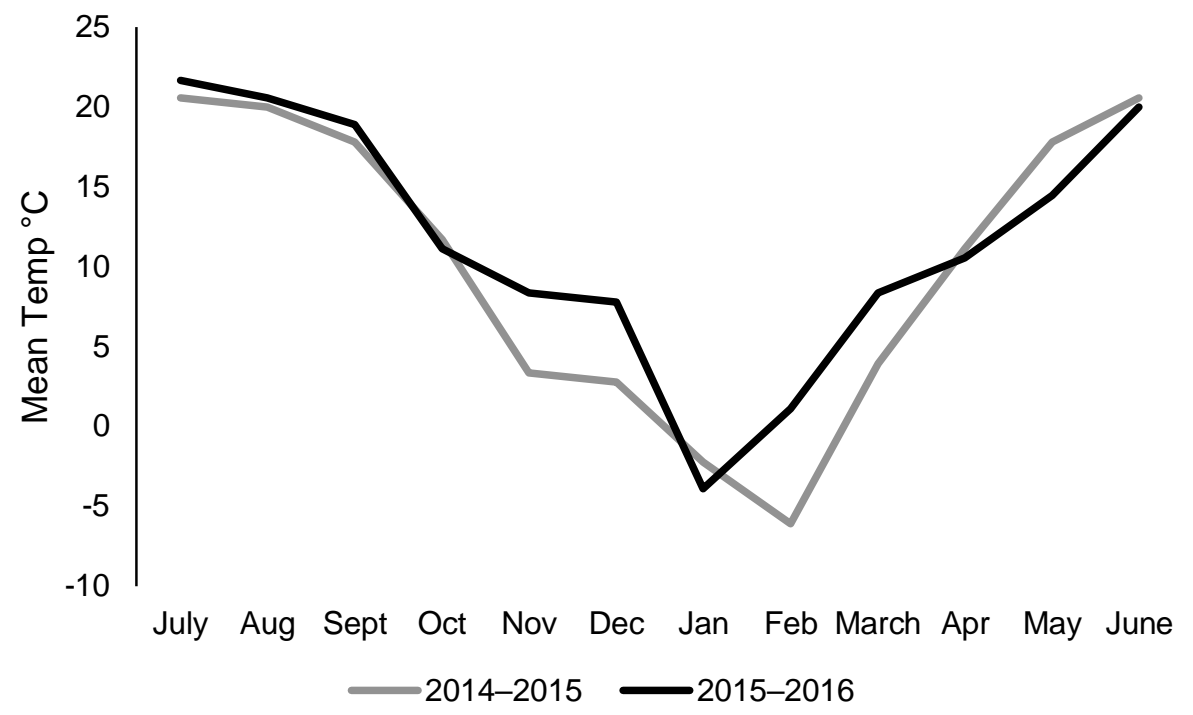

Figure S1. Monthly average temperatures separated by sample year based on the 12 months before and including sampling: July 2014 - June 2015 and July 2015 - June 2016. Weather data are from the nearest weather station (Elkins, WV), which is $40.23 \mathrm{~km}$ away. Data from The Weather Underground [United States] Elkins-Randolph County Station, WV. 


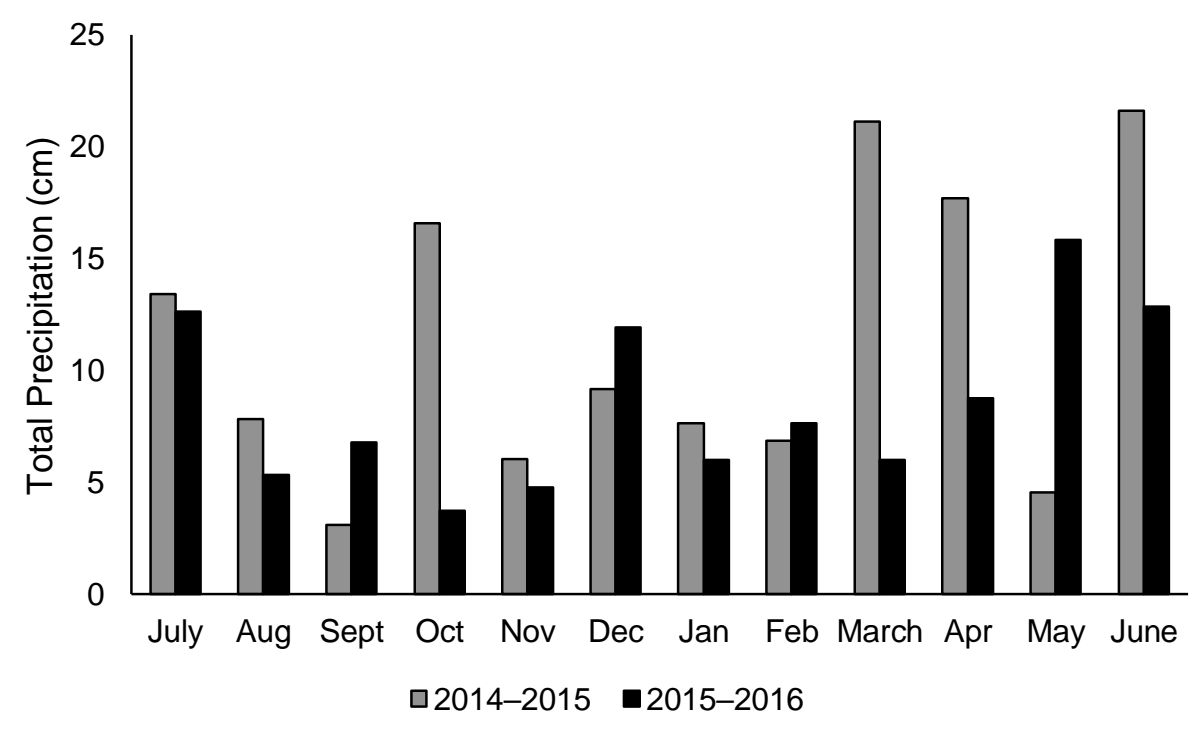

Figure S2. Monthly total precipitation separated by sample year based on the 12 months before and including sampling: July 2014 - June 2015 and July 2015 - June 2016. Weather data are from the nearest weather station (Elkins, WV), which is $40.23 \mathrm{~km}$ away. Data from The Weather Underground [United States] Elkins-Randolph County Station, WV. 


\title{
Chapter 3
}

\section{Water-borne and Plasma Corticosterone are not Correlated in Spotted Salamanders}

\author{
Alice R. Milikin ${ }^{1 *}$, SARah K. WoOdley ${ }^{2}$, Drew R. Davis ${ }^{3}$, Ignacio T. MoOre ${ }^{4}$ And James T. \\ ANDERSON $^{1}$
}

${ }^{1}$ PRESENT ADDRESS: West Virginia University, School of Natural Resources, PO Box 6125, Morgantown, WV 26506, USA; e-mail: jim.anderson@mail.wvu.edu

${ }^{2}$ PRESENT ADDRESS: Duquesne University, Department of Biological Sciences, 600

Forbes Avenue, Pittsburgh, PA 15282, USA; e-mail: woodleys@duq.edu

${ }^{3}$ PRESENT ADDRESS: University of Texas Rio Grande Valley, School of Earth, Environmental, and Marine Sciences, 100 Marine Lab Drive, South Padre Island, TX 78597, USA; e-mail: drew.davis@utrgv.edu

${ }^{4}$ PRESENT ADDRESS: Virginia Tech, Department of Biological Sciences, 926 West

Campus Drive, Blacksburg, VA 24061, USA; e-mail: itmoore@vt.edu

*CORRESPONDING AUTHOR E-MAIL: alicemillikin@gmail.com

Running head: Millikin et al. Water-borne corticosterone 


\begin{abstract}
Water-borne hormone measurement is a noninvasive method suitable for amphibians of all sizes that are otherwise difficult to sample. For this method, containment-water is assayed for hormones released by the animal. Originally developed in fish, the method has expanded to amphibians, but requires additional species-specific validations. We wanted to determine physiological relevance of water-borne corticosterone in spotted salamanders (Ambystoma maculatum) by comparing concentrations to those taken using established corticosterone sampling methods, such as plasma. Using a mixture of field and laboratory studies, we compared water-borne corticosterone levels to other traditional methods of sampling corticosterone for spotted salamander larvae, metamorphs, and adults. Despite multiple attempts, and detecting differences between age groups, we found no correlations between water-borne and plasma corticosterone levels in any age group. Water-borne sampling measures a rate of release; whereas plasma is the concentration circulating in the blood. The unique units of measurement may inherently prevent correlations between the two. These two methods may also require different interpretations of the data and the physiological meaning. We also note caveats with the method, including how to account for differences in body size and life history stages. Collectively, our results illustrate the importance of careful validation of water-borne hormone levels in each species in order to understand its physiological significance.
\end{abstract}

Key words: Ambystoma maculatum; Glucocorticoid; Hormones; Noninvasive; Validation 


\section{INTRODUCTION}

CONSERVATION physiology provides additional avenues to assess population health by measuring physiological responses to habitat quality (Wikelski and Cooke 2006). These physiological responses could predict population declines and facilitate detection of vulnerable populations (McCormick and Romero 2017). Corticosterone is a glucocorticoid hormone that is a useful parameter to measure sublethal impacts and could act as an indicator of habitat quality (Romero and Wikelski 2001; Homyack 2010; McCormick and Romero 2017). When amphibians encounter environmental changes that require a physiological or behavioral response, the hypothalamus-pituitary-interrenal (HPI) axis is activated, releasing corticosterone to make energy available (McEwen and Wingfield 2003; Romero 2004). This allows amphibians to maintain allostasis; however, sustained elevated corticosterone concentrations can suppress the immune system and growth (McEwen and Wingfield 2003).

Corticosterone levels of wild populations are typically interpreted two ways. The first measures baseline corticosterone levels of individuals by sampling within 3 min of capture to obtain corticosterone levels prior to elevation that can occur due to handling (Romero and Reed 2005). Corticosterone levels can also be quantified by comparing baseline levels to corticosterone levels after adrenocorticotropic hormone (ACTH) challenge or physical agitation. This involves collecting a sample within 3 min of capture and again after the treatment (ACTH challenge or physical agitation). If there is no change after a treatment previously shown to increase corticosterone in the study species, one possible explanation is that baseline levels were already elevated, which downregulated the HPI axis response.

Water-borne hormone sampling is a noninvasive method originally used in fish (Scott and Ellis 2007; Félix et al. 2013), which has recently expanded to amphibians (Fig. 1; Gabor et 
al. 2013, 2016; Baugh et al. 2018). While contained in water, the animal releases corticosterone through the gills, skin, and urine that can later be extracted (Scott and Ellis 2007; Félix et al. 2013; Gabor et al. 2013). Water-borne corticosterone is interpreted as a cumulative measure of the hormone over a set period of time, usually $1 \mathrm{~h}$ (Scott and Ellis 2007; Gabor et al. 2013). This reflects the corticosterone release rate, or the rate of secretion of the hormone (Scott and Ellis 2007; Gabor et al. 2013; Dantzer et al. 2014).

Documented correlations between water-borne corticosterone and treatments linked to adverse physiological effects indicate biological significance for water-borne hormone sampling (Gabor et al. 2015; Holmes et al. 2016; Charbonnier et al. 2018). Spotted salamander larvae in high intraspecific densities and juveniles in low-moisture environments had elevated water-borne corticosterone levels and the larvae had reduced growth (Charbonnier et al. 2018). More aggressive and more severe infections of Batrachochytrium dendrobatidis $(B d)$ were associated with higher water-borne corticosterone levels in the Mallorcan midwife toad (Alytes muletensis) and common midwife toad (A. obstetricians; Gabor et al. 2015). Higher water-borne corticosterone levels were associated with higher ranavirus infection intensity in larval western tiger salamanders (Ambystoma mavortium; Davis et al. 2019). In common midwife toads, $B d$ infection and higher corticosterone levels were associated with decreased ability of their righting reflex (Gabor et al. 2015). African clawed frogs (Xenopus laevis) in tanks with an unnatural background color (white) had higher levels of water-borne corticosterone along with greater body mass loss (Holmes et al. 2016). The measurable responses in water-borne corticosterone levels coupled with biological responses indicate an association between water-borne corticosterone levels and the treatments that is biologically relevant. 
Water-borne sampling can be conducted on amphibians of any size, which makes it useful for species that are difficult to sample like larval spotted salamanders (Ambystoma maculatum; Fig. 1). Larval spotted salamanders, which can weigh less than $1 \mathrm{~g}$ and measure less than $4 \mathrm{~cm}$ total length, are often too small to obtain detectable whole-body corticosterone levels or sufficient blood samples, even when the animal is sacrificed (A.R. Millikin, personal observation, this paper). This species reproduces and completes metamorphosis in vernal pools, small wetlands vulnerable to destruction (Calhoun et al. 2014). Water-borne hormone sampling could provide a beneficial tool to monitor the larval physiological health in sensitive wetlands.

Interpreting water-borne hormone data requires multiple levels of validation. Chemical validation and quality controls determine if the assays are reporting reliable values for corticosterone (Behringer and Deschner 2017). Biological validation determines if changes in hormone levels are biologically relevant by demonstrating associations with either changes in the environment or the resulting effects to the animal like reduced growth. Finally, physiological validation demonstrates a link between water-borne corticosterone levels and other measures of corticosterone in the same animal (Scott and Ellis 2007). The physiological validation is necessary to create a strong foundation for appropriate applications of the method (Madliger et al. 2018). Most research considers water-borne hormone sampling valid for a species if it is correlated with hormone levels in plasma (Scott and Ellis 2007; Gabor et al. 2013). Positive correlations between water-borne corticosterone and plasma corticosterone levels have been found in four amphibian species including adult Túngara frogs (Physalaemus pustulosus; $r=$ 0.46; Baugh et al. 2018), larval western tiger salamanders ( $r^{2}=0.60$; Davis et al. 2019), adult San Marcos salamanders (Eurycea nana; $r=0.87$ ), and adult common midwife toads ( $r=0.86$; Gabor et al. 2013). To demonstrate detection of physiologically relevant changes in 
corticosterone, studies often attempt to increase corticosterone in some individuals by injecting them with ACTH or by exposing them to physical agitation (Gabor et al. 2016, 2018; Baugh et al. 2018).

We wanted to determine whether water-borne corticosterone was correlated with plasma corticosterone levels in spotted salamanders in order to physiologically validate the method for this species. Because our main goal was to determine whether natural individual variation in corticosterone could be detected using water-borne sampling methods, we started by assessing the correlation between water-borne and whole-body corticosterone of larvae in the field. Next, we collected larvae and reared them in the laboratory until they were large enough to collect plasma. We compared water-borne and plasma corticosterone in these lab-reared larvae and metamorphs. Half of the lab-reared animals were randomly selected for physical agitation to induce an increase in corticosterone to compare with animals under baseline conditions. If we detected an increase in corticosterone in response to agitation in both water-borne and plasma samples, it would indicate physiological relevance for water-borne corticosterone in this species (Behringer and Deschner 2017). Finally, to broaden the applicability of the sampling method, we evaluated whether there was a correlation between water-borne and plasma corticosterone levels of adult spotted salamanders in the field. We tested for differences in corticosterone levels among larvae, metamorphs, and adults to test whether water-borne corticosterone would follow the same trend as plasma and to determine if the physiological factor, age, impacted corticosterone levels (Behringer and Deschner 2017).

\section{MATERIALS AND METHODS}

This study was completed with approval from West Virginia University Institutional Animal Care and Use Committee (15-0409.3), Duquesne University Institutional Animal Care 
and Use Committee (1609-09), the U.S. Forest Service, West Virginia Division of Natural Resources (Scientific Collecting Permit 2015.133, 2016.205, 2017.073), and the Pennsylvania Fish and Boat Commission (Scientific Collecting Permit 2017-01-0048).

\subsection{Larvae and Metamorphs}

2.1.1 Water-borne vs. whole-body corticosterone.-We used a seine and dip net to collect spotted salamander larvae in created vernal pools on Cheat Mountain in Monongahela National Forest, WV. On 8 June 2015 at 1429 h, we collected 16 larvae with an average weight of $0.047 \pm 0.005 \mathrm{~g}$ (range: $0.019-0.076 \mathrm{~g}$ ). Each larva was placed in an individual high-density polyethylene specimen cup (Dynarex Model 4254) in $20 \mathrm{~mL}$ of distilled water (premixed with Kent R/O Right Water Conditioner to prevent osmotic shock) and removed after $1 \mathrm{~h}$. Upon removal from the water-borne sample, larvae were immediately placed in individual microcentrifuge tubes and put in a dry ice and ethanol bath. We repeated the experiment, collecting 30 larger larvae (average weight $0.393 \pm 0.027 \mathrm{~g}$, ranging from $0.100-0.710 \mathrm{~g}$; stages 17-18; Watson and Russell 2000) on 13 June 2016 at $1232 \mathrm{~h}$. We pooled samples (3 larvae/sample) for whole-body testing to increase likelihood that corticosterone levels would be detectable. We pooled the same individuals' water-borne samples for comparison. Samples were stored at $-20^{\circ} \mathrm{C}$ until analysis.

2.1.2 Water-borne vs. plasma corticosterone.-Next, we tested the relationship between water-borne corticosterone and plasma corticosterone both at baseline and after stimulating the animals in an effort to increase corticosterone. To do so, we collected 29 larval spotted salamanders on 8 July 2017 at 1418 h from created vernal pools on Cheat Mountain in Monongahela National Forest, WV using dip nets and seines. Larvae were reared in the lab at West Virginia University for 19 days in $3 \mathrm{~L}$ of water at a density of 1 larvae/L, resulting in 3 
larvae per container. Container water was initially from the source wetland, then animals were transitioned to dechlorinated tap water. Larvae were housed at $22^{\circ} \mathrm{C}$ with a photoperiod of $14 \mathrm{~h}$ light: $10 \mathrm{~h}$ dark and fed thawed blood worms ad libitum. We changed water daily to prevent accumulation of debris, feces, food, and algae. During the 19 days in the lab, 13 of the 29 larvae completed metamorphosis. After metamorphosis, salamanders were provided both wet and dry refuge along with mesh cover. At the time of the experiment, the 16 larvae were in developmental stages $18-21$, had a total length (TL) of $4.53 \pm 0.09 \mathrm{~cm}$, a snout-vent length (SVL) of $2.83 \pm 0.07 \mathrm{~cm}$, and mass of $0.68 \pm 0.04 \mathrm{~g}$ (Watson and Russell 2000). The other 13 were metamorphs at stage 22, had a TL of $5.02 \pm 0.10 \mathrm{~cm}$, SVL of $3.06 \pm 0.06 \mathrm{~cm}$, and mass of $0.71 \pm 0.04 \mathrm{~g}($ Watson and Russell 2000).

Larvae and metamorphs were sampled for water-borne corticosterone as described above. All water-borne hormone sampling of lab-reared salamanders occurred between 1200-1700 h. To determine if we could detect a change in water-borne hormones in response to physical agitation, half of the lab-reared larvae and metamorphs were randomly assigned to one of two treatment groups. The baseline group included eight larvae and six metamorphs. The physical agitation group (hereafter agitation) included eight larvae and seven metamorphs. For the agitation group, we physically agitated salamanders while in their individual water-borne sampling cups by chasing them with blunt tweezers until they no longer exhibited a righting response $(\overline{\mathrm{X}}=30 \mathrm{~min} 54 \mathrm{~s}$, range: $20-50 \mathrm{~min})$. For both the baseline and agitation groups, immediately after collecting a water-borne hormone sample, salamanders were anesthetized in MS-222, decapitated, and a blood sample was collected within 3 min of removal from the water to test plasma levels of corticosterone (Romero and Reed 2005). Within $4 \mathrm{~h}$ of collection, blood 
samples were centrifuged for $5 \mathrm{~min}$ and plasma was collected $(\overline{\mathrm{X}}=6.34 \mu \mathrm{L}$, range: $1.50-13.50$ $\mu \mathrm{L})$ and stored at $-80^{\circ} \mathrm{C}$ until analysis. Water-borne samples were stored at $-20^{\circ} \mathrm{C}$ until analysis.

2.1.3 Corticosterone extraction and assays.-Whole-body corticosterone from field caught larvae was measured with radioimmunoassay (RIA) at Virginia Tech following methods described in Belden et al. (2003) with the following modifications. Each larva was weighed, resuspended in $4.5 \mathrm{ml}$ of distilled water, ground with a tissue tearer for a minimum of $15 \mathrm{~s}$, and transferred to a new vial for extraction. The original vial was rinsed with $0.5 \mathrm{ml}$ of distilled water and added to the extraction vial. Each sample was then triple extracted with $3 \mathrm{ml}$ of dicholoromethane and centrifuged at $2000 \mathrm{rpm}$. These extracts were dried and then resuspended in phosphate buffered saline with gelatin before beginning the assay. Samples were incubated overnight with $100 \mu \mathrm{L}$ of antibody (\#B3-163, Esoterix Endocrinology) and $100 \mu \mathrm{L}$ of tritiated steroid. Unbound steroid was removed using dextran-coated charcoal and bound steroid was collected in scintillation vials. All samples were assayed in duplicate.

Both water samples and plasma samples from lab-reared larvae and metamorphs were sent to the Endocrine Technologies Core (ETC) at the Oregon National Primate Research Center (ONPRC), where corticosterone was extracted and then measured by RIA. Plasma samples were combined with $0.1 \%$ gel-PBS and steroids were extracted with $5 \mathrm{ml}$ diethyl ether by vigorous inversion for $3 \mathrm{~min}$. Samples were centrifuged for $5 \min \left(2000 \times \mathrm{g}, 4^{\circ} \mathrm{C}\right)$ and aqueous phase was frozen using a dry ice bath. The organic phase was decanted into a new 13 x $100 \mathrm{~mm}$ tube and dried under forced air in a $37^{\circ} \mathrm{C}$ water bath. Samples were then redissolved in $0.1 \%$ gel-PBS and assayed for corticosterone using an in-house RIA. A standard curve ranging from $5 \mathrm{pg} /$ tube to 1000 pg/tube was created using 3H-corticosterone (American Radiolabeled Chemicals). The antibody used was a commercially available anti-corticosterone antibody (Abcam). Hormonal 
values were corrected for extraction losses determined by radioactive trace recovery at the same time as sample extraction, which ranged between $90 \%$ and $92 \%$. The sensitivity was $5 \mathrm{pg} / \mathrm{tube}$. Recovery for the plasma assay was $92.6 \%$ and intra-assay variation was $7.3 \%$. For water samples, corticosterone was extracted using Strata C18-E ( $55 \mu \mathrm{m}, 70 \AA$ Å), $200 \mathrm{mg} / 3 \mathrm{~mL}$ solidphase extraction (SPE) columns (Phenomenex). Columns were conditioned using methanol and equilibrated with water prior to addition of $5 \mathrm{ml}$ of water sample $(2.5 \mathrm{~mL} \times 2)$. Columns were washed with $40 \%$ methanol and steroids eluted into a new $13 \times 100 \mathrm{~mm}$ tube using $90 \%$ methanol. Samples were then dried down under forced air in a $37^{\circ} \mathrm{C}$ water bath and assayed as described above. Recovery for the water assay was $80.39 \%$ and intra-assay variation was $12.4 \%$.

\subsection{Adult Salamanders}

2.2.1 Water-borne vs. plasma corticosterone.-In Allegheny County, PA, we hand caught 28 adult spotted salamanders that were located in and migrating to ephemeral breeding pools on 6 March 2017 and 7 March 2017. Sampling occurred after dark between 1957-0058 h in rainy weather with temperatures between $5-12^{\circ} \mathrm{C}$. We immediately placed salamanders in individual high-density polyethylene buckets filled with $550 \mathrm{~mL}$ of distilled water (premixed with Kent R/O Right Water Conditioner) to collect water-borne hormones. After $1 \mathrm{~h}$, salamanders were removed from the buckets and a blood sample was collected. If salamanders were contained in the buckets for longer than $1 \mathrm{~h}$ before collecting a blood sample ( $n=26$ out of 28 samples, $\bar{X}=1 \mathrm{~h} 17 \mathrm{~min}, \max =1 \mathrm{~h} 51 \mathrm{~min}$ ), then final water-borne corticosterone levels were divided by number of hours contained (Gabor et al. 2013). We collected blood samples from adults from the caudal tail vein within 3 min of removal from buckets. Using a 21-gauge needle to access the vein, we collected blood with heparinized hematocrit capillary tubes (Woodley and Porter 2016). After collecting water and plasma samples, we measured, weighed, 
and released all adult spotted salamanders. Adult salamanders sampled averaged $17.44 \pm 0.25 \mathrm{~cm}$ TL, $9.16 \pm 0.12 \mathrm{~cm} \mathrm{SVL}$, and $16.16 \pm 0.35 \mathrm{~g}$. Within $6 \mathrm{~h}$ of collection, blood samples were centrifuged for $5 \mathrm{~min}$ and plasma was collected. Water-borne and plasma samples were stored at $-20^{\circ} \mathrm{C}$ for future analysis.

2.2.2 Water-borne hormone extraction.-Adult salamander water-borne hormone samples were assayed at Duquesne University with Corticosterone ELISA kits (\#501320, Cayman Chemicals, Inc.). Water-borne hormone samples were filtered with Q8 Whatman filter paper to remove suspended particles. We primed C18 solid phase extraction (SPE) columns (SepPak Vac 3 cc/200 mg; Waters, Inc.) using $4 \mathrm{~mL}$ of HPLC-grade methanol and $4 \mathrm{~mL}$ of nanopure water. Water-borne corticosterone samples were pulled into Tygon tubing (SaintGobain formulation 2475) and through the SPE column. Parafilm wax provided a seal between the tubing and SPE column opening. Corticosterone was eluted off the SPE column into glass test tubes using $4 \mathrm{~mL}$ methanol. Test tubes were placed in a $42^{\circ} \mathrm{C}$ water bath and methanol was evaporated with nitrogen gas using an Evap-o-rac. Samples were checked every 15 min until all methanol was evaporated (about $1 \mathrm{~h}$ ). Corticosterone left in the test tubes was resuspended in $400 \mathrm{uL}$ of $95 \%$ ELISA buffer/5\% ethanol then diluted 1:10 due to high concentrations of corticosterone. Each sample was vortexed for $10 \mathrm{~s}$, covered, and refrigerated overnight or up to two nights. If they could not be assayed within a couple days, samples were frozen at $-20^{\circ} \mathrm{C}$.

2.2.3 Water-borne hormone measurement using ELISA.- Samples and kit reagents were brought to room temperature and vortexed before plating. Samples were plated in duplicate using ELISA kits and a plate reader set to $415 \mathrm{~nm}$ (Bio-Rad 3550). Each ELISA plate included two positive and two negative controls in duplicate. The negative controls were distilled water with R/O Right Water Conditioner that had not held salamanders. Matrix effects (Scott and Ellis 
2007) result in negative controls presenting with detectable levels of corticosterone. It is standard to subtract the concentrations detected in negative controls from the sample values. The average background corticosterone recorded in our negative control samples was subtracted from salamander water-borne hormone samples. For positive controls, we combined water-borne corticosterone samples from an additional 30 larvae into one sample. The total volume was then aliquoted into individual vials of $20 \mathrm{~mL}$ to include as a positive control on each plate to determine coefficients of variation. For each plate, two positive and two negative controls (20 $\mathrm{mL}$ of each) were run through $\mathrm{C} 18$ columns, extracted and eluted at the same time as waterborne corticosterone samples. Two positive control samples were run in duplicate on every plate to assess inter- and intra-assay variation. Intra-assay variation was $18.3 \%$ and $20.2 \%$, the interassay variation was $29.0 \%$. This is within range for water-borne hormone assays: max intraassay variation of $23.1 \%$ (Gabor et al. 2013) and max inter-assay variation of 35.3\% (Gabor et al. 2016). Additionally, we expect our variation to be higher because it incorporated variation starting from the step of running the sample through C18 columns. Other studies often pool samples for a positive control after the final step of resuspension, therefore not incorporating variation from the extraction process.

To validate ELISA kits, we used a subset of water-borne negative control samples and some extra water-borne samples from free-living salamanders to compare values from ELISAs at Duquesne University to those measured with RIAs at the ETC at ONPRC. In both ELISA and RIA, negative control samples had less corticosterone than samples from salamanders. In addition, salamander water-borne hormone values from ELISA and RIA were correlated (Pearson correlation: $n=20, r=0.74, P=0.0002$ ). 
Finally, chemical validation of the ELISA assay was demonstrated with quantitative recovery and parallelism, which test accurate measurement of corticosterone within the assay itself. For recovery, a positive control sample was diluted 1:2 and combined in equal parts with the eight standards of the ELISA standard curve. The diluted positive control and the control + standard samples were plated in duplicate. Expected concentration was measured as ([known corticosterone concentration in the unaltered pooled sample + concentration of the standard] / 2). Recovery was calculated by observed concentration divided by expected concentration. Minimum observed recovery was 64\% (Millikin et al. 2019). Observed and expected values were linearly related (slope $=1.40, \mathrm{~F}_{(1,7)}=3945, \mathrm{R}^{2}=0.998, P<0.0001 ;$ Millikin et al. 2019). We demonstrated parallelism between the standard curve of the assay and successive dilutions of the positive control samples (based on eight dilutions 1:1 to 1:128, each run in duplicate) by showing the curves were not significantly different $\left(\mathrm{t}_{(12)}=1.26, P=0.23\right.$; Millikin et al. 2019).

2.2.4 Plasma samples.-Plasma samples were sent to the ETC at ONPRC, where they were extracted and then assayed for corticosterone using RIA following the methods described earlier. Plasma assay recovery was $85.8 \%$ and intra-assay variation was $10.6 \%$.

\subsection{Analysis}

We present water-borne corticosterone in units of $\mathrm{pg} / \mathrm{snout-vent} \mathrm{length/hour}(\mathrm{pg} / \mathrm{SVL} / \mathrm{h})$ to attempt to control for body size and provide data comparable to other published studies (Gabor et al. 2013). We also compare to water-borne corticosterone in units of pg/body weight/hour $(\mathrm{pg} / \mathrm{g} / \mathrm{h})$ since some research has controlled for body size using mass (Charbonnier et al. 2018). Due to missing mass data from one adult female salamander, only 27 of the 28 adults could be measured for water-borne corticosterone by weight (pg/g/h). 
All analyses were conducted in R (R Core Team 2017). We used Spearman's rank correlation to test for correlation between the water-borne corticosterone and plasma corticosterone of lab-reared larvae, metamorphs, and field-caught adults $(\alpha=0.05)$. Because we were looking for a correlation between plasma and water-borne corticosterone, we included corticosterone levels of both baseline and agitation groups in analysis. Six of 28 adult salamanders sampled took 4-5 min to collect sufficient blood samples, failing to meet the $<3$ min criteria. Because these data did not alter the trend, they were included in analysis to increase sample size and power of detection.

We tested normality for lab-reared salamanders with a Shapiro-Wilk test. We natural log transformed larval water-borne and plasma data to meet assumptions of normality for t-tests to compare corticosterone levels between baseline and agitation levels $(\alpha=0.05)$. Due to excessive zeros in metamorphs, we used Kruskal-Wallis to compare corticosterone levels between baseline and agitation groups. We also compared corticosterone levels of baseline and agitation groups with larval and metamorph data combined using Kruskal-Wallis. Corticosterone levels were compared across age groups (adult, larvae, and metamorphs) using Kruskal-Wallis followed by Dunn test ( $\alpha=0.05$; package 'dunn.test', Dinno 2017).

\section{RESULTS}

Individuals tested for whole-body corticosterone in 2015 and pooled larvae whole-body samples in 2016 both had corticosterone levels below detectible limits ( 1.3 ng/g). We did not find correlations between water-borne corticosterone and plasma corticosterone in any age group (Table 1; Fig. 2; ggplot2, Wickham 2009). Changing units from water-borne corticosterone $\mathrm{pg} / \mathrm{SVL} / \mathrm{h}$ to $\mathrm{pg} / \mathrm{g} / \mathrm{h}$ also produced no correlation with plasma corticosterone (Table 1 ; Fig. 2). In lab-reared salamanders, there was no difference between corticosterone levels for baseline and 
agitation groups for larvae, metamorphs, or both groups together $(P>0.13$; Fig. 3$)$. This held true for plasma levels and both units of water-borne hormones.

Water-borne and plasma corticosterone were different between age groups (larvae, metamorphs and adults; $P<0.01$ ), except when comparing larvae and metamorph plasma levels $(P=0.410 ;$ Fig. 4). Adults had the highest water-borne corticosterone in units of $\mathrm{pg} / \mathrm{SVL} / \mathrm{h}$; but larvae had the highest levels of water-borne corticosterone in units of $\mathrm{pg} / \mathrm{g} / \mathrm{h}$ (Fig. 4).

Corticosterone was $1.6 \times$ higher in adults than larvae when measured by $\mathrm{pg} / \mathrm{SVL} / \mathrm{h}$. However, corticosterone was $4 \times$ lower in adults than larvae when measured by $\mathrm{pg} / \mathrm{g} / \mathrm{h}$. This was caused by disparity between mass and SVL. Adult weights were $24 \times$ greater than larvae, whereas SVL was only $3 \times$ greater in adults. Adults had the lowest plasma corticosterone levels (Fig. 4).

\section{DISCUSSION}

There was no correlation between corticosterone levels in water-borne samples and plasma samples for adult spotted salamanders collected in the field or lab-reared larvae and metamorphs. Age group differences in corticosterone were inconsistent between plasma and water-borne corticosterone and also depended on the method of correcting for body size. Despite the successful chemical validation of assays (including quality controls), we were unable to physiologically validate water-borne hormones with an association between water-borne and plasma corticosterone. Our results contrast with those of other amphibian species where positive correlations between plasma levels and water-borne corticosterone were found in larval western tiger salamanders, adult San Marcos salamanders, common midwife toads, and Túngara frogs (Gabor et al. 2013; Baugh et al. 2018; Davis et al. 2019). There could be two main reasons for why we did not find a correlation. First, water-borne corticosterone and plasma corticosterone could both be biologically relevant, but inherently differ, inhibiting correlation between the two. 
Second, our methods might have been insufficient to find a correlation. Below, we discuss our results in more detail.

Chemical validation and quality control are crucial to show the assay is suitable for this species and hormone. Through chemical validation (recovery and parallelism) and quality controls (positive and negative controls), we demonstrated that the assays produced reliable levels of corticosterone for water-borne and plasma samples (Behringer and Deschner 2017). Quantitative recovery indicated the assays were able to detect corticosterone following predicted levels. In testing parallelism, the dilution curve was parallel to a standard curve of synthetic corticosterone, showing the water-borne sample was immunologically similar and could be measured based on the standard curve of the assay (Behringer and Deschner 2017). Using positive controls, we showed our assays had inter- and intra-assay variation comparable to other published studies of water-borne hormones (Gabor et al. 2013, 2016). This variation was on the higher end but that was expected as it incorporated variation introduced from the first step of extraction on C18 columns; rather than using pooled samples post-resuspension, which lacks variation from the extraction process. Finally, we used negative controls to remove any background corticosterone detected in the water separate from what was produced by the salamander.

In addition to chemical validation and quality control, validation of water-borne sampling requires species-specific physiological validation. Physiological validation is required to demonstrate that water-borne corticosterone levels are associated with the physiological state of an animal (Behringer and Deschner 2017; Madliger et al. 2018). However, we were unable to physiologically validate water-borne hormones with an association between water-borne and plasma corticosterone. The first possible explanation for our results is that water-borne 
corticosterone and plasma corticosterone may reflect different aspects of the physiological response; such that water-borne corticosterone cannot be generalized as a reflection of plasma corticosterone. These two sampling methods are producing a unit of measurement unique to that method. It is possible that the unique units of measurement inherently prevent correlations between the two. The two units may also require different interpretations of the data and physiological meaning. Water-borne hormones are based on the animal's release rate into the water; plasma hormones are a direct measure of corticosterone concentration in the animal's blood. Water-borne levels might reflect capture and confinement in a novel environment. Additionally, plasma samples reflect a specific point in time, which might be interpreted as reflecting short-term conditions. Whereas, water-borne levels measure a rate of release; which might reflect long-term conditions and represent a more comprehensive measure of corticosterone (Dantzer et al. 2014). Because water-borne sampling is still relatively new for amphibians, this claim requires additional evidence for species-specific physiological relevance of the rate.

Despite the lack of correlation between water-borne and plasma corticosterone; we have evidence that water-borne corticosterone is biologically meaningful in spotted salamanders. In a previous study, water-borne corticosterone was associated with salamander body size as well as the water temperature and diameter of vernal pools (Millikin et al. 2019). If water-borne corticosterone was a random signal, there likely would not have been an association with the body size or the environment. We also detected higher water-borne corticosterone levels in water that contained salamanders than negative control samples including nanopure water, distilled water, and water enriched with R/O Right Water Conditioner, which is what we used during 
sampling. We confirmed this with samples sent to the ETC at ONPRC. This indicates that the detected corticosterone is coming from the tested animals.

Another explanation for the association lacking between water-borne and plasma corticosterone could be methodological. We examined baseline levels after one hour of containment, which was adequate to demonstrate correlations between plasma and water-borne corticosterone in adult common midwife toads and San Marcos salamanders (Gabor et al. 2013). In adult Túngara frogs, plasma and water-borne corticosterone correlations were found after longer holding periods, two hours (Baugh et al. 2018). This might indicate that holding periods longer than one hour are required to facilitate a correlation for certain species. Additionally, laboratory effect could have impacted the quantitative values of corticosterone (Fanson et al. 2017). By using Spearman's rank correlation, we reduced the impact of variation in the absolute concentration (Fanson et al 2017). However, it is important to note that for the adult salamander samples we used two different assays and two different labs (i.e., ELISA at Duquesne University for water-borne samples and RIA at the ETC at ONPRC for plasma samples). Using different labs may have influenced results for the adults. Despite our demonstrated correlations for ELISA and RIA, using different methods for the adult samples also could have influenced the results because ELISA measured both free corticosterone and conjugated forms (sulfonated corticosterone and glucoroninated corticosterone), while the RIA measured free corticosterone. Lab effect is not a concern for the salamander larvae and metamorph data because both waterborne and plasma samples were processed by RIA at the ETC at ONPRC using methods that measured free corticosterone in both.

Additionally, it is possible that we were unable to find a correlation between water-borne and plasma corticosterone because corticosterone levels were not sufficiently variable among 
animals to provide a sufficient range to reveal a correlation. Subtle differences might have not been detected due to variance in the assay. In other studies, animals were injected with ACTH, the secretagogue of corticosterone, to produce a maximal increase in corticosterone. For example, San Marcos salamanders and Túngara frogs produced detectible increases in waterborne corticosterone levels after ACTH injections (Gabor et al. 2016; Baugh et al. 2018). Along with water-borne levels, plasma corticosterone was elevated after ACTH injection for Túngara frogs, consistent with the hypothesis that water-borne corticosterone shows similar patterns to plasma corticosterone (Baugh et al. 2018). We did not incorporate ACTH challenges in our study because the purpose of this validation was to demonstrate water-borne hormones would reflect plasma levels based on natural variation in physiology, rather than an artificial response. Another strategy to induce a corticosterone response is to handle or agitate the animal. We failed to find an increase in corticosterone due to physical agitation in either the plasma or water-borne samples, perhaps because chasing the salamander with tweezers was not sufficient to elicit an HPI response. It has been shown that disturbing the containers of salamanders in water increased water-borne corticosterone levels in Jollyville Plateau salamanders (Eurycea tonkawae; Gabor et al. 2016, 2018), but not in San Marcos salamanders (E. nana), and there were conflicting results from different populations of Barton Springs salamanders (E. sosorum; Gabor et al. 2016). Our salamanders did display loss of righting reflex, indicating a biological response to our agitation treatment. It is possible that lab-reared metamorphs had elevated baseline corticosterone due to confinement, captivity, or growth and development during metamorphosis, preventing a detectible response (Belden et al. 2010; Chambers et al. 2011; de Assis et al. 2015). It seems these were not influential factors for lab-reared larvae because water-borne corticosterone levels of lab-reared larvae were similar to those of larvae caught in the field (Millikin et al. 2019). Our 
field-caught adults also had baseline plasma corticosterone levels that were similar to other studies (Homan et al. 2003). Additionally, the range of values of water-borne and plasma corticosterone found in our study was similar to those found in other validation studies that used baseline levels of corticosterone (Gabor et al. 2013) and ACTH injections (Gabor et al. 2016), suggesting that corticosterone was sufficiently variable among individuals to detect a correlation if it existed.

Our results illustrate several additional caveats with sampling water-borne hormones. The first is the method of correcting for differences in body size. We found different patterns of results depending on how we corrected for body size, SVL versus mass. Related to this, Scott and Ellis (2007) pointed out the difficulty of comparing water-borne hormones between animals with variation in body size; as we found in the larvae and adults. This is because dividing waterborne corticosterone by body size can produce artificial differences if the groups differ greatly in body size (Scott and Ellis 2007). Also, we have evidence that dividing by body size does not completely correct for body size differences even among animals of a similar body size (Millikin et al. 2019). We found after dividing corticosterone pg by total body length, larger animals still had higher corticosterone levels making it necessary to include body size in models to control for its impact when determining predictors of corticosterone levels (Millikin et al. 2019). Another limitation is that perhaps water-borne hormones should not be compared across different amphibian life stages. Our larvae and metamorphs had similar plasma corticosterone levels. However, metamorphs produced little water-borne corticosterone. The reabsorption of gills or changes in skin during metamorphosis could alter the passage of corticosterone into the water producing different results than larvae. 
Water-borne hormone sampling has many benefits that make it a method worth further research. Corticosterone detected in plasma is a direct measure of circulating levels in that moment, whereas water-borne may reflect overall physiological condition (Romero and Reed 2005; Dantzer et al. 2014; Baugh et al. 2018). Water-borne sampling is not restricted by animal size and could provide an option for animals too small to sample or detect with other methods. We could not detect whole-body corticosterone in spotted salamander larvae, making it important to explore whether water-borne sampling is a viable alternative. Water-borne sampling could be essential for studying hormone levels in smaller larvae. It also allows for sampling the same individual multiple times and over long periods of time, even of small animals that would otherwise have to be sacrificed (Scott and Ellis 2007). Many studies have provided evidence that water-borne corticosterone provides physiologically relevant estimates that are biologically meaningful (Gabor et al. 2013, 2015, 2016, 2018; Holmes et al. 2016; Baugh et al. 2018; Charbonnier et al. 2018; Davis et al. 2019). Because water-borne hormone sampling is still a new method, additional research is necessary to determine the ideal containment time $(1 \mathrm{~h}, 2 \mathrm{~h}$, etc. $)$ for peak corticosterone release in this, and other, species. Future research is necessary to better understand how water-borne hormone levels vary among individuals and species. It should be determined if water-borne corticosterone is impacted by amount of handling time, disturbance, or recent interactions with predators. Additionally, the method used to control for body size could influence the relationship between water-borne and plasma corticosterone. Future research should explore if there are more suitable methods to control for the impact of body size on corticosterone release rate. It is possible that body condition index (MacCracken and Stebbings 2012) or surface area-to-volume ratio (Ferreira Amado et al. 2019) would more accurately account for body size and control for that influential factor on release rates. 
Despite the advantages of water-borne hormones to assess physiological status, our results illustrate the importance and challenges of physiologically validating the method. There was no correlation between plasma and water-borne corticosterone levels in spotted salamander larvae or metamorphs in the lab, or adults in the field. Water-borne and plasma corticosterone sampling might provide different data that require separate interpretation methods. Our study indicates water-borne sampling requires additional research to determine the species-specific physiological consequences of variation in water-borne hormone levels. Our study also echoes concerns around the inconsistent pattern of corticosterone levels among life stages and species (Scott and Ellis 2007; Dickens and Romero 2013; Gormally et al. 2019). The interpretation of water-borne hormone levels will depend upon physiological validation and demonstrated biological meaning.

\section{ACKNOWLEDGMENTS}

We thank Jessi Rouda, Jonathan Strickland, Adam Bucher, John Millikin, Mimi Smith, Meghan Jensen, Michelle Mabry, Carl Jacobsen, Sally Yannuzzi, Brady Porter, Kenzie Pereira, and Sara McClelland for field and lab assistance. This research was funded by the U.S. Forest Service, Natural Resources Conservation Service, National Science Foundation (01A-1458952), West Virginia University Natural History Museum, National Institute of Food and Agriculture McStennis Project WVA00117, The Explorers Club Washington Group, Society of Wetland Scientists, Society of Wetland Scientists South Atlantic Chapter, West Virginia University Stitzel Graduate Enhancement Fund, and Richard and Lois Bowman. We thank David Erikson and the staff at the Endocrine Technologies Core at the Oregon National Primate Research Center, which is supported by National Institute of Health Grant P51 OD011092. We also thank West Virginia Division of Natural Resources, Department of Biological Sciences at Duquesne 
University, and the Ruby Distinguished Doctoral Fellowship Program. This is scientific article number 3368 of the West Virginia Agricultural and Forestry Experiment Station, Morgantown.

CONFLICT OF INTEREST

None declared.

\section{AUTHOR CONTRIBUTIONS}

ARM, SKW, and JTA devised the study. JTA and ARM obtained funding. ARM and SKW collected field data. ARM conducted animal care, experiments, and lab work with help from technicians and input from SKW and DRD. ARM conducted analysis with advice from SKW and DRD. ITM processed whole-body samples. ARM wrote the manuscript with significant contributions from all authors.

DATA AVAilability STATEMENT

Data associated with this study are available in DRYAD https://doi.org/10.5061/dryad.zs7h44j4p 


\section{REFERENCES}

Baugh, A.T., B. Bastien, M. Still and N. Stowell. 2018. Validation of water-borne steroid hormones in a tropical frog (Physalaemus pustulosus). General and Comparative Endocrinology 261:67-80. https://doi.org /10.1016/j.ygcen.2018.01.025

Behringer, V., and T. Deschner. 2017. Non-invasive monitoring of physiological markers in primates. Hormones and Behavior 91:3-18. https://doi.org/10.1016/j.yhbeh.2017.02.001

Belden, L.K., I.T. Moore, R.T. Mason, J.C. Wingfield and A.R. Blaustein. 2003. Survival, the hormonal stress response and UV-B avoidance in Cascades frog Tadpoles (Rana cascadae) exposed to UV-B radiation. Functional Ecology 17(3):409-416.

Belden, L.K., J.C. Wingfield and J.M. Kiesecker. 2010. Variation in the hormonal stress response among larvae of three amphibian species. Journal of Experimental Zoology 313A(8):524-531. https://doi.org/10.1002/jez.623

Calhoun, A.J.K, J. Arrigoni, R.P. Brooks, M.L. Hunter and S.C. Richter. 2014. Creating successful vernal pools: a literature review and advice for practitioners. Wetlands 34(5):1027-1038. https://doi.org/10.1007/s13157-014-0556-8

Chambers, D.L., J.M. Wojdak, P. Du and L.K. Belden. 2011. Corticosterone level changes throughout larval development in the amphibians Rana sylvatica and Ambystoma jeffersonianum reared under laboratory, mesocosm, or free-living conditions. Copeia 2011(4):530-538. https://doi.org/10.1643/CP-09-180

Charbonnier, J.F, J. Pearlmutter, J.R. Vonesh, C.R. Gabor, Z.R. Forsburg and K.L. Grayson. 2018. Cross-life stage effects of aquatic larval density and terrestrial moisture on growth and corticosterone in the spotted salamander. Diversity 10(3):68.

https://doi.org/10.3390/d10030068 
Dantzer, B., Q.E. Fletcher, R. Boonstra and M.J. Sheriff. 2014. Measures of physiological stress: a transparent or opaque window into the status, management and conservation of species? Conservation Physiology 2(1):cou023. https://doi.org/10.1093/conphys/cou023

Davis, D.R., K.J. Ferguson, M.S. Schwarz, and J.L. Kerby. 2019. Effects of agricultural pollutants on stress hormones and viral infection in larval salamanders. Wetlands. https://doi.org/10.1007/s13157-019-01207-1

de Assis, V.R., S.C.M. Titon, A.M.G. Barsotti, B. Titon Jr. and F.R. Gomes. 2015. Effects of acute restraint stress, prolonged captivity stress and transdermal corticosterone application on immunocompetence and plasma levels of corticosterone on the cururu toad (Rhinella icterica). PLoS ONE 10(4):e0121005 https://doi.org/10.1371/journal.pone.0121005

Dickens, M.J. and L.M. Romero. 2013. A consensus endocrine profile for chronically stressed wild animals does not exist. General and Comparative Endocrinology 191:177-189. https://doi.org/10.1016/j.ygcen.2013.06.014

Dinno, A. 2017. Dunn.test: Dunn's Test of Multiple Comparisons using Rank Sums. R. package version 1.3.5. https://CRAN.R-project.org/package=dunn.test

Fanson, K.V., Z. Németh, M. Ramenofsky, J.C. Wingfield and K.L. Buchanan. 2017. Interlaboratory variation in corticosterone measurement: implications for comparative ecological and evolutionary studies. Methods in Ecology and Evolution 8(12): 1745- 1754. https://doi.org/10.1111/2041-210X.12821

Félix, A.S., A.I. Faustino, E.M. Cabral and R.F. Oliveira. 2013. Noninvasive measurement of steroid hormones in zebrafish holding-water. Zebrafish 10(1):110-115. https://doi.org/10.1089/zeb.2012.0792 
Ferreira Amado, T., Moreno Pinto, M.G., Olalla-Tárraga, M. Á. 2019. Anuran 3D models reveal the relationship between surface area-to-volume ratio and climate change. Journal of Biogeography 46(7):1429-1437. https://doi.org/10.1111/jbi.13593

Gabor, C.R., J. Bosch, J.N. Fries and D.R. Davis. 2013. A non-invasive water-borne hormone assay for amphibians. Amphibia-Reptilia 34(2):151-162. https://doi.org/10.1163/1568538100002877

Gabor, C.R., M.C. Fisher and J. Bosch. 2015. Elevated corticosterone levels and changes in amphibian behavior are associated with Batrachochytrium dendrobatidis $(B d)$ infection and Bd lineage. PLoS ONE 10(4):e0122685. https://doi.org/10.1371/journal.pone.0122685

Gabor, C.R., K.C. Zabierek, D.S. Kim, L.A. da Barbiano, M.J. Mondelli, N.F. Bendik and D.R. Davis. 2016. A non-invasive water-borne assay of stress hormones in aquatic salamanders. Copeia 104(1):172-181. https://doi.org/10.1643/OT-14-207

Gabor, C.R., D.R. Davis, D.S. Kim, K.C. Zabierek and N.F. Bendik. 2018. Urbanization is associated with elevated corticosterone in Jollyville Plateau salamanders. Ecological Indicators 85:229-235. https://doi.org/10.1016/j.ecolind.2017.10.047

Gormally, B.M.G, R. Fuller, M. McVey and L.M. Romero. 2019. DNA damage as an indicator of chronic stress: correlations with corticosterone and uric acid. Comparative Biochemistry and Physiology, Part A 227:116-122. https://doi.org/10.1016/j.cbpa.2018.10.007

Holmes, A.M., C.J. Emmans, N. Jones, R. Coleman, T.E. Smith and C.A. Hosie. 2016. Impact of tank background on the welfare of the African clawed frog, Xenopus laevis (Daudin). Applied Animal Behaviour Science 185:131-136. https://doi.org/10.1016/j.applanim.2016.09.005 
Homan, R.N., Regosin, J.V., Rodrigues, D.M., Reed, J.M., Windmiller, B.S. and L.M. Romero. 2003. Impacts of varying habitat quality on the physiological stress of spotted salamanders (Ambystoma maculatum). Animal Conservation 6(1):11-18.

https://doi.org/10.1017/S1367943003003032

Homyack, J.A. 2010. Evaluating Habitat quality of vertebrates using conservation physiology tools. Wildlife Research 37(4):332-342. https://doi.org/10.1071/WR08093

MacCracken, J.G. and J.L. Stebbings. 2012. Test of a body condition index with amphibians. Journal of Herpetology 46(3):346-350. https://doi.org/10.1670/10-292

Madliger, C.L., O.P. Love, K.R. Hultine and S.J. Cooke. 2018. The conservation physiology toolbox: status and opportunities. Conservation Physiology 6(1):coy029. https://doi.org/10.1093/conphys/coy029

McCormick, S.D., and M. Romero. 2017. Conservation endocrinology. Bioscience 67(5):429442. https://doi.org/10.1093/biosci/bix026

McEwen, B.S., and J.C. Wingfield. 2003. The concept of allostasis in biology and biomedicine. Hormones and Behavior 43(1):2-15. https://doi.org/10.1016/S0018-506X(02)00024-7

Millikin, A.R., S.K. Woodley, D.R. Davis and J.T. Anderson. 2019. Habitat characteristics in created vernal pools impact spotted salamander water-borne corticosterone levels. Wetlands 39(4):803-814. https://doi.org/10.1007/s13157-019-01130-5

R Core Team. 2017. R: A language and environment for statistical computing. R Foundation for Statistical Computing, Vienna, Austria. https://www.R-project.org/.

Romero, L.M. 2004. Physiological stress in ecology: Lessons from biomedical research. Trends in Ecology and Evolution 19(5):249-255. https://doi.org/10.1016/j.tree.2004.03.008 
Romero, L.M., and J.M. Reed. 2005. Collecting baseline corticosterone samples in the field: Is under 3 min good enough? Comparative Biochemistry and Physiology, Part A 140(1):73-79. https://doi.org/10.1016/j.cbpb.2004.11.004

Romero, L., and M. Wikelski. 2001. Corticosterone levels predict survival probabilities of Galápagos marine iguanas during El Niño events. Proceedings of the National Academies of Science 98(13):7366-7370. https://doi.org/10.1073/pnas.131091498

Scott, A.P., and T. Ellis. 2007. Measurement of fish steroids in water - A review. General and Comparative Endocrinology 153(1-3):392-400. https://doi.org/10.1016/j.ygcen.2006.11.006

Watson, S., and A. Russell. 2000. A posthatching developmental staging table for the Long-toed Salamander, Ambystoma macrodactylum krausei. Amphibia-Reptilia 21(2):143-154. https://doi.org/10.1163/156853800507336

Wickham, H. 2009. ggplot2: Elegant graphics for data analysis. Springer-Verlag New York. Wikelski, M., and S.J. Cooke. 2006. Conservation physiology. TRENDS in Ecology and Evolution 21(1):38-46. https://doi.org/10.1016/j.tree.2005.10.018

Woodley, S. K., and B.A. Porter. 2016. Handling stress increases expression of male sexual behaviour in an amphibian with an explosive mating strategy. Journal of Zoology 298(3):178-182. https://doi.org/10.1111/jzo.12295 
Table 1. Spearman's correlation of spotted salamander plasma and water-borne corticosterone levels presented across age groups. Correlations are presented for both water-borne corticosterone units of measurement: $\mathrm{pg} / \mathrm{SVL} / \mathrm{h}$ and $\mathrm{pg} / \mathrm{g} / \mathrm{h}$. Also included are statistics for adults after removing females and for adults only including individuals whose blood samples were collected within $3 \mathrm{~min}$

\begin{tabular}{llccc}
\hline \multicolumn{1}{c}{ Age } & Water-borne unit & $n$ & Spearman's $r h o$ & $P$ \\
\hline Larvae & $\mathrm{pg} / \mathrm{SVL} / \mathrm{h}$ & 16 & -0.26 & 0.32 \\
& $\mathrm{pg} / \mathrm{g} / \mathrm{h}$ & 16 & -0.33 & 0.21 \\
Metamorphs & $\mathrm{pg} / \mathrm{SVL} / \mathrm{h}$ & 13 & -0.24 & 0.42 \\
& $\mathrm{pg} / \mathrm{g} / \mathrm{h}$ & 13 & 0.12 & 0.69 \\
Adults & $\mathrm{pg} / \mathrm{SVL} / \mathrm{h}$ & 28 & -0.03 & 0.88 \\
& $\mathrm{pg} / \mathrm{g} / \mathrm{h}$ & 27 & -0.08 & 0.70 \\
Adults & $\mathrm{pg} / \mathrm{SVL} / \mathrm{h}$ & 26 & 0.15 & 0.46 \\
(no females) & $\mathrm{pg} / \mathrm{g} / \mathrm{h}$ & 26 & -0.007 & 0.97 \\
Adults & $\mathrm{pg} / \mathrm{SVL} / \mathrm{h}$ & 22 & -0.11 & 0.64 \\
(<3 min blood collection) & $\mathrm{pg} / \mathrm{g} / \mathrm{h}$ & 21 & -0.19 & 0.40 \\
\hline
\end{tabular}



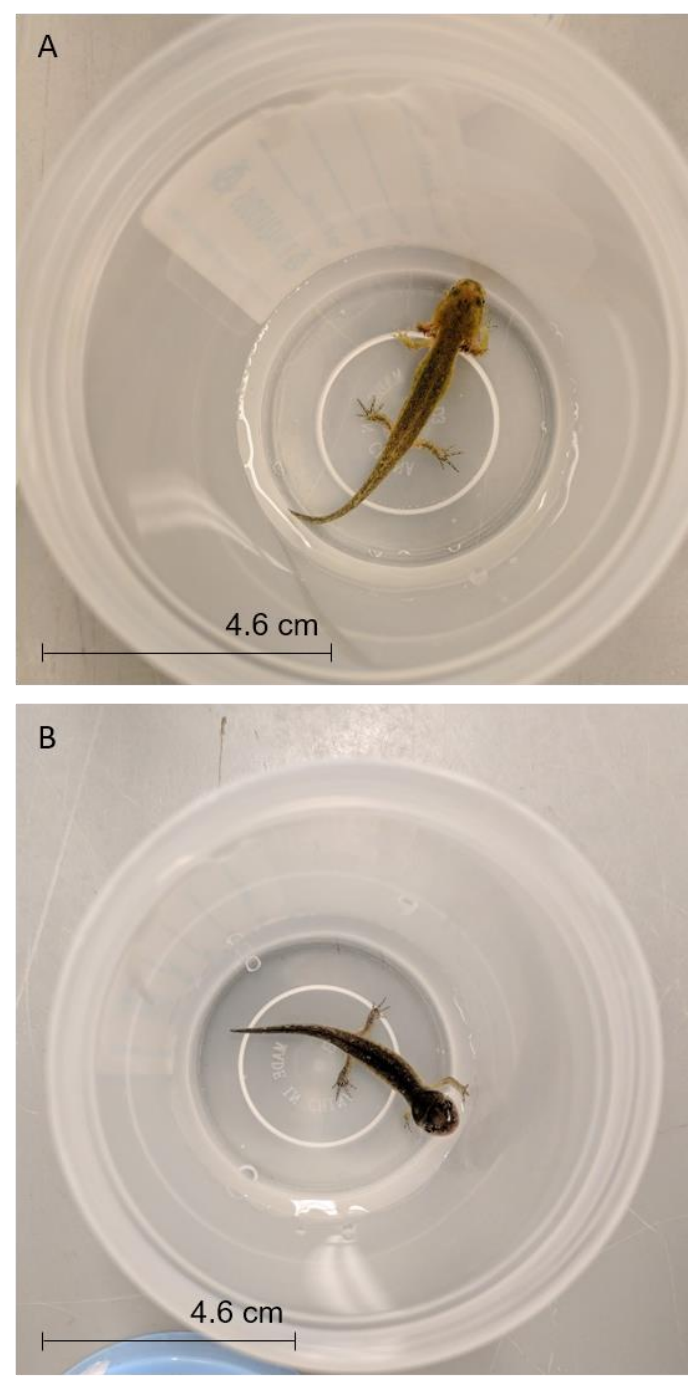

C

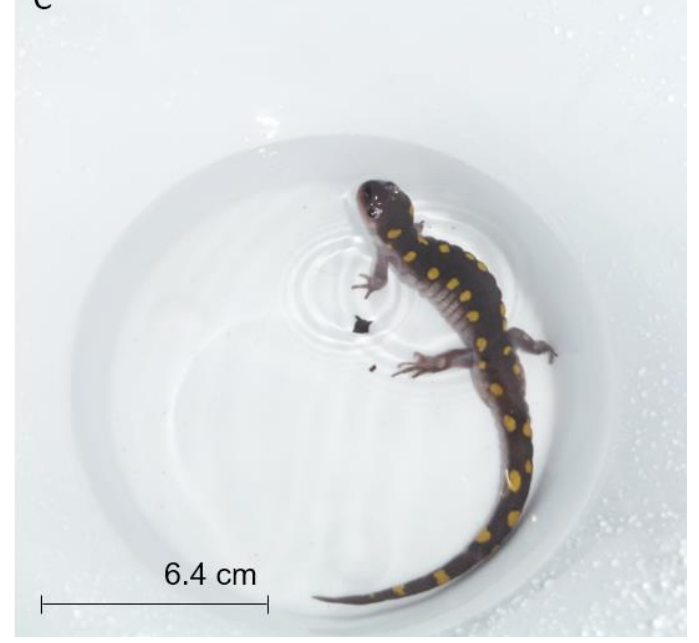

Figure 1. Photographs of a spotted salamander larva (A), metamorph (B), and adult (C) in individual containers of water for water-borne hormone sampling 

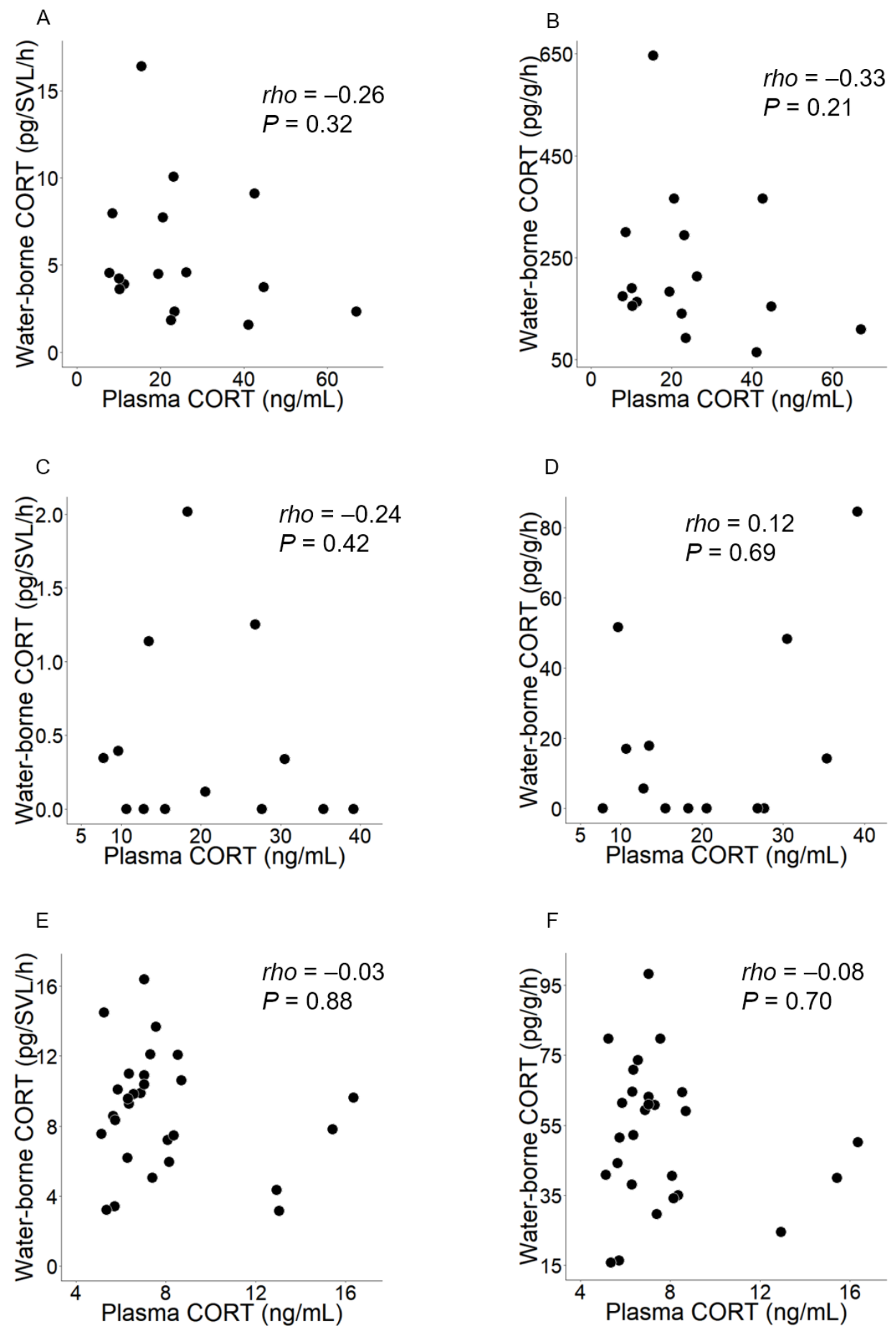

Figure 2. Biplots of spotted salamander plasma corticosterone (CORT) and water-borne CORT lacking correlations. Left side: corticosterone is presented in units of pg/SVL/h. Right side: corticosterone is presented in units of $\mathrm{pg} / \mathrm{g} / \mathrm{h}$. From top to bottom: larvae $(\mathrm{A}, \mathrm{B})$, metamorphs $(\mathrm{C}$, D), and adults (E, F). Spearman's rho and $P$ values are presented on each graph 
A

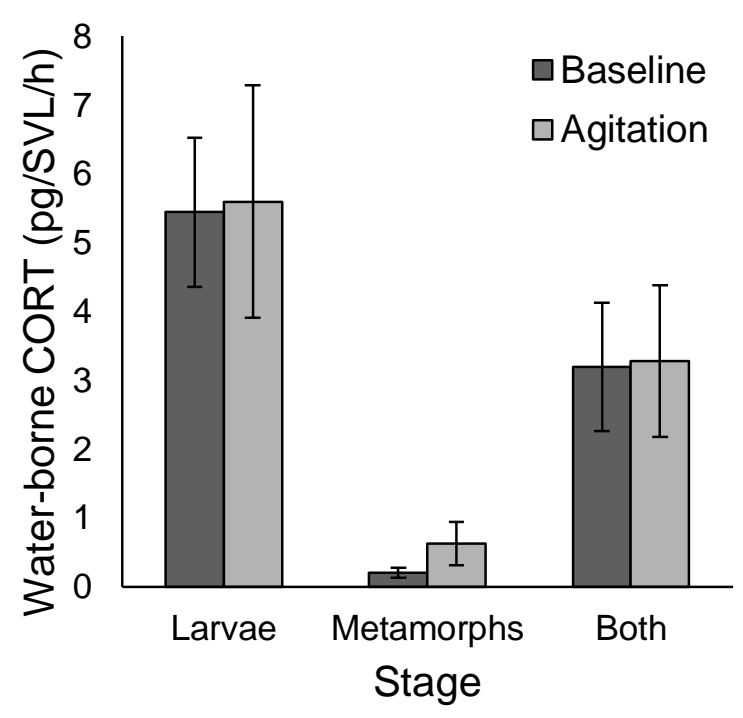

C

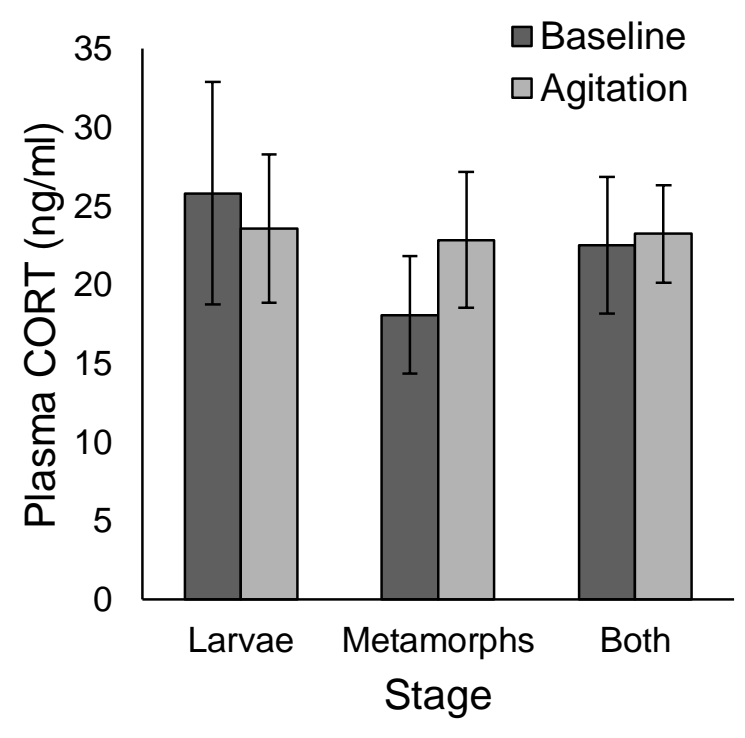

B

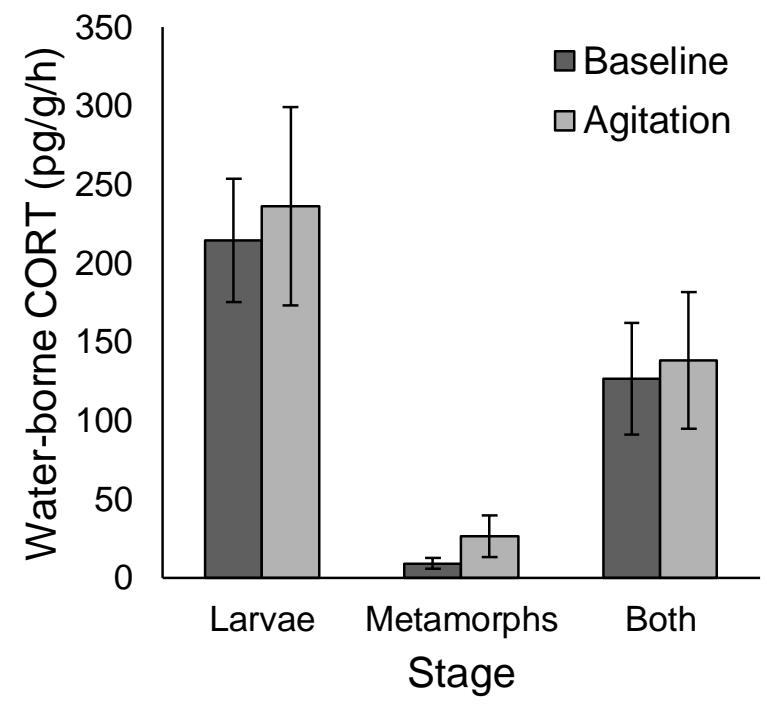

Figure 3. Graphs displaying untransformed corticosterone (CORT) \pm SE for spotted salamander baseline and agitation groups measured in different subsets of larvae $(n=8,8)$, metamorphs $(n=6,7)$, and both stages $(n=14,15)$ combined for water-borne CORT (A, B) and plasma levels (C) 

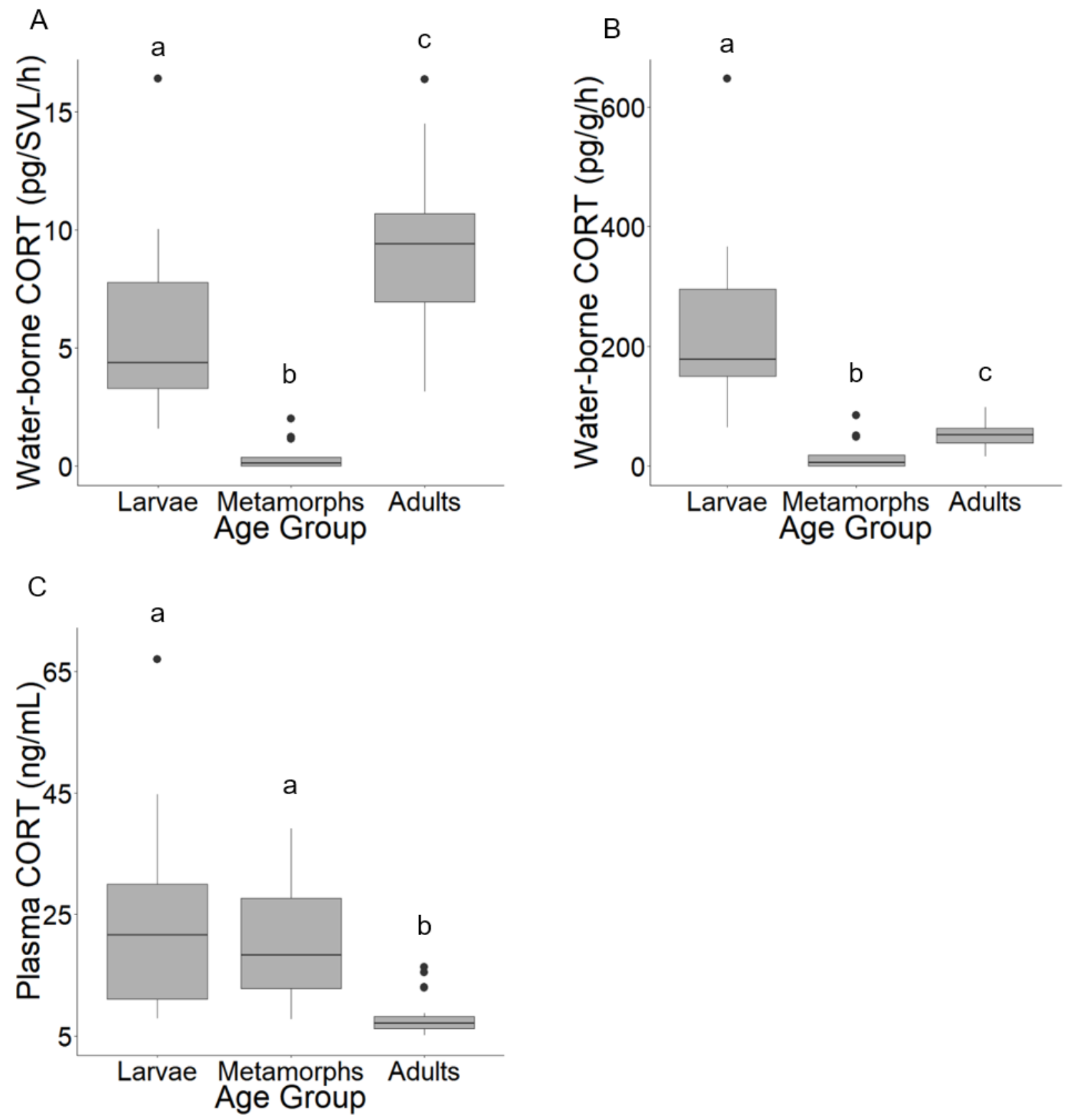

Figure 4. Boxplots displaying the median, interquartile range, lowest and highest observations, and outliers for spotted salamander corticosterone (CORT) levels across age groups (larvae: $n=$ 16, metamorphs: $n=13$, adults: $n=28$ [27 for water-borne pg/g/h]) for water-borne CORT (A, B) and plasma CORT levels (C). Letters indicate differences in CORT levels between age groups $(P<0.01 ;$ Kruskal-Wallis chi-square; Dunn test $)$ 


\title{
Chapter 4
}

\section{Pool Age and Local Habitat are Associated with Effective Number of Breeders in Spotted Salamander Populations Colonizing Created Vernal Pools}

\author{
Alice R. Millikin ${ }^{1}$, Stephanie S. Coster ${ }^{2}$, Amy B. Welsh $^{1}$, James T. Anderson ${ }^{1}$ \\ ${ }^{1}$ School of Natural Resources, West Virginia University, PO Box 6125, Morgantown, WV \\ 26506, USA; e-mail: amy.welsh@ mail.wvu.edu, jim.anderson@mail.wvu.edu \\ ${ }^{2}$ Department of Biology, Randolph-Macon College, 114 College Avenue, Ashland VA 23005, \\ USA; e-mail: stephaniecoster@rmc.edu
}

Corresponding author e-mail: alicemillikin@gmail.com

Running head: Spotted salamander genetics in created pools

Author contributions: ARM, SSC, and JTA designed the study. ARM and JTA secured funding. ARM collected field data and lab analysis with input from SSC. ARM conducted data analysis with input from SSC and ABW. ARM wrote the manuscript with significant contributions from all authors. 


\begin{abstract}
Habitat creation is an important tool for conservation to counteract habitat loss and degradation. Vernal pools, which provide breeding habitat for amphibians like spotted salamanders (Ambystoma maculatum), are susceptible to destruction due to limited detection, protection, and regulation. To inform future pool creation strategies, we investigated how spotted salamanders colonized newly created pools using a population genetics analysis. Our first objective was to examine genetic structure, differentiation, diversity, and potential for founder's effect. Our second objective was to determine if habitat characteristics were associated with effective number of breeders, relatedness, or genetic diversity. We examined impacts of vegetative cover and refuge within the pool, pool diameter, canopy cover, and predator presence. We sampled spotted salamander larvae in 31 created vernal pools (1-5 years old) in Monongahela National Forest in May and June of 2015 and 2016. The youngest pools exhibited genetic differentiation, founder's effect, and low effective number of breeders. Effective number of breeders was positively associated with pool age, vegetation cover, pool diameter, and sample size. Vegetation cover was also negatively association with relatedness. Genetic diversity did not have strong environmental predictors. Our results indicated effective number of breeders can increase and genetic differentiation can decrease within 4-5 years of pool creation, a sign of rapid colonization and potential population establishment. Our research also showed that higher vegetative cover within the pool and larger pool diameters (up to $\max =11.94 \mathrm{~m}$ ) could impact habitat quality and should be incorporated in future pool creation.
\end{abstract}

Key words: Ambystoma maculatum, amphibian, restoration, wetland, environment, population genetics 


\section{Implications for Practice}

- Larger pool diameters and increased vegetative cover within pools should be incorporated into the design of vernal pool habitat for spotted salamanders.

- Created vernal pool habitat can have established breeding populations of spotted salamanders after $4-5$ years, showing improvement over time.

- Genetic analysis can be used to help assess the success of colonization of created habitat and inform future site selection and design.

\section{INTRODUCTION}

Habitat loss is one of the greatest threats to wildlife. This has made restoration and habitat creation valuable conservation approaches to mitigate the negative effects. Vernal pools are palustrine wetlands with intermittent inundation that provide important breeding habitat to several amphibian species. These pools are vulnerable to destruction despite wetland mitigation efforts to prevent net loss of habitat. In the US, federal regulations of wetlands under the Clean Water Act currently only apply to larger wetlands with more persistent surface water connections to rivers. Lack of permanent connections to other water bodies and, in some cases, small size make it difficult to detect and protect vernal pools (DiBello et al. 2016). Some land managers have begun creating vernal pools to increase available habitat.

As with any habitat restoration or creation, an essential next step is to measure success. For vernal pools, success is often determined by measuring the reproductive effort (i.e. egg mass counts) and number of individuals that complete metamorphosis among vernal pool breeding amphibians (Calhoun et al. 2014). Population genetics also can be used to measure colonization success because it provides information about population structure and genetic diversity. Some 
created vernal pools do not successfully attract breeders or provide suitable habitat for completion of metamorphosis, because it is difficult to replicate conditions of natural pools such as the ephemeral hydroperiod, pool size, depth, canopy closure, and vegetative composition when constructing pools (Calhoun et al. 2014). Estimating number of breeders and genetic diversity at colonized pools can help inform future strategies for vernal pool creation.

Genetics provide a valuable indicator of population resilience by determining a population's risk of extinction and its ability to adapt to a stochastic environment (Spielman et al. 2004; Frankham 2005). Genetic connectivity, or dispersal among pools, sustains populations by allowing recolonization of areas that experience regular extinction events due to annual variations in habitat quality (Beebee 2005). Founder events that result in genetic bottlenecks, due to the small number of individuals establishing a new breeding population, are important to detect because the lack of genetic diversity can decrease chances of surviving stochastic events and may require additional restoration efforts to counteract long-term impacts to the population (Spielman et al. 2004; Frankham 2005). The effective number of breeders $\left(\mathrm{N}_{\mathrm{b}}\right)$ is correlated with effective population size $\left(\mathrm{N}_{\mathrm{e}}\right)$, and negatively related to the rate of increase in inbreeding in a single cohort of the population (Wang 2009; Waples et al. 2013). Therefore, $\mathrm{N}_{\mathrm{b}}$ has implications for whether the population can be sustained long-term (Reed \& Frankham 2003; Beebee 2005; Waples et al. 2013). Reduced $\mathrm{N}_{\mathrm{e}}$ can increase inbreeding and decrease genetic diversity (Reed \& Frankham 2003; Spielman et al. 2004). High levels of genetic diversity, measured by allelic richness and heterozygosity, can indicate a successful breeding population (Reed \& Frankham 2003; Spielman et al. 2004). Heterozygosity is positively correlated with population fitness, where higher heterozygosity indicates lower inbreeding, higher reproductive fitness, and reduced 
extinction risk (Reed \& Frankham 2003; Spielman et al. 2004). This is evident in threatened taxa having lower heterozygosity than closely related nonthreatened taxa (Spielman et al. 2004).

Genetic diversity and genetic structure of amphibians can be affected by the quality of their habitat. In dwarf salamanders (Eurycea quadridigitata), allelic richness and heterozygosity were higher in areas with more wetlands in the surrounding $2.5 \mathrm{~km}$ (McKee et al. 2017). In marbled newts (Triturus marmoratus), greater genetic structure and higher genetic differentiation $\left(\mathrm{F}_{\mathrm{ST}}\right)$ were observed in areas with more abundant row cropland (Costanzi et al. 2018). Tiger salamanders (Ambystoma tigrinum) had greater genetic differentiation in newly colonized wetlands, indicating a founder's effect (Cosentino et al. 2012). Additionally, larger wetlands, up to $3.8 \mathrm{ha}$, had tiger salamander larvae with higher allelic richness and lower FST values, showing larger pools supported higher genetic diversity and migration (Cosentino et al. 2012).

Habitat characteristics incorporated during vernal pool construction may impact amphibian reproductive success. Spotted salamanders (Ambystoma maculatum) require fishless, vernal pools for breeding habitat because these pools provide refuge for the larvae through metamorphosis. Predators that are normally excluded in natural pools can occur in created pools lacking ephemeral hydroperiods and can be detrimental to vernal pool amphibians (Vasconcelos \& Calhoun 2006; Denton \& Richter 2013). Pools with more vegetation or more refuge available within the pool, including rocks and woody debris, provide more suitable habitat for egg mass deposition and larval refuge from predators. Spotted salamanders oviposit more egg masses in pools with more complex vegetative structure (Egan \& Paton 2004). Size of pools is an important factor for attracting breeding salamanders as evident by higher egg mass density in larger pools (Petranka et al. 2003a; Egan \& Paton 2004; Skidds et al. 2007). Spotted salamander 
reproductive effort is also higher in pools surrounded by uncut forests, indicating canopy cover could impact habitat quality (Skidds et al. 2007; Felix et al. 2010; Scheffers et al. 2013).

Our first objective was to investigate the genetic diversity, connectivity and structure of spotted salamander populations in 31 created vernal pools in West Virginia. We explored whether there were signs of a bottleneck or founder's effect in recently created pools. We expected to detect a bottleneck or founder's effect in all regions due to how recently pools were created (1-5 years prior to sampling). Finally, we measured $\mathrm{N}_{\mathrm{b}}$ and current genetic diversity, based on expected heterozygosity $\left(\mathrm{H}_{\mathrm{E}}\right)$, allelic richness $\left(\mathrm{A}_{\mathrm{R}}\right)$, and relatedness within pools. We expected that $\mathrm{N}_{\mathrm{b}}, \mathrm{H}_{\mathrm{E}}$, and $\mathrm{A}_{\mathrm{R}}$ would increase and relatedness would decrease over time as breeding populations became more established. We also examined the impact of pool age, or time since construction, because it could determine how quickly the population stabilized or if it was at risk of extinction (Petranka et al. 2003b; Vasconcelos \& Calhoun 2006). Our second objective was to determine if habitat characteristics at the pool level were associated with genetic diversity. We expected greater vegetative cover and refuge within the pool (pool cover) would result in higher $\mathrm{N}_{\mathrm{b}}, \mathrm{H}_{\mathrm{E}}$, and $\mathrm{A}_{\mathrm{R}}$, and lower relatedness. We expected similar relationships between genetic diversity, $\mathrm{N}_{\mathrm{b}}$, relatedness and larger pools, greater canopy cover, and lower predator presence.

\section{METHODS}

\section{Study Area}

We sampled created vernal pools in Huttonsville, WV, USA from May-June in 2015 and 2016 (Fig. 1). Sampled vernal pools were located on Cheat Mountain in Monongahela National Forest at altitudes of 1,219-1,296 m above sea level. All sampled vernal pools were created by the U.S. Forest Service (USFS) and situated such that pools created in the same year are 
geographically proximate (hereafter considered three regions): Barton Bench pools were created in 2011, Lambert North pools in 2013, and Lambert South pools in 2014 (Figs. S1, S2, \& S3). Vernal pools were within $5 \mathrm{~km}$ of each other and created based on field conditions without predetermined designs or specifications as part of larger restoration projects. These areas were acquired by the USFS in the 1980s after they were strip-mined for coal in the 1970s. Restoration was initiated in 2009 and included removal of non-native Norway spruce (Picea abies) and red pine (Pinus resinosa) planted during mine reclamation, ripping to mitigate soil compaction, and planting saplings including aspens (Populus spp.), red spruce (Picea rubens), black cherry (Prunus serotina), wild raisin (Viburnum nudum), elderberry (Sambucus nigra), and service berry (Amelanchier arborea). Most vernal pools included in this study had open canopy due to recent removal of non-native trees. Mean monthly temperatures in Huttonsville, WV range from $-1-19^{\circ} \mathrm{C}$ with average annual precipitation of $172.5 \mathrm{~cm}$ (Canty 2018).

\section{Field Sampling}

Using dipnets and seines, we sampled spotted salamander larvae in 34 created vernal pools: 22 sampled both years, 8 sampled in 2015, and 4 sampled in 2016. By region, this included 11 pools in Barton Bench, 14 pools in Lambert North, and 6 pools in Lambert South. We caught $14-30($ mean $=20.73, \mathrm{SE}=0.31)$ larvae per pool per sampling year. Upon capture, we collected tail clips $(<1 \mathrm{~cm})$, which were stored fully immersed in $100 \%$ ethanol in $1.5 \mathrm{~mL}$ microcentrifuge tubes until later DNA extraction. Salamanders were released after all larvae from the pool were processed.

To investigate how environmental variables influenced spotted salamander population genetics, we collected data on conditions at each pool. We measured the diameter of each pool using the average of perpendicular transects (Millikin et al. 2019). We used the line intercept 
method to measure cover within the pool along the same two transects used for diameter (Barbour et al. 1999; Egan \& Paton 2004). Cover within the pool (pool cover) was considered any form of refuge within the pool including rocks, coarse woody debris, and vegetation. In addition to looking at all pool cover, we examined a subset of the pool cover: grass, sedge, cattail, and rush (GSCR) within the pool. Proportional cover for pool cover and GSCR were calculated as the total length of cover types divided by the length of transects at the pool (Egan \& Paton 2004). Canopy cover was measured using a spherical densiometer every $1.5 \mathrm{~m}$ along transects (Millikin et al. 2019). Predator presence was quantified by presence/absence rating $(0 / 1)$ when the following were caught in nets or observed in pools: eastern newts (Notophthalmus viridescens), diving beetle (Dytiscidae) larvae, and dragonfly (Odonata) larvae. Pools could have a rating of 0 , meaning none were present, to 3 , where all three were observed in the pool (Millikin et al. 2019). Pool age was calculated by sampling year minus creation year. Geographic location and age of the pool are not independent because pools created each year were all created in the same area.

\section{Genetic Analysis}

We extracted DNA from tail clips of spotted salamander larvae using Promega Wizard ${ }^{\circledR}$ SV 96 Genomic DNA Purification System kits. We used eight microsatellite markers (D184, D287, C151, D315, D226, D49, D328, D203) (Julian et al. 2003) and three universal primers (Table S1; Appendix 1; Blacket et al. 2012). For pools sampled both years, we tested annual variation of allele frequencies using exact $\mathrm{G}$ test in GENEPOP with sequential Bonferroni correction $(\alpha=0.05)$. If there was no difference between years, data from both years were combined to increase sample size for that pool $(\mathrm{N}=17$ pools; Table $\mathrm{S} 2)$. If pools were different 
from one year to the next, only the year with a higher sample size was retained $(\mathrm{N}=5$ pools $)$. We removed 3 pools with fewer than 10 individuals remaining (Table S2).

Initial analysis tested for excess homozygotes, scoring error, allele dropout, and null alleles in MICRO-CHECKER (Van Oosterhout et al. 2004). To avoid bias associated with relatedness in free-moving larvae in pools, we removed full siblings in COLONY (Wang 2004; Goldberg \& Waits 2010). In COLONY, we set male and female mating to polygamous without inbreeding. We conducted a medium run with full-likelihood and did not include a sibship prior. We ran the analysis in duplicate. When full siblings were detected in both runs, only one of the siblings was kept for subsequent analysis. We tested for Hardy-Weinberg equilibrium and linkage disequilibrium using GENEPOP with 10,000 iterations followed by sequential Bonferroni correction $(\alpha=0.05)$ (Raymond \& Rousset 1995).

Population Structure

We tested number of genetically distinct populations in the study area using STRUCTURE 2.3.4 (Pritchard et al. 2000). We created three a priori sampling units (region) by grouping pools that were geographically proximate and created at the same time (Barton Bench, Lambert North, Lambert South). We ran STRUCTURE with 150,000 burn-ins and 150,000 reps with the locprior model with admixture. We conducted ten runs for each value of $K=1-10$. We used STRUCTURE HARVESTER (Earl \& vonHoldt 2012) to determine optimal K based on peak average $\operatorname{Ln} \operatorname{Pr}(\mathrm{X} \mid \mathrm{K})$ (Pritchard et al. 2000). After an initial run to explore the highest level of structure, we used the model with the highest probability and ran a subsequent hierarchical analysis in each group to examine substructure. In the subsequent analyses we used the same parameters, except we set burn-in period and reps to 100,000 and set $\mathrm{K}$ to the number of pools in each region. 
To confirm groupings indicated by STRUCTURE, we ran an Analysis of Molecular Variance (AMOVA) in Arlequin ver. 3.0 (Excoffier et al. 2005) with 10,000 permutations $(\alpha=$ 0.05). Pairwise differences between pools were calculated using genetic differentiation ( $\left.\mathrm{F}_{\mathrm{ST}}\right)$ between individual pools using FSTAT with 10,000 iterations and regular Bonferroni correction ( $\alpha=0.05$; Goudet 1995). We tested for recent bottleneck using BOTTLENECK software with a two-phase mutation model, variance of 12, 95\% single-step mutations, and 1000 iterations, for the sign test, Wilcoxon sign rank test, and mode-shift test ( $\alpha=0.05$; Piry et al. 1999).

\section{Effective Number of Breeders \& Genetic Diversity}

To determine how pool creation year, sample size, and local environmental traits impacted genetic diversity, we examined the following at pool level: $\mathrm{N}_{\mathrm{b}}, \mathrm{H}_{\mathrm{E}}, \mathrm{A}_{\mathrm{R}}$, and relatedness. We used FSTAT with 10,000 iterations to calculate $\mathrm{H}_{\mathrm{E}}$ and $\mathrm{A}_{\mathrm{R}}$ (based on the minimum sample size of 10 individuals; Goudet 1995). We measured $\mathrm{N}_{\mathrm{b}}$ using COLONY (Wang 2009; Wang et al. 2011). We calculated relatedness within pools by mean within-population pairwise values using the Queller and Goodnight (1989) estimator in GenAlEx (Peakall \& Smouse 2006, 2012). We tested for differences between regions using Kruskal-Wallis rank sum test followed by Dunn's test ( $\alpha=0.05$; package 'dunn.test', Dinno 2017) due to non-normally distributed data.

\section{Environmental Factors}

Environmental analysis was conducted in R (R Core Team 2017). To explore how environmental factors influenced genetic characteristics, we compared linear regression models $(\alpha=0.05)$ and determined the best environmental predictors for $\mathrm{N}_{\mathrm{b}}$, within-pool relatedness, $\mathrm{H}_{\mathrm{E}}$, and $A_{R}$ using Akaike information criterion (AICc) (package 'AICcmodavg', Mazerolle 2017; Burnham and Anderson 2002). We examined deviance explained by each model (package 'BiodiversityR', Kindt \& Coe 2005). Environmental predictors included in the analysis were: age 
of pool, diameter of pool, pool cover, GSCR, canopy cover, and predator presence. Because pool age is linked to region, we used age in the regression models, which incorporates additional variation because age changed from sample year one to sample year two; except for relatedness because region was a stronger predictor. By including sample size, we could investigate if environmental conditions were stronger predictors than sample size alone, therefore more accurately determining habitat influence. For regression models with environmental predictors, we excluded two pools that were outliers to prevent skewing the data based on a single data point: Barton Bench pool 1 (only from $\mathrm{N}_{\mathrm{b}}$ regressions) and Lambert South pool 30 (Grubbs test $p$ $<0.001$; package 'outliers', Komsta 2011).

\section{RESULTS}

The final dataset for the genetic analysis included 785 spotted salamander samples from 31 pools: 14 based on one year of sampling and 17 based on two years of sampling (Table S2). Results from MICROCHECKER led us to drop three loci (D315, D203, D328) due to null alleles in $43-68 \%$ of pools sampled. This left 5 remaining microsatellite loci (Table S1). All pools were in Hardy-Weinberg Equilibrium and linkage equilibrium after sequential Bonferroni correction $(\mathrm{p}>0.05)$

\section{Population Structure}

At the highest level, the Bayesian clustering algorithm of STRUCTURE found the model with the highest probability was $\mathrm{K}=1$, grouping all the pools from all regions into a single population (Fig. S4). However, when examined further, the barplot reflected a cline across the three regions that we had grouped a priori by proximity and by year of creation (Fig. 2a). The cline depicted Barton Bench and Lambert South as genetically distinct ends with individuals in Lambert North displaying high admixture derived from the other populations. After the 
hierarchical STRUCTURE analysis by region, the highest probability models suggested $\mathrm{K}=1$ for Barton Bench, $K=3$ for Lambert North, and $K=2$ for Lambert South (Figs. 2b, 2c, 2d, \& S5).

The AMOVA confirmed significant genetic differentiation between the three a priori grouped regions $(p=0.0006)$, among the pools within the regions $(p<0.0001)$, and within pools $(p<0.0001)$. Pairwise $\mathrm{F}_{\mathrm{ST}}$ across pools ranged from $0-0.17($ mean $=0.03, \mathrm{SE}=0.001)($ Table S3, Fig. S6). There were 152 population pairs (33\%) that were significantly differentiated after Bonferroni correction, 65 pairs had moderate differentiation $\left(\mathrm{F}_{\mathrm{ST}}=0.05-0.10\right)$, and 22 pairs were highly differentiated $\left(\mathrm{F}_{\mathrm{ST}}>0.10\right)$ (Table S3, Fig. S6). Moderate and high differentiation were observed at pools in Lambert North and Lambert South. There was a distinct increase in differentiation from Barton Bench to Lambert North to Lambert South. Pairwise differentiation was highest in the most recently created region, Lambert South (Fig. S6). There was some differentiation in Lambert North and little to none in Barton Bench. We analyzed the three regions separately in BOTTLENECK and none of them exhibited recent bottlenecks ( $p>0.05)$.

\section{Effective Number of Breeders \& Genetic Diversity}

Effective number of breeders was higher in the older pools at Barton Bench and Lambert North than the newest pools at Lambert South ( $\mathrm{p} \leq 0.02$; Fig. 3). Effective number of breeders ranged from 4-18 at Lambert South, 7-26 at Lambert North, and 13-90 at Barton Bench averaging $12.00,18.86$, and 28.45 respectively (Table S4). Relatedness, $\mathrm{H}_{E}$, and $\mathrm{A}_{\mathrm{R}}$ were not different among regions $(\mathrm{p}>0.05)$ (Tables S4 \& S5, Fig. 3). Relatedness ranged from 0-0.49 across all regions, averaging 0.04 in Barton Bench, 0.05 in Lambert North, and 0.15 in Lambert South. Expected heterozygosity ranged from $0.64-0.83$ across all regions, averaging 0.79 at Barton Bench, 0.80 at Lambert North, and 0.77 at Lambert South. Allelic richness ranged from 
3.00-7.39 across all regions, averaging 6.51 in Barton Bench, 6.63 in Lambert North, and 5.89 in Lambert South (Tables S4 \& S5, Fig. 3).

\section{Environmental Factors}

We controlled sample size by including it as a predictor in regression models to account for its positive correlation with $\mathrm{N}_{\mathrm{b}}, \mathrm{H}_{\mathrm{E}}$, and $\mathrm{A}_{\mathrm{R}}$, and negative correlation with relatedness. Effective number of breeders was significantly correlated with multiple environmental predictors. The best model predicting $\mathrm{N}_{\mathrm{b}}$ included age of pool + GSCR + diameter of pool + sample size within pool $\left(\operatorname{adj} r^{2}=0.68, \mathrm{~F}_{[4,24]}=15.97, p<0.0001\right)($ Tables $1,2, \& 3)$. This model explained $73 \%$ of the variance in the data and was given $70 \%$ of the weight of all models in AIC, but not all coefficients were different from zero (Tables 1, 2, \& 3). All predictors of the top model had positive relationships with $\mathrm{N}_{\mathrm{b}}$ (Fig. 4). Two models had $\Delta$ AIC less than seven indicating they could be competing models. The model pool diameter + canopy cover + sample size was weighted $21 \%$ and explained $67 \%$ of the deviance (Tables $1 \& 3$ ). These predictors all had positive relationships with $\mathrm{N}_{\mathrm{b}}$ and estimates significantly different from zero (Table 1, Fig. S7). The full model, which included predictors from the top two models and predator presence, had $\triangle \mathrm{AIC}=4.57$ indicating it could also be significant, but it was only weighted $7 \%$ (Tables $1 \&$ 3, Fig. S7).

Relatedness had multiple competing models with $\triangle$ AIC less than two. These included models with the predictors pool cover, sample size, GSCR, region, and pool diameter (Table 4). In every model, predictors had negative relationships with relatedness (Tables $4 \& 5$, Fig. 5). The top model was pool cover + sample size, which was weighted $27 \%$ and explained $32 \%$ of the deviance $\left(\operatorname{adj} r^{2}=0.27, \mathrm{~F}_{[2,27]}=6.26, p=0.006\right.$; Table 5, Fig. 5). The second strongest model was GSCR + sample size with $\triangle \mathrm{AIC}$ less than one. 
The only significant regression model for $\mathrm{H}_{\mathrm{E}}$ was pool cover + sample size $(\mathrm{y}=0.77+$ 0.05 pool cover +0.0005 sample size within pool; adj $\left.r^{2}=0.16, \mathrm{~F}_{[2,27]}=3.68, p=0.04\right)$. Both predictors had positive relationships with $\mathrm{H}_{\mathrm{E}}$ (Fig. S8). The coefficients were not significantly different from zero $(\mathrm{p}>0.05)$ and individually these predictors were not significant. Allelic richness had no significant environmental predictors $(\mathrm{p}>0.05)$.

\section{DISCUSSION}

We investigated the genetic diversity of spotted salamander larvae in 31 created vernal pools in the Central Appalachians. As expected, older pools had lower genetic differentiation and higher $\mathrm{N}_{\mathrm{b}}$. Larger pools with greater vegetative cover had higher $\mathrm{N}_{\mathrm{b}}$. Greater vegetation cover also had a negative association with relatedness. Finally, there was weak evidence for a positive relationship between pool cover and $\mathrm{H}_{\mathrm{E}}$.

\section{Population Structure}

Although the study area spanned $5 \mathrm{~km}$, it was a panmictic single population with a cline in population structure from Barton Bench to Lambert North to Lambert South. This suggests that there is migration from Barton Bench and Lambert South into Lambert North, which was between the other regions both geographically and in age. Barton Bench and Lambert South had the oldest and youngest created pools, respectively, and were furthest apart geographically. Individual spotted salamanders have been documented traveling maximum distances of $467 \mathrm{~m}$; however, this species exhibits genetic connectivity among pools within distances up to $17 \mathrm{~km}$ (Montieth \& Paton 2006; Coster et al. 2015). It is possible that migrants from the other two regions into Lambert North helped increase population size, resulting in the highest genetic diversity, and similar levels of $\mathrm{N}_{\mathrm{b}}$ and relatedness to Barton Bench, despite Lambert North being two years younger. 
Genetic differentiation between regions was low indicating movement and migration among regions and no major obstructions to gene flow. Several pairwise comparisons were significant and some were highly differentiated at pools in Lambert North and Lambert South. Genetic differentiation between some pools might indicate that it takes longer than 1-3 years for colonizers to establish and disperse among pools. These results are consistent with research conducted in Maine, where spotted salamander breeding effort and reproductive success was variable for six years after pool creation (Vasconcelos \& Calhoun 2006). In tiger salamanders, newly colonized wetlands had greater genetic differentiation than established populations (Cosentino et al. 2012). Additionally, female spotted salamanders do not reach sexual maturity for 3-5 years, meaning it would take at least as long to measure reproductive success of offspring produced in the created pools (Wilbur 1977; Flageole \& Leclair 1992). The pools in our study were colonized as early as the first breeding season after pool creation, reflecting spotted salamanders' rapid colonizing ability. This was also seen in created pools in North Carolina, where salamanders colonized 9 out of 10 pools the first year of creation, the same rate as natural pools sampled (Petranka et al. 2003a). However, determining long-term success requires monitoring longer than three years, even when breeding is evident the first year of creation.

We expected to detect a bottleneck as the result of a founder's effect in all regions, where the low number of colonizing individuals bring limited genetic diversity to the newly created pools but did not detect any bottlenecks. A possible founder's effect in the younger pools at Lambert South was evident from the higher genetic differentiation of these pools compared to the older pools (Cosentino et al. 2012). Additionally, salamanders in pools at Lambert South had the lowest $\mathrm{N}_{\mathrm{b}}, \mathrm{H}_{\mathrm{E}}$, and $\mathrm{A}_{\mathrm{R}}$, and highest relatedness. However, the latter three were not 
significantly different from other regions. Only $\mathrm{N}_{\mathrm{b}}$ was significantly different among regions, and only at Lambert South. In such newly created pools, a smaller breeding population, lower genetic diversity, and higher relatedness may indicate that these breeding pools were exhibiting signs of a founder's effect despite lack of significance in bottleneck tests. The ability to detect a bottleneck could have been limited due to low number of loci, immigration among regions, and size of the source population (Cornuet \& Luikart 1996; Williamson-Natesan 2005; Peery et al. 2012).

\section{Effective Number of Breeders \& Genetic Diversity}

Effective number of breeders was highest in the oldest pools (4-5 years old) and lowest in the newest pools (1-2 years old). Only Barton Bench had $\mathrm{N}_{\mathrm{b}}$ values comparable to those of an established spotted salamander population in Maine across 19 pools (Whiteley et al. 2014). Even the maximum $\mathrm{N}_{\mathrm{b}}$ for the regions with younger pools was lower than the range of the population in Maine (Whiteley et al. 2014). This indicates $\mathrm{N}_{\mathrm{b}}$ increased within a couple of years in these created vernal pools and shows potential for populations inhabiting created pools to establish breeding populations of a similar size to those of natural pools. Additionally, in three created pools in Maine, the abundance of breeding spotted salamanders increased 3-6 years after construction (Vasconcelos \& Calhoun 2006). Spotted salamanders sampled across 26 natural pools in Connecticut and Massachusetts had an average $\mathrm{N}_{\mathrm{e}}$ of 570 (Richardson 2012). Based on the $\mathrm{N}_{\mathrm{b}} / \mathrm{N}_{\mathrm{e}}$ ratios of Allegheny Mountain dusky salamanders (Desmognathus ochrophaeus) (0.734, Waples et al. 2013), we can estimate that our maximum $\mathrm{N}_{\mathrm{b}}=90$ at Barton Bench would be roughly equivalent to $\mathrm{N}_{\mathrm{e}}=123$, lower than the established population in Connecticut and Massachusetts (Richardson 2012). In all regions, genetic diversity ( $\mathrm{H}_{\mathrm{E}}$ and $\left.\mathrm{A}_{\mathrm{R}}\right)$ was similar to breeding populations in Maine, Connecticut, and Massachusetts, except the low $A_{R}$ of pool 30 in 
Lambert South (Richardson 2012; Whiteley et al. 2014). Genetic diversity did not differ by pool age. Relatedness, $H_{E}$, and $A_{R}$ were similar across regions despite expectations that $H_{E}$ and $A_{R}$ would increase and relatedness would decrease over time as breeding populations got established. It is possible longer time periods are necessary to detect changes in genetic diversity in colonizing populations. However, in tiger salamanders, population age, based on three years of data, was not an important predictor for $A_{R}$ (Cosentino et al. 2012). Because genetic diversity at our pools was similar to established natural populations (Richardson 2012; Whiteley et al. 2014), it is possible that the quick colonization of our pools resulted in natural diversity levels.

\section{Environmental Factors}

Habitat quality can impact population genetics of amphibians (McKee et al. 2017; Costanzi et al. 2018). We found multiple habitat characteristics influenced $\mathrm{N}_{\mathrm{b}}$, including positive associations with pool age, pool diameter, and GSCR. In addition to differences in $\mathrm{N}_{\mathrm{b}}$ among regions, age also was a top predictor for $\mathrm{N}_{\mathrm{b}}$ indicating that time since creation had an impact on $N_{b}$. The changes in $N_{b}$ with pool age highlight the importance of monitoring populations over time. Larger pools (up to $11.94 \mathrm{~m}$ diameter) had higher $\mathrm{N}_{\mathrm{b}}$, indicating that larger pools may attract more breeders. Others have found that larger pools had higher spotted salamander occupancy, more egg masses, and higher larval survival rates (Petranka et al. 2003a; Egan \& Paton 2004; Groff et al. 2017; Rothenberger et al. 2019). Similarly, California tiger salamanders (Ambystoma californiense) had higher $\mathrm{N}_{\mathrm{e}}$ in larger vernal pools, which is correlated with $\mathrm{N}_{\mathrm{b}}$ (Wang et al. 2011). Tiger salamander wetland colonization was positively related to wetland area (Cosentino et al. 2011). Larger wetlands also had higher immigration rates for marbled salamanders (Ambystoma opacum) (Greenwald et al. 2009). Larger wetlands produced lower genetic differentiation in tiger salamanders, potentially indicating higher gene flow (Cosentino et 
al. 2012). Salamanders may show preference for larger breeding pools, or higher colonization rates may be a product of the target effect, where salamanders are more likely to encounter larger pools during spring migrations to breeding sites (Lomolino 1990; Cosentino et al. 2011). These data indicate larger pools can support successful breeding populations (Cosentino et al. 2012). Additionally, larger pools in our study system produced spotted salamander larvae with lower stress hormone levels (Millikin et al. 2019). It is important to note that the created pools in this study were smaller in size than natural pools with breeding spotted salamander populations in Maine, which had average diameters of 15-25 m (unpublished data from study system of Coster et al. 2015), compared to the average diameter of $7 \mathrm{~m}$ in this study.

The top models indicate GSCR and canopy cover are positive predictors of $\mathrm{N}_{\mathrm{b}}$. Greater pool cover and vegetation cover was also negatively associated with relatedness within pools. This could confirm expectations that pools with higher coverage of GSCR would provide more suitable habitat for egg mass deposition and larval refuge from predators (Formanowicz \& Bobka 1989). Higher availability of GSCR in a pool may attract more breeding adults or provide more surface area for egg masses. Spotted salamander egg mass density and larval survival was higher in breeding pools with greater vegetative cover (Egan \& Paton 2004; Kern et al. 2013; Rothenberger et al. 2019). Canopy cover is more difficult to interpret because only 7 of the 31 pools had any canopy cover and they were all in the Barton Bench region. The positive relationship between canopy cover and $\mathrm{N}_{b}$ may reflect higher levels of $\mathrm{N}_{b}$ in Barton Bench due to pool age. However, spotted salamanders oviposited more egg masses in pools with surrounding forest cover and avoided clear-cut forests (Skidds et al. 2007; Felix et al. 2010; Scheffers et al. 2013). Pools with greater canopy cover also had a higher density of spotted salamander larvae 
(Peterman et al. 2014). Therefore, canopy cover could be an important factor for spotted salamander breeding habitat.

There is weak evidence that as pool cover increased, $\mathrm{H}_{\mathrm{E}}$ increased. This may be related to the higher reproductive effort in pools with more vegetation (Egan \& Paton 2004; Kerns et al. 2013). We did not find an effect of pool size on $A_{R}$ or $H_{E}$, which was also true for the California tiger salamander in vernal pools (Wang et al. 2011). Pond size negatively impacted allelic diversity of California tiger salamanders in deeper, permanent, artificial pools (Wang et al. 2011). Conversely, $A_{R}$ of tiger salamanders in Illinois increased with wetland area (Cosentino et al. 2012).

An inherent difficulty of newly created habitat is the dependency on migration and colonization. There were pools in Lambert North and Lambert South with larvae present in 2015 but not 2016. At one pool in Lambert North, we caught 22 larvae in 2015, but none in 2016. After removing full siblings, only three individuals remained with $\mathrm{N}_{\mathrm{b}}=4$. Lambert North pool 25 was surprising because after successfully catching 21 larvae in two person-hours in 2015, we only found 2 larvae in 2016, despite observing 12 egg masses and sampling the entire area of the pool multiple times over the course of two person-hours. This pool had $\mathrm{N}_{b}=12$, lower than the region's average $\left(\mathrm{N}_{\mathrm{b}}=19\right)$. Lambert South pool 30 was an extreme among our sampled pools, with the lowest $\mathrm{N}_{\mathrm{b}}$, highest relatedness, and lowest genetic diversity (Lambert South region means in parentheses): $\mathrm{N}_{\mathrm{b}}=4$ (vs 12$)$, relatedness $=0.49(\mathrm{vs} 0.13), \mathrm{H}_{\mathrm{E}}=0.64(\mathrm{vs} 0.77)$, and $\mathrm{A}_{\mathrm{R}}=$ 3 (vs 5.89). These unique pools demonstrate the stochastic nature of newly colonized pools, as presence of breeding spotted salamanders one year does not indicate an established population. 
Long-term monitoring is important to determine viability of populations in created pools because it may take many years for a population to establish (Vasconcelos \& Calhoun 2006).

\section{Conclusions}

Time since pool creation and habitat quality relates to the genetic diversity and differentiation of spotted salamanders in created vernal pools. Pools were colonized quickly by spotted salamanders and $\mathrm{N}_{\mathrm{b}}$ increased as quickly as $4-5$ years after habitat creation. These older pools also had low genetic differentiation and no bottlenecks, indicating an establishing breeding population. Vegetation cover within the pool (GSCR) and pool diameter were important predictors of $\mathrm{N}_{\mathrm{b}}$ indicating it would be valuable to incorporate vegetative cover within created pools to provide oviposition sites and refuge for larvae. Future vernal pool creation would benefit from creating larger vernal pools and future research should determine ideal pool size to attract and support spotted salamander breeding populations. At our study site, there should be continued monitoring to determine if $\mathrm{N}_{\mathrm{b}}$ increases and genetic differentiation decreases with time since creation at the youngest pools. In general, this work highlights that genetic analyses can be used to help assess the success of colonization, and, combined with environmental data, help inform future site selection and creation of vernal pools. Moreover, long-term monitoring is essential to track changes and to ultimately determine if created pools are sustaining viable breeding populations.

\section{ACKNOWLEDGEMENTS}

This study approved by West Virginia University's Institutional Animal Care and Use Committee (15-0409.3), the U.S. Forest Service, and West Virginia Division of Natural Resources (Scientific Collecting Permit 2015.133, 2016.205). We thank Jessi Rouda, Jonathan

Strickland, Adam Bucher, John Millikin, Lauren Schumacher, and Meghan Jensen for field and 
lab assistance. This research was funded by the U.S. Forest Service, Natural Resources Conservation Service, National Science Foundation (01A-1458952), West Virginia University Natural History Museum, National Institute of Food and Agriculture McStennis Project WVA00117 and Hatch Project WVA00690, The Explorers Club Washington Group, Society of Wetland Scientists, Society of Wetland Scientists South Atlantic Chapter, West Virginia University Stitzel Graduate Enhancement Fund, and Richard and Lois Bowman. We also thank West Virginia Division of Natural Resources and the Ruby Distinguished Doctoral Fellowship Program. This is scientific article number XXXX of the West Virginia Agricultural and Forestry Experiment Station, Morgantown. 


\section{REFERENCES}

Barbour MG, Burk JH, Pitts WD, Gilliam FS, Schwartz, MW (1999) Terrestrial Plant Ecology. Benjamin and Cummings, Menlo Park, CA

Beebee TJC (2005) Conservation genetics of amphibians. Heredity 95:423-427

Blacket MJ, Robin C, Good RT, Lee SF, Miller AD (2012) Universal primers for fluorescent labelling of PCR fragments - an efficient and cost-effective approach to genotyping by fluorescence. Molecular Ecology Resources 12:456-463

Burnham KP, Anderson DR (2002) Model selection and multimodel inference: a practical information-theoretic approach. Springer Science \& Business Media, LLC, New York, NY

Calhoun AJK, Arrigoni J, Brooks RP, Hunter ML, Richter SC (2014) Creating successful vernal pools: a literature review and advice for practitioners. Wetlands 34:1027-1038

Canty JL (2018) Weatherbase. http://weatherbase.com. Accessed 22 Jun 2018

Cornuet J-M, Luikart G (1996) Description and power analysis of two tests for detecting recent population bottlenecks from allele frequency data. Genetics 144:2001-2014

Cosentino BJ, Phillips CA, Schooley RL, Lowe WH, Douglas MR (2012) Linking extinctioncolonization dynamics to genetic structure in a salamander metapopulation. Proceedings of the Royal Society B 279:1575-1582

Cosentino BJ, Schooley RL, Phillips CA (2011) Spatial connectivity moderates the effect of predatory fish on salamander metapopulation dynamics. Ecosphere 2:1-14

Costanzi J-M, Mège P, Boissinot A, Isselin-Nondedeu F, Guérin S, Lourdais O, Trochet A, Le Petitcorps Q, Legrand A, Varenne F, Grillet P, Morin-Pinaud S, Picard D (2018) Agricultural landscapes and the Loire River influence the genetic structure of the Marbled Newt in Western France. Scientific Reports 8:14177 
Coster SS, Babbitt KJ, Cooper A, Kovach AI (2015) Limited influence of local and landscape factors on finescale gene flow in two pond-breeding amphibians. Molecular Ecology 24:742758

Denton RD, Richter SC (2013) Amphibian communities in natural and constructed ridge top wetlands with implications for wetland construction. The Journal of Wildlife Management $77: 886-896$

DiBello FJ, Calhoun AJ, Morgan DE, Shearin AF (2016) Efficiency and detection accuracy using print and digital stereo aerial photography for remotely mapping vernal pools in New England landscapes. Wetlands 36:505-514

Dinno A (2017) Dunn.test: Dunn's test of multiple comparisons using rank sums. R package version 1.3.5. https://CRAN.R-project.org/package=dunn.test

Earl DA, vonHoldt BM (2012) STRUCTURE HARVESTER: a website and program for visualizing STRUCTURE output and implementing the Evanno method. Conservation Genetics Resources 4:359-361. Web version: v0.6.94 July 2014

Egan RS, Paton PWC (2004) Within-pond parameters affecting oviposition by wood frogs and spotted salamanders. Wetlands 24:1-13

Excoffier L, Laval G, Schneider S (2005) Arlequin (version 3.0): an integrated software package for population genetics data analysis. Evolutionary Bioinformatics Online 1:47-50

Felix ZI, Wang Y, Schweitzer CJ (2010) Effects of experimental canopy manipulation on amphibian egg deposition. The Journal of Wildlife Management 74:496-503

Flageole S, Leclair R (1992) Demography of a salamander (Ambystoma maculatum) population studied by skeletochronology. Canadian Journal of Zoology 70:740-749 
Formanowicz DR, Bobka MS (1989) Predation risk and microhabitat preference: an experimental study of the behavioral responses of prey and predator. The American Midland Naturalist 121:379-386

Frankham R (2005) Genetics and extinction. Biological Conservation 126:131-140

Goldberg CS, Waits LP (2010) Quantification and reduction of bias from sampling larvae to infer population and landscape genetic structure. Molecular Ecology Resources 10:304-313

Goudet J (1995) FSTAT (Version 1.2): a computer program to calculate F-statistics. Journal of Heredity 86:485-486

Greenwald KR, Gibbs HL, Waite TA (2009) Efficacy of land-cover models in predicting isolation of marbled salamander populations in a fragmented landscape. Conservation Biology 23:1232-1241

Groff LA, Loftin CS, Calhoun AJK (2017) Predictors of breeding site occupancy by amphibians in montane landscapes. The Journal of Wildlife Management 81:269-278

Julian SE, King TL, Savage WK (2003) Isolation and characterization of novel tetranucleotide microsatellite DNA markers for the spotted salamander, Ambystoma maculatum. Molecular Ecology Resources 3:7-9

Kern MM, Nassar AA, Guzy JC, Dorcas ME (2013) Oviposition site selection by spotted salamanders (Ambystoma maculatum) in an isolated wetland. Journal of Herpetology 47:445-449

Kindt R, Coe R (2005) Tree diversity analysis. A manual and software for common statistical methods for ecological and biodiversity studies. World Agroforestry Centre (ICRAF), Nairobi. ISBN 92-9059-179-X 
Komsta L (2011) Outliers: tests for outliers. R package version 0.14. https://CRAN.Rproject.org/package $=$ outliers

Lomolino MV (1990) The target area hypothesis: the influence of island area on immigration rates of non-volant mammals. Oikos 57:297-300

Mazerolle MJ (2017) AICcmodavg: model selection and multimodel inference based on (Q)AIC(c). R package version 2.1-1. https://cran.r-project.org/package=AICcmodavg

McKee AM, Maerz JC, Smith LL, Glenn TC (2017) Habitat predictors of genetic diversity for two sympatric wetland-breeding amphibian species. Ecology and Evolution 7:6271-6283

Millikin AR, Woodley SK, Davis DR, Anderson JT (2019) Habitat Characteristics in Created Vernal Pools Impact spotted salamander Water-borne Corticosterone Levels. Wetlands 39:803-814

Montieth, KE, Paton, PWC (2006) Emigration behavior of spotted salamanders on golf courses in southern Rhode Island. Journal of Herpetology 40:195-205

Peakall R, Smouse PE (2006) GENALEX 6: Genetic analysis in Excel. Population genetic software for teaching and research. Molecular Ecology Notes 6:288-295

Peakall R, Smouse PE (2012) GenAlEx 6.5: Genetic analysis in Excel. Population genetic software for teaching and research-an update. Bioinformatics 28:2537-2539

Peery MZ, Kirby R, Reid BN, Stoelting R, Doucet-Bëer E, Robinson S, Vásquez-Carrillo C, Pauli JN, Palsbøll, PJ (2012) Reliability of genetic bottleneck tests for detecting recent population declines. Molecular Ecology 21:3403-3418

Peterman WE, Anderson TL, Drake DL, Ousterhout BH, Semlitsch RD (2014) Maximizing pond biodiversity across the landscape: a case study of larval ambystomatid salamanders. Animal Conservation 17:275-285 
Petranka JW, Kennedy CA, Murray SS (2003a) Response of amphibians to restoration of a southern Appalachian wetland: a long-term analysis of community dynamics. Wetlands 23:1030-1042

Petranka JW, Murray SS, Kennedy CA (2003b) Responses of amphibians to restoration of a southern Appalachian wetland: perturbations confound post-restoration assessment. Wetlands $23: 278-290$

Piry S, Luikart G, Cornuet J-M (1999) BOTTLENECK: a computer program for detecting recent reductions in the effective population size using allele frequency data. Journal of Heredity 90:502-503

Pritchard JK, Stephens M, Donnelly P (2000) Inference of population structure using multilocus genotype data. Genetics 155:945-959

Queller DC, Goodnight KF (1989) Estimating relatedness using genetic markers. Evolution $43: 258-275$

R Core Team (2017) R: A language and environment for statistical computing. R Foundation for Statistical Computing, Vienna, Austria. URL https://www.R-project.org/

Raymond M, Rousset F (1995) GENEPOP (version 1.2): Population genetics software for exact tests and ecumenicism. Journal of Heredity 86:248-249

Reed DH, Frankham R (2003) Correlation between fitness and genetic diversity. Conservation Biology 17:230-237

Richardson JL (2012) Divergent landscape effects on population connectivity in two cooccurring amphibian species. Molecular Ecology 21:4437-4451 
Rothenberger MB, Vera MK, Germanoski D, Ramirez E (2019) Comparing amphibian habitat quality and functional success among natural, restored, and created vernal pools. Restoration Ecology

Scheffers BR, Furman BLS, Evans JP (2013) Salamanders continue to breed in ephemeral ponds following the removal of surrounding terrestrial habitat. Herpetological Conservation and Biology 8:715-723

Skidds DE, Golet FC, Paton PW, Mitchell JC (2007) Habitat correlates of reproductive effort in wood frogs and spotted salamanders in an urbanizing watershed. Journal of Herpetology 41:439-451

Spielman D, Brook BW, Frankham R (2004) Most species are not driven to extinction before genetic factors impact them. Proceedings of the National Academy of Sciences 101:1526115264

Van Oosterhout C, Hutchinson WF, Wills DP, Shipley P (2004) MICRO-CHECKER: software for identifying and correcting genotyping errors in microsatellite data. Molecular Ecology Resources 4:535-538

Vasconcelos D, Calhoun AJK (2006) Monitoring created seasonal pools for functional success: a six-year case study of amphibian responses, Sears Island, Maine, USA. Wetlands 26:9921003

Wang IJ, Johnson JR, Johnson BB, Shaffer HB (2011) Effective population size is strongly correlated with breeding pond size in the endangered California tiger salamander, Ambystoma californiense. Conservation Genetics 12:911-920

Wang J (2004) Sibship reconstruction from genetic data with typing errors. Genetics 166:19631979 
Wang J (2009) A new method for estimating effective population sizes from a single sample of multilocus genotypes. Molecular Ecology 18:2148-2164

Waples RS, Luikart G, Faulker JR, Tallmon DA (2013) Simple life-history traits explain key effective population size ratios across diverse taxa. Proceedings of the Royal Society B 280:20131339

Whiteley AR, McGarigal K, Schwartz MK (2014) Pronounced differences in genetic structure despite overall ecological similarity for two Ambystoma salamanders in the same landscape. Conservation Genetics 15:573-591

Wilbur HM (1977) Propagule size, number, and dispersion pattern in Ambystoma and Asclepias. The American Naturalist 111:43-68

Williamson-Natesan EG (2005) Comparison of methods for detecting bottlenecks from microsatellite loci. Conservation Genetics 6:551-562 
Table 1. Hypothesized models predicting effective number of breeders of spotted salamanders (Ambystoma maculatum). Predictors include: age of pool; cover of grass, sedge, cattail, and rush within pool (GSCR); diameter of pool; sample size within pool; canopy cover; predator presence; and the null $\sim$ 1. $\triangle \mathrm{AICc}=$ change in AIC corrected for small sample size; $\mathrm{w}_{\mathrm{i}}=\mathrm{weight}$ of the model; asterisks indicate when all predictors in a model had an estimate and 95\% CI interval not overlapping zero

\begin{tabular}{|c|c|c|c|c|}
\hline Model & $\triangle \mathrm{AICc}$ & $\mathrm{W}_{\mathrm{i}}$ & $\begin{array}{l}\text { Deviance } \\
\text { Explained }\end{array}$ & $\begin{array}{l}\text { All Model } \\
\text { Coefficients } \\
\neq 0\end{array}$ \\
\hline Age + GSCR + Diameter + Sample Size & 0.00 & 0.70 & 0.73 & \\
\hline Diameter + Canopy Cover + Sample Size & 2.41 & 0.21 & 0.67 & $*$ \\
\hline $\begin{array}{l}\text { Age + GSCR + Diameter + Predators + } \\
\text { Canopy Cover + Sample Size }\end{array}$ & 4.57 & 0.07 & 0.75 & \\
\hline GSCR + Predators + Sample Size & 8.69 & 0.01 & 0.59 & \\
\hline Age + GSCR + Diameter & 9.90 & 0.00 & 0.57 & * \\
\hline Sample Size & 12.13 & 0.00 & 0.44 & $*$ \\
\hline Diameter + Canopy Cover & 14.21 & 0.00 & 0.45 & $*$ \\
\hline GSCR + Predators & 18.10 & 0.00 & 0.37 & $*$ \\
\hline Predators & 21.21 & 0.00 & 0.23 & $*$ \\
\hline Diameter & 22.10 & 0.00 & 0.21 & $*$ \\
\hline GSCR & 23.25 & 0.00 & 0.17 & $*$ \\
\hline Age & 23.41 & 0.00 & 0.17 & $*$ \\
\hline$\sim 1$ & 26.28 & 0.00 & 0.00 & \\
\hline
\end{tabular}


Table 2. Coefficients for top model predicting effective number of breeders for spotted salamanders (Ambystoma maculatum): $\mathrm{y}=$ age of pool + GSCR (grass, sedge, cattail, rush coverage) + diameter of pool + sample size within pool

\begin{tabular}{lrrrrrr}
\hline & \multicolumn{5}{c}{ Std } & \multicolumn{5}{c}{95 Confidence } & \\
Coefficients & Estimate & Error & \multicolumn{2}{c}{ Interval } & \multicolumn{1}{c}{$\mathrm{c}$} & \multicolumn{1}{c}{$\mathrm{p}$} \\
\hline Intercept & -6.46 & 3.39 & -13.10 & 0.18 & -1.91 & 0.07 \\
Age & 2.10 & 0.63 & 0.87 & 3.32 & 3.36 & 0.003 \\
GSCR & 11.46 & 6.05 & -0.40 & 23.32 & 1.89 & 0.07 \\
Diameter & 0.012 & 0.003 & 0.006 & 0.018 & 3.85 & 0.001 \\
Sample Size & 0.26 & 0.07 & 0.12 & 0.40 & 3.704 & 0.001 \\
\hline
\end{tabular}

Table 3. Summary statistics of predictors included in spotted salamander (Ambystoma maculatum) population genetics models including age of pool; canopy cover; diameter (m) of pool; cover of grass, sedge, cattail, and rush within pool (GSCR); cover by any form of refuge within the pool such as vegetation, rocks, and coarse woody debris (pool cover); predator presence; and sample size per pool

\begin{tabular}{lrrr}
\hline Predictor & \multicolumn{1}{c}{ Min } & \multicolumn{1}{c}{ Max } & \multicolumn{1}{c}{ Mean \pm SE } \\
\hline Age & 1.5 & 5 & $3.12 \pm 0.21$ \\
Canopy Cover $(0-1)$ & 0.00 & 0.52 & $0.06 \pm 0.03$ \\
Diameter (m) & 3.16 & 11.94 & $6.77 \pm 0.40$ \\
GSCR (0-1) & 0.01 & 0.44 & $0.15 \pm 0.02$ \\
Pool Cover (0-1) & 0 & 0.53 & $0.23 \pm 0.02$ \\
Predators (0-3) & 0.00 & 3.00 & $1.72 \pm 0.13$ \\
Sample Size per Pool & 10.00 & 44.00 & $26.17 \pm 2.00$ \\
\hline
\end{tabular}


Table 4. Hypothesized models predicting relatedness for spotted salamanders (Ambystoma maculatum). Predictors include: pool cover which includes any form of refuge such as vegetation, rocks, coarse woody debris; sample size within pool; cover of grass, sedge, cattail, and rush within pool (GSCR); region; diameter of pool; predator presence; and the null $\sim 1$. $\triangle \mathrm{AICc}=$ change in AIC corrected for small sample size $; \mathrm{w}_{\mathrm{i}}=$ weight of the model; asterisks indicate when all predictors in a model had an estimate and 95\% CI interval not overlapping zero

\begin{tabular}{|c|c|c|c|c|}
\hline Model & $\triangle \mathrm{AICc}$ & $\mathrm{W}_{\mathrm{i}}$ & $\begin{array}{l}\text { Deviance } \\
\text { Explained }\end{array}$ & $\begin{array}{l}\text { All } \\
\text { predictors } \\
\text { significant } \\
\mathrm{p}<0.05\end{array}$ \\
\hline Pool Cover + Sample Size & 0.00 & 0.27 & 0.32 & \\
\hline GSCR + Sample Size & 0.89 & 0.17 & 0.30 & \\
\hline Sample Size & 1.11 & 0.16 & 0.23 & $*$ \\
\hline Pool Cover + Sample Size + Region & 1.69 & 0.12 & 0.34 & \\
\hline Pool Cover + Sample Size + Diameter & 1.92 & 0.1 & 0.34 & \\
\hline Pool Cover + Sample Size + Predators & 2.46 & 0.08 & 0.33 & \\
\hline GSCR & 3.20 & 0.05 & 0.17 & $*$ \\
\hline Pool Cover & 4.76 & 0.03 & 0.12 & \\
\hline$\sim 1$ & 6.27 & 0.01 & 0.00 & \\
\hline Pool Cover + Region + Diameter + Predators & 6.62 & 0.01 & 0.30 & \\
\hline
\end{tabular}


Table 5. Coefficients for top model predicting relatedness for spotted salamanders (Ambystoma maculatum): $\mathrm{y}=$ pool cover + sample size within pool

\begin{tabular}{lrrrrrr}
\hline & & \multicolumn{2}{c}{ Std } & \multicolumn{2}{c}{$95 \%$ Confidence } & \\
Coefficients & Estimate & Error & \multicolumn{2}{c}{ Interval } & \multicolumn{1}{c}{$\mathrm{t}$} & \multicolumn{1}{c}{$\mathrm{p}$} \\
\hline Intercept & 0.13 & 0.02 & 0.08 & 0.17 & 5.66 & $<0.0001$ \\
Pool Cover & -0.10 & 0.05 & -0.21 & 0.003 & -1.91 & 0.07 \\
Sample Size & -0.002 & 0.0006 & -0.003 & -0.0005 & -2.76 & 0.01 \\
\hline
\end{tabular}




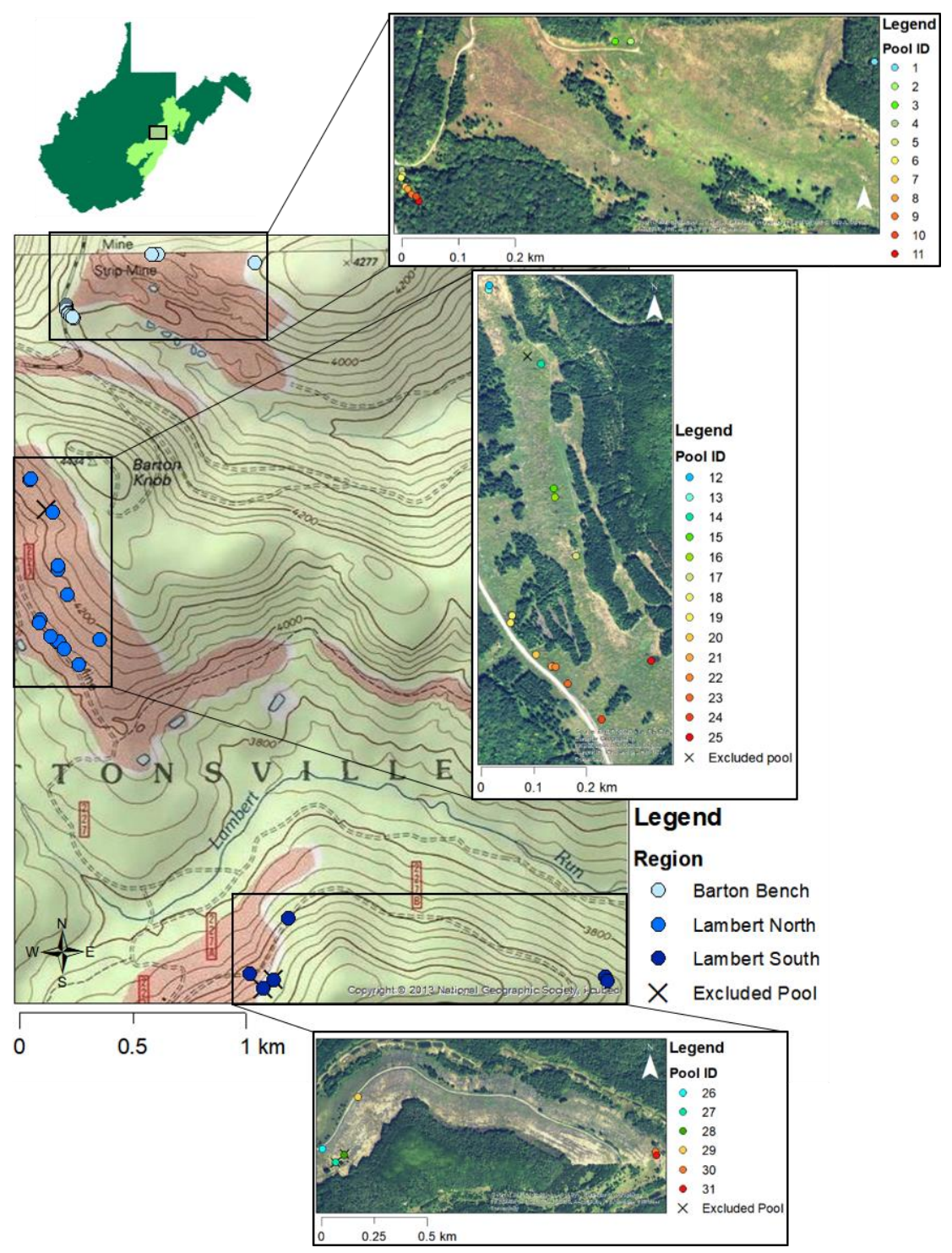

Figure 1. Map displaying study area in Randolph County, WV in the Greenbrier District of Monongahela National Forest. Circles represent locations of sampled created vernal pools designated by region. Pools at Barton Bench were created in $2011(\mathrm{n}=11)$, Lambert North pools were created in $2013(n=14)$, and Lambert South pools were created $2014(n=6)$. State map displays Monongahela National Forest and the general area of sampling with a black box. USA topo map accessed through ESRI @ 2013 National Geographic Society, i-cubed; world impagery source: Esri, DigitalGlobe, GeoEye, Earthstar Geographics, CNES/Airbus DS, USDA, USGS, AeroGRID, IGN, and the GIS User Community 
a)

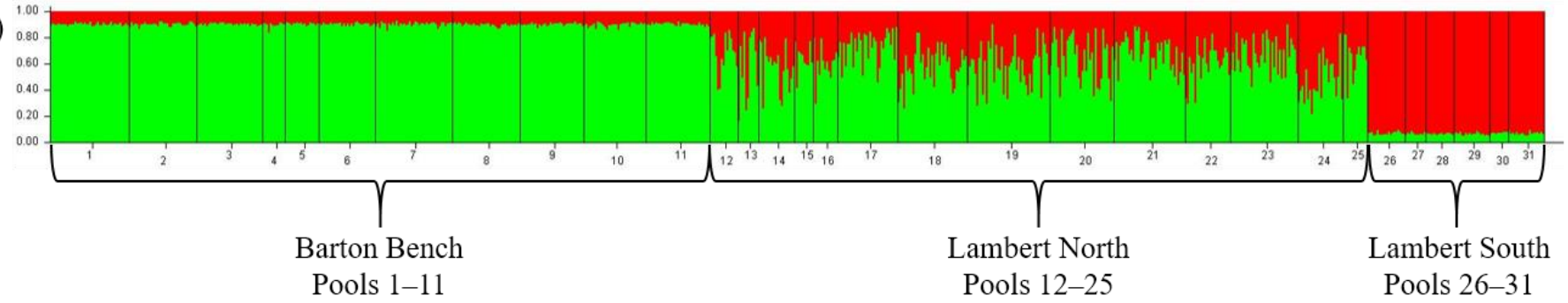

b)

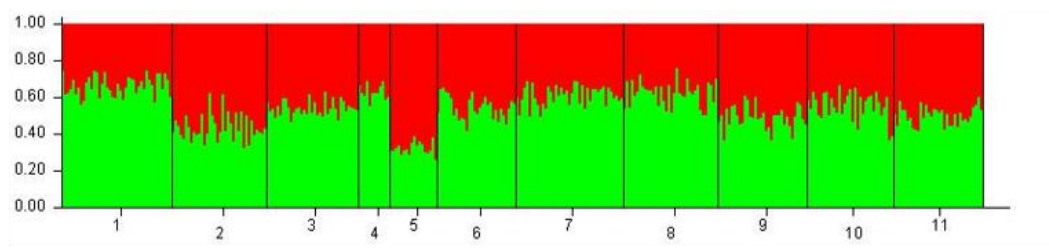

C) 0.8
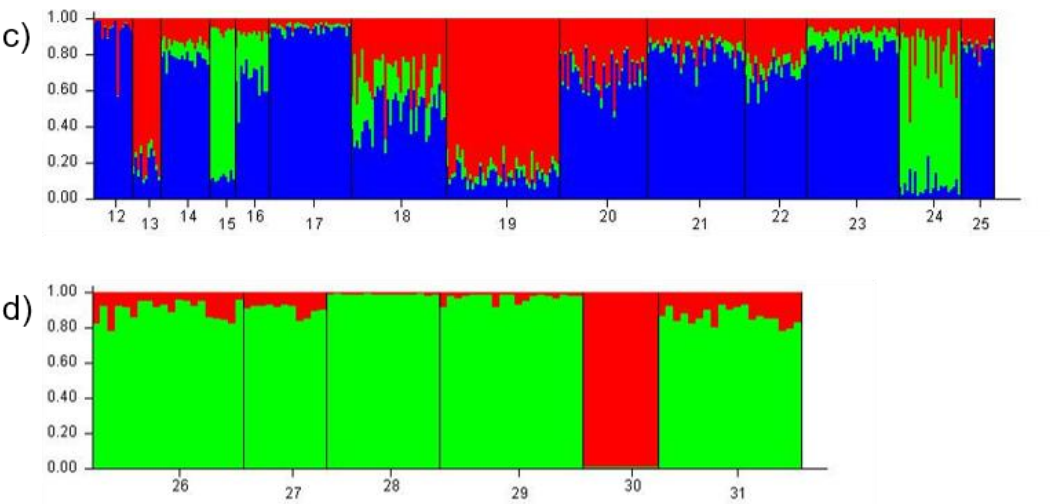

2 Figure 2. STRUCTURE Barplots displaying most likely K. Colors indicate the individual membership coefficients for each cluster.

3 Numbers reflect pool IDs. (a) Barplot for entire study area including all three regions (Barton Bench, Lambert North, Lambert South)

4 and displaying cline across regions. (b) Barplot for pools in Barton Bench region created in 2011; most likely $\mathrm{K}=1$. [Presenting

5 barplot $\mathrm{K}=2$ to visually display the allele proportions reflect $\mathrm{K}=1$.] (c) Barplot for pools in Lambert North region created in 2013;

6 most likely $\mathrm{K}=3$. (d) Barplot for pools in Lambert South region created in 2014; most likely K = 2 
a)

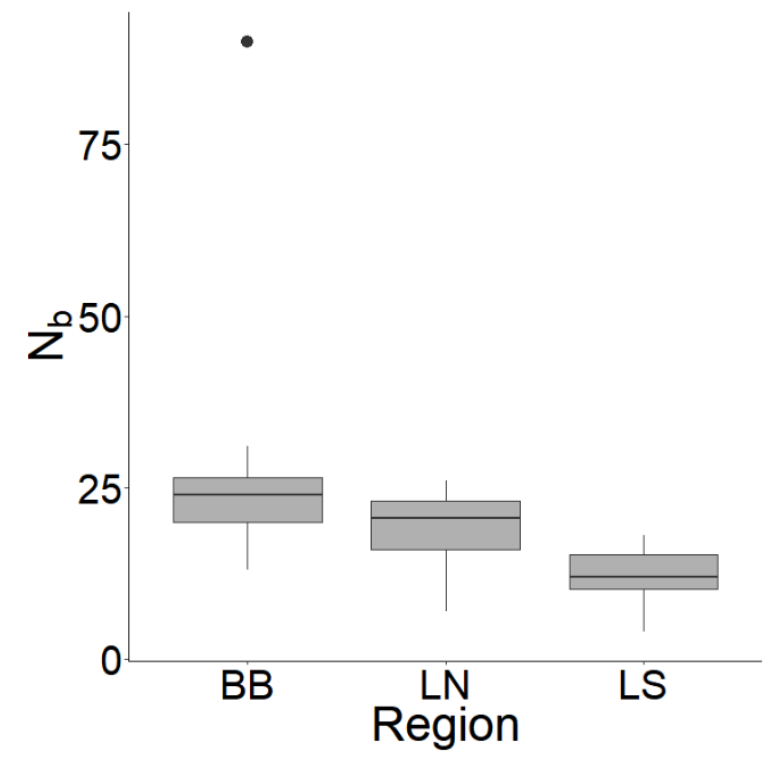

c)

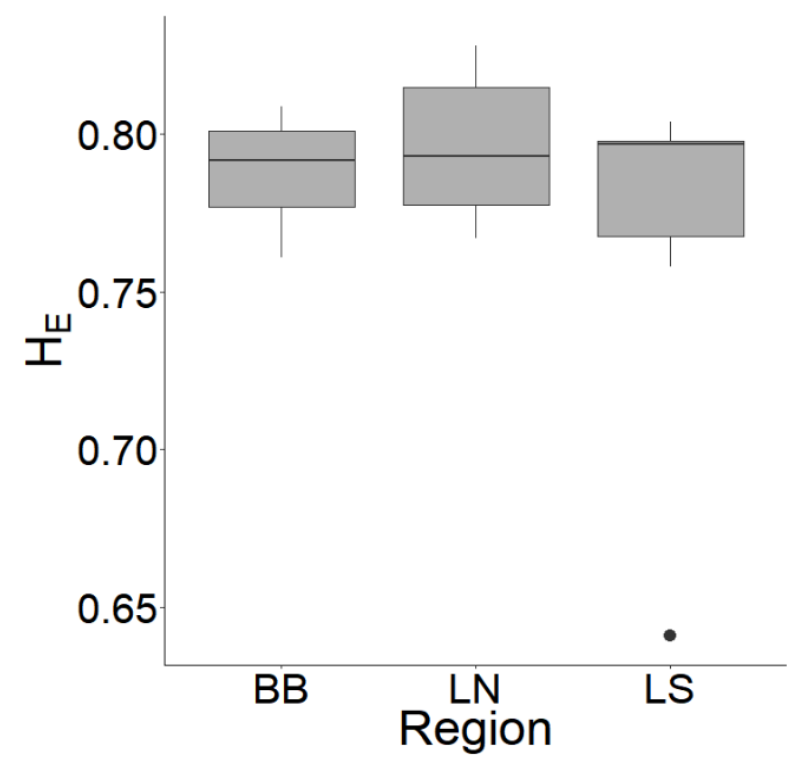

b)

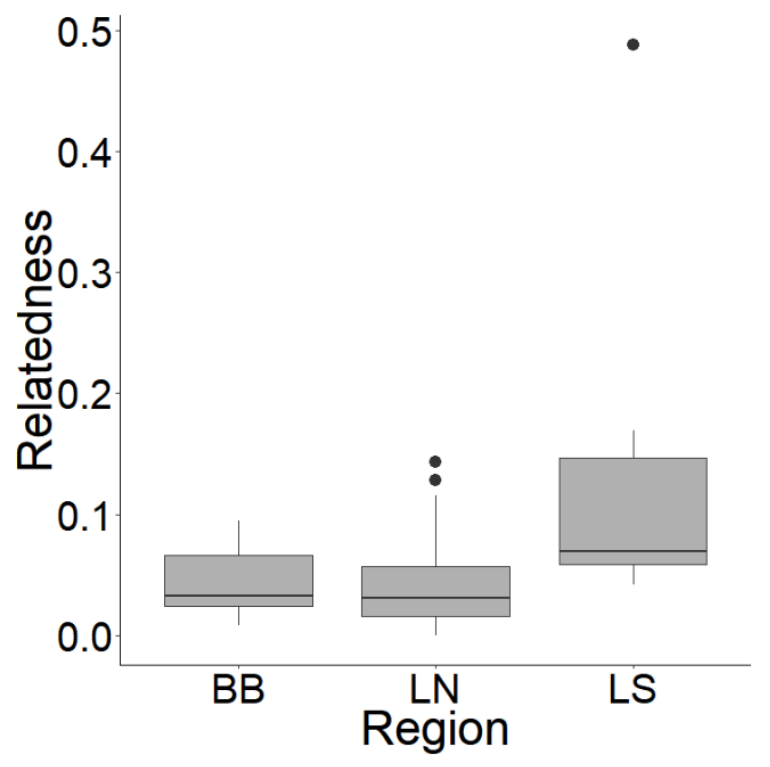

d)

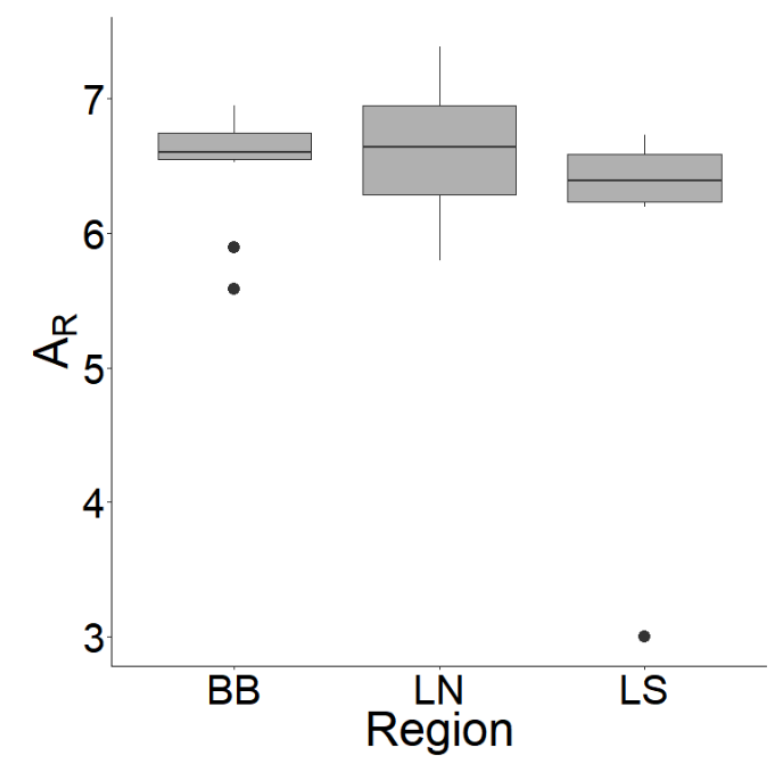

Figure 3. Boxplots displaying ranges in (a) effective number of breeders $\left(\mathrm{N}_{\mathrm{b}}\right)$, (b) relatedness, (c) expected heterozygosity $\left(H_{E}\right)$, and $(d)$ allelic richness $\left(A_{R}\right)$ for spotted salamanders (Ambystoma maculatum) across regions: Barton Bench (BB), Lambert South (LN), Lambert North (LS). Letters indicate significant differences between regions (Dunn's Test $p<0.05$ ) 
a)

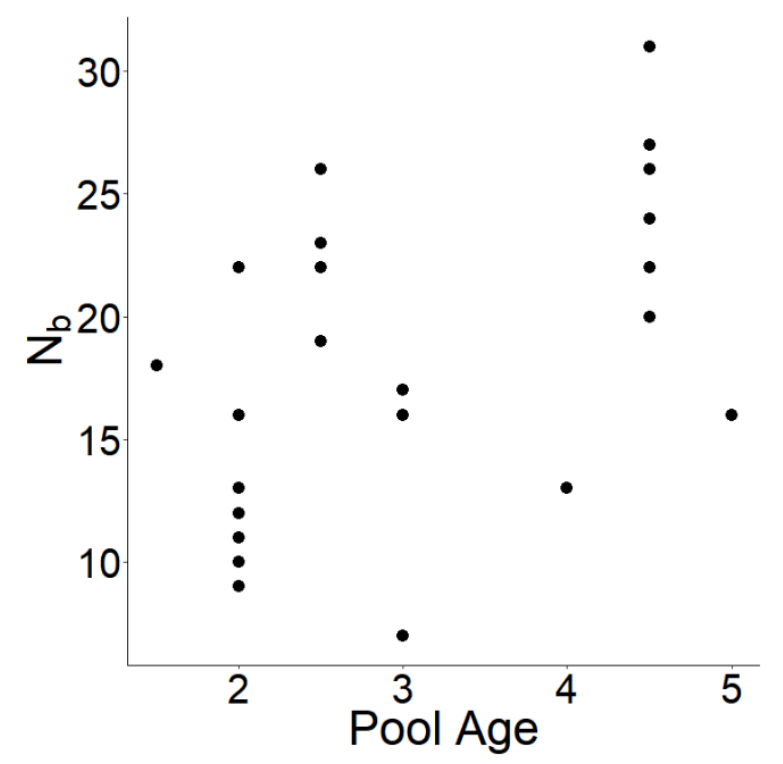

c)

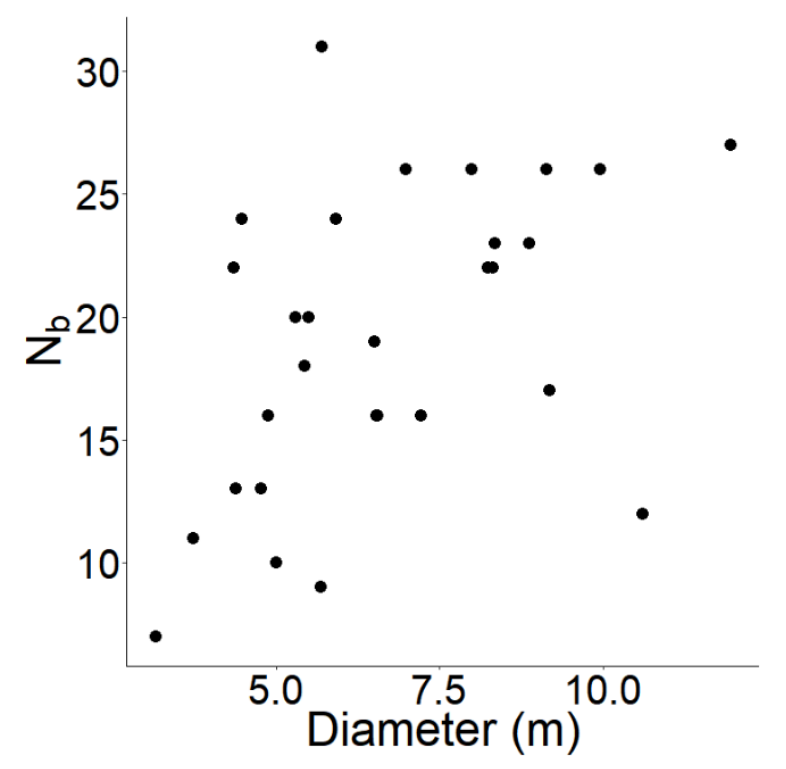

b)

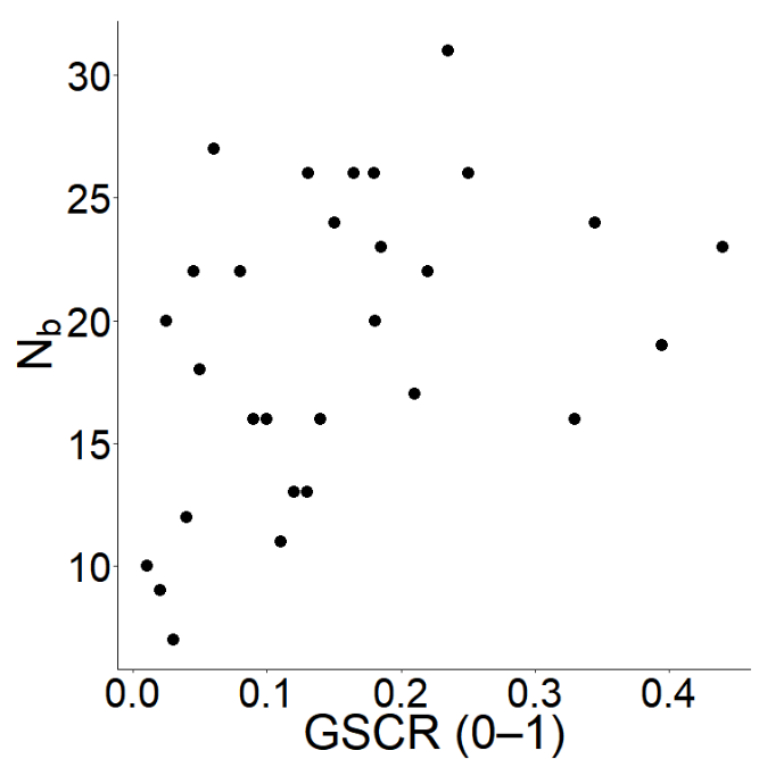

d)

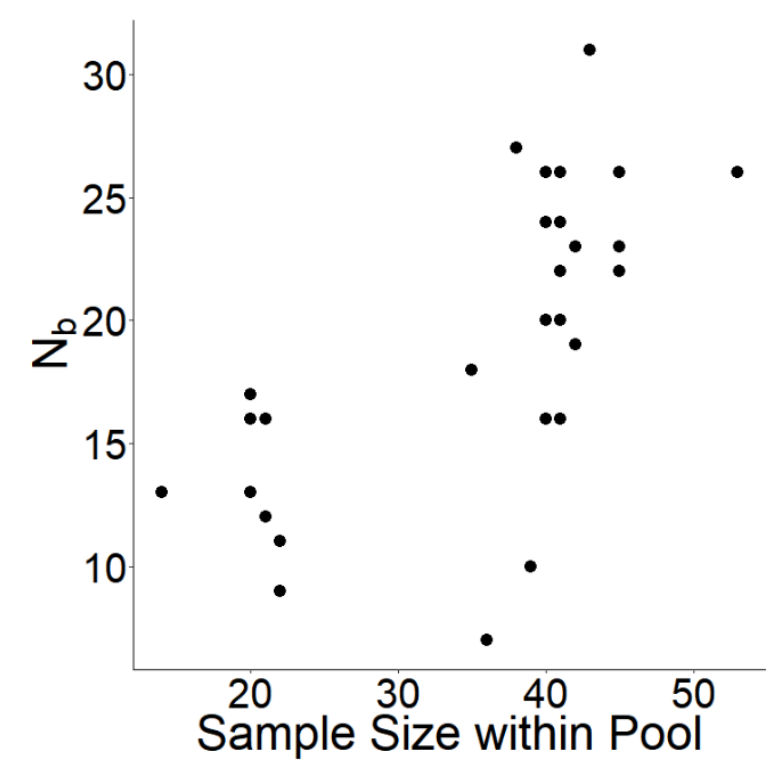

Figure 4. Biplots displaying relationship between $\mathrm{N}_{\mathrm{b}}$ and predictors from the strongest model including: (a) age of pool, (b) GSCR (0-1) (grass, sedge, cattail, and rush coverage within pool), (c) diameter (m) of pool, and (d) sample size within pool. Some ages are in-between years due to combining samples collected over two years 

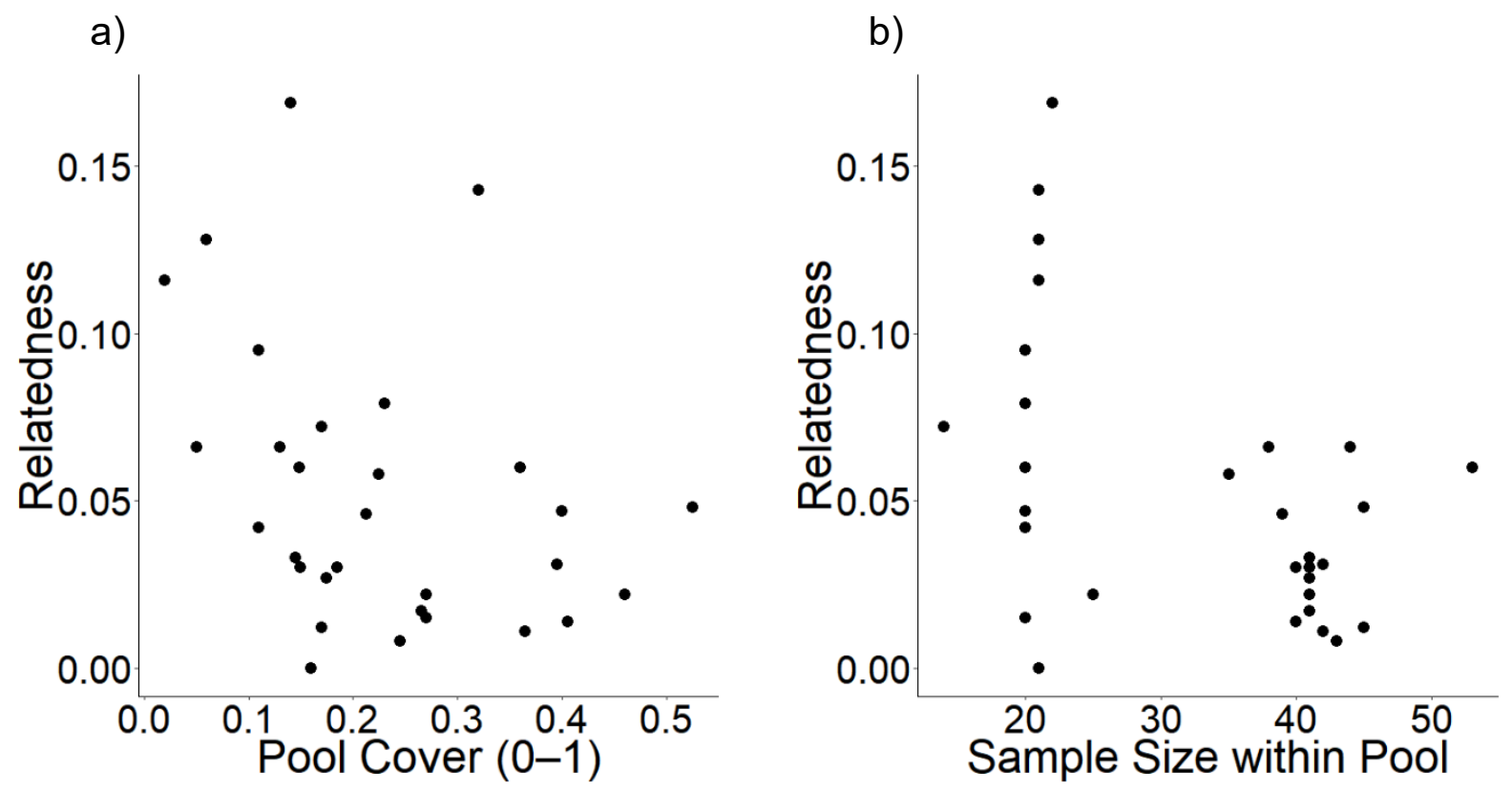

Figure 5. Biplots displaying relationship between relatedness and predictors from the strongest model including: (a) GSCR (0-1) (grass, sedge, cattail, and rush coverage within pool) and (b) sample size within pool 


\section{SUPPLEMENTAL INFORMATION}

Title: Pool age and local habitat are associated with effective number of breeders in spotted salamander populations colonizing created vernal pools

Journal: Restoration Ecology

Authors: Alice R. Millikin ${ }^{1}$, Stephanie S. Coster, Amy B. Welsh, James T. Anderson

${ }^{1}$ School of Natural Resources, West Virginia University, PO Box 6125, Morgantown, WV 26506, USA; e-mail: alicemillikin@gmail.com 


\section{Appendix 1. Supplemental Methods: PCR Details}

Microsatellite loci are from Julian et al. (2003). Universal primers are from Blacket et al. (2012). We amplified markers with multiplex polymerase chain reactions (Table S1). PCR consisted of $30 \mathrm{ng}$ of genomic DNA, 2 x Qiagen multiplex buffer, 5x Q solution, and 0.05-0.2 $\mu \mathrm{M}$ of each primer with a final volume of $10 \mu \mathrm{L}$ (Table S1). The amplification cycle for Set A multiplex consisted of $95^{\circ} \mathrm{C}$ for $15 \mathrm{~min}$, a touchdown protocol of 14 cycles at $94^{\circ} \mathrm{C}$ for $30 \mathrm{sec}$, $65^{\circ} \mathrm{C}$ for $90 \mathrm{sec}\left(\right.$ decreasing $1{ }^{\circ} \mathrm{C}$ every cycle), and $72^{\circ} \mathrm{C}$ for $60 \mathrm{sec}$; followed by a touchdown of 31 cycles at $94^{\circ} \mathrm{C}$ for $30 \mathrm{sec}, 50^{\circ} \mathrm{C}$ for $90 \mathrm{sec}, 72^{\circ} \mathrm{C}$ for $60 \mathrm{sec}$; and a final extension of $60^{\circ} \mathrm{C}$ for 30 min. For Set B, we changed the first touchdown from 14 cycles to 12 cycles; the rest of the protocol remained the same (EPPENDORF Mastercycler nexus, or BIO RAD C1000 Touch thermal cycler). We re-ran samples once if one locus did not amplify. If $\geq 2$ loci still did not amplify, we did not include the sample in analyses. 
Table S1. Details of microsatellites with PCR conditions. Microsatellite loci are from Julian et al. (2003). Universal primers are from Blacket et al. (2012). * Loci excluded from analysis

\begin{tabular}{|c|c|c|c|c|}
\hline Locus & Multiplex & $\begin{array}{l}\text { Primer } \\
{[\mu \mathrm{M}]}\end{array}$ & $\begin{array}{l}\text { Universal } \\
\text { Primer }\end{array}$ & $\begin{array}{l}\text { Fluorescent } \\
\text { dye }\end{array}$ \\
\hline D184 & A & 0.1 & A & 5 CY55 \\
\hline D287 & A & 0.05 & B & 5TYE665 \\
\hline $\mathrm{C} 151$ & A & 0.1 & $\mathrm{C}$ & 5 CY55 \\
\hline D315* & A & 0.2 & A & 5 Alex $750 \mathrm{~N}$ \\
\hline D226 & B & 0.1 & A & $5 \mathrm{CY} 55$ \\
\hline D49 & B & 0.05 & B & 5TYE665 \\
\hline D328* & B & 0.1 & $\mathrm{C}$ & $5 \mathrm{CY} 55$ \\
\hline D203* & $\mathrm{B}$ & 0.2 & A & 5 Alex750N \\
\hline
\end{tabular}


Table S2. List of all pools sampled specifying which were included in analysis. Regions include Barton Bench (BB), Lambert North (LN), and Lambert South (LS). Sample size is the number of spotted salamander (Ambystoma maculatum) larvae per pool included in analysis. Years sampled were 2015, 2016, or both. Years combined indicates whether data from two years were combined: yes Y, no N, or N/A if only sampled one year. Sample year included is bolded for pools with only one year of sampling included in analysis. Final pool sample size included 31 pools: 14 based on one year of sampling and 17 based on two years of sampling

\begin{tabular}{|c|c|c|c|c|c|c|c|}
\hline Region & $\begin{array}{l}\text { Pool } \\
\text { ID }\end{array}$ & $\begin{array}{l}\text { Sample } \\
\text { Size }\end{array}$ & $\begin{array}{l}\text { Year } \\
\text { Created }\end{array}$ & $\begin{array}{l}\text { Year } \\
\text { Sampled }\end{array}$ & $\begin{array}{l}\text { Years } \\
\text { Combined }\end{array}$ & $\begin{array}{l}\text { Sample } \\
\text { Year } \\
\text { Included }\end{array}$ & Notes \\
\hline $\mathrm{BB}$ & 1 & 42 & 2011 & both & $\mathrm{Y}$ & both & \\
\hline $\mathrm{BB}$ & 2 & 36 & 2011 & both & $\mathrm{Y}$ & both & \\
\hline $\mathrm{BB}$ & 3 & 35 & 2011 & both & $\mathrm{Y}$ & both & \\
\hline $\mathrm{BB}$ & 4 & 12 & 2011 & 2015 & N/A & 2015 & \\
\hline $\mathrm{BB}$ & 5 & 18 & 2011 & both & $\mathrm{N}$ & 2016 & excluded 2015 \\
\hline $\mathrm{BB}$ & 6 & 30 & 2011 & both & $\mathrm{Y}$ & both & \\
\hline $\mathrm{BB}$ & 7 & 41 & 2011 & both & $\mathrm{Y}$ & both & \\
\hline $\mathrm{BB}$ & 8 & 36 & 2011 & both & $\mathrm{Y}$ & both & \\
\hline $\mathrm{BB}$ & 9 & 34 & 2011 & both & $\mathrm{Y}$ & both & \\
\hline $\mathrm{BB}$ & 10 & 33 & 2011 & both & $\mathrm{Y}$ & both & \\
\hline $\mathrm{BB}$ & 11 & 34 & 2011 & both & $\mathrm{Y}$ & both & \\
\hline $\mathrm{LN}$ & 12 & 15 & 2013 & 2016 & N/A & 2016 & \\
\hline LN & 13 & 11 & 2013 & both & $\mathrm{N}$ & 2016 & $\begin{array}{r}\text { excluded } 2015 \\
\text { no larvae present in }\end{array}$ \\
\hline $\mathrm{LN}$ & 14 & 19 & 2013 & 2015 & N/A & 2015 & $\begin{array}{r}2016 \\
\text { no larvae present in }\end{array}$ \\
\hline $\mathrm{LN}$ & 15 & 10 & 2013 & 2015 & N/A & 2015 & $\begin{array}{r}2016 \\
\text { no larvae present in }\end{array}$ \\
\hline $\mathrm{LN}$ & 16 & 13 & 2013 & 2016 & N/A & 2016 & 2015 \\
\hline LN & 17 & 32 & 2013 & both & $\mathrm{Y}$ & both & \\
\hline $\mathrm{LN}$ & 18 & 37 & 2013 & both & $\mathrm{Y}$ & both & \\
\hline LN & 19 & 44 & 2013 & both & $\mathrm{Y}$ & both & \\
\hline LN & 20 & 34 & 2013 & both & $\mathrm{Y}$ & both & \\
\hline $\mathrm{LN}$ & 21 & 38 & 2013 & both & $\mathrm{Y}$ & both & \\
\hline
\end{tabular}


Table S2 continued

\begin{tabular}{|c|c|c|c|c|c|c|c|}
\hline \multicolumn{5}{|c|}{ Final } & \multicolumn{3}{|c|}{ Sample } \\
\hline Region & $\begin{array}{l}\text { Pool } \\
\text { ID }\end{array}$ & $\begin{array}{r}\text { Sample } \\
\text { Size }\end{array}$ & $\begin{array}{r}\text { Year } \\
\text { Created }\end{array}$ & $\begin{array}{r}\text { Year } \\
\text { Sampled }\end{array}$ & $\begin{array}{r}\text { Years } \\
\text { Combined }\end{array}$ & $\begin{array}{r}\text { Year } \\
\text { Included }\end{array}$ & Notes \\
\hline $\mathrm{LN}$ & 22 & 24 & 2013 & both & $\mathrm{Y}$ & both & \\
\hline LN & 23 & 36 & 2013 & both & $\mathrm{Y}$ & both & \\
\hline $\mathrm{LN}$ & 24 & 24 & 2013 & both & $\mathrm{N}$ & 2015 & $\begin{array}{r}\text { excluded } 2016 \\
\text { two larvae }\end{array}$ \\
\hline LN & 25 & 13 & 2013 & 2015 & N/A & 2015 & present in 2016 \\
\hline LS & 26 & 20 & 2014 & both & $\mathrm{Y}$ & both & \\
\hline LS & 27 & 11 & 2014 & 2016 & N/A & 2016 & \\
\hline LS & 28 & 15 & 2014 & 2016 & N/A & 2016 & \\
\hline LS & 29 & 19 & 2014 & both & $\mathrm{N}$ & 2016 & excluded 2015 \\
\hline LS & 30 & 10 & 2014 & 2015 & N/A & 2015 & $\begin{array}{r}\text { no larvae } \\
\text { present in } 2016 \\
\text { excluded } 2015\end{array}$ \\
\hline $\mathrm{LS}$ & 31 & 19 & 2014 & both & $\mathrm{N}$ & 2016 & excluded 2015 \\
\hline & \multicolumn{6}{|c|}{ Excluded from analysis } & $\begin{array}{l}\text { final } \mathrm{N}=3 \text {; } \\
\text { no larvae }\end{array}$ \\
\hline $\mathrm{LN}$ & N/A & N/A & 2013 & 2015 & N/A & N/A & present in 2016 \\
\hline LS & N/A & N/A & 2014 & 2015 & N/A & N/A & $\begin{array}{r}\text { final } \mathrm{N}=9 \\
\text { final } \mathrm{N}=8 \\
\text { no }\end{array}$ \\
\hline LS & N/A & N/A & 2014 & 2015 & N/A & N/A & present in 2016 \\
\hline
\end{tabular}


Table S3. $F_{\text {st }}$ table displaying $F_{\text {st }}$ values in the top half and p-values in the bottom half. Significant values are bolded. Pool ID listed by region: Barton Bench 1-11 (BB), Lambert North 12-25 (LN), and Lambert South 26-31 (LS)

\begin{tabular}{|c|c|c|c|c|c|c|c|c|c|c|c|c|}
\hline Region & Pool ID & 1 & 2 & 3 & 4 & 5 & 6 & 7 & 8 & 9 & 10 & 11 \\
\hline $\mathrm{BB}$ & 1 & 0.000 & 0.010 & 0.016 & 0.009 & 0.040 & 0.014 & 0.017 & 0.024 & 0.014 & 0.011 & 0.026 \\
\hline BB & 2 & 0.021 & 0.000 & 0.003 & 0.014 & 0.004 & 0.005 & 0.006 & 0.014 & -0.001 & 0.006 & 0.005 \\
\hline BB & 3 & 0.011 & 0.677 & 0.000 & 0.022 & 0.029 & 0.012 & 0.008 & 0.013 & 0.012 & 0.006 & 0.017 \\
\hline BB & 4 & 0.118 & 0.005 & 0.010 & 0.000 & 0.040 & 0.008 & 0.004 & 0.011 & 0.012 & 0.020 & 0.027 \\
\hline BB & 5 & 0.000 & 0.113 & 0.001 & 0.001 & 0.000 & 0.013 & 0.020 & 0.032 & 0.008 & 0.035 & 0.009 \\
\hline BB & 6 & 0.085 & 0.099 & 0.031 & 0.065 & 0.004 & 0.000 & 0.001 & 0.000 & 0.000 & 0.015 & 0.003 \\
\hline BB & 7 & 0.000 & 0.015 & 0.099 & 0.037 & 0.001 & 0.040 & 0.000 & -0.001 & 0.003 & 0.010 & 0.002 \\
\hline BB & 8 & 0.000 & 0.001 & 0.038 & 0.028 & 0.000 & 0.291 & 0.084 & 0.000 & 0.009 & 0.017 & 0.009 \\
\hline BB & 9 & 0.000 & 0.153 & 0.021 & 0.053 & 0.038 & 0.193 & 0.024 & 0.026 & 0.000 & 0.010 & 0.007 \\
\hline BB & 10 & 0.000 & 0.067 & 0.033 & 0.037 & 0.001 & 0.041 & 0.018 & 0.002 & 0.050 & 0.000 & 0.012 \\
\hline $\mathrm{BB}$ & 11 & 0.000 & 0.026 & 0.023 & 0.001 & 0.013 & 0.022 & 0.014 & 0.021 & 0.022 & 0.123 & 0.000 \\
\hline LN & 12 & 0.182 & 0.518 & 0.642 & 0.049 & 0.212 & 0.501 & 0.500 & 0.550 & 0.232 & 0.474 & 0.174 \\
\hline LN & 13 & 0.000 & 0.000 & 0.014 & 0.001 & 0.000 & 0.000 & 0.000 & 0.002 & 0.000 & 0.001 & 0.001 \\
\hline LN & 14 & 0.000 & 0.044 & 0.030 & 0.007 & 0.001 & 0.137 & 0.166 & 0.043 & 0.015 & 0.229 & 0.007 \\
\hline LN & 15 & 0.000 & 0.004 & 0.010 & 0.002 & 0.002 & 0.000 & 0.000 & 0.000 & 0.002 & 0.008 & 0.001 \\
\hline LN & 16 & 0.036 & 0.009 & 0.004 & 0.089 & 0.005 & 0.009 & 0.019 & 0.005 & 0.053 & 0.037 & 0.006 \\
\hline LN & 17 & 0.005 & 0.008 & 0.016 & 0.013 & 0.000 & 0.002 & 0.001 & 0.001 & 0.000 & 0.000 & 0.000 \\
\hline LN & 18 & 0.000 & 0.042 & 0.087 & 0.031 & 0.000 & 0.040 & 0.130 & 0.101 & 0.048 & 0.007 & 0.008 \\
\hline LN & 19 & 0.000 & 0.000 & 0.000 & 0.000 & 0.000 & 0.001 & 0.000 & 0.000 & 0.000 & 0.000 & 0.000 \\
\hline LN & 20 & 0.000 & 0.449 & 0.043 & 0.011 & 0.571 & 0.298 & 0.037 & 0.095 & 0.122 & 0.019 & 0.248 \\
\hline LN & 21 & 0.000 & 0.035 & 0.002 & 0.000 & 0.001 & 0.031 & 0.003 & 0.000 & 0.033 & 0.001 & 0.062 \\
\hline LN & 22 & 0.004 & 0.002 & 0.000 & 0.019 & 0.000 & 0.015 & 0.000 & 0.002 & 0.005 & 0.001 & 0.000 \\
\hline LN & 23 & 0.000 & 0.001 & 0.044 & 0.003 & 0.000 & 0.067 & 0.002 & 0.075 & 0.002 & 0.009 & 0.001 \\
\hline LN & 24 & 0.000 & 0.000 & 0.000 & 0.001 & 0.000 & 0.000 & 0.000 & 0.000 & 0.000 & 0.000 & 0.000 \\
\hline $\mathrm{LN}$ & 25 & 0.000 & 0.004 & 0.061 & 0.000 & 0.000 & 0.029 & 0.002 & 0.092 & 0.006 & 0.007 & 0.003 \\
\hline $\mathrm{LS}$ & 26 & 0.000 & 0.004 & 0.030 & 0.005 & 0.001 & 0.001 & 0.002 & 0.007 & 0.001 & 0.001 & 0.001 \\
\hline LS & 27 & 0.001 & 0.000 & 0.000 & 0.006 & 0.000 & 0.000 & 0.000 & 0.000 & 0.000 & 0.000 & 0.000 \\
\hline LS & 28 & 0.000 & 0.000 & 0.000 & 0.000 & 0.000 & 0.000 & 0.000 & 0.000 & 0.000 & 0.000 & 0.000 \\
\hline LS & 29 & 0.000 & 0.000 & 0.000 & 0.000 & 0.000 & 0.000 & 0.000 & 0.000 & 0.000 & 0.000 & 0.000 \\
\hline LS & 30 & 0.000 & 0.000 & 0.000 & 0.000 & 0.000 & 0.000 & 0.000 & 0.000 & 0.000 & 0.000 & 0.000 \\
\hline LS & 31 & 0.000 & 0.008 & 0.000 & 0.000 & 0.001 & 0.005 & 0.000 & 0.003 & 0.054 & 0.103 & 0.001 \\
\hline
\end{tabular}


Table S3 continued

\begin{tabular}{|c|c|c|c|c|c|c|c|c|c|c|c|c|c|c|c|}
\hline Region & Pool ID & 12 & 13 & 14 & 15 & 16 & 17 & 18 & 19 & 20 & 21 & 22 & 23 & 24 & 25 \\
\hline $\mathrm{BB}$ & 1 & 0.012 & 0.060 & 0.019 & 0.034 & 0.015 & 0.008 & 0.019 & 0.024 & 0.032 & 0.018 & 0.013 & 0.021 & 0.027 & 0.039 \\
\hline BB & 2 & 0.001 & 0.048 & 0.009 & 0.022 & 0.022 & 0.007 & 0.000 & 0.013 & 0.002 & 0.011 & 0.011 & 0.018 & 0.021 & 0.028 \\
\hline BB & 3 & 0.010 & 0.021 & 0.017 & 0.025 & 0.040 & 0.008 & 0.013 & 0.014 & 0.018 & 0.022 & 0.017 & 0.010 & 0.035 & 0.016 \\
\hline BB & 4 & 0.020 & 0.062 & 0.024 & 0.038 & 0.017 & 0.009 & 0.013 & 0.029 & 0.025 & 0.026 & 0.017 & 0.019 & 0.024 & 0.053 \\
\hline BB & 5 & 0.011 & 0.063 & 0.031 & 0.042 & 0.037 & 0.033 & 0.017 & 0.018 & -0.004 & 0.016 & 0.035 & 0.029 & 0.048 & 0.035 \\
\hline BB & 6 & 0.005 & 0.039 & 0.014 & 0.043 & 0.039 & 0.012 & 0.010 & 0.006 & 0.003 & 0.006 & 0.010 & 0.010 & 0.035 & 0.017 \\
\hline BB & 7 & 0.003 & 0.039 & 0.009 & 0.036 & 0.027 & 0.008 & 0.003 & 0.013 & 0.007 & 0.009 & 0.015 & 0.010 & 0.032 & 0.023 \\
\hline BB & 8 & 0.002 & 0.042 & 0.011 & 0.045 & 0.043 & 0.015 & 0.006 & 0.017 & 0.008 & 0.016 & 0.016 & 0.007 & 0.033 & 0.013 \\
\hline $\mathrm{BB}$ & 9 & 0.002 & 0.054 & 0.010 & 0.023 & 0.018 & 0.012 & 0.005 & 0.012 & 0.003 & 0.006 & 0.010 & 0.012 & 0.020 & 0.021 \\
\hline BB & 10 & 0.002 & 0.043 & 0.004 & 0.027 & 0.023 & 0.013 & 0.012 & 0.024 & 0.024 & 0.013 & 0.015 & 0.010 & 0.027 & 0.028 \\
\hline BB & 11 & 0.005 & 0.039 & 0.015 & 0.045 & 0.043 & 0.024 & 0.008 & 0.017 & 0.005 & 0.002 & 0.019 & 0.019 & 0.032 & 0.022 \\
\hline LN & 12 & 0.000 & 0.043 & -0.003 & 0.026 & 0.030 & 0.009 & -0.002 & 0.015 & 0.002 & 0.004 & 0.012 & 0.003 & 0.011 & 0.013 \\
\hline LN & 13 & 0.015 & 0.000 & 0.055 & 0.074 & 0.105 & 0.044 & 0.050 & 0.027 & 0.044 & 0.046 & 0.034 & 0.041 & 0.062 & 0.038 \\
\hline LN & 14 & 0.600 & 0.000 & 0.000 & 0.015 & 0.013 & 0.011 & -0.002 & 0.016 & 0.010 & 0.009 & 0.011 & 0.009 & 0.019 & 0.017 \\
\hline $\mathrm{LN}$ & 15 & 0.016 & 0.001 & 0.060 & 0.000 & 0.013 & 0.022 & 0.026 & 0.041 & 0.040 & 0.043 & 0.039 & 0.037 & 0.022 & 0.061 \\
\hline LN & 16 & 0.056 & 0.000 & 0.250 & 0.113 & 0.000 & 0.019 & 0.020 & 0.036 & 0.035 & 0.028 & 0.024 & 0.028 & 0.031 & 0.055 \\
\hline LN & 17 & 0.112 & 0.000 & 0.002 & 0.000 & 0.002 & 0.000 & 0.015 & 0.021 & 0.017 & 0.019 & 0.010 & 0.013 & 0.031 & 0.031 \\
\hline LN & 18 & 0.416 & 0.000 & 0.485 & 0.001 & 0.086 & 0.000 & 0.000 & 0.011 & 0.000 & 0.013 & 0.009 & 0.012 & 0.014 & 0.022 \\
\hline LN & 19 & 0.005 & 0.001 & 0.005 & 0.000 & 0.001 & 0.000 & 0.002 & 0.000 & 0.007 & 0.014 & 0.011 & 0.017 & 0.029 & 0.020 \\
\hline $\mathrm{LN}$ & 20 & 0.748 & 0.000 & 0.276 & 0.000 & 0.049 & 0.014 & 0.395 & 0.004 & 0.000 & 0.011 & 0.011 & 0.012 & 0.035 & 0.016 \\
\hline LN & 21 & 0.078 & 0.000 & 0.047 & 0.000 & 0.016 & 0.000 & 0.004 & 0.000 & 0.012 & 0.000 & 0.006 & 0.010 & 0.025 & 0.021 \\
\hline LN & 22 & 0.018 & 0.008 & 0.009 & 0.000 & 0.023 & 0.000 & 0.022 & 0.001 & 0.038 & 0.039 & 0.000 & 0.011 & 0.020 & 0.014 \\
\hline LN & 23 & 0.507 & 0.000 & 0.019 & 0.001 & 0.000 & 0.000 & 0.006 & 0.000 & 0.013 & 0.002 & 0.000 & 0.000 & 0.030 & 0.009 \\
\hline LN & 24 & 0.011 & 0.000 & 0.000 & 0.011 & 0.004 & 0.000 & 0.001 & 0.000 & 0.000 & 0.000 & 0.000 & 0.000 & 0.000 & 0.058 \\
\hline LN & 25 & 0.080 & 0.010 & 0.168 & 0.000 & 0.002 & 0.000 & 0.007 & 0.001 & 0.039 & 0.022 & 0.079 & 0.008 & 0.000 & 0.000 \\
\hline LS & 26 & 0.283 & 0.000 & 0.208 & 0.026 & 0.158 & 0.000 & 0.223 & 0.000 & 0.016 & 0.002 & 0.003 & 0.008 & 0.004 & 0.001 \\
\hline LS & 27 & 0.000 & 0.000 & 0.000 & 0.000 & 0.001 & 0.000 & 0.000 & 0.000 & 0.000 & 0.000 & 0.000 & 0.000 & 0.001 & 0.000 \\
\hline LS & 28 & 0.003 & 0.000 & 0.000 & 0.000 & 0.001 & 0.000 & 0.000 & 0.000 & 0.000 & 0.000 & 0.000 & 0.000 & 0.000 & 0.000 \\
\hline LS & 29 & 0.000 & 0.000 & 0.010 & 0.000 & 0.009 & 0.000 & 0.002 & 0.000 & 0.000 & 0.000 & 0.000 & 0.000 & 0.000 & 0.007 \\
\hline LS & 30 & 0.000 & 0.000 & 0.000 & 0.000 & 0.000 & 0.000 & 0.000 & 0.000 & 0.000 & 0.000 & 0.000 & 0.000 & 0.000 & 0.000 \\
\hline LS & 31 & 0.132 & 0.000 & 0.312 & 0.001 & 0.027 & 0.000 & 0.041 & 0.001 & 0.047 & 0.000 & 0.001 & 0.000 & 0.000 & 0.004 \\
\hline
\end{tabular}


Table S3 continued

\begin{tabular}{lrrrrrrrr}
\hline Region & \multicolumn{1}{r}{ Pool ID } & 26 & 27 & 28 & 29 & 30 & 31 \\
\hline BB & 1 & 0.017 & 0.038 & $\mathbf{0 . 0 5 6}$ & $\mathbf{0 . 0 3 4}$ & $\mathbf{0 . 1 2 4}$ & $\mathbf{0 . 0 1 8}$ \\
BB & 2 & 0.012 & $\mathbf{0 . 0 4 7}$ & $\mathbf{0 . 0 3 5}$ & $\mathbf{0 . 0 3 6}$ & $\mathbf{0 . 1 1 0}$ & 0.000 \\
BB & 3 & 0.017 & $\mathbf{0 . 0 5 4}$ & $\mathbf{0 . 0 5 8}$ & $\mathbf{0 . 0 3 7}$ & $\mathbf{0 . 1 0 6}$ & 0.015 \\
BB & 4 & 0.012 & 0.046 & $\mathbf{0 . 0 5 3}$ & 0.049 & $\mathbf{0 . 1 2 1}$ & 0.027 \\
BB & 5 & 0.032 & $\mathbf{0 . 0 9 3}$ & $\mathbf{0 . 0 6 3}$ & $\mathbf{0 . 0 6 3}$ & $\mathbf{0 . 1 1 0}$ & 0.018 \\
BB & 6 & 0.026 & 0.064 & $\mathbf{0 . 0 5 5}$ & $\mathbf{0 . 0 4 3}$ & $\mathbf{0 . 0 7 3}$ & 0.015 \\
BB & 7 & 0.013 & $\mathbf{0 . 0 5 8}$ & $\mathbf{0 . 0 4 8}$ & $\mathbf{0 . 0 3 2}$ & $\mathbf{0 . 0 9 1}$ & 0.015 \\
BB & 8 & 0.016 & $\mathbf{0 . 0 5 4}$ & $\mathbf{0 . 0 4 6}$ & $\mathbf{0 . 0 3 4}$ & 0.064 & 0.013 \\
BB & 9 & 0.014 & $\mathbf{0 . 0 6 9}$ & $\mathbf{0 . 0 4 0}$ & $\mathbf{0 . 0 3 5}$ & $\mathbf{0 . 0 9 9}$ & 0.002 \\
BB & 10 & 0.012 & $\mathbf{0 . 0 5 3}$ & $\mathbf{0 . 0 3 8}$ & 0.019 & $\mathbf{0 . 1 2 8}$ & 0.001 \\
BB & 11 & 0.025 & $\mathbf{0 . 0 6 0}$ & $\mathbf{0 . 0 5 3}$ & $\mathbf{0 . 0 4 0}$ & $\mathbf{0 . 0 9 2}$ & 0.014 \\
LN & 12 & 0.006 & 0.064 & 0.031 & 0.025 & $\mathbf{0 . 0 8 2}$ & -0.003 \\
LN & 13 & $\mathbf{0 . 0 6 8}$ & $\mathbf{0 . 0 6 7}$ & $\mathbf{0 . 1 1 3}$ & $\mathbf{0 . 0 8 2}$ & $\mathbf{0 . 1 0 4}$ & 0.056 \\
LN & 14 & 0.000 & 0.062 & $\mathbf{0 . 0 3 8}$ & 0.013 & $\mathbf{0 . 1 0 5}$ & -0.006 \\
LN & 15 & 0.011 & 0.085 & $\mathbf{0 . 0 7 8}$ & $\mathbf{0 . 0 4 6}$ & $\mathbf{0 . 1 6 4}$ & 0.018 \\
LN & 16 & -0.002 & 0.075 & 0.048 & 0.024 & $\mathbf{0 . 1 7 1}$ & 0.018 \\
LN & 17 & $\mathbf{0 . 0 1 4}$ & $\mathbf{0 . 0 6 4}$ & $\mathbf{0 . 0 5 4}$ & $\mathbf{0 . 0 3 1}$ & $\mathbf{0 . 1 0 7}$ & $\mathbf{0 . 0 1 9}$ \\
LN & 18 & 0.002 & 0.049 & $\mathbf{0 . 0 3 7}$ & 0.018 & $\mathbf{0 . 1 0 5}$ & -0.002 \\
LN & 19 & $\mathbf{0 . 0 2 7}$ & $\mathbf{0 . 0 6 0}$ & $\mathbf{0 . 0 7 1}$ & $\mathbf{0 . 0 4 3}$ & $\mathbf{0 . 0 7 8}$ & 0.016 \\
LN & 20 & 0.021 & $\mathbf{0 . 0 7 8}$ & $\mathbf{0 . 0 5 6}$ & $\mathbf{0 . 0 4 1}$ & $\mathbf{0 . 0 8 6}$ & 0.006 \\
LN & 21 & 0.014 & $\mathbf{0 . 0 7 0}$ & $\mathbf{0 . 0 5 4}$ & $\mathbf{0 . 0 2 7}$ & $\mathbf{0 . 0 9 0}$ & $\mathbf{0 . 0 1 7}$ \\
LN & 22 & 0.015 & 0.057 & $\mathbf{0 . 0 6 6}$ & 0.026 & $\mathbf{0 . 1 0 2}$ & 0.017 \\
LN & 23 & 0.007 & $\mathbf{0 . 0 7 5}$ & $\mathbf{0 . 0 5 1}$ & $\mathbf{0 . 0 2 3}$ & $\mathbf{0 . 1 0 2}$ & $\mathbf{0 . 0 1 7}$ \\
LN & 24 & 0.013 & 0.040 & $\mathbf{0 . 0 4 6}$ & $\mathbf{0 . 0 2 9}$ & $\mathbf{0 . 1 1 8}$ & 0.018 \\
LN & 25 & 0.039 & $\mathbf{0 . 0 9 3}$ & $\mathbf{0 . 0 7 5}$ & 0.032 & 0.071 & 0.022 \\
LS & 26 & 0.000 & $\mathbf{0 . 0 5 4}$ & 0.036 & 0.012 & $\mathbf{0 . 1 3 2}$ & 0.009 \\
LS & 27 & $\mathbf{0 . 0 0 0}$ & 0.000 & $\mathbf{0 . 0 7 4}$ & $\mathbf{0 . 0 8 6}$ & $\mathbf{0 . 1 6 5}$ & $\mathbf{0 . 0 5 8}$ \\
LS & 28 & 0.000 & $\mathbf{0 . 0 0 0}$ & 0.000 & 0.060 & $\mathbf{0 . 1 6 7}$ & $\mathbf{0 . 0 3 3}$ \\
LS & 29 & 0.001 & $\mathbf{0 . 0 0 0}$ & $\mathbf{0 . 0 0 0}$ & 0.000 & $\mathbf{0 . 1 6 1}$ & 0.017 \\
LS & 30 & $\mathbf{0 . 0 0 0}$ & $\mathbf{0 . 0 0 0}$ & $\mathbf{0 . 0 0 0}$ & $\mathbf{0 . 0 0 0}$ & 0.000 & $\mathbf{0 . 1 1 5}$ \\
LS & 31 & 0.002 & $\mathbf{0 . 0 0 0}$ & $\mathbf{0 . 0 0 0}$ & 0.007 & $\mathbf{0 . 0 0 0}$ & 0.000 \\
\hline & & & & & & & \\
\hline
\end{tabular}


Table S4. Summary statistics of effective number of breeders $\left(\mathrm{N}_{\mathrm{b}}\right)$, relatedness $\left(\bar{r}_{\mathrm{QG}}\right)$, expected heterozygosity $\left(\mathrm{H}_{\mathrm{E}}\right)$, and allelic richness $\left(\mathrm{A}_{\mathrm{R}}\right)$ for spotted salamanders (Ambystoma maculatum) separated by region: Barton Bench (BB), Lambert North (LN), and Lambert South (LS)

\begin{tabular}{lrrlrlcccccccc}
\hline Region & \multicolumn{4}{c}{} & \multicolumn{3}{c}{$\mathrm{N}_{\mathrm{b}}$} & \multicolumn{3}{c}{$\mathrm{H}_{\mathrm{E}}$} & \multicolumn{3}{c}{$\mathrm{A}_{\mathrm{R}}$} \\
\hline & Min & Max & Mean \pm SE & Min & Max & Mean \pm SE & Min & Max & Mean \pm SE & Min & Max & Mean \pm SE \\
BB & 13 & 90 & $28.45 \pm 6.34$ & 0.01 & 0.10 & $0.04 \pm 0.01$ & 0.76 & 0.81 & $0.79 \pm 0.00$ & 5.59 & 6.95 & $6.51 \pm 0.12$ \\
LN & 7 & 26 & $18.86 \pm 1.68$ & 0.00 & 0.14 & $0.05 \pm 0.01$ & 0.77 & 0.83 & $0.80 \pm 0.01$ & 5.8 & 7.39 & $6.63 \pm 0.12$ \\
LS & 4 & 18 & $12.00 \pm 2.02$ & 0.04 & 0.49 & $0.15 \pm 0.07$ & 0.64 & 0.8 & $0.77 \pm 0.03$ & 3 & 6.73 & $5.89 \pm 0.58$ \\
\hline
\end{tabular}


Table S5. Pool level values of effective number of breeders $\left(\mathrm{N}_{\mathrm{b}}\right)$, relatedness, expected heterozygosity $\left(\mathrm{H}_{\mathrm{E}}\right)$, and allelic richness $\left(\mathrm{A}_{\mathrm{R}}\right)$ for spotted salamanders (Ambystoma maculatum) with region indicated as Barton Bench (BB), Lambert North (LN), and Lambert South (LS)

\begin{tabular}{|c|c|c|c|c|c|}
\hline Region & $\begin{array}{l}\text { Pool } \\
\text { ID }\end{array}$ & $\mathrm{N}_{\mathrm{b}}$ & Relatedness & $\mathrm{H}_{\mathrm{E}}$ & $A_{R}$ \\
\hline BB & 1 & 90 & 0.07 & 0.78 & 6.73 \\
\hline BB & 2 & 26 & 0.03 & 0.79 & 6.53 \\
\hline BB & 3 & 27 & 0.07 & 0.77 & 6.57 \\
\hline BB & 4 & 13 & 0.07 & 0.77 & 5.89 \\
\hline BB & 5 & 16 & 0.10 & 0.76 & 5.59 \\
\hline BB & 6 & 20 & 0.05 & 0.79 & 6.57 \\
\hline BB & 7 & 31 & 0.01 & 0.81 & 6.76 \\
\hline BB & 8 & 24 & 0.03 & 0.80 & 6.78 \\
\hline BB & 9 & 20 & 0.03 & 0.80 & 6.64 \\
\hline BB & 10 & 22 & 0.02 & 0.79 & 6.95 \\
\hline BB & 11 & 24 & 0.01 & 0.81 & 6.61 \\
\hline LN & 12 & 17 & 0.02 & 0.82 & 6.90 \\
\hline LN & 13 & 7 & 0.14 & 0.77 & 6.27 \\
\hline LN & 14 & 16 & 0.00 & 0.83 & 7.39 \\
\hline LN & 15 & 9 & 0.12 & 0.77 & 5.80 \\
\hline LN & 16 & 16 & 0.05 & 0.78 & 7.01 \\
\hline LN & 17 & 23 & 0.01 & 0.81 & 6.97 \\
\hline LN & 18 & 26 & 0.02 & 0.80 & 6.66 \\
\hline LN & 19 & 26 & 0.06 & 0.78 & 6.21 \\
\hline LN & 20 & 22 & 0.03 & 0.79 & 6.63 \\
\hline LN & 21 & 26 & 0.01 & 0.82 & 7.14 \\
\hline LN & 22 & 19 & 0.03 & 0.80 & 6.87 \\
\hline LN & 23 & 23 & 0.05 & 0.78 & 6.33 \\
\hline LN & 24 & 22 & 0.02 & 0.82 & 6.16 \\
\hline LN & 25 & 12 & 0.13 & 0.77 & 6.48 \\
\hline LS & 26 & 18 & 0.06 & 0.80 & 6.64 \\
\hline LS & 27 & 11 & 0.17 & 0.76 & 6.20 \\
\hline LS & 28 & 13 & 0.08 & 0.80 & 6.35 \\
\hline LS & 29 & 16 & 0.06 & 0.80 & 6.73 \\
\hline LS & 30 & 4 & 0.49 & 0.64 & 3.00 \\
\hline LS & 31 & 10 & 0.04 & 0.80 & 6.43 \\
\hline
\end{tabular}




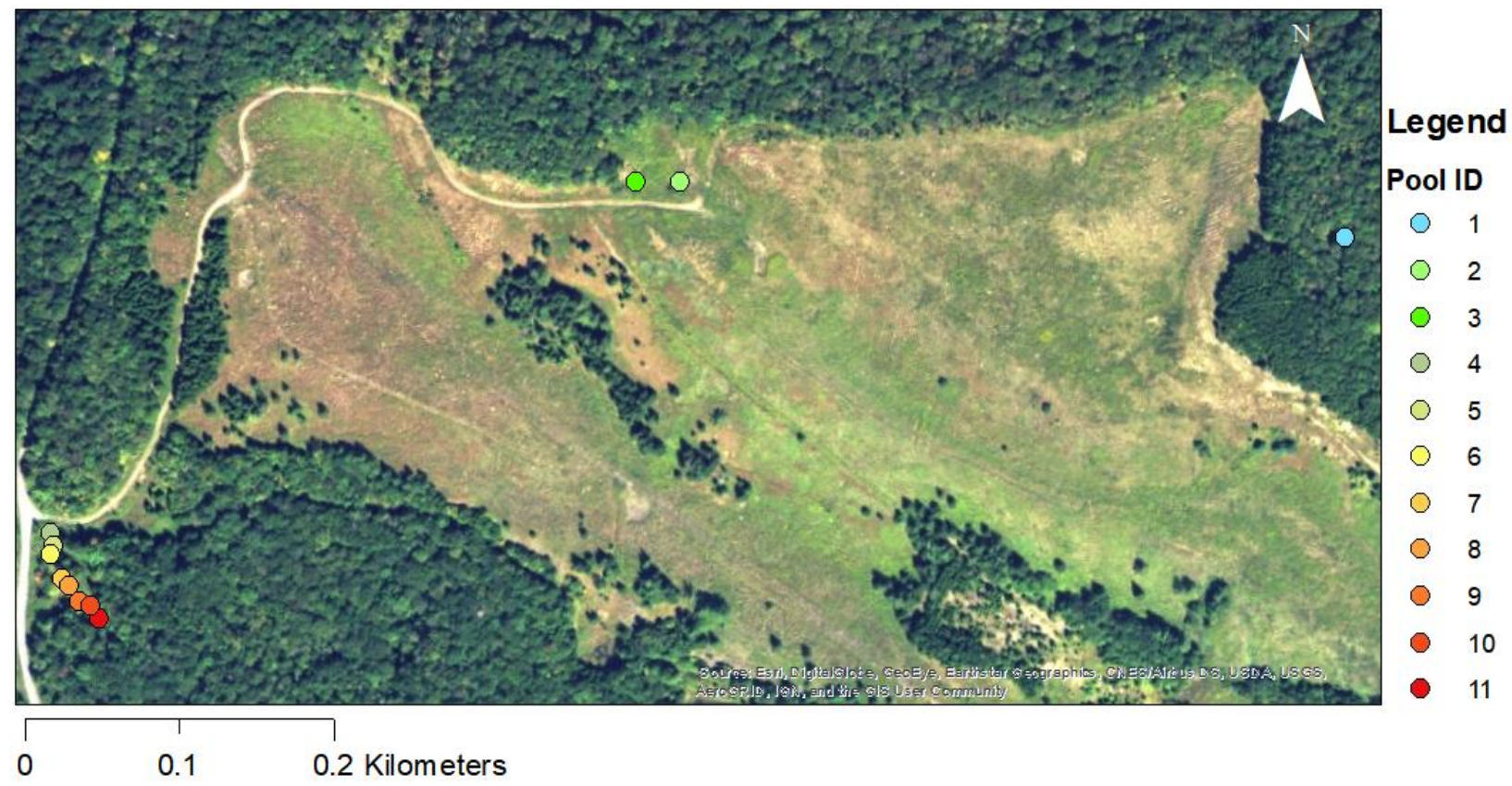

Figure S1. Map displaying the Barton Bench study region. Circles represent sampled created vernal pool locations designated by individual pool ID. World imagery source: Esri, DigitalGlobe, GeoEye, Earthstar Geographics, CNES/Airbus DS, USDA, USGS, AeroGRID, IGN, and the GIS User Community 


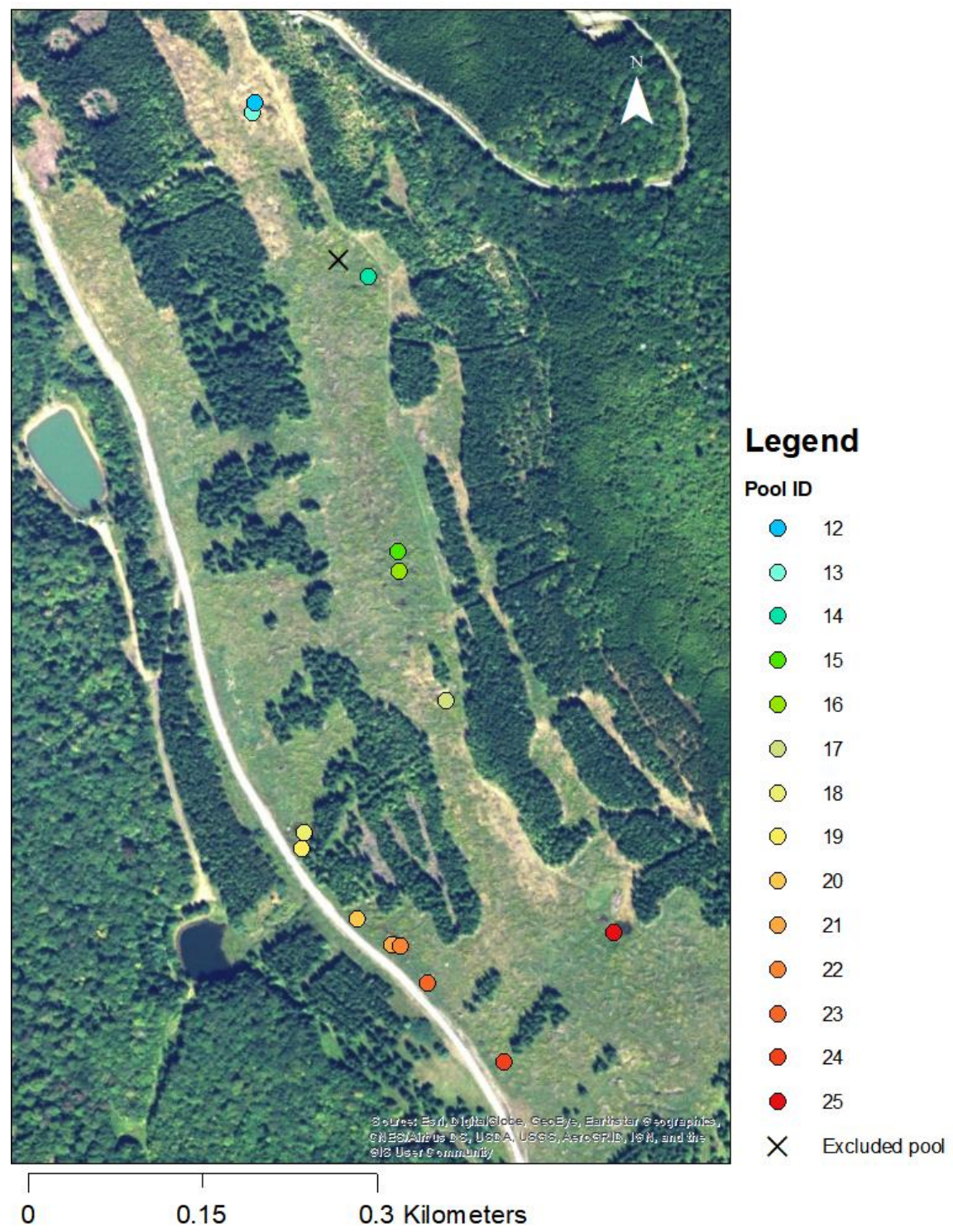

Figure S2. Map displaying the Lambert North study region. Circles represent sampled created vernal pool locations designated by individual pool ID. World imagery source: Esri, DigitalGlobe, GeoEye, Earthstar Geographics, CNES/Airbus DS, USDA, USGS, AeroGRID, IGN, and the GIS User Community 


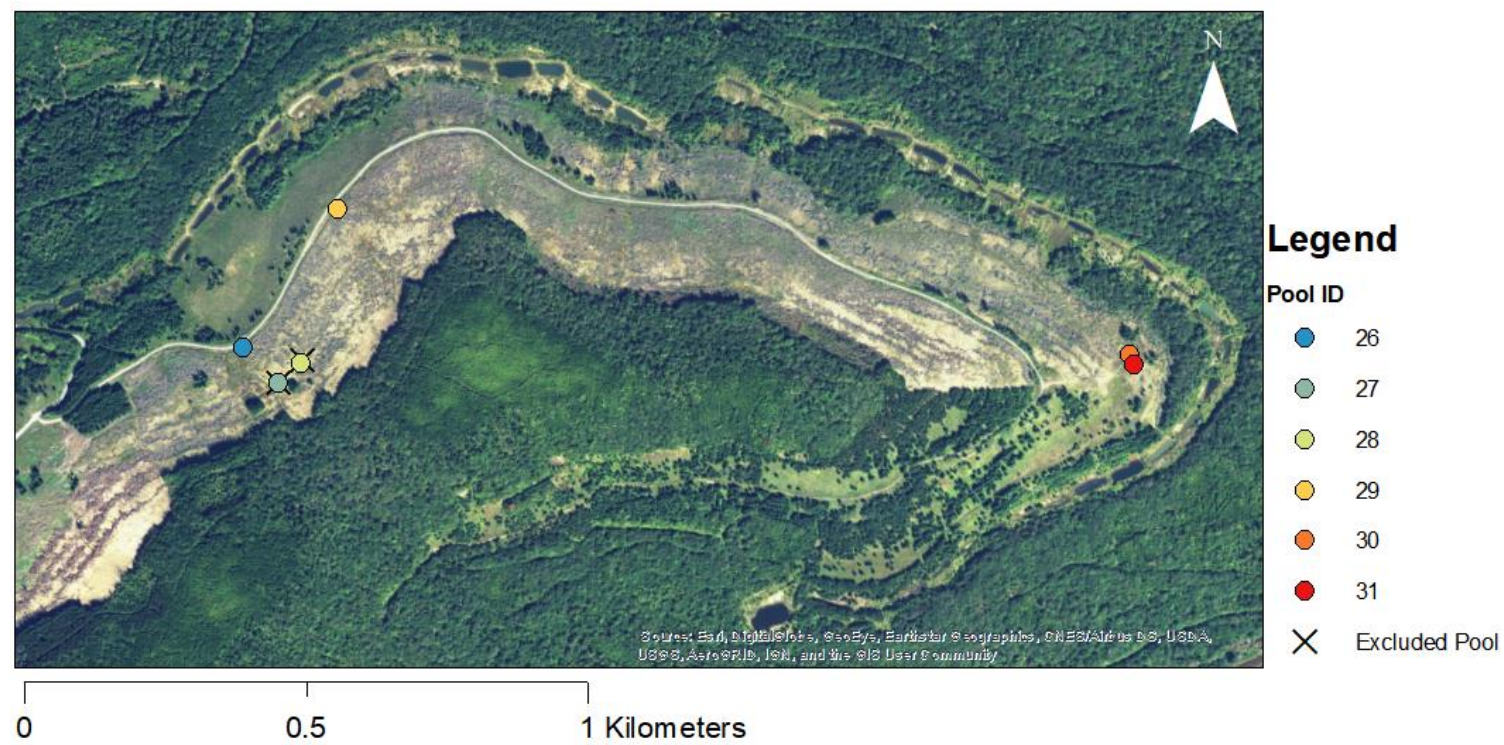

Figure S3. Map displaying the Lambert South study region. Circles represent sampled created vernal pool locations designated by individual pool ID. World imagery source: Esri, DigitalGlobe, GeoEye, Earthstar Geographics, CNES/Airbus DS, USDA, USGS, AeroGRID, IGN, and the GIS User Community 


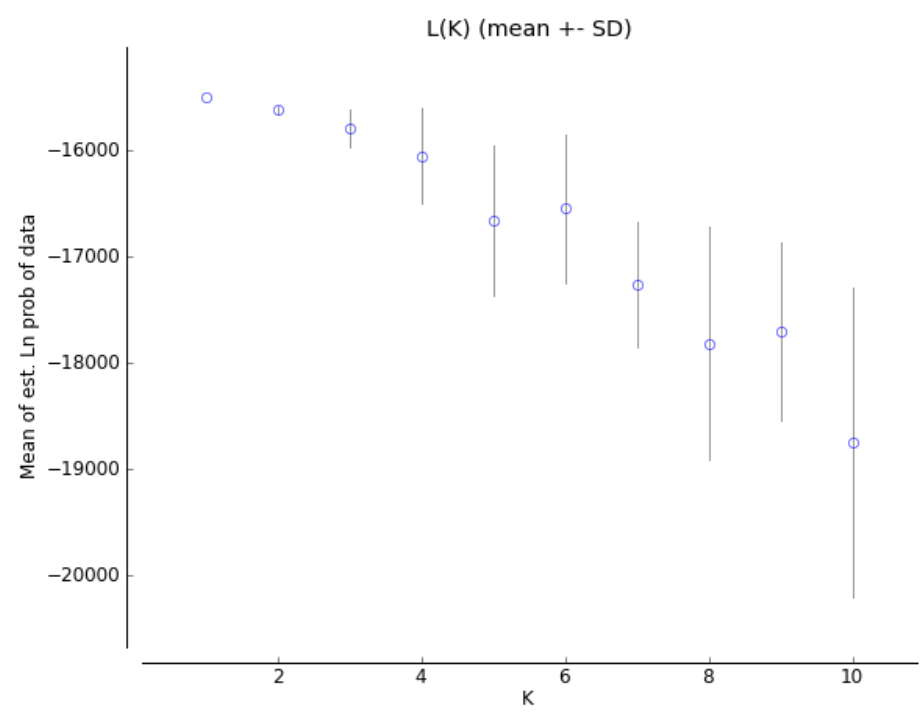

Figure S4. Plot of most likely number of spotted salamander (Ambystoma maculatum) populations (K) across the entire study area (encompassing all three regions together) by the mean of estimated ln probability of the data. Analysis included all regions grouped together using 5 microsatellite loci run on STRUCTURE with graph produced by STRUCTURE HARVESTER 

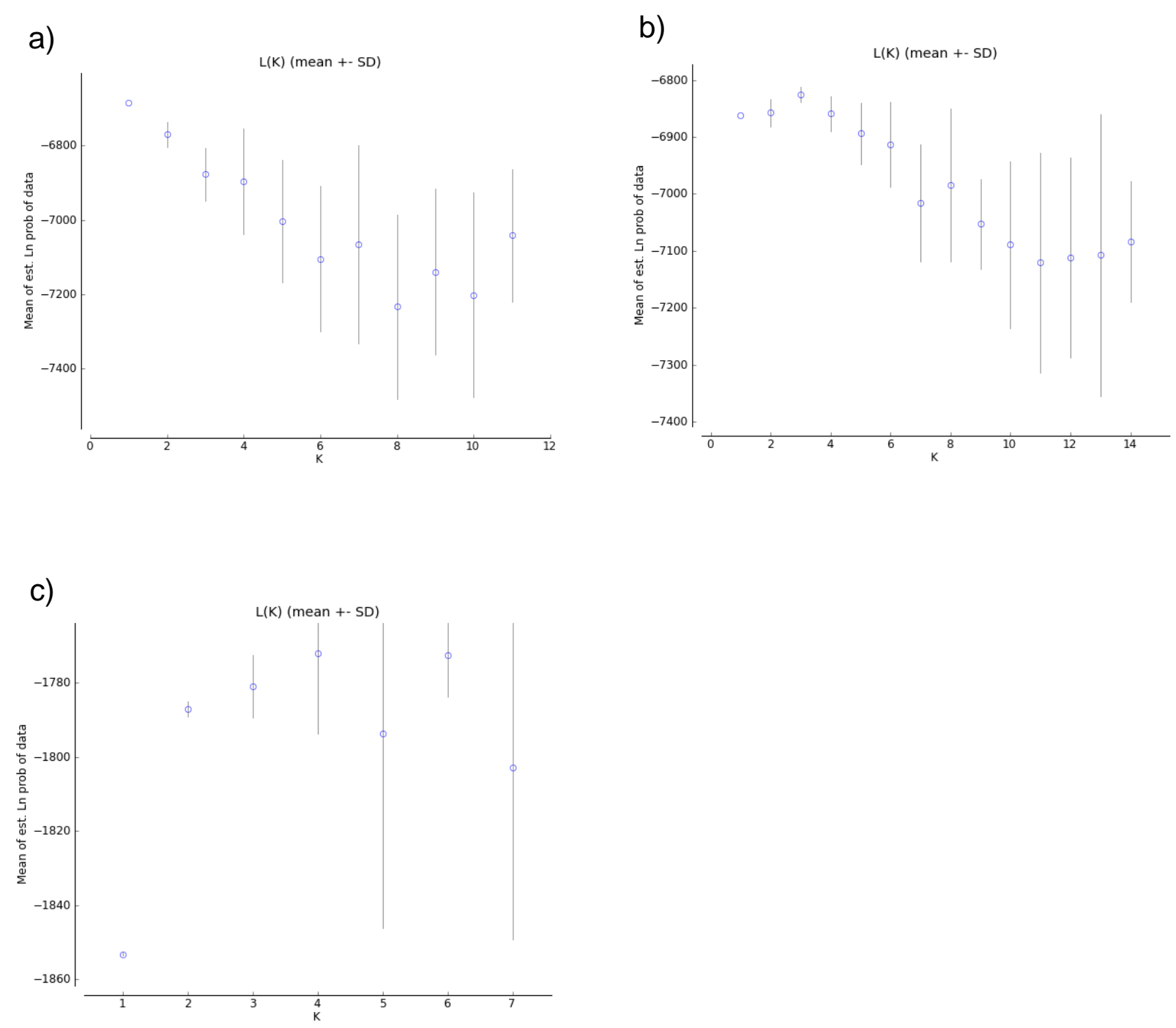

Figure S5. Plot of most likely number of spotted salamander (Ambystoma maculatum) populations (K) by the mean of estimated Ln probability of the data for regions (a) Barton Bench (b) Lambert North and (c) Lambert South. Analysis included 5 microsatellite loci run on STRUCTURE with graph produced by STRUCTURE HARVESTER 


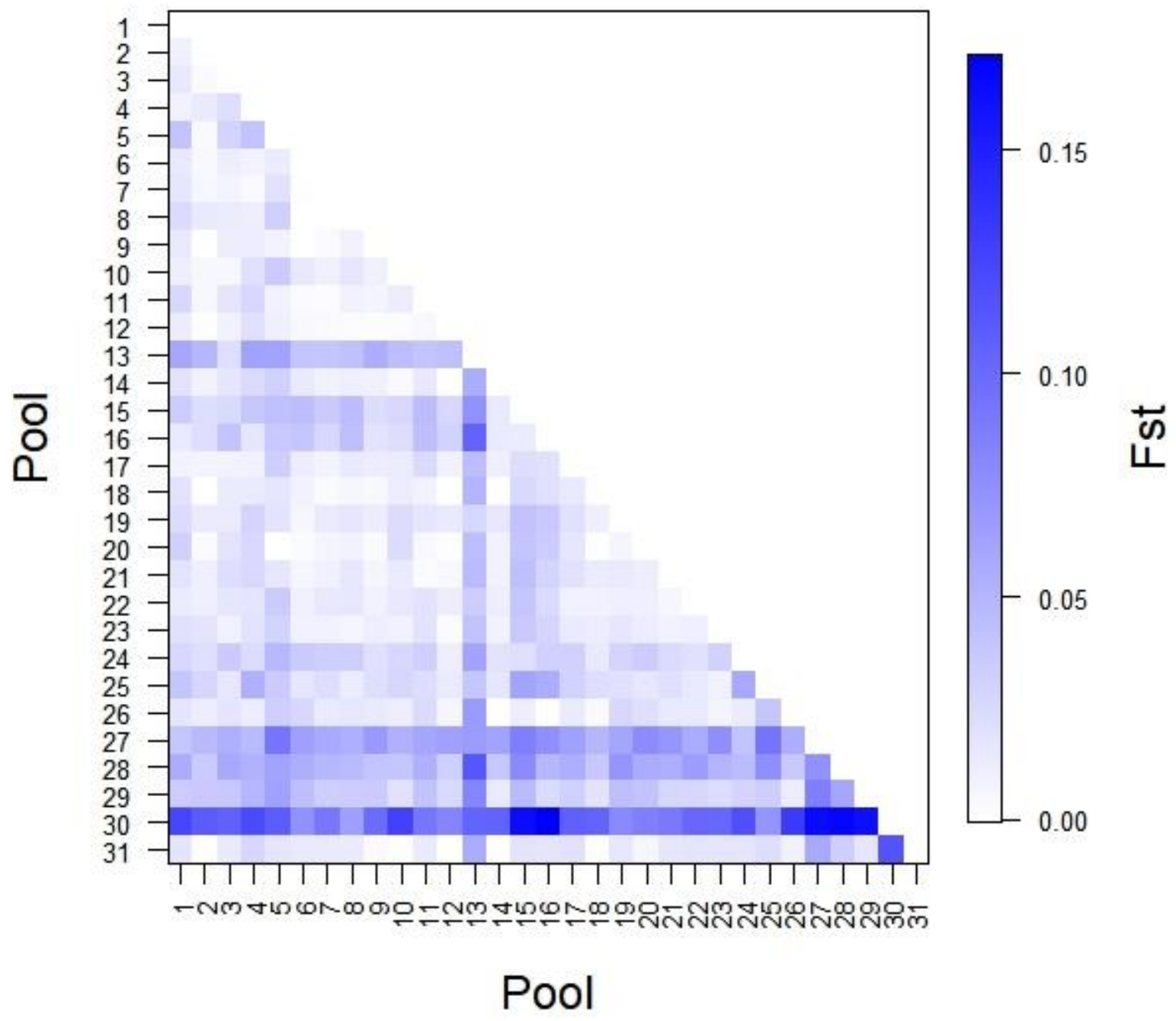

Figure S6. Matrix of $\mathrm{F}_{\mathrm{ST}}$ values between pools. Darker color indicates higher genetic differentiation between pools. Pool ID listed by region: Barton Bench 1-11, Lambert North 1225, and Lambert South 26-31 

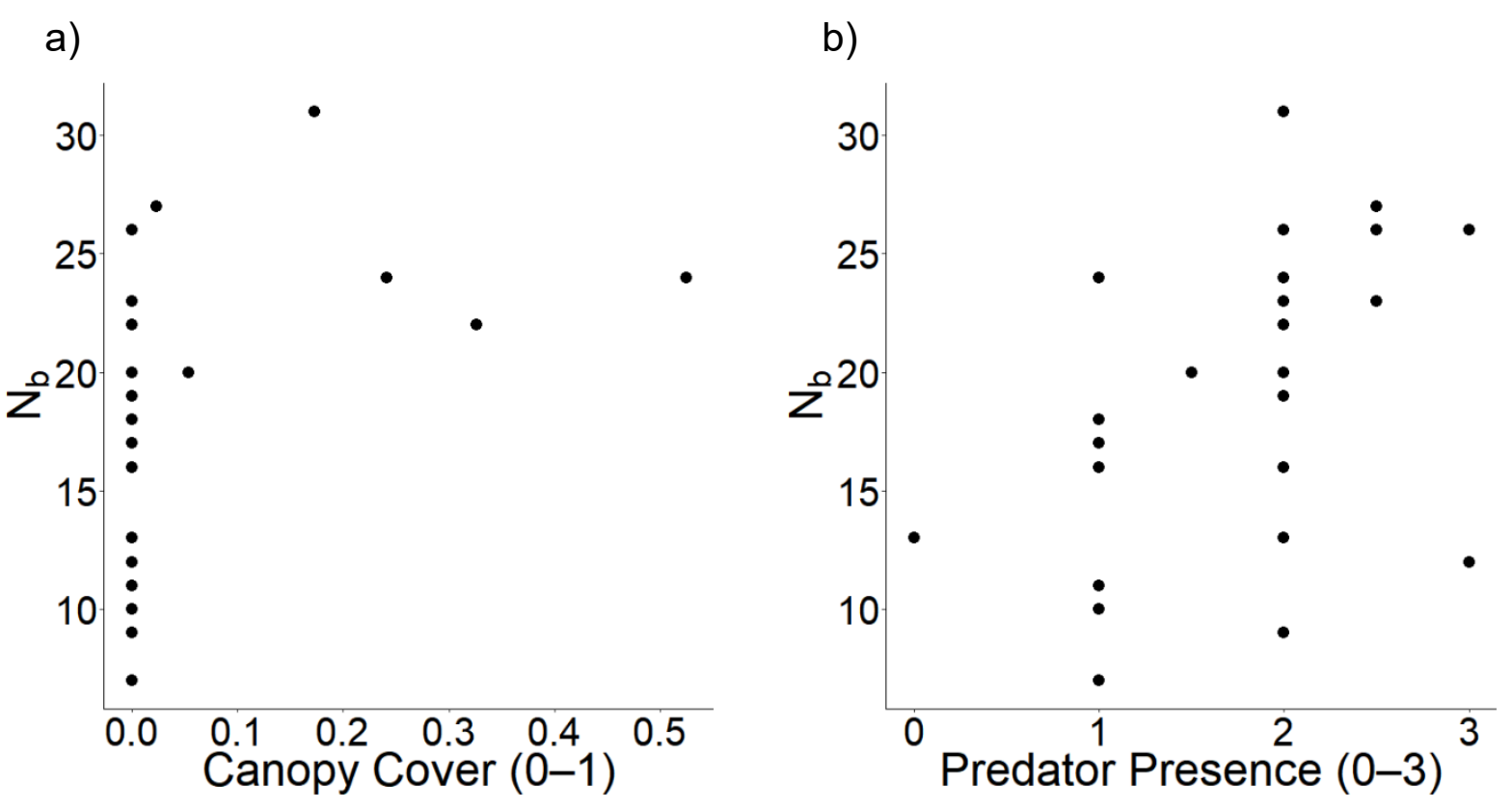

Figure S7. Biplots displaying relationship between $\mathrm{N}_{\mathrm{b}}$ and predictors from significant models including (a) canopy cover and (b) predator presence (predator group presence rating from 0-3 based on eastern newts, diving beetle larvae, and dragonfly larvae). Some values of predator presence are in-between the set values due to combining samples across two years of sampling 
a)

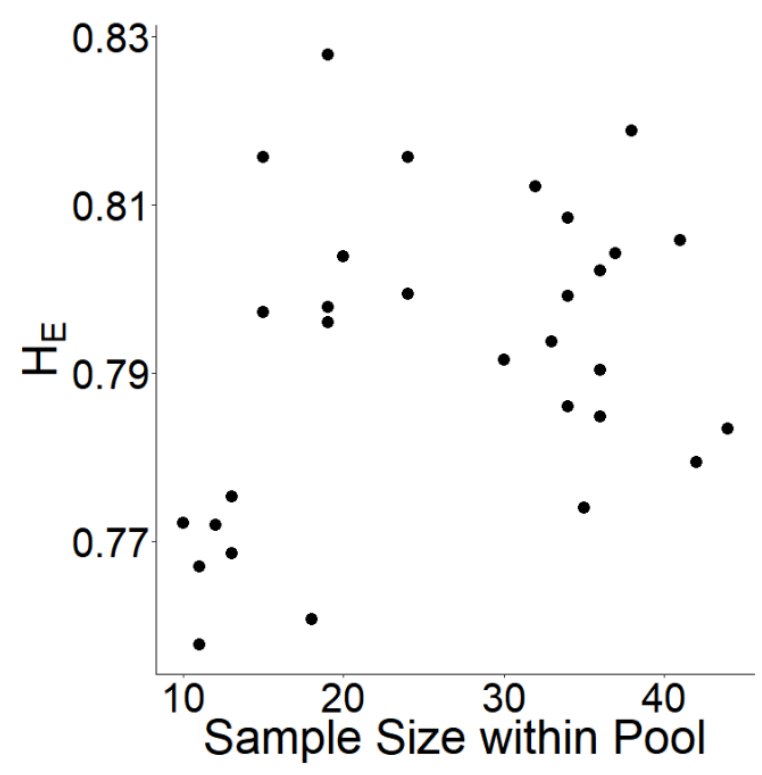

b)

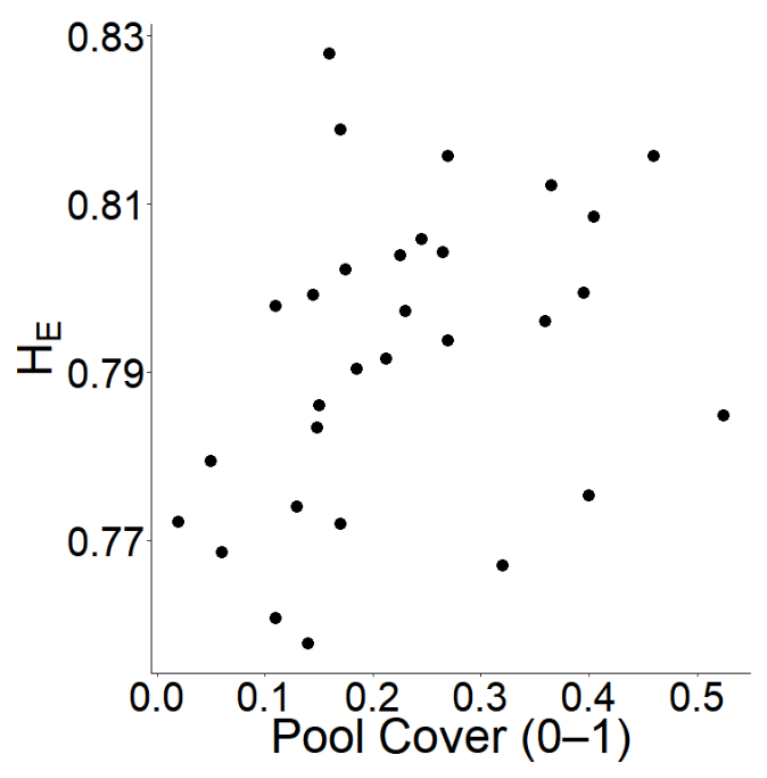

Figure S8. Biplots displaying relationship between $\mathrm{H}_{\mathrm{E}}$ and predictors: (a) sample size within the pool and (b) pool cover (which includes any form of refuge within the pool such as vegetation, rocks, and coarse woody debris) 


\section{Chapter 5}

\section{Prevalence of Ranavirus in Spotted Salamander Larvae from Created Vernal Pools in West Virginia, USA}

Alice R. Millikin ${ }^{\mathrm{a} \text {, }}$, Drew R. Davis ${ }^{\mathrm{b}}$, Donald J. Brown ${ }^{\mathrm{a}, \mathrm{c}}$, Sarah Woodley ${ }^{\mathrm{d}}$, Stephanie Coster ${ }^{\mathrm{e}}$, Amy Welsh ${ }^{\mathrm{a}}$, Jacob L. Kerby ${ }^{\mathrm{f}}$, James T. Anderson ${ }^{\mathrm{a}}$

${ }^{a}$ School of Natural Resources, West Virginia University, PO Box 6125, Morgantown, WV

26506, USA; e-mail: donald.brown1@ mail.wvu.edu, amy.welsh@mail.wvu.edu, jim.anderson@mail.wvu.edu

${ }^{\mathrm{b} S c h o o l ~ o f ~ E a r t h, ~ E n v i r o n m e n t a l, ~ a n d ~ M a r i n e ~ S c i e n c e s, ~ U n i v e r s i t y ~ o f ~ T e x a s ~ R i o ~ G r a n d e ~ V a l l e y, ~}$ 100 Marine Lab Drive, South Padre Island, TX 78597, USA; e-mail: drew.davis@utrgv.edu 'U.S.D.A. Forest Service, Northern Research Station, PO Box 404, Parsons, WV 26287, USA

${ }^{\mathrm{d} D e p a r t m e n t ~ o f ~ B i o l o g i c a l ~ S c i e n c e s, ~ D u q u e s n e ~ U n i v e r s i t y, ~} 600$ Forbes Avenue, Pittsburgh, PA 15282, USA; e-mail: woodleys@duq.edu

'Department of Biology, Randolph-Macon College, 114 College Avenue, Ashland VA 23005, USA; e-mail: stephaniecoster@rmc.edu

fDepartment of Biology, University of South Dakota, 414 E Clark St, Vermillion, South Dakota 57069, USA; e-mail: jacob.kerby@usd.edu

*Corresponding author e-mail: alicemillikin@gmail.com 


\begin{abstract}
Ranavirus is a disease of concern for amphibians due to its potential to cause mass-mortality events, spread in a population through sublethal infections, and transmit across species. Vernal pool breeding amphibians can have greater susceptibility to ranavirus potentially related to the rapid development of larvae. Additionally, these unique habitats are subject to loss and degradation that has resulted in mitigation efforts creating new pools. Determining how to reduce the risk of disease exposure and spread, and how disease influences the population and individual animal could inform habitat creation, management, and monitoring strategies. We investigated whether spotted salamander ranavirus prevalence and viral load were associated with habitat characteristics, genetic diversity, corticosterone levels, and body size. Across May and June of 2015 and 2016, we sampled 34 vernal pools created 1-5 years earlier in Monongahela National Forest, WV, USA. We collected tail clips from 1,128 spotted salamander larvae and water-borne hormone samples from 436 of those larvae along with environmental data (pool age, water temperature, water $\mathrm{pH}$, predator presence, pool depth, pool diameter, refuge within the pool and vegetative cover). Over the two sample years, we detected ranavirus in $62 \%$ of pools. Prevalence at pools ranged from $0-63 \%$, averaging $7.68 \pm 0.02 \%$. Salamanders infected with ranavirus had greater total length, which was also positively correlated with viral load. We did not find associations between ranavirus prevalence or viral load and habitat characteristics, salamander genetic diversity, relatedness, effective number of breeders, or corticosterone levels. We found infected larvae in over half the pools sampled, but with generally low prevalence rates. The widespread occurrence of ranavirus illustrates the risk of disease exposure, even in newly created habitat. The correlation between ranavirus and salamander total length could reflect differences in susceptibility through developmental stages or increased risk
\end{abstract}


of exposure over time. To determine the risks and impact of ranavirus, it is critical to document occurrence and prevalence of the disease to establish distribution and determine risk of the disease spreading. This is especially relevant for determining where to create new vernal pools meant to mitigate habitat loss.

Keywords: Disease, Wetlands, Amphibian, Restoration, Pathogen 


\section{INTRODUCTION}

Ranaviruses are DNA viruses in the family Iridoviridae that can cause infections leading to hemorrhaging and necrosis of multiple organs, resulting in die-offs of amphibian populations (Chinchar 2002; Gray et al. 2009). Green et al. (2002) attributed most amphibian die-offs reported in the United States from 1996-2001 to ranaviruses. Ranavirus is considered an emerging infectious disease due to increasing detections across an expanding distribution and due to the resulting mass die-offs and population declines, making it a pathogen of concern for the conservation of amphibians (Earl and Gray 2014; Price et al. 2014; Duffus et al. 2015). Reptiles and fish are also susceptible to ranaviruses and can act as reservoirs for the pathogen, capable of transmitting it to amphibians (Brenes et al. 2014a, b). The disease can be transmitted to uninfected individuals by physical contact, through shared water or soil, and consumption of infected tissue during predation, necrophagy, and cannibalism (Harp and Petranka 2006; Gray et al. 2009; Robert et al. 2011).

Susceptibility to ranaviruses varies greatly among amphibian species, with higher susceptibility associated with those species inhabiting semi-permanent pools and larvae with rapid development (Hoverman et al. 2011). Amphibians like wood frogs (Rana sylvatica) and spotted salamanders (Ambystoma maculatum) rely on the ephemerally flooded wetlands, vernal pools, for fishless breeding habitat for larvae that typically complete metamorphosis after 2-4 months. Wood frogs and spotted salamanders have high and intermediate susceptibility to ranaviruses, respectively (Hoverman et al. 2011), with die-offs previously documented for both species (Green et al. 2002; Docherty et al. 2003).

In addition to risk of infection from ranaviruses, habitat degradation and destruction also threaten many vernal pool breeding amphibians. Major threats to vernal pools stem from 
difficulties in detecting vernal pools in forested areas and limited protection for smaller pools $(<$ 0.04 ha) that lack surface water connections to rivers (DiBello et al. 2016). This has resulted in conservation efforts to create new vernal pool habitat to mitigate habitat loss. Successful habitat creation should attract vernal pool breeding amphibians and provide suitable habitat to sustain populations.

One important factor for producing ideal habitat conditions for amphibians is reducing the risk of spreading disease. In North Carolina, ranavirus outbreaks and drought reduced larval survival of spotted salamanders and wood frogs in created and natural pools (Petranka et al. 2003). Ranavirus mortality rates of amphibians can be influenced by local habitat characteristics (Gahl and Calhoun 2008, 2010). Arizona tiger salamanders (Ambystoma mavortium nebulosum) in pools with less vegetative cover had higher infection rates of Ambystoma tigrinum virus (ATV), potentially due to the congregation of individuals around pool edges (Greer and Collins 2008). Ranavirus gene copy number and mortality rate of spotted salamander and wood frog larvae increase in higher water temperatures (Brand et al. 2016; Hall et al. 2018). However, the association between temperature and mortality rates is strain- and species-dependent (Rojas et al. 2005; Echaubard et al. 2014). Environmental manipulation has the potential to reduce disease risk for wild populations (Wobeser 2002; Campbell Grant et al. 2018). Determining which habitat characteristics influence host susceptibility to pathogens, pathogen occurrence and prevalence, and infection intensity would help inform management efforts to create and maintain ideal habitat (Campbell Grant et al. 2018).

In addition to habitat manipulation, monitoring genetic diversity could provide valuable insight into population susceptibility. Populations with higher genetic diversity could be more resilient to disease outbreaks (Daszak et al. 2000). Italian agile frogs (Rana latastei) with lower 
genetic diversity due to range expansion and isolation had higher mortality from ranavirus infection (Pearman and Garner 2005). Diseases like ranaviruses have the potential to cause genetic bottlenecks in populations due to mortality of entire age classes (Petranka et al. 2003; Beebee 2012). In the endangered Bob's robber frog (Craugastor punctariolus), museum specimens and extant populations were infected with the same strain of Ranavirus, and extant populations had lower genetic diversity (Puschendorf et al. 2019). This could indicate ranavirus has contributed to the decline of this species and its reduced genetic diversity.

Physiological state could influence disease mortality risk in amphibians. Susceptibility to ranaviruses can vary by developmental stage. Mortality rates due to ranavirosis are higher in wood frog metamorphs than earlier larval stages (Warne et al. 2011; Haislip et al. 2011; Hall et al. 2018). Conversely, prevalence of Frog Virus 3 decreased in American bullfrog (Rana catesbeiana) tadpoles as development progressed (Gray et al. 2007). Additionally, tiger salamander larvae and metamorphs can sustain sublethal infection, allowing the disease to persist in the population (Brunner et al. 2004; Greer et al. 2009).

The hormone, corticosterone, is another aspect of an individual's physiology that can be associated with infection. Disease can elevate the concentration of corticosterone and impact fitness of amphibian tadpoles (Warne et al. 2011; Gabor et al. 2013). Corticosterone is a glucocorticoid hormone that mobilizes resources for amphibians when additional energy is needed for growth, development, or to respond to stressors in the environment (Romero 2004; Denver 2009; Crespi et al. 2013). This hormone also helps regulate the immune system (RollinsSmith 2017). In wood frogs, tadpoles infected with ranavirus had higher corticosterone concentrations, faster development rates, and decreased body weight (Warne et al. 2011). 
Conversely, in northern leopard frog (Rana pipiens) tadpoles, sublethal infections of ranavirus reduced growth and development (Echaubard et al. 2010).

Our objectives were to survey for ranavirus in larval spotted salamanders from created vernal pools, and determine if habitat characteristics, population genetics, or individual physiology coincided with occurrence, prevalence, or viral load. We examined whether disease prevalence was related to pool age, water temperature, water $\mathrm{pH}$, pool depth, pool diameter, vegetative cover and refuge within the pool, predator presence, number of pools within $1 \mathrm{~km}$, and average distance to other pools sampled. We tested for correlations between ranavirus occurrence, prevalence, or viral load and genetic diversity, effective number of breeders, or genetic relatedness. We tested for an association between average corticosterone level and prevalence in a pool. We also compared individual corticosterone levels between larvae that were infected with ranavirus to those that were not and tested for an association with viral load. Finally, we tested whether larval body size was associated with occurrence or viral load.

\section{METHODS}

We sampled vernal pools created by the U.S. Forest Service (USFS) in Monongahela

National Forest, West Virginia, USA (Fig. 1). Vernal pools were located on Cheat Mountain near Huttonsville, West Virginia at altitudes of 1,219-1,296 m above sea level. Pools created in the same year were also located geographically proximate to each other (hereafter regions): pools at Barton Bench were created in 2011, at Lambert North in 2013, and at Lambert South in 2014 (Fig. 1). All sampled pools were within $5 \mathrm{~km}$ of each other. Vernal pool creation was based on field conditions rather than predetermined designs as part of larger restoration projects (USFS 2014). The area was strip-mined for coal in the 1970s, then acquired by the USFS in the 1980s. Initial restoration efforts began in 2009 including removal of non-native Norway spruce (Picea 
abies) and red pine (Pinus resinosa) planted during mine reclamation, ripping to mitigate soil compaction, and planting saplings including aspens (Populus spp.), red spruce (Picea rubens), black cherry (Prunus serotina), wild raisin (Viburnum nudum), elderberry (Sambucus nigra), and service berry (Amelanchier arborea; Sandeno 2011; USFS 2014). Due to recent removal of nonnative trees, most of the pools included in this study had an open canopy (Millikin et al. 2019).

\section{Field Sampling}

From May-June in 2015 and 2016, we caught spotted salamander larvae in vernal pools using dipnets and seines. We attempted to sample 46 pools: 29 both years, 13 only in 2015, and 4 only in 2016 . We successfully sampled $20.51 \pm 0.34$ (range: $14-30$ ) larvae in 34 pools: 22 pools sampled both years, 8 pools sampled only in 2015, and 4 pools sampled only in 2016 (Table 1). We removed one pool from 2015 due to detecting ranavirus in a negative control (water) resulting in: 21 pools sampled both years, 8 pools sampled in 2015, and 5 pools sampled in 2016 . In 2015, we collected tail clips from 589 salamanders from 29 pools (after dropping 27 samples from a plate with a positive negative control including one whole pool): 193 larvae from 10 pools in Barton Bench, 281 larvae from 13 pools in Lambert North, and 115 larvae from 6 pools in Lambert South. In 2016, we collected tail clips from 539 salamanders from 26 pools: 205 larvae from 10 pools in Barton Bench, 232 larvae from 11 pools in Lambert North, and 102 larvae from 5 pools in Lambert South. When we caught a salamander, we collected a tail clip (< $1 \mathrm{~cm}$ ), which was immediately submerged in $100 \%$ ethanol in a $1.5 \mathrm{~mL}$ microcentrifuge tube for storage until later DNA extraction for ranavirus screening and genetic analysis. Next, we measured salamanders for total length (to the nearest $\mathrm{mm}$ ) and released them back at the capture site after processing. To prevent cross-contamination, we sterilized all equipment with $10 \%$ bleach between pools (nets, waders) and between processing larvae (scissors, forceps). 


\section{Molecular Analysis}

We extracted DNA from tail clips of spotted salamander using Promega Wizard® SV 96 Genomic DNA Purification System kits at West Virginia University. We standardized DNA concentration in water to $15 \mathrm{ng} / \mu 1$ and shipped it frozen to the Disease Testing Center at the University of South Dakota to test for ranavirus using quantitative PCR (qPCR). To determine ranavirus prevalence and estimate the number of viral gene copies per larvae, we followed the protocol described by Forson and Storfer (2006). Each qPCR plate contained a negative control (no-template, water) and standardized dilution series of gBlocks containing the target sequence of DNA (major capsid protein) for a standard curve $\left(1 \mathrm{e}^{2}-1 \mathrm{e}^{5}\right)$. We ran $2 \mu 1$ of each sample in triplicate and considered it positive for ranavirus if two of the three replicates amplified and the quantity was above 1.0 (Whitfield et al. 2012; Davis and Kerby 2016; Watters et al. 2018; Butterfield et al. 2019). We used StepOne software v2.3 to quantify viral gene copies based on average gene copies in the three replicates per sample (Applied Biosystems, Foster City, California, USA).

\section{Habitat Variables}

Following methods outlined by Millikin et al. (2019), we recorded habitat characteristics at each pool to determine if habitat quality influenced disease prevalence. Pool diameter was based on an average of the longest distance across the pool and the perpendicular measurement. Pool depth was based on an average of three measurements along the longer transect of the pool. Using the line intercept method, we measured available cover within the pool along the two transects used for diameter (Egan and Paton 2004). We measured the beginning and end of each cover type intersecting the transects to the nearest $\mathrm{cm}$. Pool cover was considered any form of refuge within the pool including rocks, coarse woody debris, and vegetation. We also looked at a 
subset of the pool cover, the predominant vegetation: grass, sedge, cattail, and rush (GSCR). The proportion of pool cover and GSCR were each calculated as the total length of cover intersecting transects divided by the cumulative length of both transects at the pool (Egan and Paton 2004). We determined number of pools within $1 \mathrm{~km}$ of each pool in ArcMap 10.5.1 using spatial join and we calculated average distance to other pools using point distance.

Predator presence was a measure of presence/absence $(0 / 1)$ of red-spotted newts (Notophthalmus viridescens), diving beetle (Dytiscidae) larvae, and dragonfly (Odonata) larvae. This was determined by direct observation of predators in the pool or if predators were captured while sampling for salamanders. Pools were rated from 0, meaning no predators were detected, to 3, where all three taxa were observed in the pool (Millikin et al. 2019). Pool age was determined by the sample year minus the creation year. We used a PCTestr ${ }^{\mathrm{TM}} 35$ Oakton ${ }^{\circledR}$ Waterproof Multi-Parameter Testr ${ }^{\mathrm{TM}}$ to measure the water temperature and $\mathrm{pH}$.

\section{Genetic Diversity and Corticosterone}

We also tested whether available genetic and hormone (Millikin et al. 2019) data from this study system were correlated with ranavirus prevalence, viral load, or were different between larvae that were and were not infected with ranavirus. We analyzed genetic data from larvae in 22 pools in 2015 and 25 pools in 2016 (Millikin 2019). We examined whether occurrence, prevalence, or viral load were correlated with genetic expected heterozygosity, allelic richness, relatedness, and effective number of breeders (Millikin 2019). We calculated expected heterozygosity and allelic richness using FSTAT with 10,000 iterations based on minimum sample size of 10 individuals (Goudet 1995). We measured relatedness with the mean within-population pairwise values using the Queller and Goodnight (1989) estimator in GenAlEx (Peakall and Smouse 2006, 2012). We used COLONY to estimate effective number of breeders 
(Wang 2009; Wang et al. 2011; Millikin 2019). We sampled 436 of the same larvae for waterborne corticosterone levels: 181 larvae across 27 pools in 2015, 255 larvae across 26 pools in 2016 (Millikin et al. 2019). Water-borne corticosterone units account for body size by dividing by total length of the larvae and is based on corticosterone release rate per hour (pg/TL/h; Millikin et al. 2019).

\section{Statistical Analysis}

We treated pools as the sampling unit for analyses, except when looking at individual corticosterone levels and individual total length. We considered prevalence the proportion of individual larvae with positive ranavirus detection out of total number of larvae sampled at a pool. We standardized the mean quantity of ranaviruses to number of viral copies in $100 \mathrm{ng}$ of DNA by taking the average quantity detected in a sample of $2 \mu 1$ (containing $15 \mathrm{ng}$ of DNA/ $\mu \mathrm{l}$, or $30 \mathrm{ng} / 2 \mu \mathrm{l}$ sample) and multiplying it by (100/30).

All analyses were conducted in $\mathrm{R}$ ( $\mathrm{R}$ Core Team 2017). We used beta regressions to estimate relationships between environmental predictors and prevalence of ranavirus. Beta regression is an extension of linear regression that is designed for analyzing response data that are restricted to a defined interval, such as rate and proportion data (Ferrari and Cribari-Neto 2004). The models use a beta distribution, which allows for an asymmetric structure, and thus does not require rate and proportion response data to be normalized for analyses (Cribari-Neto and Zeileis 2010). We compared models predicting prevalence at each pool using Akaike's Information Criterion corrected for small sample size (AICc, package 'AICcmodavg' [Mazerolle 2017, Burnham and Anderson 2002]). Predictors included in the models were: pool age, water temperature, water $\mathrm{pH}$, predator presence, pool depth, pool diameter, pool cover, GSCR, pools within $1 \mathrm{~km}$, average distance to other pools, average salamander total length, average 
corticosterone level, expected heterozygosity, allelic richness, relatedness, and effective number of breeders.

Because our data lacked a normal distribution, we used a nonparametric Kruskal-Wallis test to compare prevalence and viral load among regions and sample years $(\alpha=0.05)$. We used non-metric multidimensional scaling (NMDS) ordination to use habitat characteristics of pools to visualize differences in pools with and without ranavirus present (package 'vegan', Oksanen et al. 2018). We used Bray-Curtis distance measurement, a random starting point, and two dimensions (Roberts 1986).

We used Kruskal-Wallis to test whether pools with and without ranavirus differed in genetic expected heterozygosity, allelic richness, relatedness, and effective number of breeders. We used Kruskal-Wallis to compare individual levels of corticosterone between larvae infected with and those without ranavirus. We used Spearman rank to test for a correlation between viral load and corticosterone level. Finally, we used Kruskal-Wallis to test for differences in total length between larvae that were and were not infected with ranavirus. We also tested for correlations between viral load and total length of larvae using Spearman rank. Total length data were missing for ten of the larvae sampled for ranavirus.

\section{RESUlts}

We detected ranavirus in 84 of 1,128 larvae (7\%) from 21 of the 34 pools $(62 \%)$. At pools sampled both years, 13 of the 21 pools $(62 \%)$ tested positive at least one year: 6 pools changed from negative to positive between years; 1 pool changed from positive to negative; 6 pools were positive both years, and prevalence at these 6 pools stayed the same or decreased between years (Table 1). We detected ranavirus at 4 of the 8 pools that were only sampled in 
$2015 ; 3$ of the pools with positive detections had 0-2 larvae in 2016. In pools sampled only in 2016, 4 of the 5 pools had positive detections.

Ranavirus prevalence across sample years averaged $<10 \%$ in all regions (Table 2).

Prevalence was higher when examining percent of pools infected compared to percent of larvae. Prevalence of all larvae in a region was $\leq 13 \%$ in 2015 and 2016. Prevalence of pools infected was $\leq 46 \%$ in 2015 but as high as $70 \%$ in 2016 (Table 2).

Within-pool prevalence ranged from 0-63\% and averaged 7.68 $\pm 0.02 \%$ (Table 1). In 2015, prevalence ranged from 0-55\%: 0-21\% in Barton Bench, 0-55\% in Lambert North, and 0-11\% in Lambert South (Fig. 2). In 2016, prevalence ranged from 0-63\%: 0-63\% in Barton Bench, 0-10\% in Lambert North, and 0-5\% in Lambert South (Fig. 2).

We found no difference in prevalence or viral load among regions or between sample years ( $\mathrm{p} \geq 0.27$; Fig. 2). No environmental predictors were more supported than a null model for explaining prevalence of ranavirus (Table S1). The NMDS ordination indicated almost complete overlap of pools with positive detections and pools without ranavirus in two projected dimensions $(\mathrm{k}=2)$ with stress $=0.25$ (Fig. 3).

In 2015,8 out of 22 pools (36\%) with genetics data had positive detections for ranavirus. In 2016, 16 out of 25 pools (64\%) with genetics data had positive detections. There were no differences in any genetic parameters between pools with or without ranavirus ( $\mathrm{p} \geq 0.28$; Fig. S1). There was no association between viral load and genetic diversity, effective number of breeders, or relatedness $(\mathrm{p} \geq 0.08)$.

We only detected ranavirus in 35 out of 436 individuals (8\%) sampled for corticosterone: 14 out of 181 individuals (8\%) in 2015, and only 21 out of 255 (8\%) sampled for corticosterone in 2016. We found no difference in corticosterone levels between individual larvae infected with 
ranavirus (mean $\pm \mathrm{SE}: 1.97 \pm 0.19 \mathrm{pg} / \mathrm{TL} / \mathrm{h}$ ) and those that were not (mean $\pm \mathrm{SE}: 2.06 \pm 0.09$ $\mathrm{pg} / \mathrm{TL} / \mathrm{h} ; \mathrm{p}=0.51 ;$ Fig. S2). Corticosterone levels were also not correlated with viral load ( $\mathrm{p}=$ $0.53)$.

Larvae infected with ranavirus had greater total length, averaging $22.52 \pm 0.64 \mathrm{~mm}$, than those that were not infected, which averaged $21.00 \pm 0.19 \mathrm{~mm}\left(\right.$ Kruskal-Wallis chi $^{2}=7.71, \mathrm{p}=$ 0.005; Fig. 4). Total length was positively correlated with viral load (Spearman rho $=0.08, \mathrm{p}=$ 0.006; Fig. 5). Of these larvae, 1,034 were negative for ranavirus and 84 tested positive.

\section{DISCUSSION}

Our results indicate presence of ranavirus is widespread among created vernal pools in the Monongahela National Forest. However, the majority of pools had low prevalence of ranavirus among salamanders. Larval total length was higher in individuals infected with ranavirus than those that were not, which might be a product of larval susceptibility through development.

It is possible that we observed greater lengths in infected larvae due to increased developmental rates or variation in susceptibility at different developmental stages. In wood frogs, lethal doses of ranavirus increased developmental rates but decreased body weight (Warne et al. 2011). Conversely, northern leopard frogs with sublethal ranavirus infections had reduced growth and development (Echaubard et al. 2010). Mortality due to ranavirus was higher in metamorphs than larval stages for wood frogs, green frogs (Rana clamitans), and northern leopard frogs (Warne et al. 2011; Haislip et al. 2011; Hall et al. 2018). Observed die-offs often involve late stage tadpoles and metamorphs (Green et al. 2002). This might indicate higher susceptibility later in larval development, particularly metamorphosis, which could reflect our findings of higher prevalence among larger larvae. However, this does not hold true for all 
species. Eastern spadefoot (Scaphiopus holbrookii) and Cope's gray treefrogs (Hyla chrysoscelis) experimentally exposed to ranavirus in mesocosms had higher infection rate and mortality during the larval stages than metamorphosis (Haislip et al. 2011). Ranavirus prevalence decreased in American bullfrog tadpoles through development (Gray et al. 2007). In mesocosms, infection prevalence did not differ among wood frog developmental stages but was high for all stages (>82\%; Haislip et al. 2011). Our findings of larger spotted salamander larvae with higher infection loads could coincide with larval age, making the association a product of increased time spent in the infected pool.

In the state of West Virginia, ranavirus has been detected in Kanawha, Berkeley, Mineral, Roane, and Cabell Counties (Smith et al. 2016; Kevin Oxenrider, WV DNR personal communication). Our results add Randolph County to the list and also document ranavirus presence in the middle of the state, between counties where ranavirus was previously detected (Fig. 6). Ranavirus was detected in eastern box turtles (Terrapene carolina) in Kanawha, Mineral, Roane, and Cabell Counties, and in green frogs in Berkeley (Smith et al. 2016; Kevin Oxenrider, WV DNR personal communication). Our surveillance adds spotted salamanders to the list of species with ranavirus in West Virginia. Ranavirus has been detected in spotted salamanders in the bordering states of Maryland, Ohio, and Pennsylvania, as well as Connecticut, Maine, Massachusetts, New Jersey, New York, North Carolina, Rhode Island, and Tennessee (Duffus et al. 2015; Smith et al. 2016). It is possible that ranavirus is prevalent throughout West Virginia, but has not been detected yet.

Disease risk is a major concern for habitat creation because resulting die-offs and spread of disease could result in an overall negative effect to the population. The fact that we detected ranavirus in over half our created pools exemplifies that risk. Ranavirus infection in both created 
and natural pools in North Carolina decreased amphibian juvenile output (Petranka et al. 2007). Ranavirus prevalence of eastern newts was $33 \%$ and $70 \%$ at two of five created vernal pools in Daniel Boone National Forest, showing the potential for high infection rates in created habitat (Richter et al. 2013). Additionally, the disease can persist in the population through sublethal infections sustained by amphibian larvae, allowing the larvae to complete metamorphosis and return or disperse to other pools to spread the disease (Brunner et al. 2004; Greer et al. 2009).

At two pools sampled both years, we had positive detections for ranavirus the first year and found no larvae the following year. An additional pool (LN56) that was positive in 2015 had 12 egg masses present in the second sample year, but we only found two larvae after sampling (two-person hours). We did not survey for or observe mortality, die-offs, or infection, and it is difficult to determine the cause for a lack of larvae at this site. However, it is worth noting that pool LN56 had a ranavirus prevalence of 50\% in 2015, presence of egg masses in 2016, but no detection of larvae in 2016. One pool sampled both years changed from positive to negative for ranavirus. Due to annual variation in pathogen prevalence, it is difficult to definitively know why this switch occurred. Unfortunately, six other pools changed from negative to positive, and six more were positive both years of sampling, which could indicate sustained infections and spread of the disease at the created pools.

The lack of associations between ranavirus prevalence and habitat characteristics contributes to the still growing body of knowledge to determine best practices for habitat management and creation. The lack of association between water temperature and prevalence reflects the uncertainty around this relationship, which has been found to vary widely by species and viral strain (Echaubard et al. 2014; Brand et al. 2016; Youker-Smith et al 2018). We did not find an association between predator presence and ranavirus prevalence. Predators can act as 
disease reservoirs, alter behavior of prey, or act as a natural stressor with potential for immunosuppression, any of which might influence disease susceptibility. In line with our results, predator cues did not affect mortality or infection of green frog, wood frog, Cope's gray treefrog, or upland chorus frog (Pseudacris feriarum) tadpoles (Haislip et al. 2012; Reeve et al. 2013). However, in the United Kingdom, presence of newts increased ranavirus prevalence in common frogs (Rana temporaria; North et al. 2015). Ranavirus prevalence was also not associated with vegetative cover. Arizona tiger salamanders in pools with less vegetative cover had higher disease prevalence with observed larval clustering around the pool edge (Greer and Collins 2008). Amphibian larval density does not always affect disease susceptibility, transmission rates, or survival (Echaubard et al. 2010; Brunner et al. 2017; Hall et al. 2018). We did not find that water $\mathrm{pH}$ coincided with infection rates, which also held true for amphibian populations in California and Maine (Tornabene et al. 2018; Gahl and Calhoun 2010). We found no association between ranavirus prevalence with either pool size or pool depth. Conversely, prevalence of ranavirus in common frogs increased with pond depth (North et al. 2015). Additionally, for wood frogs and green frogs in created vernal pools, models predicted that deeper water would increase disease prevalence, potentially due to its effect on water temperature or the decreased likelihood of pool sediment freezing, allowing disease reservoir species to persist in the pool (YoukerSmith et al. 2018).

Corticosterone levels did not differ between larvae that were or were not infected with ranavirus. It is possible that the viral load observed was not sufficient to activate the HPI axis to elicit a corticosterone response. This relationship might also depend on progression of the disease. Wood frogs that were exposed to lethal doses of ranavirus exhibited elevated 
corticosterone levels (Warne et al. 2011). It is also possible that ranavirus does not activate the HPI axis in spotted salamander larvae.

There were no correlations among genetic diversity parameters and disease prevalence. It is possible that higher genetic diversity improves a population's ability to survive a disease outbreak (Daszak et al. 2000; Pearman and Garner 2005). Die-offs resulting from ranavirus might also result in reduced genetic diversity (Petranka et al. 2003; Beebee 2012; Puschendorf et al. 2019). Our study was limited to observing infection loads, rather than mortality or signs of disease. The observed infection loads at these created pools may be low enough to prevent detectable differences between pools infected and those that were not. Pools sampled were also newly created, with the oldest created only five years prior to sampling. Impacts to the population genetics from disease introduction could take longer to observe. It is also possible that we did not detect an association between ranavirus prevalence and genetic parameters because our genetics data were based on a limited number of markers, or because the markers we looked at were neutral microsatellite markers. These non-coding markers may not indicate genetic potential for disease resilience.

In a concurrent study, we documented genetic connectivity and gene flow among the created pools in this study system (Millikin 2019). Connectivity among pools is beneficial to ensure initial colonization and recolonization of created pools after extinction events like drought years. It also enables the spread of rare alleles enhancing genetic diversity. Unfortunately, the connectivity we observed, which sustains metapopulations, might be facilitating the spread of ranavirus. We did not observe a trend in ranavirus prevalence across regions, any spatial patterns, or associations with distance to other pools or density of pools. Presence of ranavirus 
across the created pools indicates it was already widespread across the regions, likely reflecting the high connectivity we observed.

Ranavirus is a pathogen of concern for amphibians because of its impact to individual fitness, ability to spread through sublethal infections, and resulting mass mortality events (Echaubard et al. 2010; Green et al. 2002). Efforts to create suitable habitat should prioritize reducing the risk of disease introduction. This includes determining the distribution of the disease, which areas are at risk of exposure, and monitoring ranavirus prevalence and its effect on the population. Our results did not reveal important habitat traits to consider during habitat creation and future research should pursue ways to reduce disease exposure and risk, particularly for newly created habitats. Additionally, continued monitoring of amphibian larvae inhabiting created pools can provide insight to susceptibility among developmental stages (Haislip et al. 2011). Documenting and monitoring the occurrence of ranavirus is critical to ensure created vernal pools can provide suitable breeding habitat rather than acting as a reservoir for disease.

\section{ACKNOWLEDGMENTS}

This research was approved by the West Virginia University Institutional Animal Care and Use Committee (15-0409.3), the U.S. Forest Service, and the West Virginia Division of Natural Resources (Scientific Collecting Permit 2015.133, 2016.205). We thank Jessi Rouda, Jonathan Strickland, Adam Bucher, and John Millikin for field and lab assistance. This work was funded by the U.S. Forest Service, Natural Resources Conservation Service, National Science Foundation (01A-1458952), West Virginia University Natural History Museum, National Institute of Food and Agriculture McStennis Project WVA00117, The Explorers Club Washington Group, Society of Wetland Scientists, Society of Wetland Scientists South Atlantic Chapter, West Virginia University Stitzel Graduate Enhancement Fund, and Richard and Lois 
Bowman. We also thank West Virginia Division of Natural Resources, Department of Biological Sciences at Duquesne University, and the Ruby Distinguished Doctoral Fellowship Program. This is scientific article number XXXX of the West Virginia Agricultural and Forestry Experiment Station, Morgantown. 


\section{REFERENCES}

Beebee T. 2012. Impact of Ranavirus on garden amphibian populations. Herpetological Bulletin $120: 1-3$

Brand MD, Hill RD, Brenes R, Chaney J C, Wilkes RP, Grayfer L, Miller DL, Gray MJ. 2016. Water temperature affects susceptibility to ranavirus. EcoHealth 13:350-359. https://doi.org/10.1007/s10393-016-1120-1

Brenes R, Gray MJ, Waltzek TB, Wilkes RP, Miller DL. 2014a. Transmission of ranavirus between ectothermic vertebrate hosts. PLoS ONE 9:e92476. https://doi.org/10.1371/journal.pone.0092476

Brenes R, Miller DL, Waltzek B, Wilkes RP, Tucker JL, Chaney JC, Hardman RH, Brand MD, Huether RR, Gray MJ. 2014b. Susceptibility of fish and turtles to three ranaviruses isolated from different ectothermic vertebrate classes. Journal of Aquatic Animal Health 26:118-126. https://doi.org/10.1080/08997659.2014.886637

Brunner JL, Beaty L, Guitard A, Russell D. 2017. Heterogeneities in the infection process drive ranavirus transmission. Ecology 98:576-582. https://doi.org/10.1002/ecy.1644

Brunner J, Schock D, Davidson E, Collins J. 2004. Intraspecific reservoirs: complex life history and the persistence of a lethal ranavirus. Ecology 85:560-566. https://doi.org/10.1890/02$\underline{0374}$

Burnham KP, Anderson DR (2002) Model selection and multimodel inference: a practical information-theoretic approach. Springer Science \& Business Media, LLC, New York, NY

Butterfield MM, Davis DR, Madison JD, Kerby JL. 2019. Surveillance of Ranavirus in false map turtles (Graptemys pseudogeographica) along the lower Missouri River, USA. Herpetological Review 50:76-78. 
Campbell Grant EH, Adams MJ, Fisher RN, Grear DA, Halstead BJ, Hossack BR, Muths E, Richgels KLD, Russel RE, Smalling KL, Hardin Waddle J, Wallis SC, LeAnn White C. 2018. Identifying management-relevant research priorities for responding to diseaseassociated amphibian declines. Global Ecology and Conservation 16:e00441. https://doi.org/10.1016/j.gecco.2018.e00441

Chinchar VG. 2002. Ranaviruses (family Iridoviridae): emerging cold-blooded killers. Archives of Virology 147:447-470.

Crespi EJ, Williams TD, Jessop TS, Delehanty B. 2013. Life history and the ecology of stress: how do glucocorticoid hormones influence life-history variation in animals? Functional Ecology 27:93-106. https://doi.org/10.1111/1365-2435.12009

Cribari-Neto F, Zeileis A. 2010. Beta regression in R. Journal of Statistical Software 34:1-24.

Daszak P, Cunningham AA, Hyatt AD. 2000. Wildlife ecology - emerging infectious diseases of wildlife - threats to biodiversity and human health. Science 287:443-449. https://doi.org/10.1126/science.287.5452.443

Davis DR, Kerby JL. 2016. First detection of ranavirus in amphibians from Nebraska, USA. Herpetological Review 47:46-50.

Denver RJ. 2009. Stress hormones mediate environment-genotype interactions during amphibian development. General and Comparative Endocrinology 164:20-31. https://doi.org/10.1016/j.ygcen.2009.04.016

DiBello FJ, Calhoun AJK, Morgan DE, Shearin AF. 2016. Efficiency and detection accuracy using print and digital stereo aerial photography for remote mapping vernal pools in New England landscapes. Wetlands 36:505-514. https://doi.org/10.1007/s13157-016-0759-2 
Docherty DE, Meteyer CU, Wang J, Mao J, Case ST, Chinchar VG. 2003. Diagnostic and molecular evaluation of three Iridovirus-associated salamander mortality events. Journal of Wildlife Diseases 39(3):556-566. https://doi.org/10.7589/0090-3558-39.3.556

Duffus ALJ, Marschang RE, Waltzek TB, Stöhr A, Allender MC, Gotesman M, Whittington R, Hick P, Hines M. 2015. Distribution and host range of ranaviruses. In: Gray MJ, Chinchar VG (eds) Ranaviruses: lethal pathogens of ectothermic vertebrates. Springer, Secaucus

Earl JE, Gray MJ. 2014 Introduction of ranavirus to isolated wood frog populations could cause local extinction. Ecohealth 11:581. https://doi.org/10.1007/s10393-014-0950-y

Echaubard P, Leduc J, Pauli B, Chinchar G, Robert J, Lesbarrères D. 2014. Environmental dependency of amphibian-ranavirus genotypic interactions: evolutionary perspectives on infectious diseases. Evolutionary Applications 7:723-733. https://doi.org/10.1111/eva.12169

Echaubard P, Little K, Pauli B, Lesbarrères D. 2010. Context-dependent effects of ranaviral infection on northern leopard frog life history traits. PLoS ONE 5:e13723. https://doi.org/10.1371/journal.pone.0013723

Egan RS, Paton PWC. 2004. Within-pond parameters affecting oviposition by wood frogs and spotted salamanders. Wetlands 24:1-13. https://doi.org/10.1672/02775212(2004)024[0001:WPAOBW]2.0.CO;2

Ferrari SLP, Cribari-Neto F. 2004. Beta regression for modelling rates and proportions. Journal of Applied Statistics 31:799-815. https://doi.org/10.1080/0266476042000214501

Forson D, Stofer A. 2006. Atrazine increases ranavirus susceptibility in the tiger salamander, Ambystoma tigrinum. Ecological Applications 16:2325-2332. https://doi.org/10.1890/10510761(2006)016[2325:AIRSIT]2.0.CO;2 
Gabor CR, Fisher MC, Bosch J. 2013. A non-invasive stress assay shows that tadpole populations infected with Batrachochytrium dendrobatidis have elevated corticosterone levels. PLoS ONE 8:e56054. https://doi.org/10.1371/journal.pone.0056054

Gahl MK, Calhoun AJK. 2008. Landscape setting and risk of Ranavirus mortality events. Biological Conservation 141:2679-2689. https://doi.org/10.1016/j.biocon.2008.08.003

Gahl MK, Calhoun AJK. 2010. The role of multiple stressors in ranavirus-caused amphibian mortalities in Acadia National Park wetlands. Canadian Journal of Zoology 88:108-121. https://doi.org/10.1139/Z09-124

Goudet J. 1995. FSTAT (Version 1.2): a computer program to calculate F-statistics. Journal of Heredity $86: 485-486$.

Gray MJ, Miller DL, Hoverman JT. 2009. Ecology and pathology of amphibian ranaviruses. Diseases of Aquatic Organisms 87:243-266. https://doi.org/10.3354/dao02138

Gray MJ, Miller DL, Schmutzer AC, Baldwin CA. 2007. Frog Virus 3 prevalence in tadpole populations inhabiting cattle-access and non-access wetlands in Tennessee, USA. Diseases of Aquatic Organisms 77:97-103. https://doi.org/10.3354/dao01837

Green DE, Converse KA, Schrader AK. 2002. Epizootiology of sixty-four amphibian morbidity and mortality events in the USA, 1996-2001. Annals of the New York Academy of Sciences 969:323-339. https://doi.org/10.1111/j.1749-6632.2002.tb04400.x

Greer AL, Brunner JL, Collins JP. 2009. Spatial and temporal patterns of Ambystoma tigrinum virus (ATV) prevalence in tiger salamanders Ambystoma tigrinum nebulosum. Diseases of Aquatic Organisms 85:1-6. https://doi.org/10.3354/dao02061 
Greer AL, Collins JP. 2008. Habitat fragmentation as a result of biotic and abiotic factors controls pathogen transmission through a host population. Journal of Animal Ecology 77:364-369. https://doi.org/10.1111/j.1365-2656.2007.01330.x

Haislip NA, Gray MJ, Hoverman JT, Miller DL. 2011. Development and disease: how susceptibility to an emerging pathogen changes through anuran development. PLoS ONE 6:e22307. https://doi.org/10.1371/journal.pone.0022307

Haislip NA, Hoverman JT, Miller DL, Gray MJ. 2012. Natural stressors and disease risk: does the threat of predation increase amphibian susceptibility to ranavirus? Canadian Journal of Zoology 90:893-902. https://doi.org/10.1139/z2012-060

Hall EM, Goldberg CS, Brunner JL, Crespi EJ. 2018. Seasonal dynamics and potential drivers of ranavirus epidemics in wood frog populations. Oecologia 188:1253-1262.

\section{https://doi.org/10.1007/s00442-018-4274-4}

Harp EM, Petranka JW. 2006. Ranavirus in wood frogs (Rana sylvatica): potential sources of transmission within and between ponds. Journal of Wildlife Diseases 42:307-318. https://doi.org/10.7589/0090-3558-42.2.307

Hoverman JT, Gray MJ, Haislip NA, Miller DL. 2011. Phylogeny, life history, and ecology contribute to differences in amphibian susceptibility to ranaviruses. EcoHealth 8:301-319. https://doi.org/10.1007/s10393-011-0717-7

Mazerolle MJ (2017) AICcmodavg: model selection and multimodel inference based on (Q)AIC(c). R package version 2.1-1. https://cran.r-project.org/package=AICcmodavg Millikin AR. 2019. Population health of spotted salamanders in created vernal pools: an integrative approach. PhD Dissertation, West Virginia University. 
Millikin AR, Woodley SK, Davis DR, Anderson JT. 2019. Habitat characteristics in created vernal pools impact spotted salamander water-borne corticosterone levels. Wetlands. https://doi.org/10.1007/s13157-019-01130-5

North AC, Hodgeson DJ, Price SJ, Griffiths AGF. 2015. Anthropogenic and ecological drivers of amphibian disease (ranavirosis). PLoS ONE 10: e0127037.

\section{https://doi.org/10.1371/journal.pone.0127037}

Oksanen J, Blanchet FG, Friendly M, Kindt R, Legendre P, McGlinn D, Minchin PR, O'Hara RB, Simpson GL, Solymos P, Stevens MHH, Szoecs E, Wagner H. 2018. vegan: Community ecology package. R package version 2.4-6. https://CRAN.R-project.org/package=vegan

Peakall R, Smouse PE. 2006. GENALEX 6: Genetic analysis in Excel. Population genetic software for teaching and research. Molecular Ecology Notes 6:288-295.

Peakall R, Smouse PE. 2012. GenAlEx 6.5: Genetic analysis in Excel. Population genetic software for teaching and research-an update. Bioinformatics 28:2537-2539. https://doi.org/10.1093/bioinformatics/bts460

Pearman PB, Garner TWJ. 2005. Susceptibility of Italian agile frog populations to an emerging strain of Ranavirus parallels population genetic diversity. Ecology Letters 8:401-408. https://doi.org/10.1111/j.1461-0248.2005.00735.x

Petranka JW, Harp EM, Holbrook CT, Hamel JA. 2007. Long-term persistence of amphibian populations in a restored wetland complex. Biological Conservation 138:371-380. https://doi.org/10.1016/j.biocon.2007.05.002

Petranka JW, Murray SS, Kennedy CA. 2003. Responses of amphibians to restoration of a southern Appalachian wetland: perturbations confound post-restoration assessment. Wetlands 23:278-290. https://doi.org/10.1672/7-20 
Price SJ, Garner TW, Nichols RA, Balloux F, Ayres C, de Alba AM, Bosch J. 2014. Collapse of amphibian communities due to an introduced Ranavirus. Current Biology 24:2586-2591. http://dx.doi.org/10.1016/j.cub.2014.09.028

Puschendorf R, Wallace M, Chavarría MM, Crawford AJ, Wynne F, Knight M, Janzen DH, Hallwachs W, Palmer CV, Price SJ. 2019. Cryptic diversity and ranavirus infection of a critically endangered Neotropical frog before and after population collapse. Animal Conservation. https://doi.org/10.1111/acv.12498

Queller DC, Goodnight KF. 1989. Estimating relatedness using genetic markers. Evolution 43:258-275.

R Core Team. 2017. R: a language and environment for statistical computing. R Foundation for Statistical Computing, Vienna, Austria. URL https://www.R-project.org/

Reeve BC, Crespi EJ, Whipps CM, Brunner JL. 2013. Natural stressors and ranavirus susceptibility in larval wood frogs (Rana sylvatica). EcoHealth 10:190-200. https://doi.org/10.1007/s10393-013-0834-6

Richter SC, Drayer AN, Strong JR, Kross CS, Miller DL, Gray MJ. 2013. High prevalence of ranavirus infection in permanent constructed wetlands in eastern Kentucky, USA. Herpetological Review 44:464-466.

Robert J, George E, Andino FD, Chen G. 2011. Waterborne infectivity of the Ranavirus frog virus 3 in Xenopus laevis. Virology 417:410-417. http://dx.doi.org/10.1016/j.virol.2011.06.026

Roberts DW. 1986. Ordination on the basis of fuzzy set theory. Vegetatio 66:123-131. https://doi.org/10.1007/BF00039905 
Rojas S, Richards K, Jancovich JK, Davidson EW. 2005. Influence of temperature on Ranavirus infection in larval salamanders Ambystoma tigrinum. Diseases of Aquatic Organisms 63:95100. https://doi.org/10.3354/dao063095

Rollins-Smith LA. 2017. Amphibian immunity-stress, disease, and climate change.

Developmental and Comparative Immunology 66:111-119.

$$
\text { http://dx.doi.org/10.1016/j.dci.2016.07.002 }
$$

Romero LM. 2004. Physiological stress in ecology: lessons from biomedical research. TRENDS in Ecology and Evolution 19:249-255. https://doi.org/10.1016/j.tree.2004.03.008

Sandeno CM. 2011. Project status report - Barton Bench ecological restoration Greenbrier ranger district Monongahela National Forest. W.V. Department of Environmental Protection, Division of Mining and Reclamation.

Smith SA, Monsen-Collar KJ, Green DE, Niederriter HS, Hall ML, Terrell KA, Gipe KD, Urban CA, Patterson CA, Seigel RA, Zarate B, Kleopfer JD, Capbell-Grant EH, Driscoll CP. 2016. Detecting the extent of mortality events from Ranavirus in amphibians of the Northeastern U.S. Report to the Northeastern Association of Fish and Wildlife Agencies (NEAFWA) for Regional Conservation Needs (RCN).

Tornabene BJ, Blaustein AR, Briggs CJ, Calhoun DM, Johnson PT, McDevitt-Galles T, Rohr JR, Hoverman JT. 2018. The influence of landscape and environmental factors on ranavirus epidemiology in a California amphibian assemblage. Freshwater Biology 63:639-651.

\section{https://doi.org/10.1111/fwb.13100}

United States Forest Service. 2014. Mower Tract ecological restoration final report.

Wang IJ, Johnson JR, Johnson BB, Shaffer HB. 2011. Effective population size is strongly correlated with breeding pond size in the endangered California tiger salamander, 
Ambystoma californiense. Conservation Genetics 12:911-920.

https://doi.org/10.1007/s10592-011-0194-0

Wang J. 2009. A new method for estimating effective population sizes from a single sample of multilocus genotypes. Molecular Ecology 18:2148-2164. https://doi.org/10.1111/j.1365294X.2009.04175.X

Warne RW, Crespi EJ, Brunner JL. 2011. Escape from the pond: stress and developmental responses to ranavirus infection in wood frog tadpoles. Functional Ecology 25:139-146. https://doi.org/10.1111/j.1365-2435.2010.01793.x

Watters JL, Davis DR, Yuri T, Siler CD. 2018. Concurrent infection of Batrachochytrium dendrobatidis and ranavirus among native amphibians from northeastern Oklahoma, USA. Journal of Aquatic Animal Health 30:291-301. https://doi.org/10.1002/aah.10041

Whitfield SM, Donnelly MA, Geerdes E, Kerby J. 2012. Ranavirus infection in native amphibians at La Selva Biological Station, Costa Rica: first report of ranavirus in Central America. Herpetological Review 43:425-427.

Wobeser G. 2002. Disease management strategies for wildlife. Revue Scientifique et TechniqueOffice International des Epizooties 21:159-178. https://doi.org/10.20506/rst.21.1.1326

Youker-Smith TE, Boersch-Supan PH, Whipps CM, Ryan SJ. 2018. Environmental drivers of Ranavirus in free-living amphibians in constructed ponds. EcoHealth 15:608-618. https://doi.org/10.1007/s10393-018-1350-5 
Table 1. Spotted salamander (Ambystoma maculatum) ranavirus prevalence and mean quantity of viral copies per 100ng DNA (mean \pm standard error) at each pool separated by sampling year. Data from West Virginia, USA. N: number of larvae tested per pool per sample year; prevalence $=$ percent of larvae positive for ranavirus out of total larvae sampled at a pool; pools include those from Barton Bench (B,BB), Lambert North (LN), and Lambert South (LS)

\begin{tabular}{|c|c|c|c|c|c|c|}
\hline Pool & $2015 \mathrm{~N}$ & $\begin{array}{c}2016 \\
\mathrm{~N}\end{array}$ & $\begin{array}{c}2015 \\
\text { Prevalence } \\
\end{array}$ & $\begin{array}{c}2016 \\
\text { Prevalence } \\
\end{array}$ & $\begin{array}{c}2015 \\
\text { Viral Copies } \\
\end{array}$ & $\begin{array}{c}2016 \\
\text { Viral Copies } \\
\end{array}$ \\
\hline B1 & 14 & - & $21 \%$ & - & $43.00 \pm 28.33$ & - \\
\hline B11 & 20 & 20 & $10 \%$ & $5 \%$ & $35.96 \pm 24.75$ & $14.37 \pm 14.37$ \\
\hline B2 & 20 & 20 & $0 \%$ & $0 \%$ & $0 \pm 0$ & $0 \pm 0$ \\
\hline B4 & 20 & 20 & $0 \%$ & $0 \%$ & $0 \pm 0$ & $0 \pm 0$ \\
\hline B5 & 20 & 23 & $0 \%$ & $4 \%$ & $0 \pm 0$ & $17.52 \pm 17.52$ \\
\hline B7 & 20 & 21 & $0 \%$ & $10 \%$ & $0 \pm 0$ & $13.70 \pm 10.90$ \\
\hline $\mathrm{B} 8$ & 15 & 21 & $0 \%$ & $10 \%$ & $0 \pm 0$ & $5.72 \pm 3.94$ \\
\hline B9 & 20 & 21 & $5 \%$ & $0 \%$ & $15.67 \pm 15.67$ & $0 \pm 0$ \\
\hline BB2 & 24 & 20 & $0 \%$ & $10 \%$ & $0 \pm 0$ & $170.50 \pm 169.88$ \\
\hline BB8 & 20 & 20 & $0 \%$ & $30 \%$ & $0 \pm 0$ & $\begin{array}{r}442.62 \pm 197.32 \\
488,985.60 \pm\end{array}$ \\
\hline BB9 & - & 19 & - & $63 \%$ & - & $402,591.20$ \\
\hline LN10 & 25 & 20 & $28 \%$ & $10 \%$ & $148.02 \pm 60.25$ & $84.83 \pm 76.43$ \\
\hline LN104 & 15 & 21 & $27 \%$ & $10 \%$ & $102.66 \pm 48.74$ & $12.76 \pm 9.95$ \\
\hline LN105 & - & 20 & - & $5 \%$ & - & $21.98 \pm 21.98$ \\
\hline LN11 & 22 & 20 & $0 \%$ & $0 \%$ & $0 \pm 0$ & $0 \pm 0$ \\
\hline LN18 & 25 & 20 & $16 \%$ & $10 \%$ & $56.27 \pm 28.29$ & $18.23 \pm 12.66$ \\
\hline LN2 & 21 & 20 & $0 \%$ & $0 \%$ & $0 \pm 0$ & $0 \pm 0$ \\
\hline LN24 & 25 & 20 & $0 \%$ & $0 \%$ & $0 \pm 0$ & $0 \pm 0$ \\
\hline LN4 & 23 & 30 & $0 \%$ & $0 \%$ & $0 \pm 0$ & $0 \pm 0$ \\
\hline LN5 & 20 & 21 & $0 \%$ & $0 \%$ & $0 \pm 0$ & $0 \pm 0$ \\
\hline LN56 & 18 & - & $50 \%$ & - & $291.31 \pm 77.39$ & - \\
\hline LN62 & 22 & 20 & $5 \%$ & $5 \%$ & $13.20 \pm 13.20$ & $8.88 \pm 8.88$ \\
\hline LN77 & - & 20 & - & $5 \%$ & - & $6.75 \pm 6.75$ \\
\hline LN78 & 22 & - & $55 \%$ & - & $\begin{array}{r}679.05 \pm \\
250.85\end{array}$ & - \\
\hline LN94 & 21 & - & $0 \%$ & - & $0 \pm 0$ & - \\
\hline LN96 & 22 & - & $0 \%$ & - & $0 \pm 0$ & - \\
\hline
\end{tabular}


Table 1 continued.

\begin{tabular}{lrrrrrr}
\hline & 2015 & 2016 & 2015 & 2016 & 2015 & \multicolumn{2}{c}{$\begin{array}{c}2016 \\
\text { Pool }\end{array}$} \\
N & \multicolumn{1}{c}{$\mathrm{N}$} & Prevalence & Prevalence & Viral Copies & \multicolumn{1}{c}{ Viral Copies } \\
\hline LS1 & - & 22 & - & $0 \%$ & - & $0 \pm 0$ \\
LS119 & 20 & - & $0 \%$ & - & $0 \pm 0$ & - \\
LS120 & 19 & 20 & $11 \%$ & $5 \%$ & $99.51 \pm 68.98$ & $7.38 \pm 7.38$ \\
LS125-34 & 22 & - & $5 \%$ & - & $20.63 \pm 20.63$ & - \\
LS125-5 & 17 & 20 & $0 \%$ & $0 \%$ & $0 \pm 0$ & $0 \pm 0$ \\
LS2 & - & 20 & - & $5 \%$ & - & $2.18 \pm 2.18$ \\
LS49 & 16 & - & $0 \%$ & - & $0 \pm 0$ & - \\
LS69 & 21 & 20 & $0 \%$ & $5 \%$ & $0 \pm 0$ & $3.05 \pm 3.05$ \\
\hline
\end{tabular}


Table 2. Spotted salamander (Ambystoma maculatum) ranavirus prevalence at each region (Barton Bench, Lambert North, Lambert South) presented by sample year: 2015 and 2016, and with years combined: 2015-2016. Data from West Virginia, USA. Larvae: $n=$ sample size of larvae/region, $\%=$ percent of larvae infected. Pools: $\mathrm{n}=$ sample size of pools/region, $\%=$ percent of pools infected

\begin{tabular}{|c|c|c|c|c|c|c|c|c|c|c|}
\hline \multirow{3}{*}{ Region } & \multicolumn{6}{|c|}{ Larvae } & \multicolumn{4}{|c|}{ Pools } \\
\hline & \multicolumn{2}{|c|}{2015} & \multicolumn{2}{|c|}{2016} & \multicolumn{2}{|c|}{$2015-16$} & \multicolumn{2}{|c|}{2015} & \multicolumn{2}{|c|}{2016} \\
\hline & $\mathrm{n}$ & $\%$ & $\mathrm{n}$ & $\%$ & $\mathrm{n}$ & $\%$ & $\mathrm{n}$ & $\%$ & $\mathrm{n}$ & $\%$ \\
\hline Barton Bench & 193 & $3 \%$ & 205 & $13 \%$ & 398 & $8 \%$ & 10 & $30 \%$ & 10 & $70 \%$ \\
\hline Lambert North & 281 & $13 \%$ & 232 & $4 \%$ & 513 & $9 \%$ & 13 & $46 \%$ & 11 & $55 \%$ \\
\hline Lambert South & 115 & $3 \%$ & 102 & $3 \%$ & 217 & $3 \%$ & 6 & $33 \%$ & 5 & $60 \%$ \\
\hline
\end{tabular}




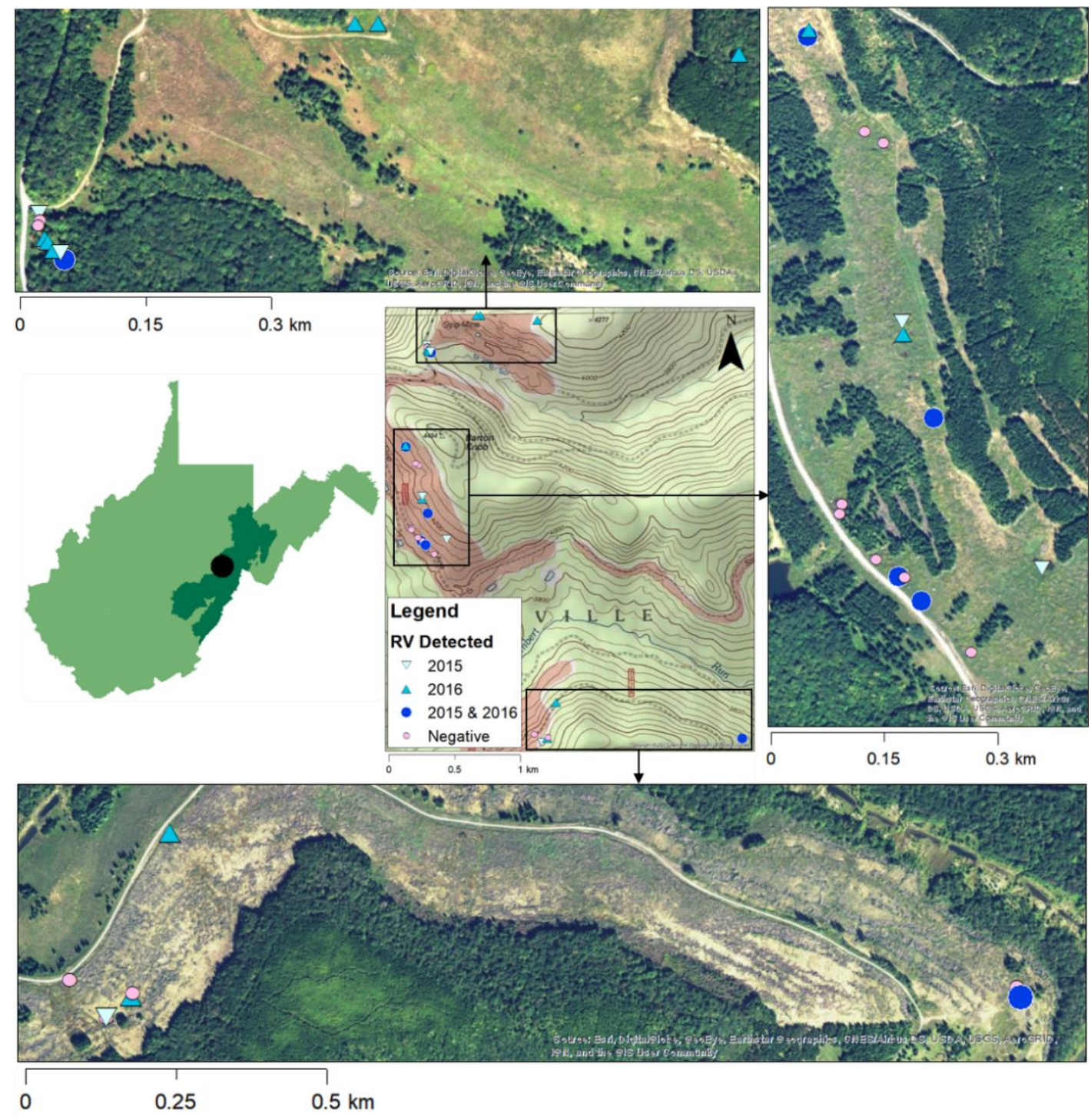

Figure 1. Map displaying study area in Randolph County, West Virginia, USA in the Greenbrier District of Monongahela National Forest. Triangles and circles represent locations of sampled created vernal pools. Regions are separated geographically from north to south: Barton Bench, Lambert North, Lambert South. State map displays Monongahela National Forest and the general area of sampling with a black circle. USA topo map accessed through ESRI (C) 2013 National Geographic Society, i-cubed; world impagery source: Esri, DigitalGlobe, GeoEye, Earthstar Geographics, CNES/Airbus DS, USDA, USGS, AeroGRID, IGN, and the GIS User Community 


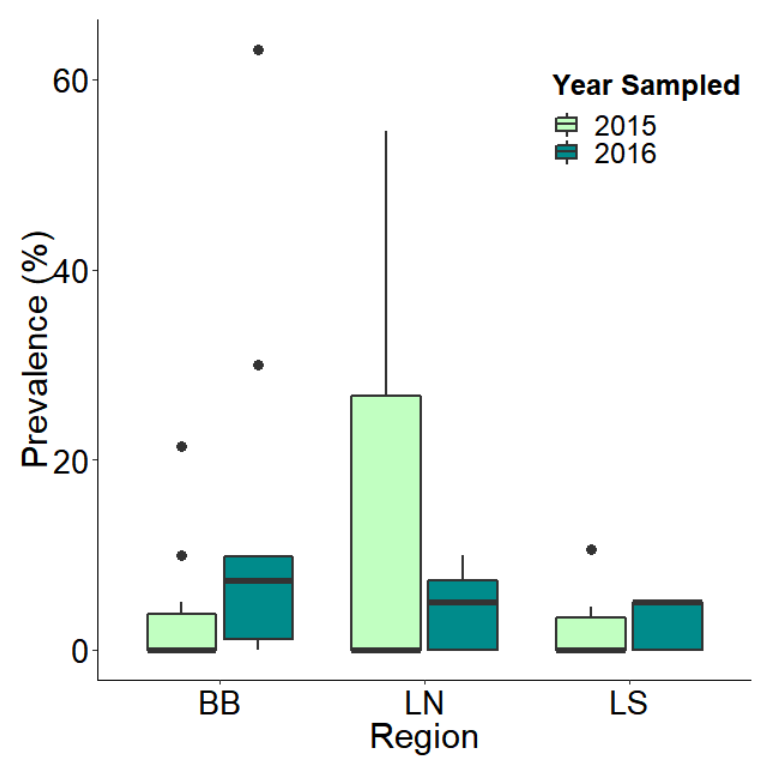

Figure 2. Boxplots displaying ranges of ranavirus prevalence in spotted salamander (Ambystoma maculatum) larvae within pools (percentage of larvae with positive detections out of total sampled at a pool) of each region: Barton Bench (BB), Lambert North (LN), and Lambert South (LS), separated by year sampled: 2015 and 2016. Data from West Virginia, USA. BB $2015 \mathrm{n}=$ 10 pools, $2016 \mathrm{n}=10$ pools; $\mathrm{LN} 2015 \mathrm{n}=13$ pools, $2016 \mathrm{n}=11$ pools; $\mathrm{LS} 2015 \mathrm{n}=6$ pools, $2016 n=5$ pools 


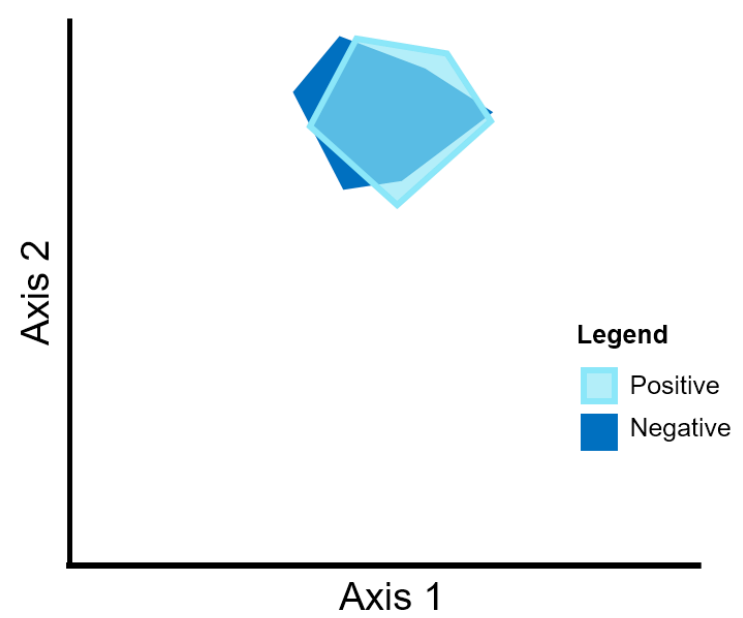

Figure 3. Non-metric multidimensional scaling ordination of vernal pools based on environmental characteristics. Data from West Virginia, USA. Polygons demonstrate overlap of pools with positive and negative detections of ranavirus in spotted salamander (Ambystoma maculatum) larvae from sampling in 2015 and 2016: positive detections in 28 pools, negative in 27 pools 
a

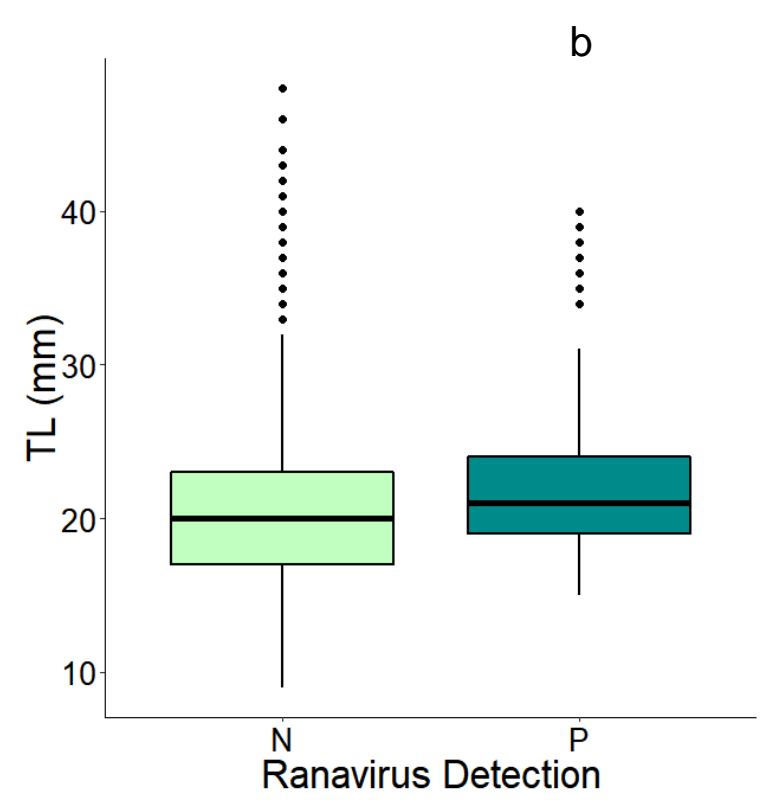

Figure 4. Boxplot displaying ranges in individual spotted salamander (Ambystoma maculatum) larval total length (TL (mm)) separated by larvae with negative $(\mathrm{N})$ and positive $(\mathrm{P})$ detections for ranavirus: 1034 larvae tested negative with TL mean \pm SE: $21.00 \pm 0.19 \mathrm{~mm}, 84$ larvae tested positive with TL mean \pm SE: $22.52 \pm 0.64 \mathrm{~mm}$. Data from West Virginia, USA. Letters indicate significant difference (Kruskal-Wallis $\left.\mathrm{chi}^{2}=7.71, \mathrm{p}=0.005\right)$ 


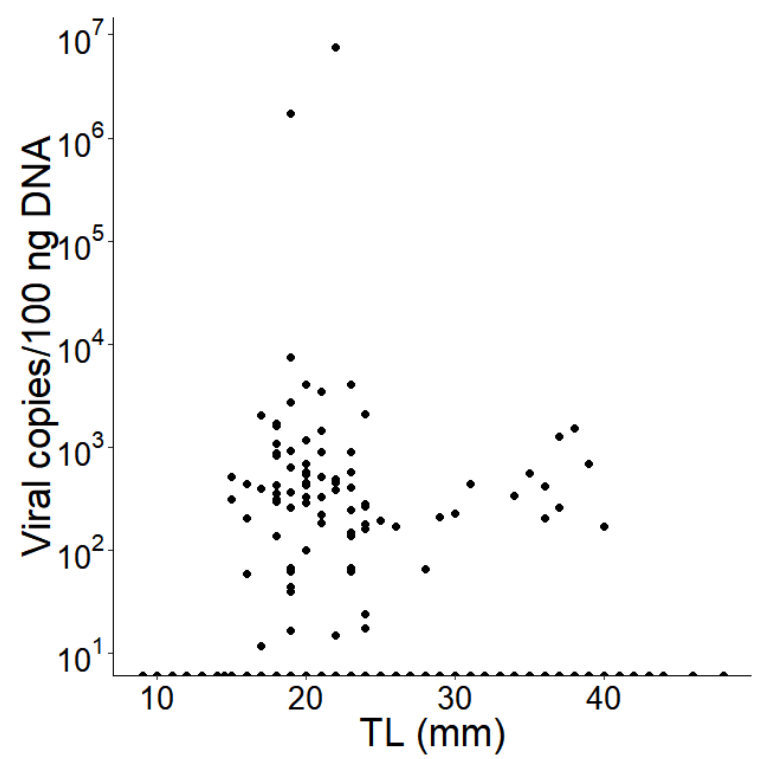

Figure 5. Biplot displaying correlation between spotted salamander (Ambystoma maculatum) larval total length and individual viral copies of Ranavirus per 100 ng of DNA (Spearman rho = 0.08, $\mathrm{p}=0.006)$. Data from West Virginia, USA. Note the log scale. Each dot represents one larvae: 1034 larvae that tested negative, and 84 larvae that tested positive for ranavirus 


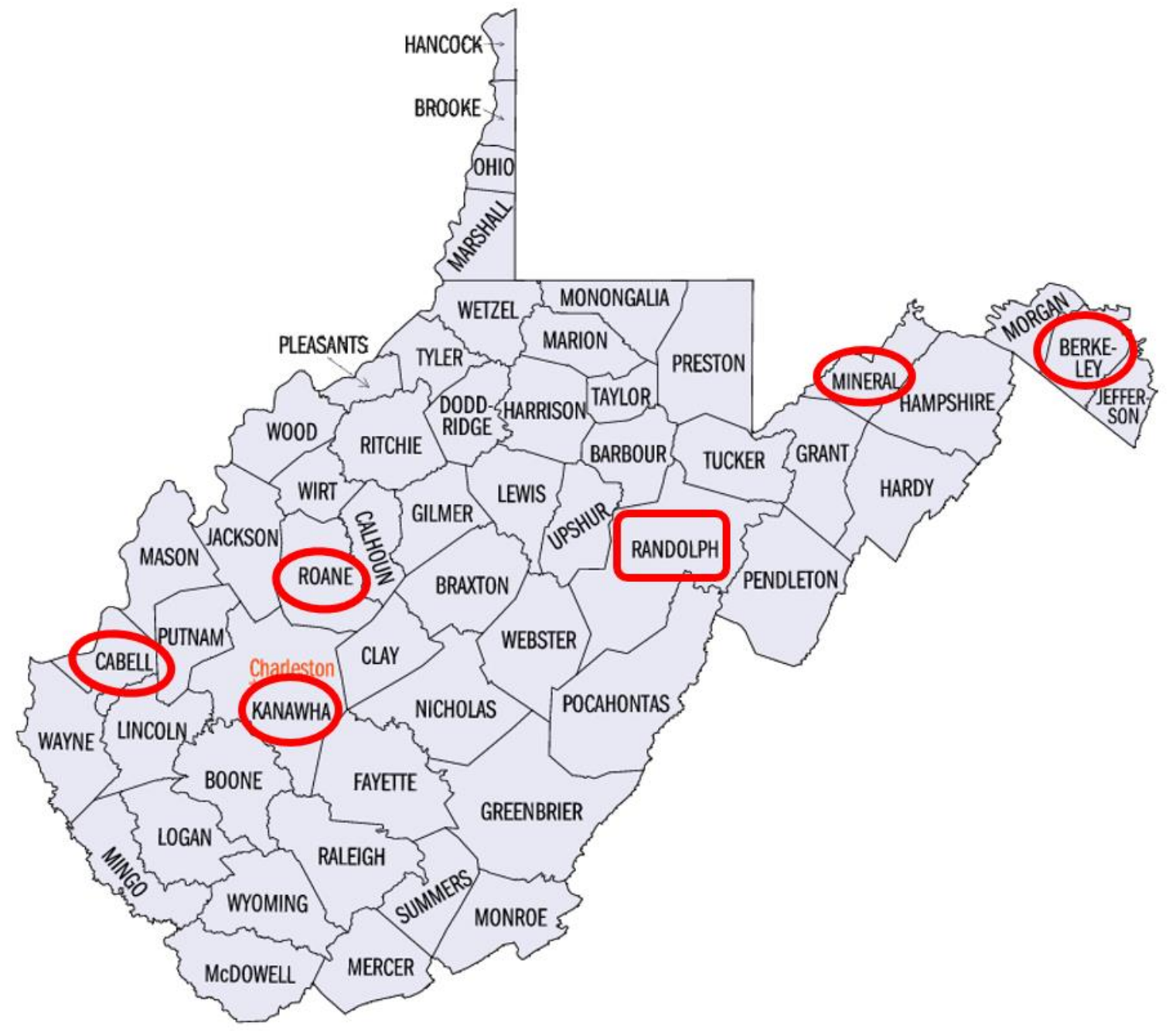

Figure 6. Map of West Virginia, USA displaying counties. Counties with ranavirus documented prior to this study are circled: Cabell, Kanawha, Roane, Mineral, Berkely (Smith et al. 2016; Kevin Oxenrider, WV DNR personal communication). Our research detected ranavirus in Randolph County (indicated by a rounded rectangle), adding it to the list of West Virginia counties with ranavirus 


\section{Appendix}

Table S1. Hypothesized models predicting ranavirus prevalence for spotted salamanders (Ambystoma maculatum). Predictors include: the null 1, pool water temperature, pool diameter, average corticosterone (CORT) per pool (pg/TL/h), pool age, number of positive pools within 1 $\mathrm{km}$, average salamander total length, allelic richness, average distance to all sampled pools, pool water $\mathrm{pH}$, number of sampled pools within $1 \mathrm{~km}$, pool cover, expected heterozygosity, genetic relatedness, predators present, effective number of breeders, and pool depth. $\triangle \mathrm{AICc}$ is the change in AIC corrected for small sample size; $\mathrm{w}_{\mathrm{i}}$ is the weight of the model

\begin{tabular}{lrl} 
Model & $\Delta$ AICc & $\mathrm{w}_{\mathrm{i}}$ \\
\hline$\sim 1$ & 0 & 0.12 \\
Water Temp & 0.46 & 0.10 \\
Pool Diameter & 0.76 & 0.08 \\
Average CORT & 1.36 & 0.06 \\
Water Temp + Diameter & 1.55 & 0.06 \\
Age & 1.67 & 0.05 \\
Positive Pools within 1 km & 2.03 & 0.04 \\
Average total length & 2.06 & 0.04 \\
Allelic Richness & 2.07 & 0.04 \\
Average distance to sampled pools & 2.07 & 0.04 \\
Water pH & 2.08 & 0.04 \\
Pools within 1 km & 2.09 & 0.04 \\
Pool cover & 2.1 & 0.04 \\
Expected heterozygosity & 2.21 & 0.04 \\
Relatedness & 2.22 & 0.04 \\
Predators & 2.23 & 0.04 \\
Effective number of breeders & 2.26 & 0.04 \\
Pool depth & 2.29 & 0.04 \\
Diameter + Pool cover & 3.11 & 0.03 \\
Water Temp + Diameter + CORT + Age & 5.32 & 0.01 \\
Predators + Water Temp + Depth + Diameter & 5.62 & 0.01 \\
\hline
\end{tabular}



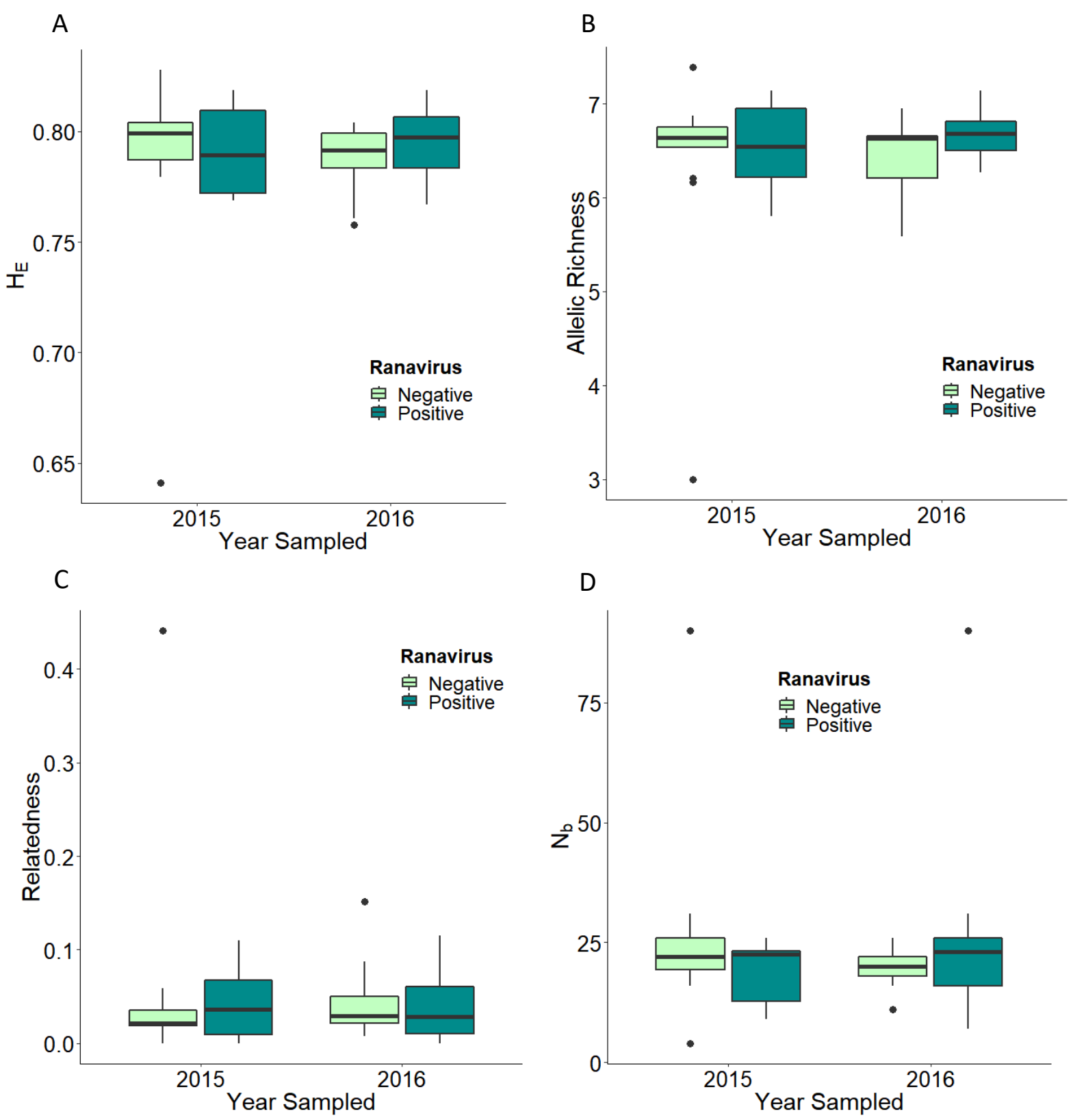

Figure S1. Boxplots displaying ranges in spotted salamander (Ambystoma maculatum) (a) expected heterozygosity $\left(\mathrm{H}_{\mathrm{E}}\right)$, (b) allelic richness, (c) relatedness, and (d) effective number of breeders $\left(\mathrm{N}_{\mathrm{b}}\right)$ at pools with negative and positive detection for ranavirus separated by year sampled. Data from West Virginia, USA 


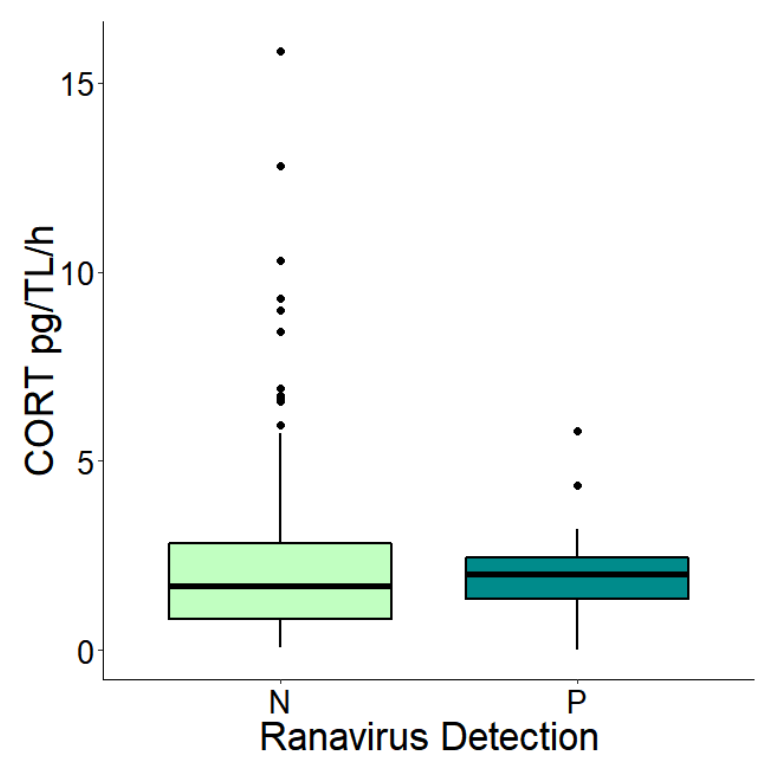

Figure S2. Boxplot displaying ranges in individual spotted salamander (Ambystoma maculatum) larval water-borne corticosterone levels pg/ total body length/ hour (CORT pg/TL/h) separated by larvae with negative $(\mathrm{N})$ and positive $(\mathrm{P})$ detections for ranavirus: 401 larvae tested negative, 35 larvae tested positive. Data from West Virginia, USA. There was no difference in corticosterone levels between the two groups 


\section{Chapter 6}

\section{Conclusion}

Habitat restoration and creation are critical components of wildlife conservation to mitigate habitat loss and degradation. Creating ideal habitat requires extensive knowledge of which habitat traits attract colonizers, which habitat traits will maintain a healthy population, and which factors pose a risk to the population, like stress, disease, or low genetic diversity. There are many ways to measure the success of habitat restoration and creation, and it is often based on wildlife reproductive effort, survival of juveniles, and population size. Integrative monitoring efforts that incorporate multiple disciplines improve our understanding of wildlife population health and can inform future habitat site selection and creation methods. This will facilitate creation of ideal habitat conducive to healthy wildlife populations. Here, I have demonstrated that wildlife hormone levels, population genetics, and disease prevalence can inform land managers of the current status of spotted salamander populations colonizing created vernal pools and reveal which habitat characteristics are conducive to healthy populations.

Genetic structure and diversity and disease prevalence provided valuable insight into the current status of spotted salamanders in created vernal pools. Pools were colonized quickly by spotted salamanders and effective number of breeders $\left(\mathrm{N}_{\mathrm{b}}\right)$ increased as quickly as 4-5 years

after habitat creation. These older pools also had low genetic differentiation and no bottlenecks, indicating an establishing breeding population. At our study site, there should be continued monitoring to determine if $\mathrm{N}_{\mathrm{b}}$ increases and genetic differentiation decreases with time since creation at the youngest pools. Ranavirus was detected in over half the vernal pools sampled, but 
generally occurred at a low prevalence, averaging $8 \%$. This indicated ranavirus was widespread in these created pools, illustrating the risk of disease exposure, even in newly created habitat. Larvae infected with ranavirus had larger total lengths, which could indicate differences in susceptibility through development or increased risk over time. Surveillance for ranavirus at these pools will contribute to distribution maps for ranavirus, adding a species and county record for West Virginia.

Assessing spotted salamander larvae hormone levels and $\mathrm{N}_{\mathrm{b}}$ revealed larger pools (diameters up to $12.75 \mathrm{~m}$ ) with greater vegetation cover likely provide more suitable habitat for this species. Spotted salamander larvae corticosterone levels, a hormone related to stress, were reduced in pools with larger diameters. Effective number of breeders was higher in pools with larger diameters and greater vegetation cover. Relatedness also decreased with greater pool cover and vegetation cover. Future vernal pool creation would benefit from creating larger vernal pools and incorporating vegetative cover for amphibian oviposition sites and larval refuge. Future research should determine ideal pool size to attract and support spotted salamander breeding populations.

This research illustrates the value of incorporating interdisciplinary approaches to assess the success of habitat creation and colonizing wildlife populations. Evaluating hormone levels, population genetics, and disease prevalence revealed quickly establishing populations, low prevalence of disease, and that pool size and vegetative cover were important for habitat quality for spotted salamanders. Long-term monitoring is essential to track these changes over time and to ultimately determine if created pools are sustaining viable breeding populations. Increasing our understanding of how the habitat impacts wildlife and monitoring risks to the population will inform and improve future habitat creation. 